

\title{
ARCHITECTURAL DESIGN: A PHOTO MONOGRAPH 100+ PHOTO STUDENT WORKS
}

Authors: $\quad$ Bujar Q. Bajçinovci, Vlora Aliu

Submitted:

6. August 2018

Published:

13. August 2018

Volume:

5

Issue: $\quad 6$

Affiliation: University of Prishtina, Faculty of Civil Engineering and Architecture, Kosovo

Languages: Albanian

Keywords:

DOI: Architecture, Kosovo, Design 10.17160/josha.5.6.451

Abstract: $\quad$ The photo monograph incorporates professional works of the Architectural Design courses, followed by student models, photos, discussion and citations by various authors as the academic comparative references. The core of this photo monograph are the student works, design models for the future generations, and it is intended as the basic literature of Bachelor and Master courses we taught at the Department of Architecture, University of Prishtina. The monograph is divided into two chapters: The first chapter, present and elaborates the intro of the syllabus for Architectural Design 4, 5, and Studio Design. The second chapter is the main chapter of this photo monograph which extendedly 


\title{
ARCHITECTURAL DESIGN: A PHOTO MONOGRAPH $100+$ \\ PHOTO STUDENT WORKS
}

\begin{abstract}
This book is originally and especially dedicated to the students of Architecture Department of the University of Prishtina for Educational, and Not-for-profit purposes. The photo monograph incorporates contemporary knowledge of the Architectural Design Principles, followed by Student Projects, discussion and citations by various authors as the academic comparative references. Seeing the lack of literature in the field of Architecture, especially in Albanian language, We was inspired by the research and writing this monograph, which elaborates the Architectural Design Principles. The book is a free and not-for-profit purposes, it is intented as basic literature of Master courses which We taught at University of Prishtina. In the monograph We have presented Student Projects and drawings as example models for future generations at the Department of Architecture. There are two chapters, each chapter extensive explain and discuss issues related to the specific topic of the Architectural Design.
\end{abstract}

ARCHITECTURAL DESIGN: A PHOTO MONOGRAPH

$100+$

PHOTO STUDENT WORKS

Language: Albanian

\section{Prof.Ass.Dr. BUJAR BAJÇINOVCI Dipl.Eng.Arch. Mr.Sc. VLORA ALIU Arch. Faculty of Civil Engineering and Architecture University of Prishtina, Kosovo.}

\section{Prishtinë 2018}


Falënderim i posaqëm për studentët dhe kolegët, për vullnetin, sygjerimet dhe për përkrahjen për ta botuar këtë monografi.

\section{ARCHITECTURAL DESIGN: A PHOTO MONOGRAPH}

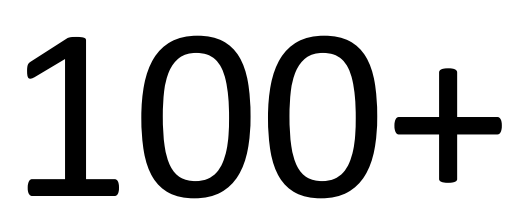

\section{PHOTO STUDENT WORKS \\ Language: Albanian}

Bujar Bajçinovci \& Vlora Aliu @. Attribution-NonCommercial 4.0 International (CC BY-NC 4.0). This book is licensed under a ( Creative Commons Attribution-NonCommercial 4.0 International License. ) license. See the license for more details: You can share this book as long as you credit the author, and don't use for the commercial purposes, and do make it available to everyone else under the same terms.

Copyright, Authors: Prof.Ass.Dr. Bujar Bajçinovci \& Mr.Sc. Vlora Aliu \& Cited Students et al. 2018.

Mësimdhënës, Katedra e Projektimit

Studentët, Lënda: Projektim 4, 5, Studio

Fakulteti i Ndërtimtarisë dhe Arkitekturës

Universiteti i Prishtinës, Kosovë.

Gusht, 2018

Kopërtina. Bujar Bajçinovci

Photo: Bujar Bajçinovci

Source: Bujar Bajçinovci. FNA, University of Prishtina. 


\title{
FOTO MONOGRAFI - PROJEKTIMI ARKITEKTONIK \\ $100+$
}

FOTO PUNIME TË STUDENTËVE

\author{
FOTO MONOGRAFI PROFESIONALE \\ NGA LEMIA E PROJEKTIMIT ARKITEKTONIK
}

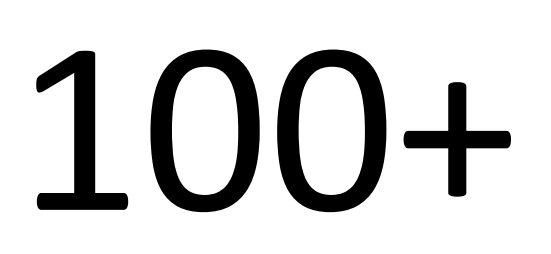

FOTO PUNIME TË STUDENTËVE

BUJAR BAJÇINOVCI \& VLORA ALIU et al.

Prishtinë 2018 


\section{PARATHËNIE}

Foto monografia fillimisht i'u dedikohet studentëve të Arkitekturës, me punime bashkëkohore profesionale nga lëmia e projektimit arkitektonik. Libri dhurohet falas pa pagesë studënteve, si literaturë bazike për Departamentin e Arkitekturës, Universiteti i Prishtinës. Monografia në vete ngërthen njohurit bashkëkohore të lëmisë së projektimit, duke u përcjellë me shembuj konkret nga projektet e studentëve, pjesë dhe fotografi nga autor të ndryshëm. Duke parë mungesën e literaturës në lëminë e Arkitekturës ky libër ka për qëllim të shërbejë si udhëzues praktik për parimet e projektimit, konceptin e ndërtimit dhe të funksionit të tërësisë kompozicionale të ndërtesave bashkëkohore në nxënien e kurikules të projektimit arkitektonik. Në monografi kemi prezantuar Projektet e Studentëve dhe vizatimet nga lënda: Projektim 4, 5, dhe Studio, si modele shembull për gjeneratat e ardhëshme të Departamentit të Arkitekturës, Universiteti i Prishtinës.

Autorët: Bujar Bajçinovci dhe Vlora Aliu et al.

Katedra e Projektimit

Fakulteti i Ndërtimtarisë dhe Arkitekturës

Universiteti i Prishtinës

Gusht, 2018 
PËRMBAJTJA :

$100+$

PARATHËNIE

PËRMBAJTJA

SHKURTESAT - PËRKUFIZIMET

INDEKSI I SHKURTESAVE

FALENDERIM

I : HYRJE

II : $\quad 100+$ FOTO PUNIME TË STUDENTËVE 


\section{SHKURTESAT - PËRKUFIZIMET}

\section{Monografi:}

Monografia është një shkrim i veçantë specialistik mbi një temë të vetme dhe zakonisht është lëndë shkencore.

\section{Ndërtim:}

Nënkupton ngritje, instalim, zhvendosje, riparim, zgjerim, ndryshim, shndërrim ose demolim i ndërtimeve, përfshirë ndërtesat, infrastrukturën, ndihmesat vizuale, ndihmesat tjera duke përfshirë punët për mirëmbajtjen e ndërtimeve ekzistuese. 
INDEKSI I SHKURTESAVE

$\begin{array}{ll}\text { AEA } & \text { Agjencia Evropiane për Ambient } \\ \text { ASK } & \text { Agjencioni i Statistikave të Kosovës } \\ \text { BE } & \text { Bashkimi Evropian } \\ \text { BPV } & \text { Bruto Produkti Vendor } \\ \text { MMPH } & \text { Ministria e mjedisit dhe planifikimit hapësinor } \\ \text { MSH } & \text { Ministria e Shëndetësisë } \\ \text { MTI } & \text { Ministria e Tregtisë dhe Industrisë } \\ \text { OBT } & \text { Organizata Botërore e Tregtisë } \\ \text { PZhU } & \text { Plani i Zhvillimit Urban }\end{array}$


HYRJE

KJO FAQE ËSHTË LËNË QËLLIMISHT E ZBRAZËT! 
FOTO MONOGRAFI - PROJEKTIMI ARKITEKTONIK. 100+ FOTO PUNIME TË STUDENTËVE 2018. (CBujar Bajçinovci \& Vlora Aliu \& Studentët e Cituar. Faqe: 141

MONOGRAFIA TRAJTON NJOHURITË PROFESIONALE NGA LEMIA E PROJEKTIMIT ARKITEKTONIK. SECILI KAPITULL, PASQYRON DETAJET TEKNIKE TË PROJEKTIMIT DUKE U ILUSTRUAR ME FOTOGRAFI, VIZATIME DHE RASTE STUDIMORE. MONOGRAFIA PËRVEÇ SE PLOTËSON NJË MUNGESË JO TË VOGËL PROFESIONALE NË LITERATURËN BAZIKE UNIVERSITARE, AJO NË VEÇANTI PËRSHKRUAN KONCEPTET E PROJEKTIMIT BASHKËKOHOR ARKITEKTONIK TË PUNUAR NGA STUDENTËT.

MONOGRAFIA I'U DEDIKOHET STUDENTËVE TË DEPARTAMENTIT TË ARKITEKTURËS, UNIVERSITETIT TË PRISHTINËS.

LIBRI JU DHUROHET FALAS STUDENTËVE 
HYRJE

KJO FAQE ËSHTË LËNË QËLLIMISHT E ZBRAZËT! 


\section{HYRJE}

Dojektimi arkitektonik përballet me sfida të mëdha, si rezultat i ndryshimeve evidente klimatike si dhe shprehive krejtësisht të reja të jetesës, kurse, globalizimi përshkruhet si një proces në të cilin ekonomitë rajonale, shoqëritë dhe kulturat, integrohen përmes një rrjeti global të ideve politike, komunikimit, transportit dhe vlerës integrale të tregut global. Fenomeni i globalizimit është një proces i pandalshëm historik i cili reflekton me rinovimet përkatëse teknologjike, shkencës, strategjive të reja ekonomike dhe ekologjike (Bajçinovci, 2017).

Departamenti i Arkitekturës, Universiteti i Prishtinës.

Lëndët: Projektim 4, 5, 8, dhe Studio.

\section{PËRSHKRIMI I LËNDËVE:}

Kurset zhvillojnë dhe shtjellojnë tematikën e projektimit arkitektonik, respektivisht Projektimin e Strukturave Hibride, Komplekset Industriale, Fermat Vertikale dhe komplekset e transportit ajror - Aeroportet. Kursi zhvillohen një herë në javë dhe janë kurse me participim interaktiv. Qëllimet e kurseve janë që të iniciojnë, përdorin principet themelore të teorisë dhe procesit të projektimit, ngërthimit simbiotik të teknologjisë dhe projektimit të komplekseve arkitektonike. Po ashtu kurset në veçanti shtjellojnë konceptet e projektimit të qëndrueshëm, ruajtjes së mjedisit dhe shëndetit publik. Kurset potencojnë procesin kreativ si qasje në identifikimin dhe zgjidhjen e problemeve bashkëkohore në Arkitekturë.

\section{REZULTATET E PRITURA TË NXËNIES:}

- Pas kompletimi te kursit, studentët duhet të kenë përvetësuar kuptuarjen e proceseve themelore të projektimit të komplekseve arkitektonike;

- Studentët duhet të kenë zhvilluar aftësitë dhe teknikat në hulumtim, dizajn dhe trajta të ndryshme kreative të implementimit në projektim;

- Studentët kanë përfytu aftësi të nevojshme për projektimin e strukturave arkitektonike;

- Studentët do të përfitojne njohuri dhe aftësi të analizojne në mënyrë kritike dhe vetanake projektet e komplekseve arkitektonike;

- Studentët do të përfitojne njohuri dhe aftësi që të shqyrtojnë dhe analizojnë strukturat artkitektonike në relacionin me planifikimin urban, hapësinor, mjedisin dhe shëndetin publik.

Mësimdhënia ka karakterin e diskutimeve interaktive, duke $\mathrm{i}$ inkuadruar në diskutim të gjithë studentët. Puna në grupe, të cilat marrin angazhime konkrete në formë të projekteve, seminareve dhe eseve. Ligjërata ex cathedra, ushtrime dhe vizita në terren. 
TEMATIKA E ZHVILLUAR - PROJEKTIM 4:

- Zhvillimi i transportit rrugor

- Rrugët e Kosovës

- Transportit rrugor EU

- Karakteristikat e mjeteve transportuese

- KOSOVA - Transporti dhe Siguria

- Treguesit e sigurisë rrugore

- Faktorët kryesorë që shkaktojnë aksidentet

- Strategjia e sigurisë rrugore e UN

- Mjedisi si nocion i të kuptuarit arkitektonik

- Veçoritë sociale

- Mjedisi dhe shoqëria

- Shëndeti publik

- Ndarja e profileve të rrugëve sipas gjërësisë urbane

- Projektimi - Parimet

- Faktorët ekologjik në përzgjedhjen e lokacionit

- Ndotja e mjedisit me gazrat nga automjetet

- Komunikacioni stacionar

- Tipologjitë dhe karakteristikat e vendparkingjeve

- Ndërtesat e komunikacionit stacionar, garazhat

- Teoritë e përzgjedhjes së lokacionit

- Ndarja e garazhave sipas tipologjisë dhe modelit funksional

- Strukturat garazhuese me rampa të drejta të gjata

- Strukturat garazhuese me rampa të drejta të shkurta njëfish të shmangura

- Strukturat garazhuese me rampa të drejta të shkurta dyfish të shmangura

- Tipologjia dhe pozita e rampave në garazhë

- Strukturat garazhuese me etazha të drejta me rampa spirale

- Strukturat garazhuese me etazha të pjerta rethore

- Strukturat garazhuese me etazha të pjerta të Drejta

- Sistemi konstruktiv - vendparkingjet

- Kërkesat për lëvizjen e këmbësorëve

- Pajisjet e tjera në strukturat e garazheve

- Strukturat garazhuese me parkim automatik

- Ndërtesat komerciale ekonomike

- Teoritë e përcaktimit të lokacioneve për ndërtesat komerciale ekonomike

- Planifikimi i ndërtesave komerciale ekonomike

- Konceptet kompozicionale të ndërtesave komerciale ekonomike

- Projektimi i ndërtesave komerciale ekonomike

- Zonat funksionale

- Komunikimi vertikal

- Skemat funksionale organizative

- Ventilim i tërthortë 
- Ajrimi

- Ndriçimi natyror në ndërtesave komerciale ekonomike

- Ndriçimi artificial

- Siguria nga zjarri

- Higjiena

- Hibridizimi

- Rivitalizimi urban

- Harmonia simbiotike, ndërtesa dhe mjedisi

- Ndërtesat me kohë të plotë të funksionimi

- Ndërtesat, simbiozë në vertikale dhe

- Horizontale

- Ndërtesa hibride me funksione dhe qëllime komplekse, dinamike

- Ndërtesa hibride - kompozicionet komplekse, adaptive dhe dinamike

- Ndërtesa hibride - biostrukturat, organike dhe Biomimike

TEMATIKA E ZHVILLUAR - PROJEKTIM 5:

- Komplekset industriale

- Histroriku

- Teoritë e lokacioneve industriale

- Rrugët e Kosovës

- Përzgjedhja e lokacionit në kontekst nacional

- Përzgjedhja e lokacionit në kontekst local

- Teoria e lokacioneve industriale, Alfred Weber

- Teoria e balansit hapësinor

- Teoria e polarizimit

- Teoria e Tony Garnier, Cite Industrielle

- Teoria e Kratzer-it

- Teoria e Masood A. Badri

- Përzgjedhja e lokacionit në kontekst të gjërë

- Përzgjedhja e lokacionit në kontekst të ngushtë

- Faktorët ekologjik në përzgjedhjen e lokacionit

- Burimet e ndotjes

- Ndërtesa industriale dhe mjedisi

- $\quad$ Ndotja e mjedisit me gazra dhe avuj

- Klasifikimi i industrisë

- Klasifikimi sipas veprimtarisë

- Klasifikimi sipas teknologjisë

- Klasifikimi sipas emanimeve në mjedis

- Klasifikimi sipas standardeve internacionale

- Zonat industriale

- Teoritë e zonave industriale

- Vendndodhja dhe rrethina

- Tampon zonat mbrojtëse

- Planifikimi hapësinor i zonave industriale

- Mjedisi dhe shoqëria

- Shëndeti publik 
- Komplekset industriale

- Kompozicionet hapësinore të organizimit të K.I.

- Kompozicioni pavilon

- Kompozicioni bllok

- Kompozicioni i përzier

- Kompozicioni atrial

- Kompozicioni i sistemeve të hapura

- Kërkesat e proceseve teknologjike

- $\quad$ Analiza e vendit të punës

- Organizimi i vendeve të punës

- Modelet e komfortit

- Tipologjia e organizimit të procesit prodhues

- Sistemi analitik

- Sistemi sintetik

- Sistemi kontinual

- Sistemi diskontinual

- Sistemi horizontal

- Sistemi rrethor

- Sistemi I lirë

- Sistemi vertikal

- Sistemet monolite dhe të parafabrikuara

- Strukturat nga beton armea

- Kontruksionet vijore

- Kontruksionet nga guacat

- Kontruksionet nga guacat në dy drejtime

- Kontruksionet e kombinuar

- $\quad$ Strukturat montazhe nga beton armea

- Halla montazhe me konstruksion ram

- Halla montazhe me lanternë

- Halla montazhe me mbajtes asimetrik

- Halla montazhe - sistemi shed

- Halla montazhe - sistemi boalo

- Halla montazhe - sistemi me konstruksion të varur

- Halla montazhe - sistemi i kombinuar

- Halla montazhe - strukturat futuristike

- Strukturat nga çeliku

- Kontruksionet vijore nga profilet e çelikut

- Kontruksionet nga kapriatat vijore

- Kontruksionet nga kapriatat vijore në dy drejtime

- Kontruksionet hapësinore

- Kontruksionet e varura

- Strukturat nga druri i lameluar

- Kontruksionet kapriatë nga druri i lameluar

- Kontruksionet e lehta nga druri i lameluar

- Mbajtësit nga druri i lameluar i ngjitur

- Mbajtësit e kombinuar

- Funksionet e përgjithshme në komplekset indust.

- Partia hyrëse në kompleks industrial

- Restorani

- Laboratorët

- Garderobat

- Tualetët

- Ambulanta

- Garazhat

- Punëtorit

- Zjarrfikesit 
- Parimet dhe kriteret në përzgjedhjen e sist. Konst.

- Kriteret në përzgjedhjen e materialit për konst.

- Ndarja e komunikacionit në kompleks

- Komunikacioni i jashtëm

- Komunikacioni i këmbësorëve

- Komunikacioni automobilistik

- Komunikacioni hekurudhor

- Komunikacioni ujor

- Komunikacioni ajror

- Komunikacioni i brendshëm

- Pajisjet për transport horizontal

- Pajisjet për transport vertikal

- Pajisjet për transport të kombinuar

- Pajisjet për transport ajror, dronët

- Racionalizimi i transportit

- Sistemi i paletave

- Sistemi i kontenjerëve

- Depot e paletave

- Depot me vendosje të lartë

- Depot me vendosje të ultë

- Raste studimore

- Shembuj

- Megastrukturat

- Historiku

- Rentabiliteti ekonomik

- Komunikimi vertikal

- Energjia

- Ndotja

- Ajrimi

- Bio kultivimi

- Skemat funksionale organizative

- Skemat funksionale kultivuese

- E ardhmja dhe ushqimi

- Rendimentet në fermat vertikale

- Mbrojtja nga moti

- Ruajtja e resurseve

- Projektimi i qëndrueshëm arkitektonik

- Parimet udhëheqëse

- Zhvillimi urban

- Komplekset

TEMATIKA E ZHVILLUAR - STUDIO DESIGN:

- Histroriku

- Zhvillimi i qendrave hulumtuese

- Multimedia

- Klasifikimi i qendrave hulumtuese

- Ndarja e qendrave hulumtuese

- Qendra hulumtuese sipas qëllimit

- Qendra hulumtuese sipas rëndësisë 
- Qendra hulumtuese sipas llojit të ekspertizave

- Qendra hulumtuese sipas fushave shkencore

- Standardet

- Projektimi - parimet

- Lokacioni-orientimi

- Kushtet topografike

- Kushtet urbane - ndërtimore

- Kushtet e komunikacionit - qasja

- Kushtet mjedisore

- Kushtet sipas emanimit të rezikut

- Faktorët ekologjik në përzgjedhjen e lokacionit

- Burimet e ndotjes

- Laboratorët dhe mjedisi

- Principet bioklimatike në përzgjedhjen e lokacionit

- Zonat e mbrojtura civile

- Zonat e mbrojtura ushtarake

- Planifikimi hapësinor

- Mjedisi dhe shoqëria

- Shëndeti publik

- Komplekset e qendrave hulumtuese

- Kompozicionet hapësinore të organizimit funksional

- Kompozicioni pavilon

- Kompozicioni bllok

- Kompozicioni i përzier

- Kompozicioni atrial

- Kompozicioni i sistemeve të hapura

- Kërkesat e proceseve hulumtuese

- $\quad$ Analiza e vendit të punës

- Organizimi i vendeve të punës

- Modelet e komfortit

- Barierat fizike - ngritja dhe zbritja

- Tipologjitë e organizimit të laboratorëve

- Ndarja funksionale organizative e laboratorëve

- Kontrolla e sigurisë - rrezet X

- Sistemi analitik

- $\quad$ Sistemi sintetik

- Sistemi kontinual

- Sistemi diskontinual

- Sistemi horizontal

- Sistemi vertikal

- Ajrimi

- Klimatizimi

- Ndriçimi në laboratore

- Raste studimore

- Qendra hulumtuese CGI

- Qendra hulumtuese VNM

- Qendra hulumtuese FOR

- Shembuj

- Pyrgu kontrollues

- Terminalet

- Qendra multimediale

- Zhvillimi i qendrave multimediale

- Struktura kompozicionale dhe funksionale e qendrave multimediale

- Zonimi i qendrave multimediale 
- Kompleksi teknik

- Struktura e kompleksi teknik

- Përkrahja funksionale e kompleksi teknik

- Pajisjet teknologjike

- Design studio

- Zërimi

- Video

- Multimedia modelet

- TV stacionet

- Studiot muzikore

- 'Game modeling' laboratori

- Radio stacionet

- Qendrat për perfomansa vizuele

- Qendrat për instalime artistike

- TI laboratoret

- $\quad$ SGI laboratoret

- 'Motion capture' laboratori

- Efektet speciale laboratori

- Principet bioklimatike projektuese

- Projektimi i qëndrueshëm arkitektonik

- Modeli kompozicional i funksioneve hibride

- Teknologjitë bashkëkohore - sistemet

- Higjiena - Kërkesat

- Personat me kërkesa të veçanta

TEMATIKA E ZHVILLUAR - PROJEKTIM 8:

- Histroriku

- Zhvillimi i aeroporteve

- Fushat ajrore në republikën e kosovës

- Klasifikimi i aeroporteve

- Ndarja e aeroporteve

- Aeroporte sipas qëllimit

- Aeroporte sipas rëndësisë

- Aeroporte sipas llojit të fluturakëve që përdorin

- Aeroporte sipas gjatësisë të shtegut fluturues aterrues

- Standardet

- ICEAO

- Struktura organizative e acc-së

- Projektimi - parimet

- Lokacioni-orientimi

- Kushtet topografike

- Kushtet urbane - ndërtimore

- Kushtet e komunikacionit - qasja

- Kushtet meteorologjike

- Faktorët ekologjik në përzgjedhjen e lokacionit

- Burimet e ndotjes

- Aeroporti dhe mjedisi

- Ndotja e mjedisit me gazrat nga aeroporti

- Zonat e mbrojtura dhe sipërfaqet imagjinare

- Shtigjet fluturuese aterruese

- Llojet e shtigjeve fluturuese aterruese

- Caktimi i gjatësisë i shtigjeve fluturuese/ateru. 
- Karakteristikat teknike të shtigjeve

- Tipet e shtigjeve

- $\quad$ Sistemi paralel i shtigjeve

- $\quad$ Sistemi i shmangur i shtigjeve

- $\quad$ Sistemi i hapur i tipologjisë " $V$ " i shtigjeve

- $\quad$ Sistemi i kryqëzuar i tipologjisë " $X$ " i shtigjeve

- Sistemi i tipologjisë së mbyllur të shtigjeve

- Gjatësia e shtigjeve fluturuese aterruese

- Karakteristikat dhe mundësitë e shmangies së shtigjeve

- Platformat pranuese dhe vendqëndrimi i aeroplanëve

- Platformat me operim të trajtës së thjeshtë

- Platformat me operim të trajtës lineare

- Platforma me operim të trajtës së zgjatur "Finger"

- Plaforma me operim të trajtës "Satelit"

- Platforma me operim të trajtës së kombinuar "Finger Satelit"

- $\quad$ Platforma me operim të trajtës së hapur

- Platformat parkuese dhe taksimi i aeroplanëve

- Urat fleksibile për hyrje/dalje nga terminali

- Barierat fizike - ngritja dhe zbritja

- Ndërtesa kryesore operative - terminali

- Ndarja funksionale organizative e terminalit

- Trakti publik i terminalit

- Trakti i aviacionit

- Zhvillimi konceptual dhe funksioni vertikal I aeroporteve

- Komunikimi i pasagjerëve në ndërtesë -

- marrja e bagazhit

- Komunikimi i pasagjerëve në ndërtesë - shiriti i pafundëm - eskalatorët

- Holli - "book in" - marja e biletave

- Holli - "check in" - transporteri i bagazhit

- Kontrolla e sigurisë - rrezet X

- Bokset për pritje

- Hotelet në kompleksin e aeroporteve

- Evoluimi i aeroplanëve dhe kapacitetet

- Ajrimi

- Klimatizimi

- Ndriçimi në aerodrome

- Raste studimore

- Phoenix sky harbor international airport - phx

- Terminali 3

- Terminali 4, Barry M. Goldwater Terminal

- Pyrgu kontrollues

- John F. Kennedy international airport - JFK

- Terminali 4

- Transporti ajror në republikën e kosovës

- Kargo terminalet

- Zhvillimi i kargo terminaleve

- Struktura kompozicionale dhe funksionale e kargo terminaleve

- Dimensionët e kontenjerëve të kargo transportit 
- Kompleksi teknik

- Struktura e kompleksi teknik

- Përkrahja funksionale e kompleksi teknik

- Pastrimi i shtigjeve fluturuese/aterruese

- Regjimi dimëror operativ

- Operimet e zjarrfikjes

- Operimet gjatë rasteve të shpëtimit

- Aeroporte modele

- Dubai international airport - DXB

- Orlando international airport - MCO

- Genoa Cristoforo Colombo airport - GOA

- Sacramento international airport - SMF

- Seattle-tacoma international airport - SEA

- Frankfurt international airport - FRA

- Incheon airport, Seoul - ICN

- Dallas/F. worth international airport - DFW

- Chicago, O'hare airport - ORD

- Higjiena - Kërkesat - Tualetët

- Barazia humane

- Personat me kërkesa të veçanta

- Simbolet - Parimet udhëheqëse

- Planifikimi hapësinor - Zhvillimi urban 
HYRJE

KJO FAQE ËSHTË LËNË QËLLIMISHT E ZBRAZËT! 


\section{0+ FOTO PUNIME TË STUDENTËVE}

\subsection{PUNIMET E STUDENTËVE}

Niveli Bachelor 2016/17¹ . Fakulteti i Ndërtimtarisë dhe Arkitekturës, Universiteti i Prishtinës. Departamenti i Arkitekturës. Lënda: Projektim 4. Studentët: Alen Ajdarpasic, Fjollëza Bunjaku.



Figura 1. Analizat e Situacionit (Burimi): Alen Ajdarpasic, Fjollëza Bunjaku, 2016.

1 Alen Ajdarpasic, Fjollëza Bunjaku. Lënda: Projektim 4. Punimi i tërë sipas dorëzimit final. FNA, UP. 


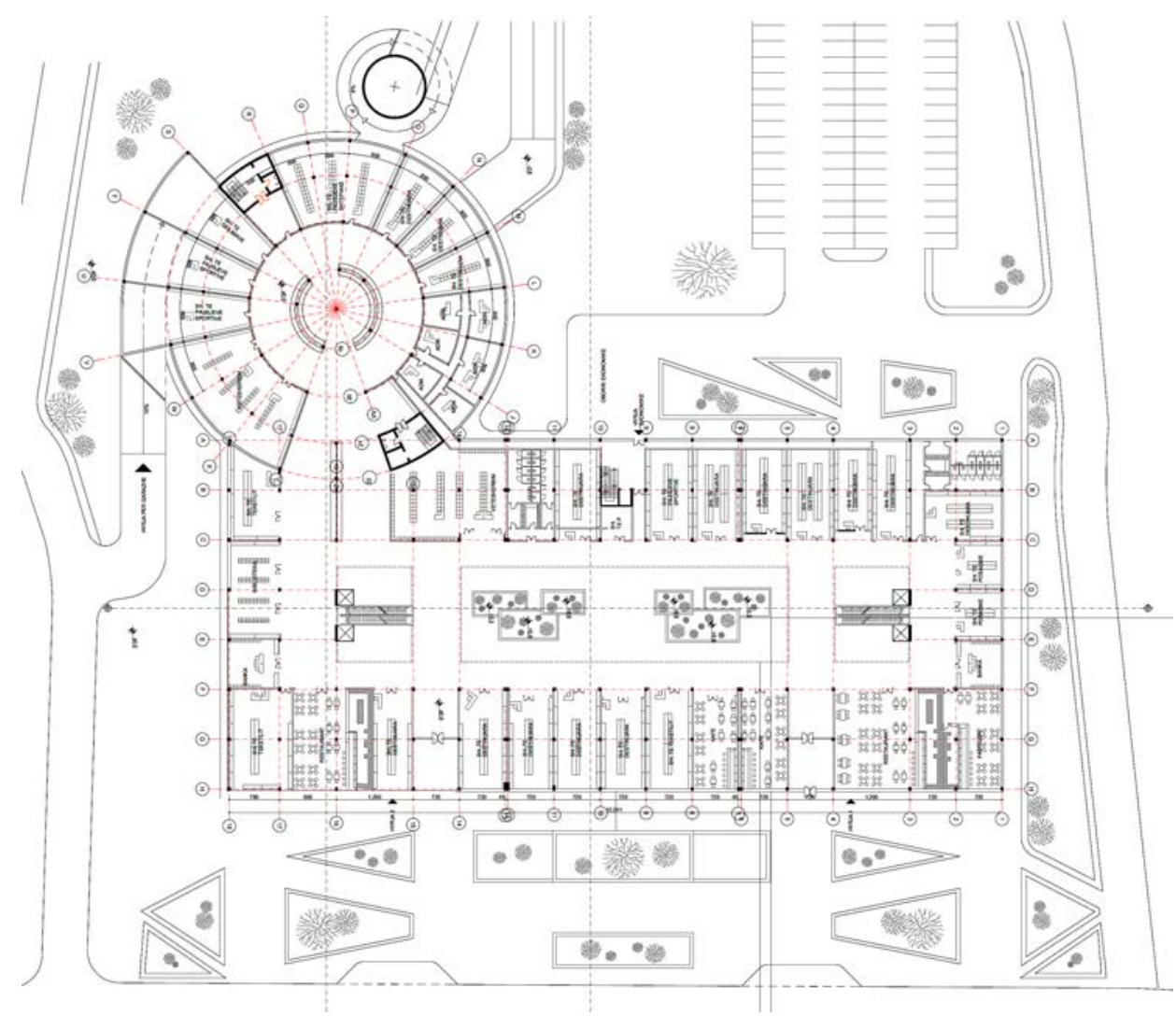

Figura 2. Baza e përdhesës

(Burimi): Alen Ajdarpasic, Fjollëza Bunjaku, 2016.

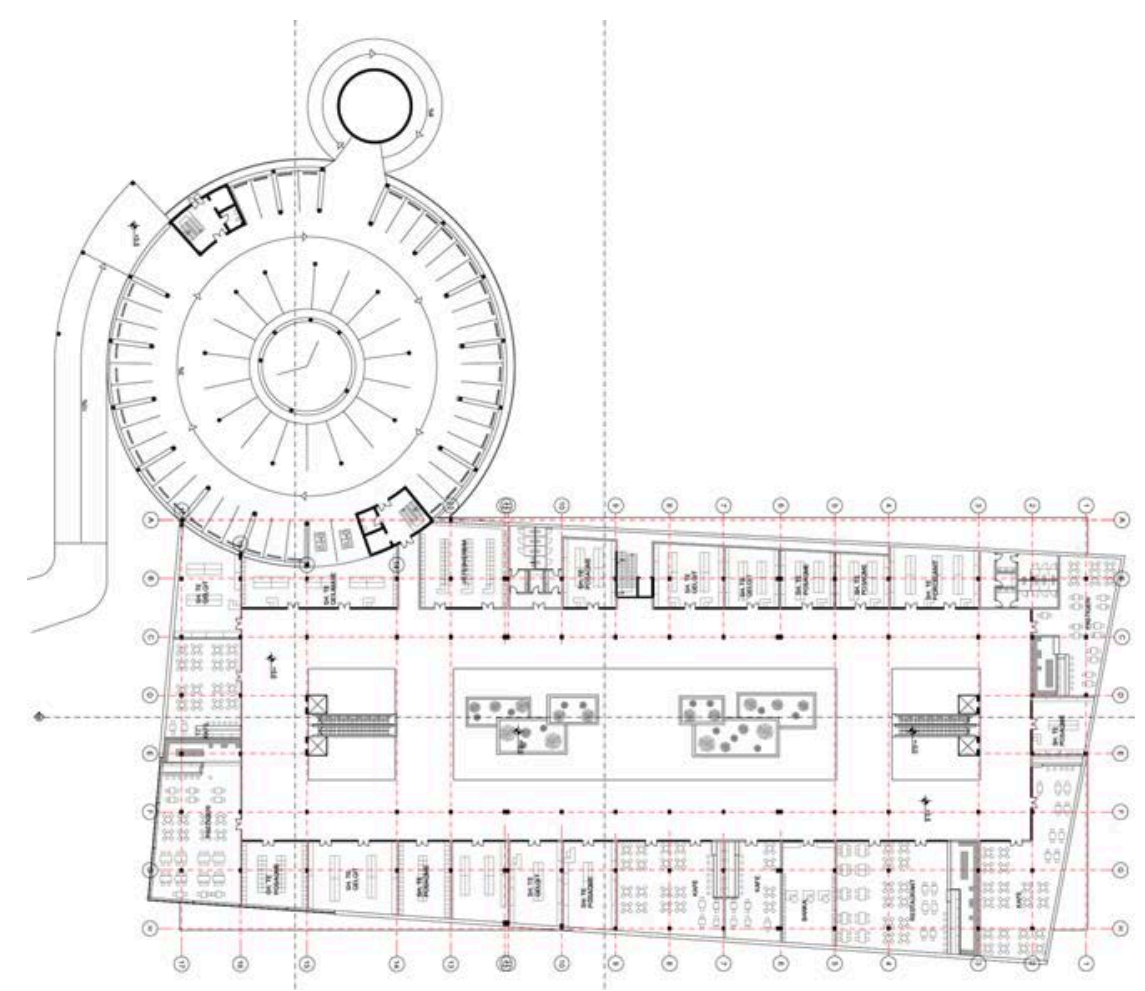

Figura 3. Baza e katit

(Burimi): Alen Ajdarpasic, Fjollëza Bunjaku, 2016. 

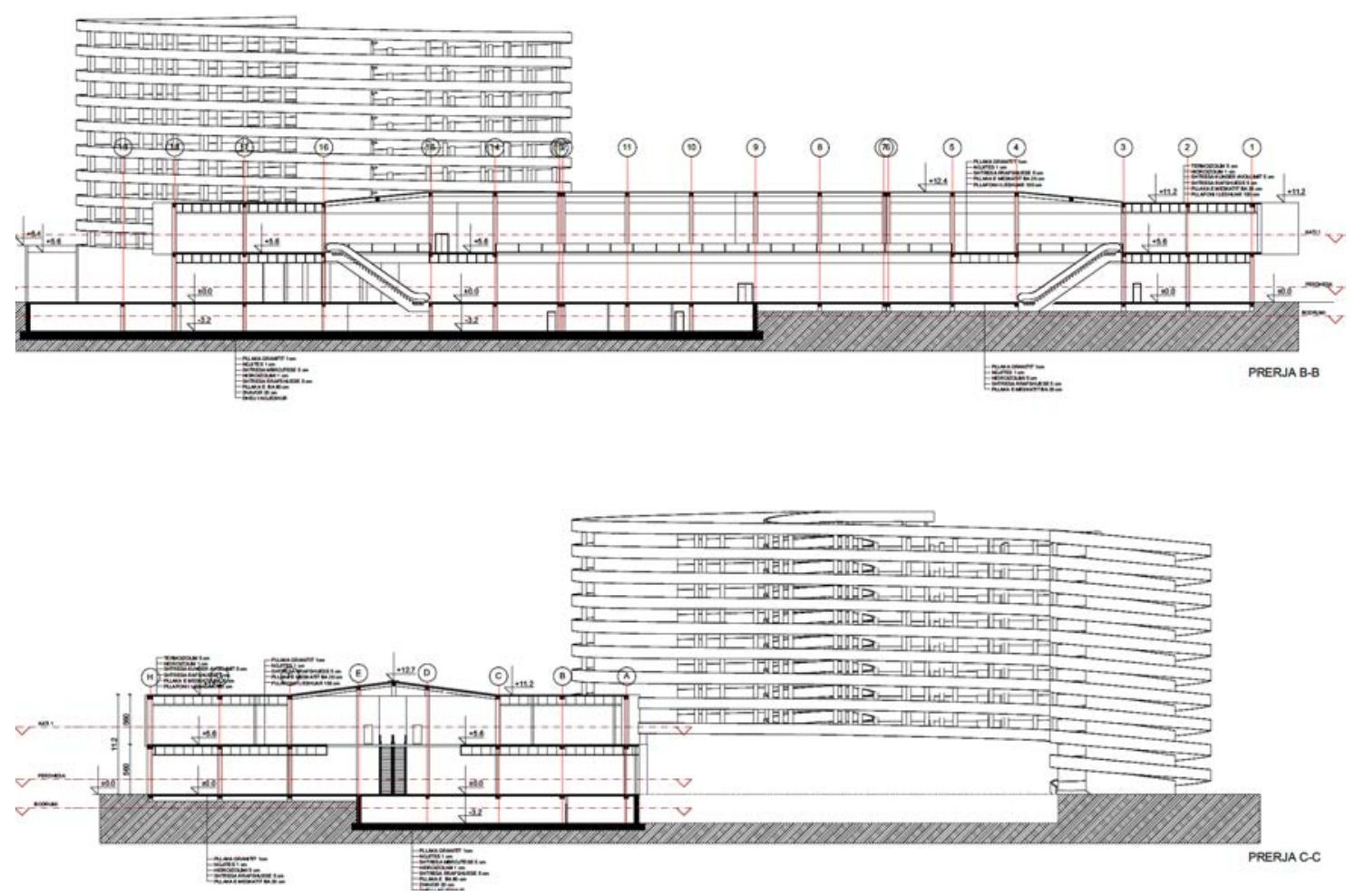

Figura 4. Prerjet

(Burimi): Alen Ajdarpasic, Fjollëza Bunjaku, 2016.

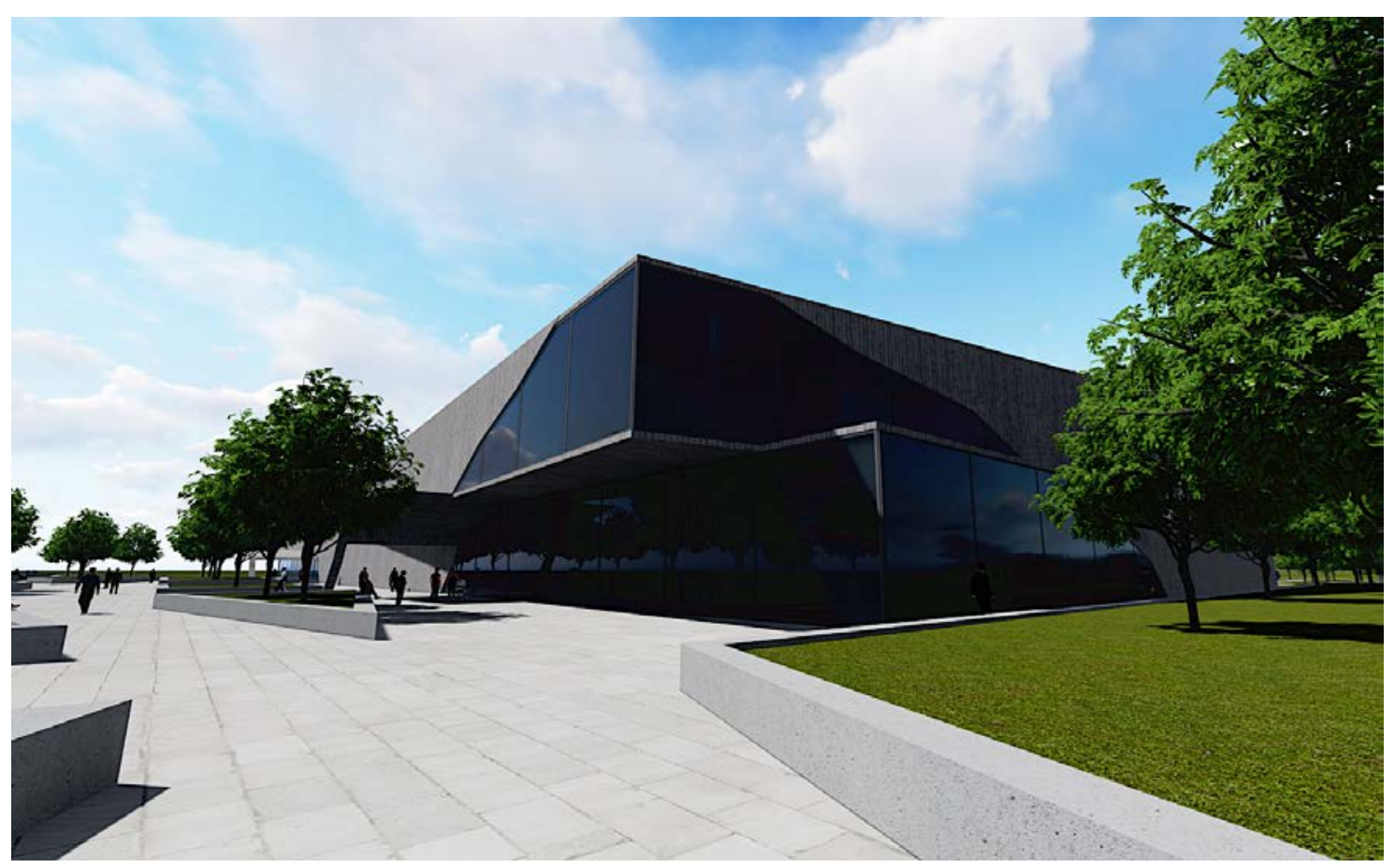

Figura 5. Perspektiva

(Burimi): Alen Ajdarpasic, Fjollëza Bunjaku, 2016. 


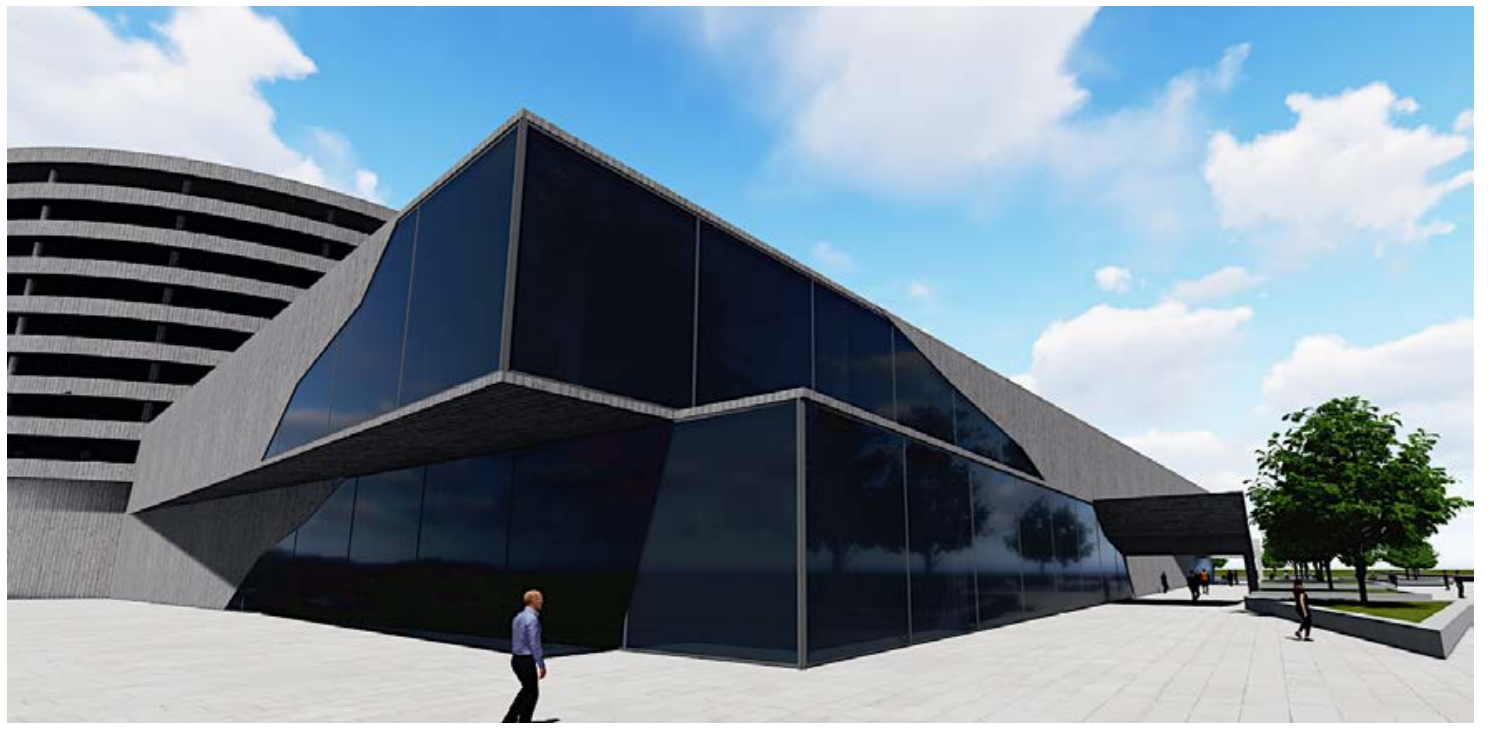

Figura 6. Perspektiva

(Burimi): Alen Ajdarpasic, Fjollëza Bunjaku, 2016.

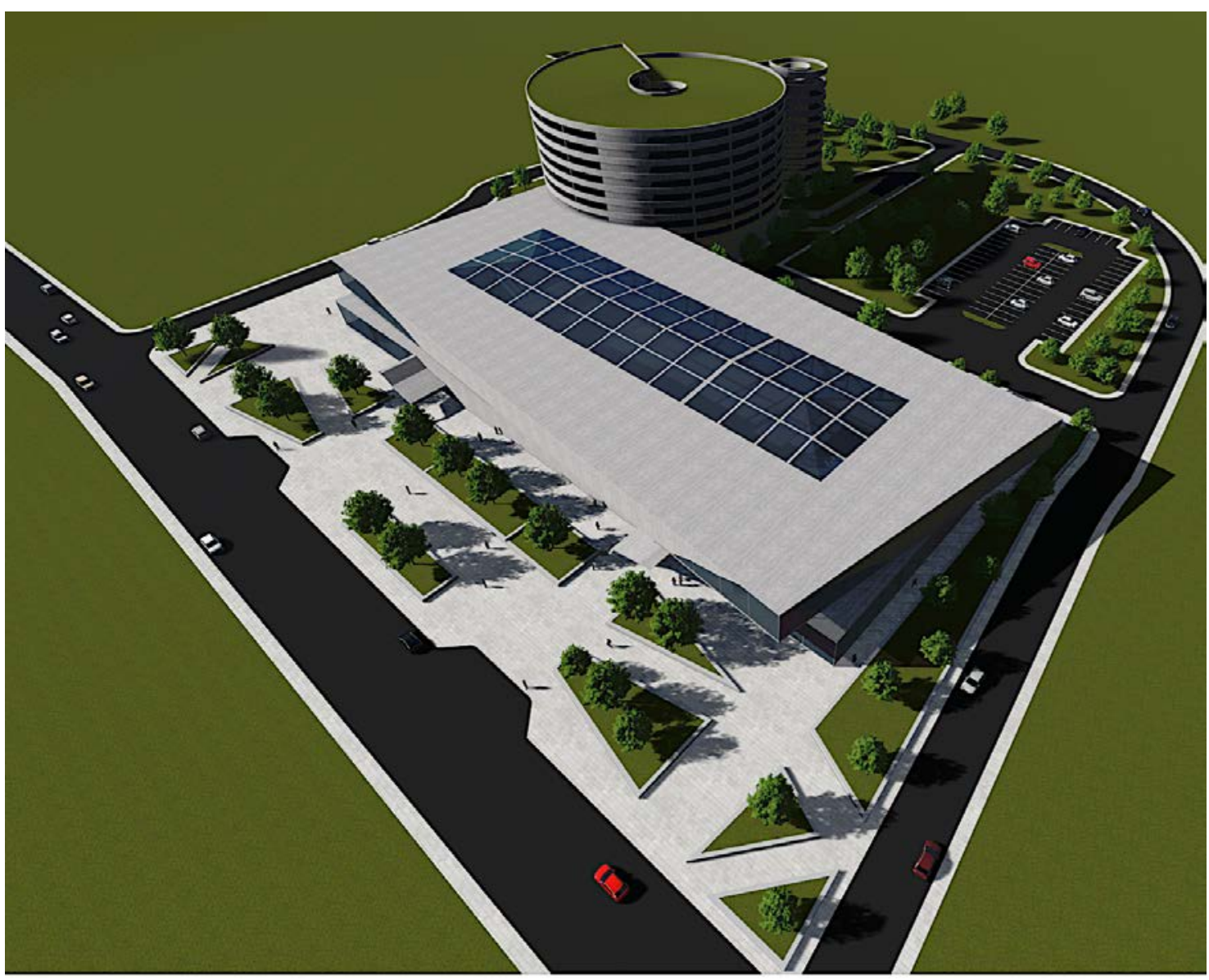

Figura 7. Perspektiva

(Burimi): Alen Ajdarpasic, Fjollëza Bunjaku, 2016. 


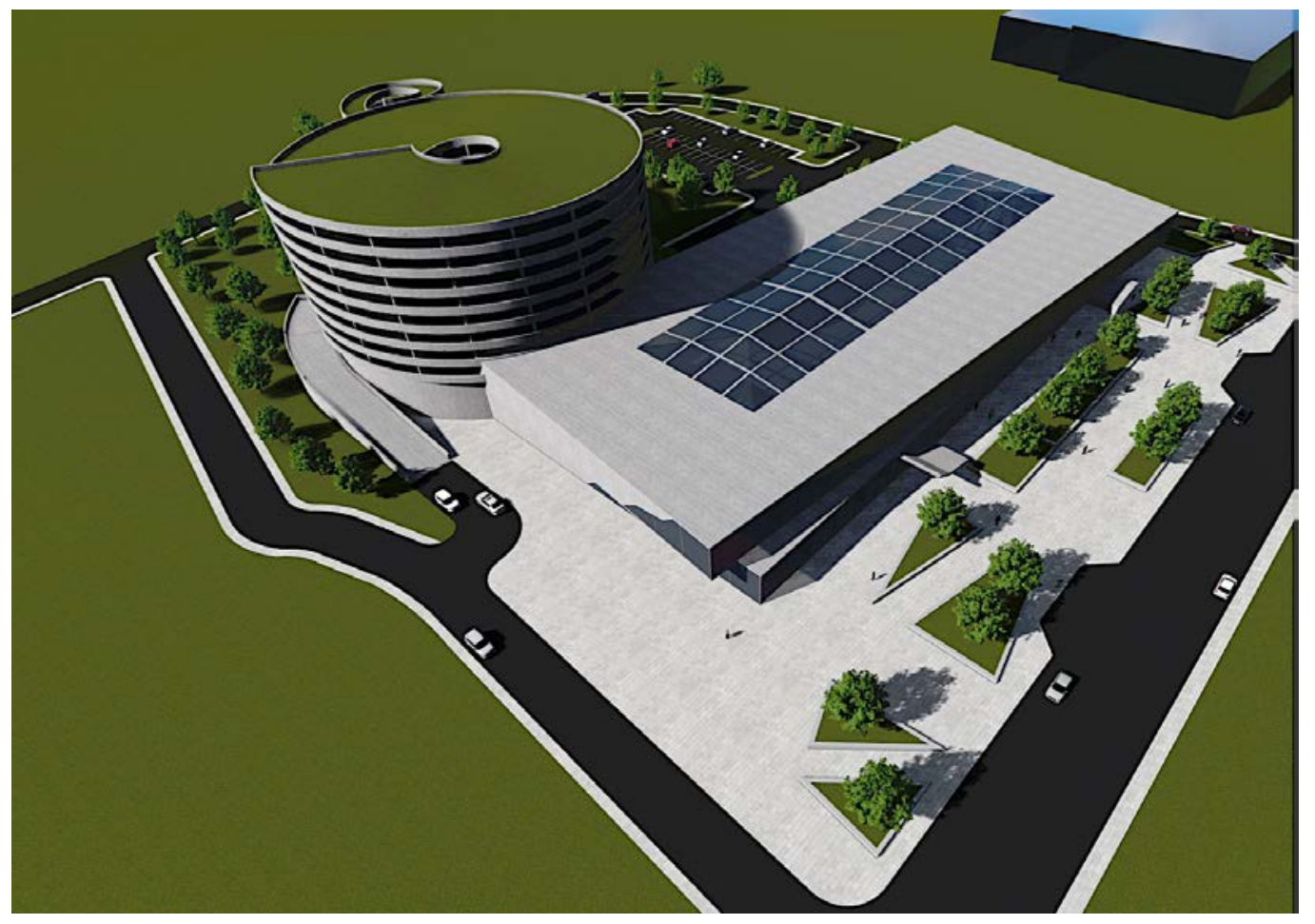

Figura 8. Perspektiva

(Burimi): Alen Ajdarpasic, Fjollëza Bunjaku, 2016.

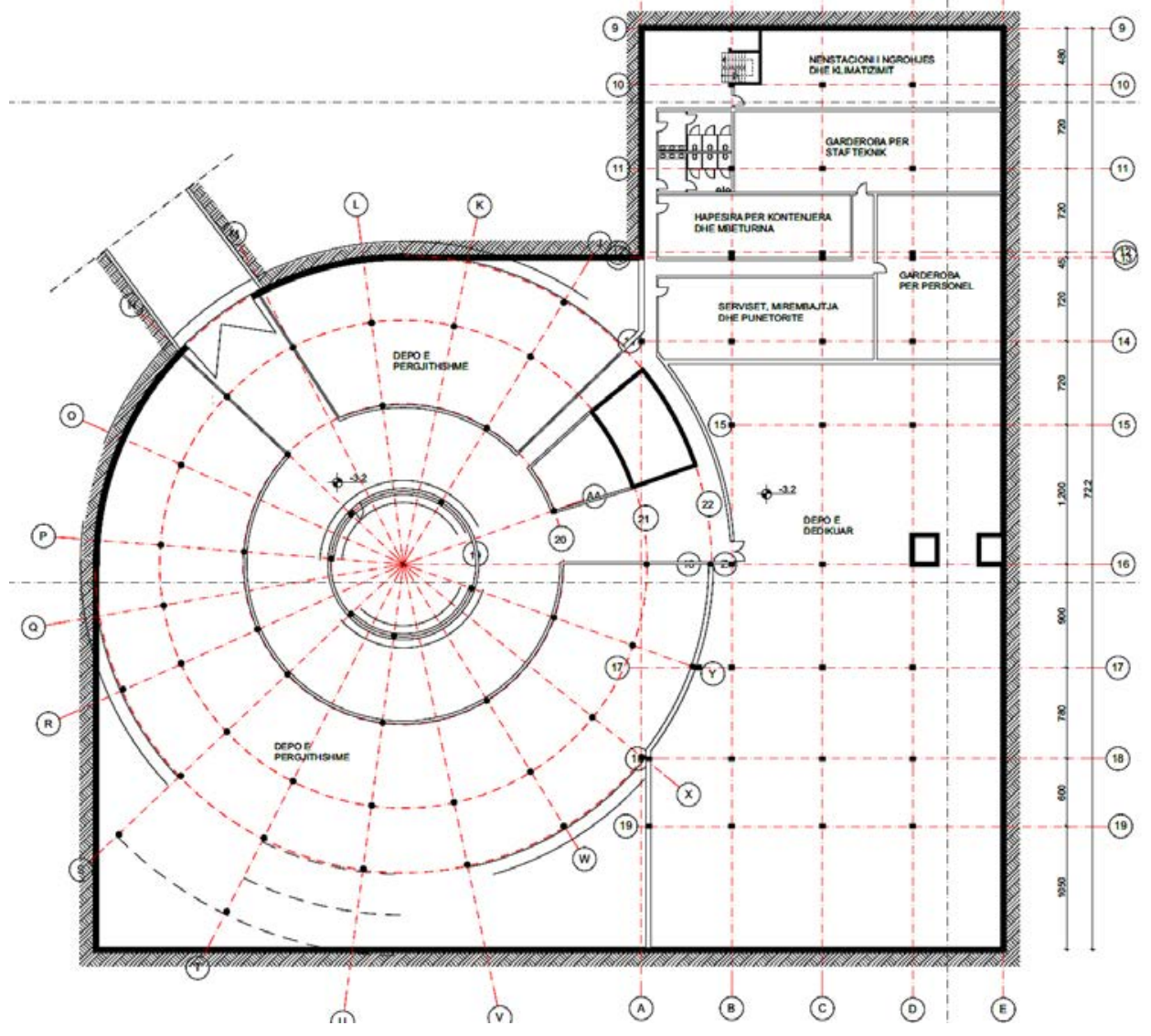

Figura 9. Baza e bodrumit

(Burimi): Alen Ajdarpasic, Fjollëza Bunjaku, 2016. 
Niveli Bachelor 2016/17². Fakulteti i Ndërtimtarisë dhe Arkitekturës, Universiteti i Prishtinës. Departamenti i Arkitekturës. Lënda: Projektim 4.

Studentët: Festim Haliti, Uran Sadikaj.
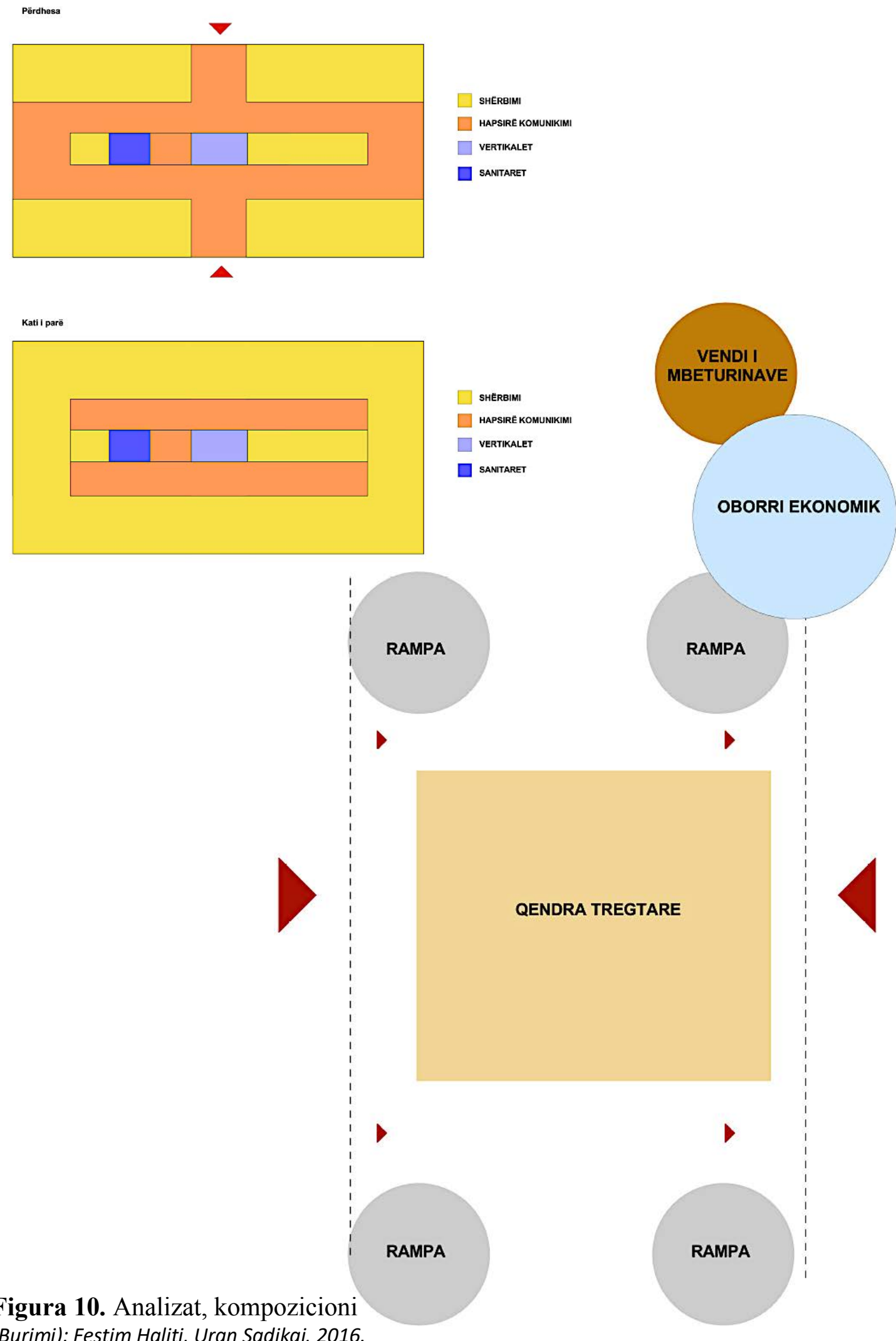

Figura 10. Analizat, kompozicioni
(Burimi): Festim Haliti, Uran Sadikaj, 2016

2 Festim Haliti, Uran Sadikaj. Lënda: Projektim 4. Punimi i tërë sipas dorëzimit final. FNA, UP. 




Figura 11. Baza e përdhesës

(Burimi): Festim Haliti, Uran Sadikaj, 2016. 

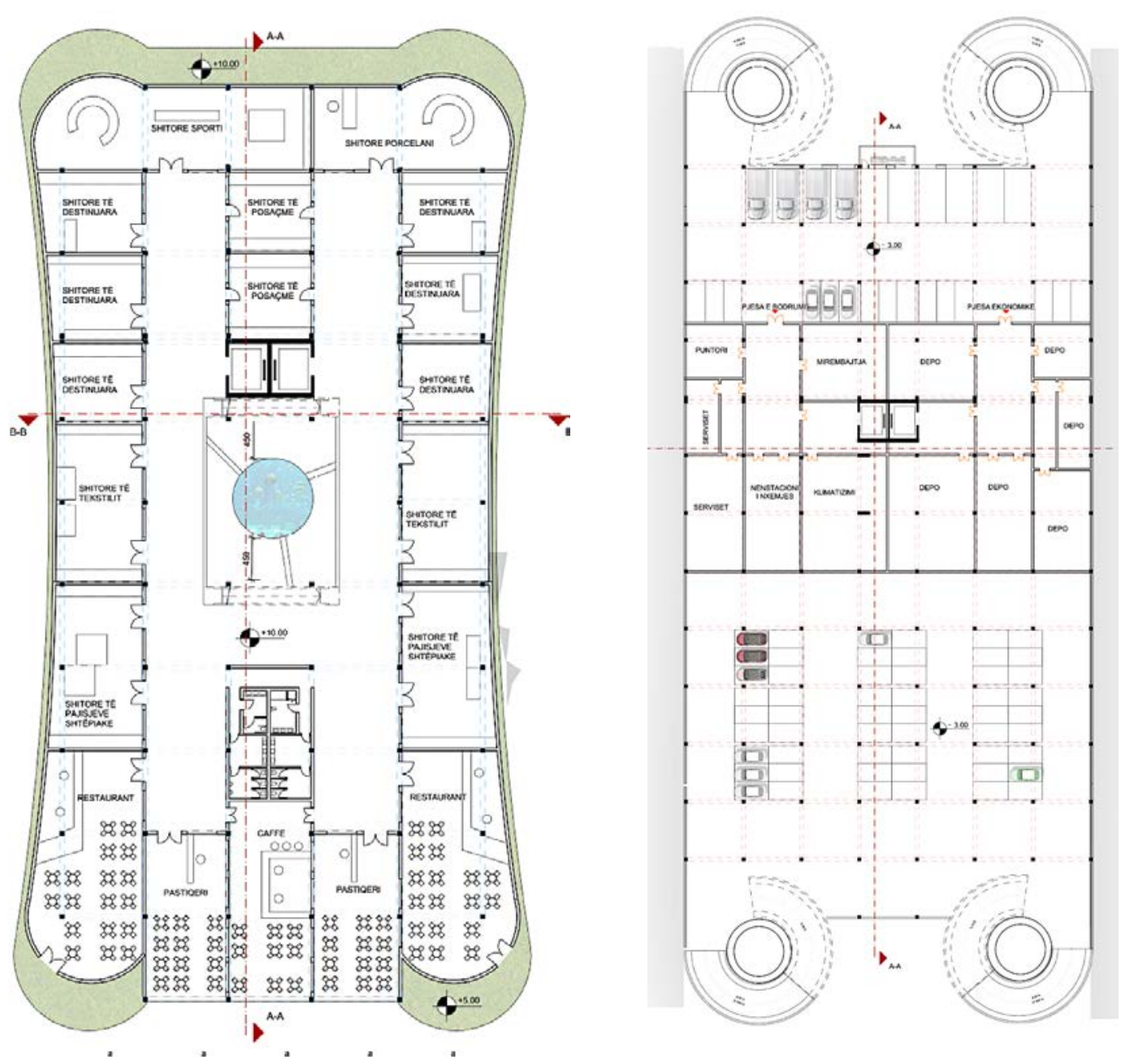

Figura 12. Baza e katit dhe bodrumit (Burimi): Festim Haliti, Uran Sadikaj, 2016.

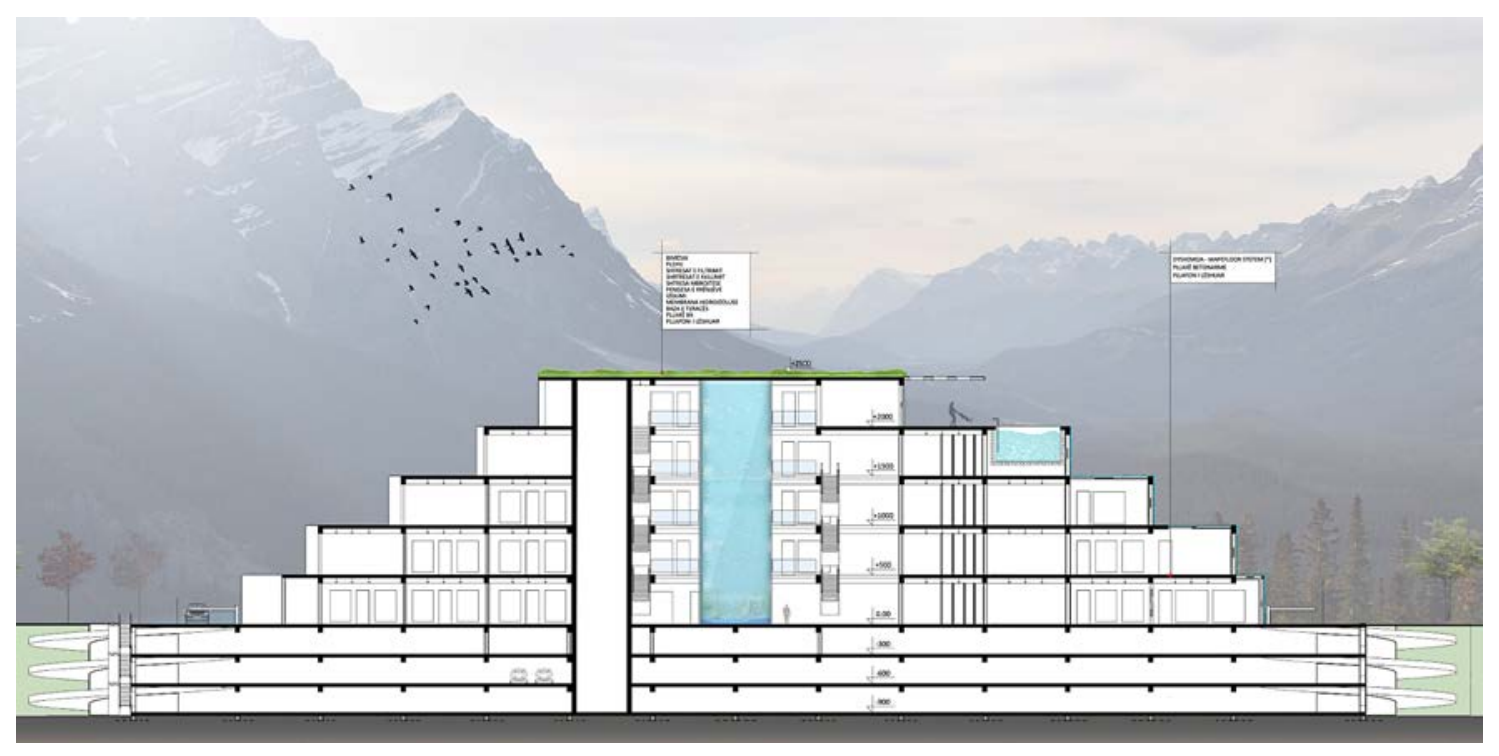

Figura 13. Prerja A

(Burimi): Festim Haliti, Uran Sadikaj, 2016. 


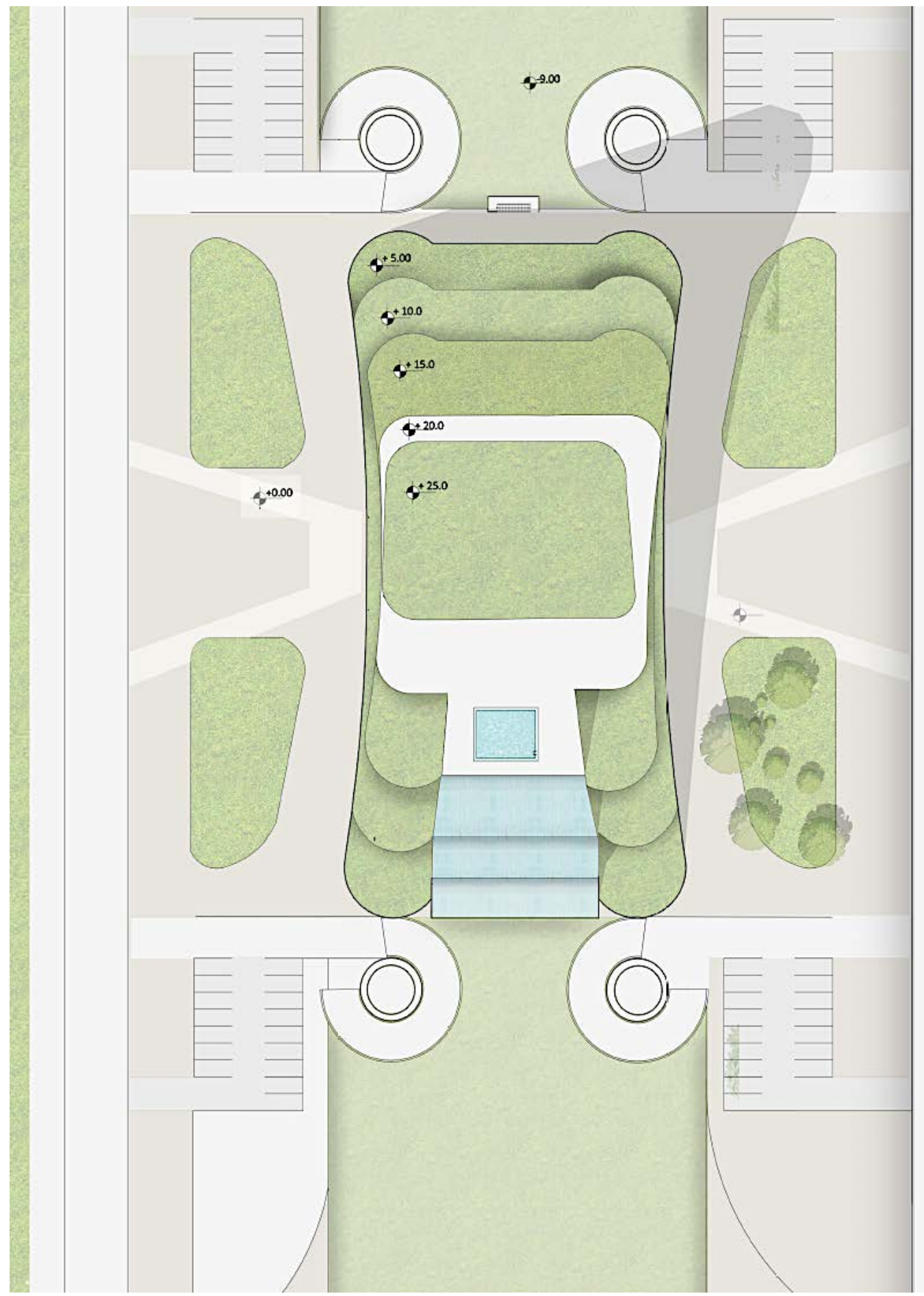

Figura 14. Situacioni

(Burimi): Festim Haliti, Uran Sadikaj, 2016. 


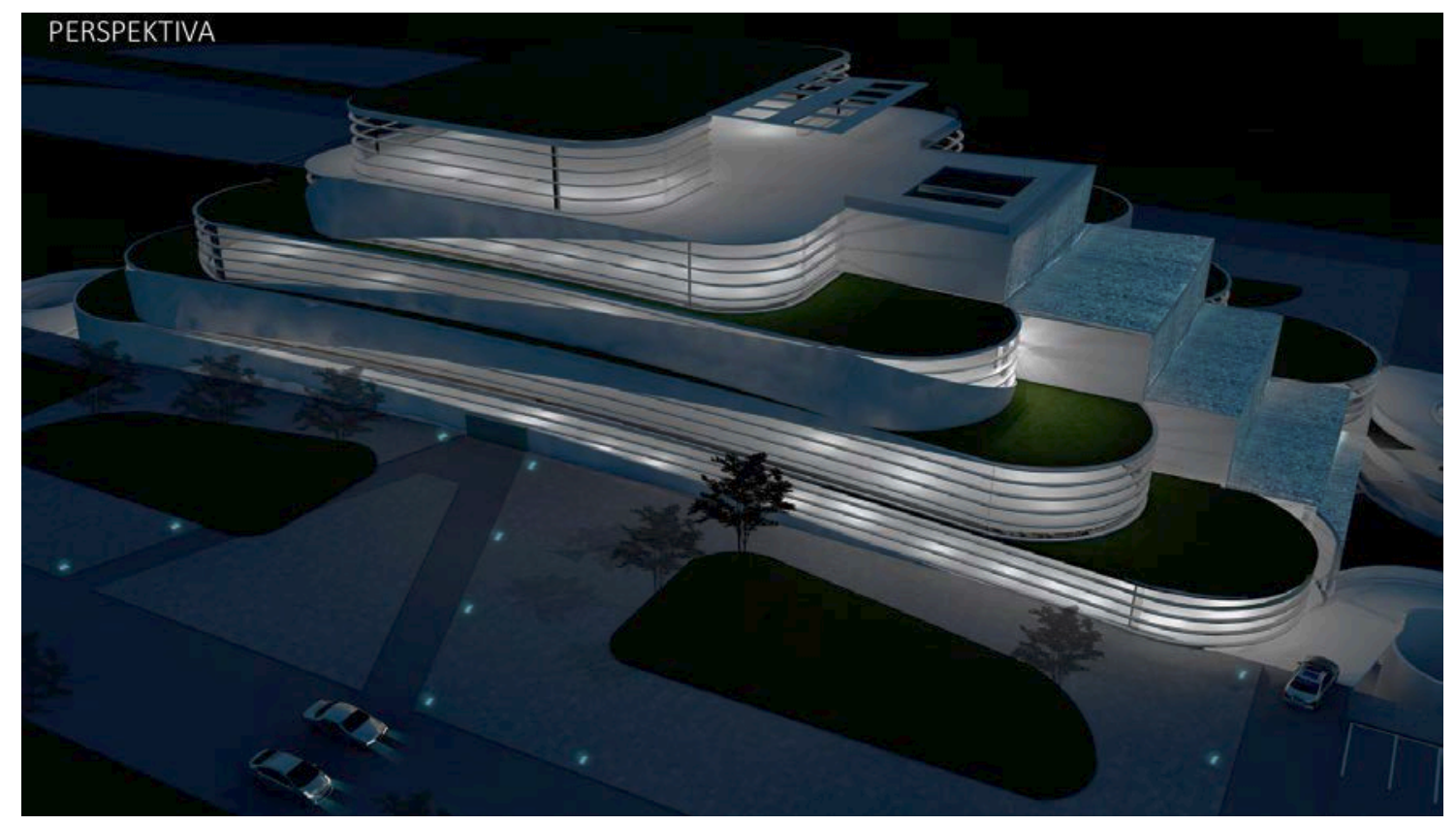

Figura 15. Perspektiva

(Burimi): Festim Haliti, Uran Sadikaj, 2016

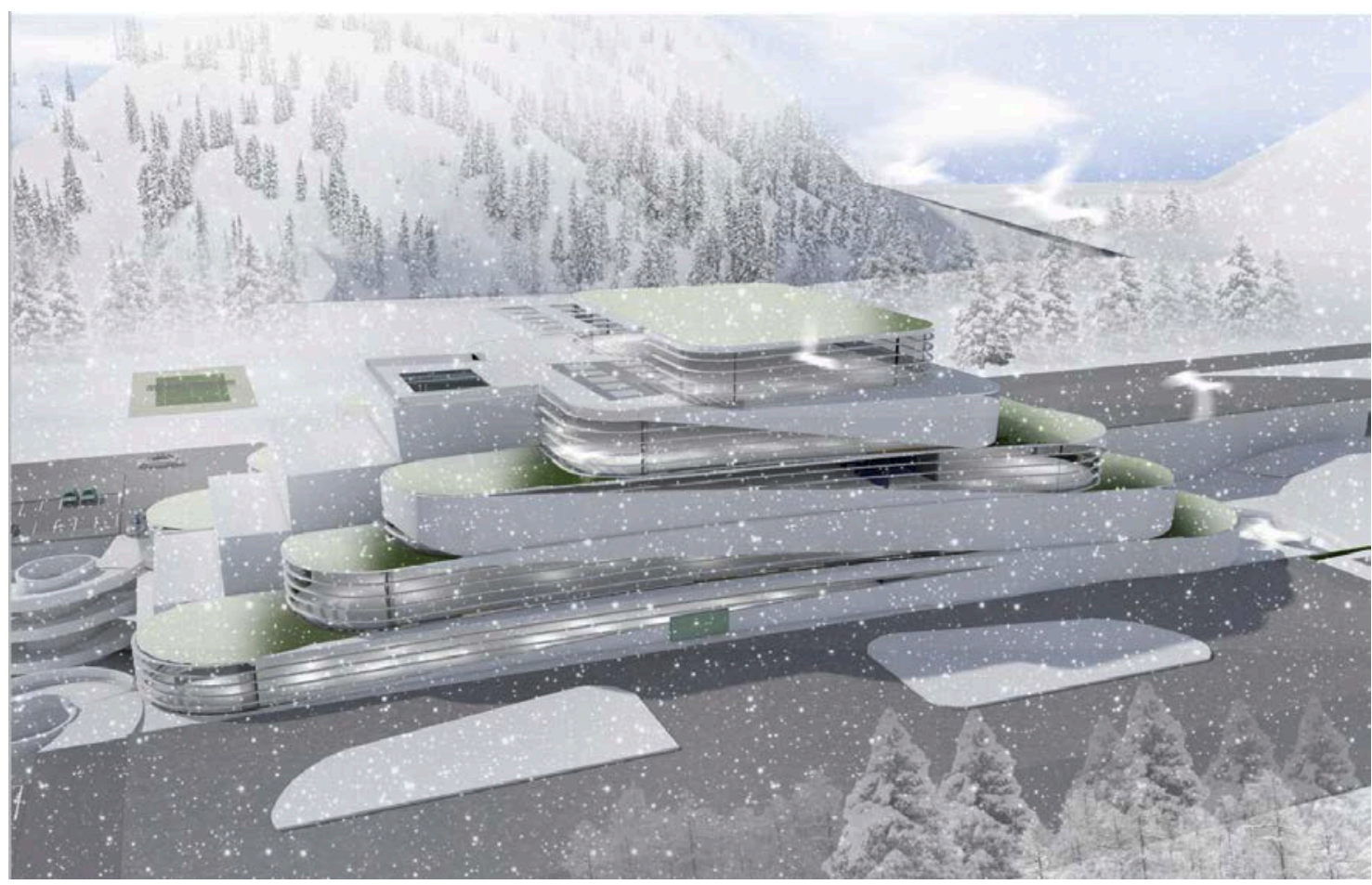

Figura 16. Perspektiva

(Burimi): Festim Haliti, Uran Sadikaj, 2016 


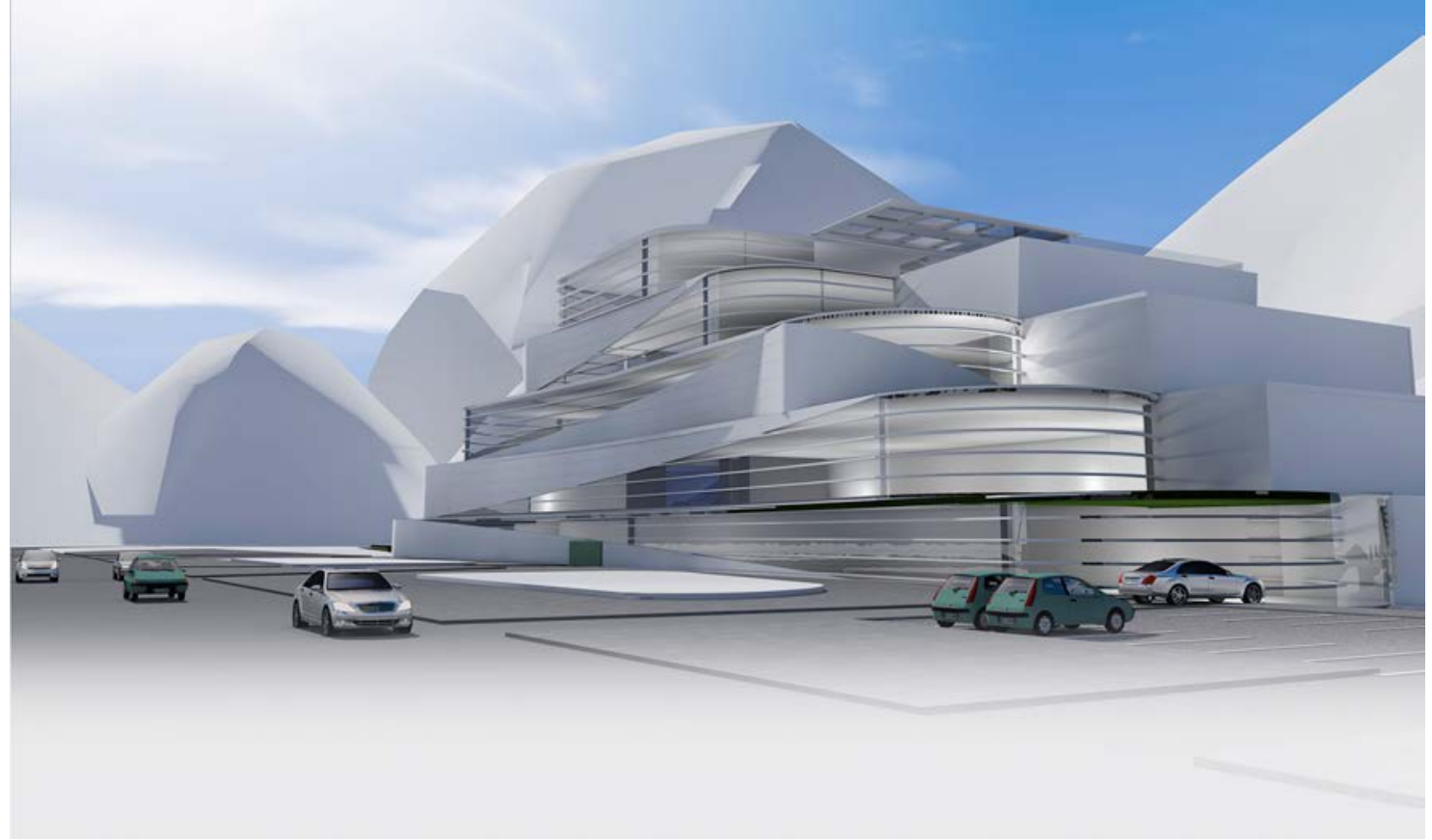

Figura 17. Perspektiva

(Burimi): Festim Haliti, Uran Sadikaj, 2016

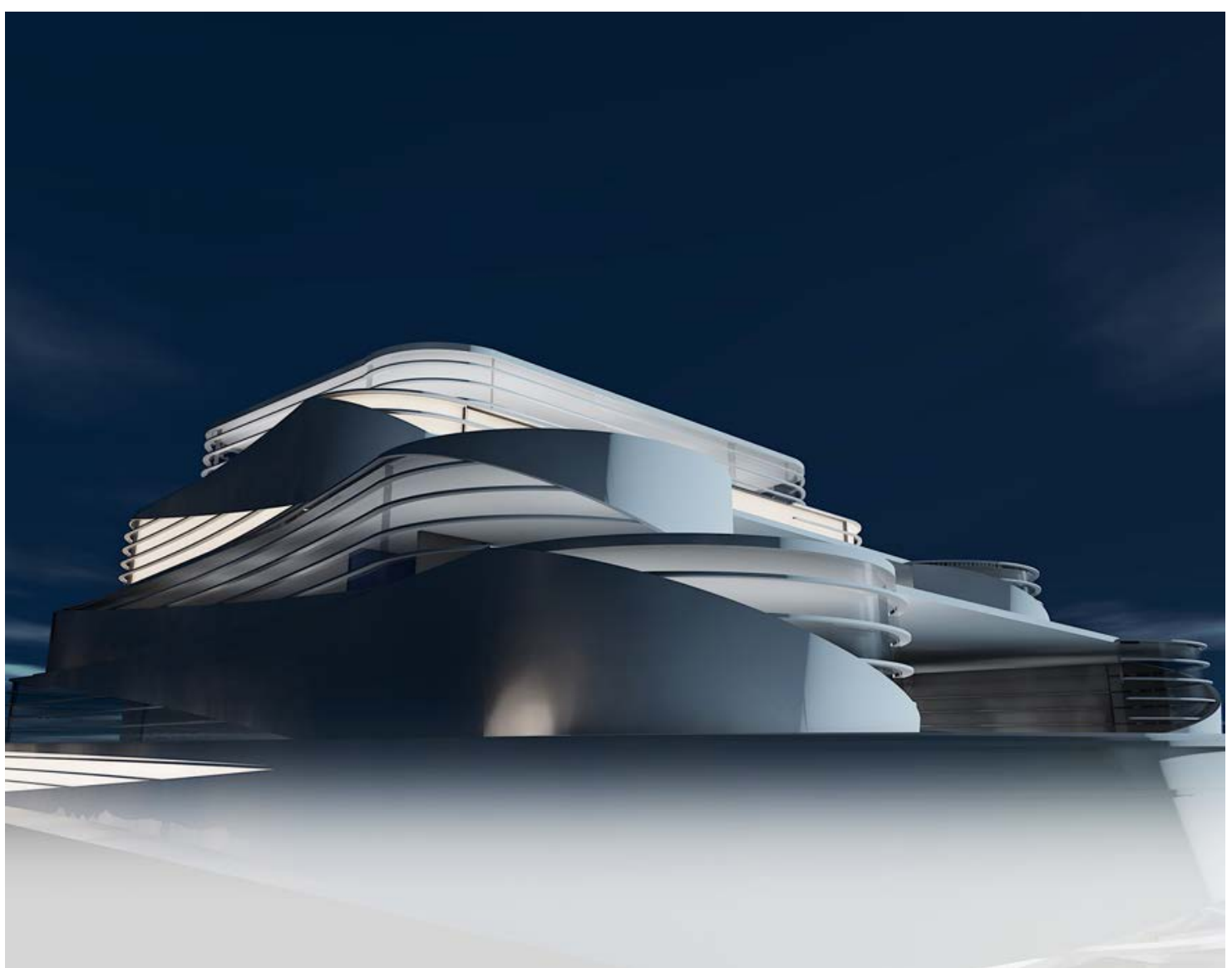

Figura 18. Perspektiva

(Burimi): Festim Haliti, Uran Sadikaj, 2016 


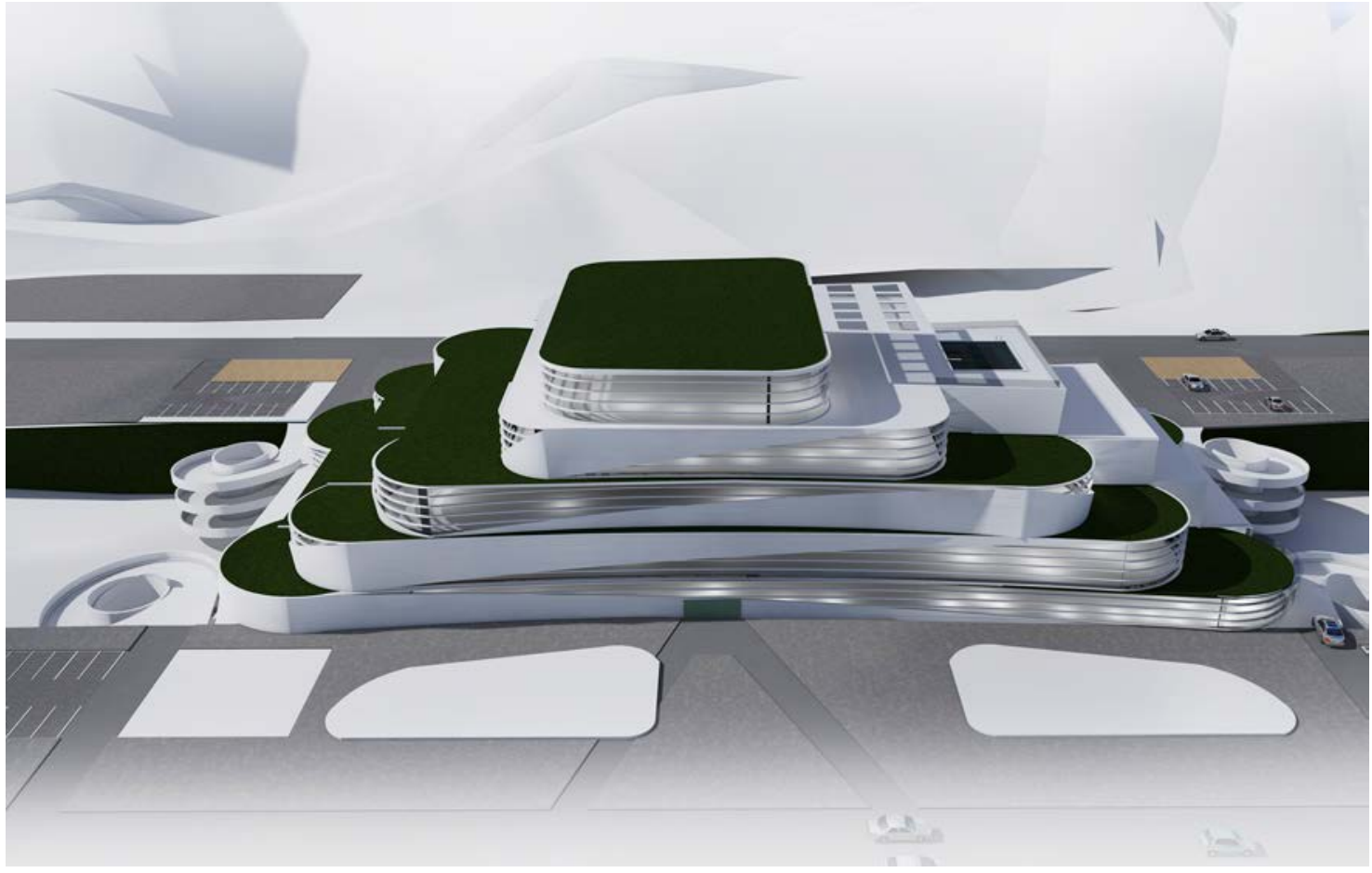

Figura 19. Perspektiva

(Burimi): Festim Haliti, Uran Sadikaj, 2016

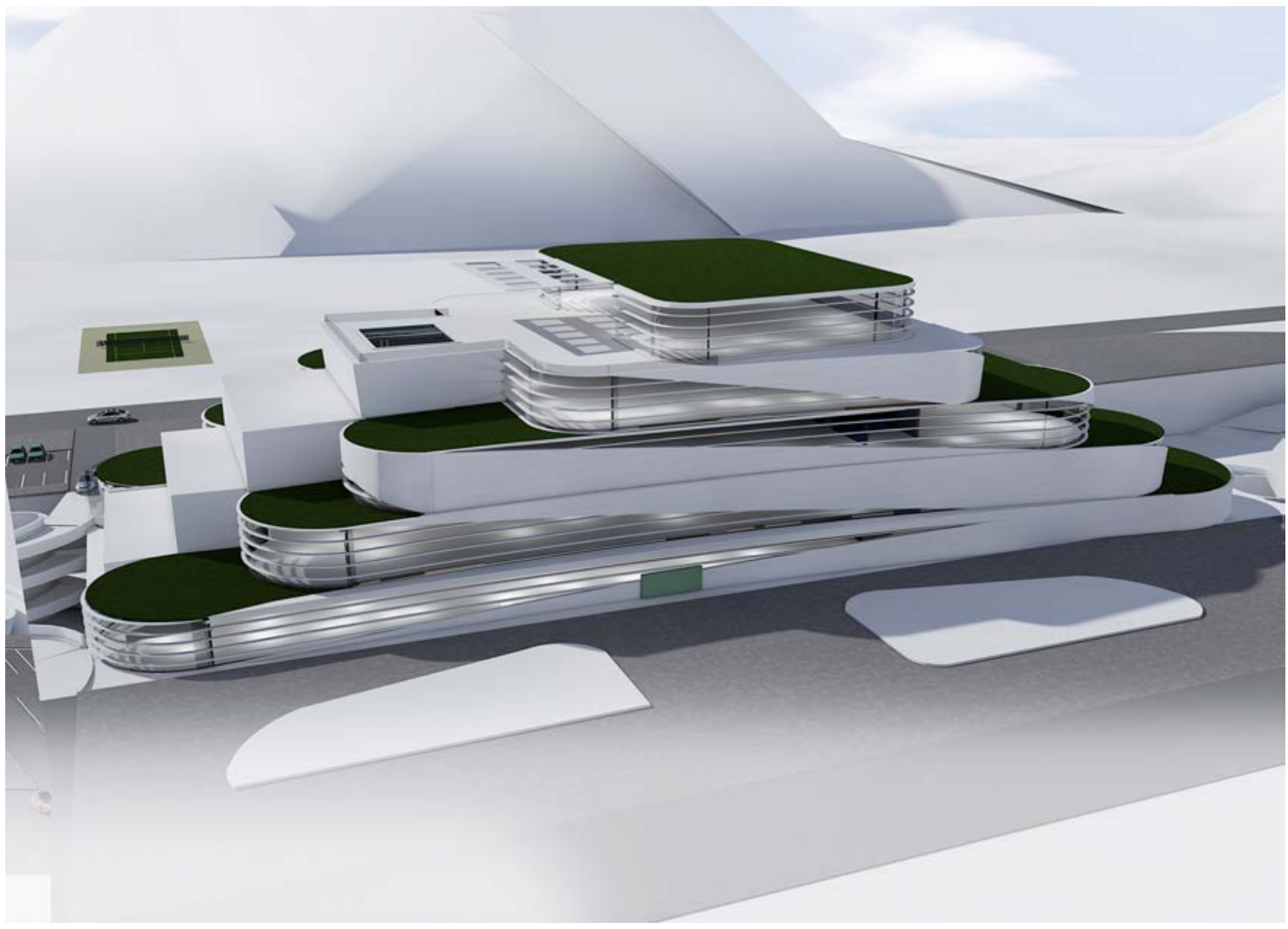

Figura 20. Perspektiva

(Burimi): Festim Haliti, Uran Sadikaj, 2016 
Niveli Bachelor 2016/1733. Fakulteti i Ndërtimtarisë dhe Arkitekturës, Universiteti i Prishtinës. Departamenti i Arkitekturës. Lënda: Projektim 4.

Studentët: Diella Shabani, Diellza Demiri.

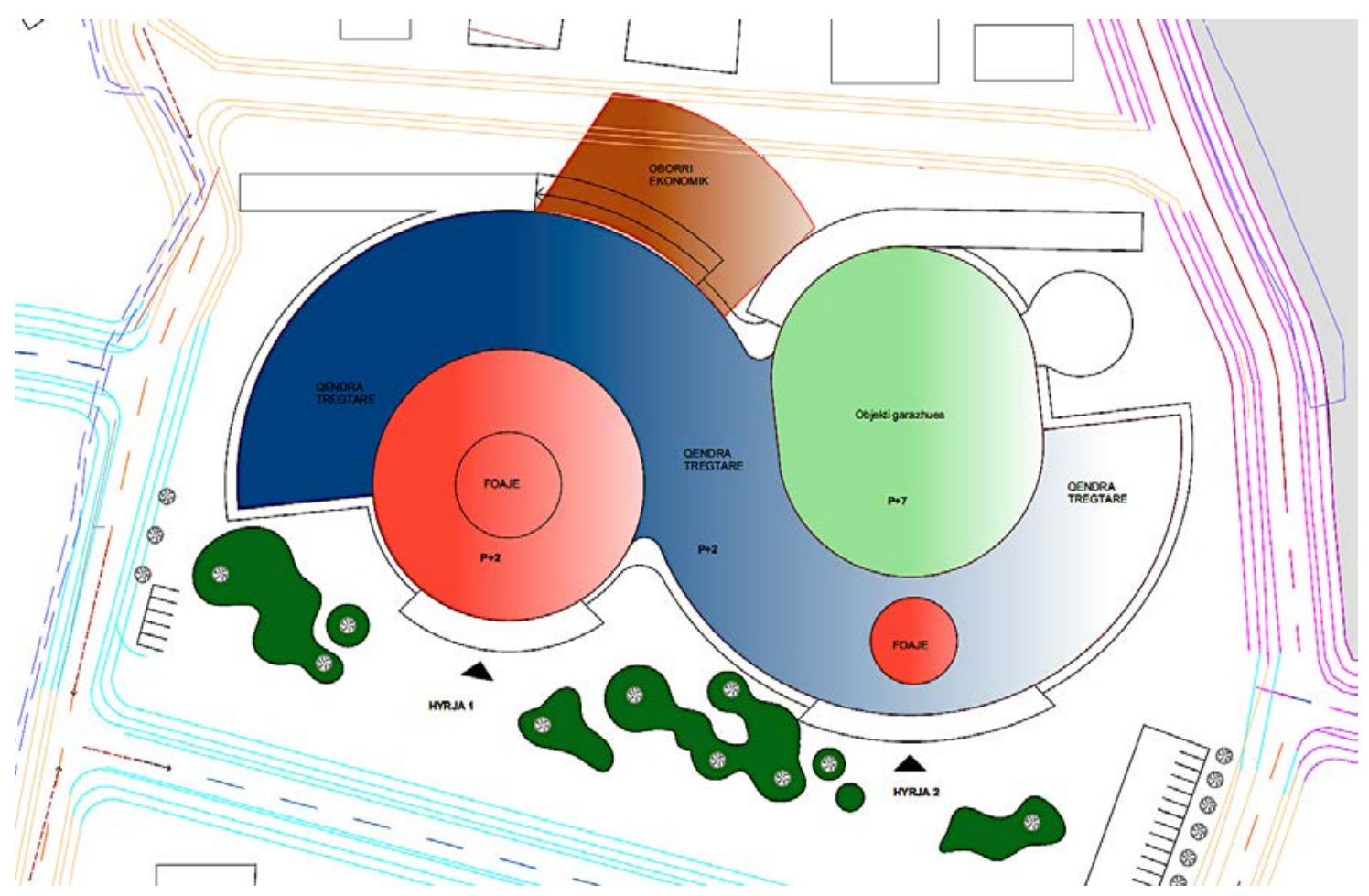

Figura 21. Situacioni

(Burimi): Diella Shabani, Diellza Demiri, 2016

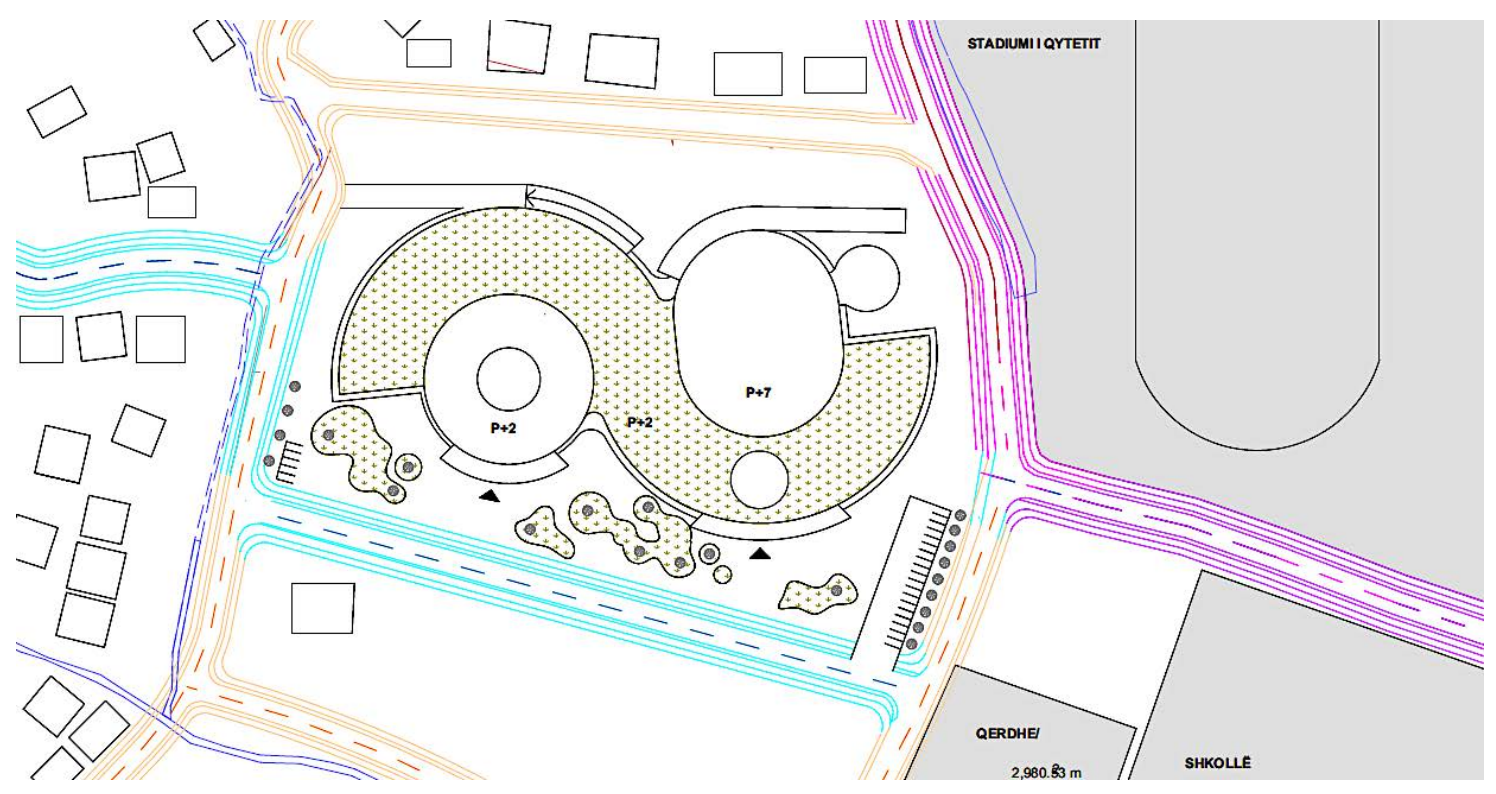

Figura 22. Situacioni

(Burimi): Diella Shabani, Diellza Demiri, 2016

3 Diella Shabani, Diellza Demiri. Lënda: Projektim 4. Punimi i tërë sipas dorëzimit final. FNA, UP. 




Figura 23. Baza e përdhesës

(Burimi): Diella Shabani, Diellza Demiri, 2016

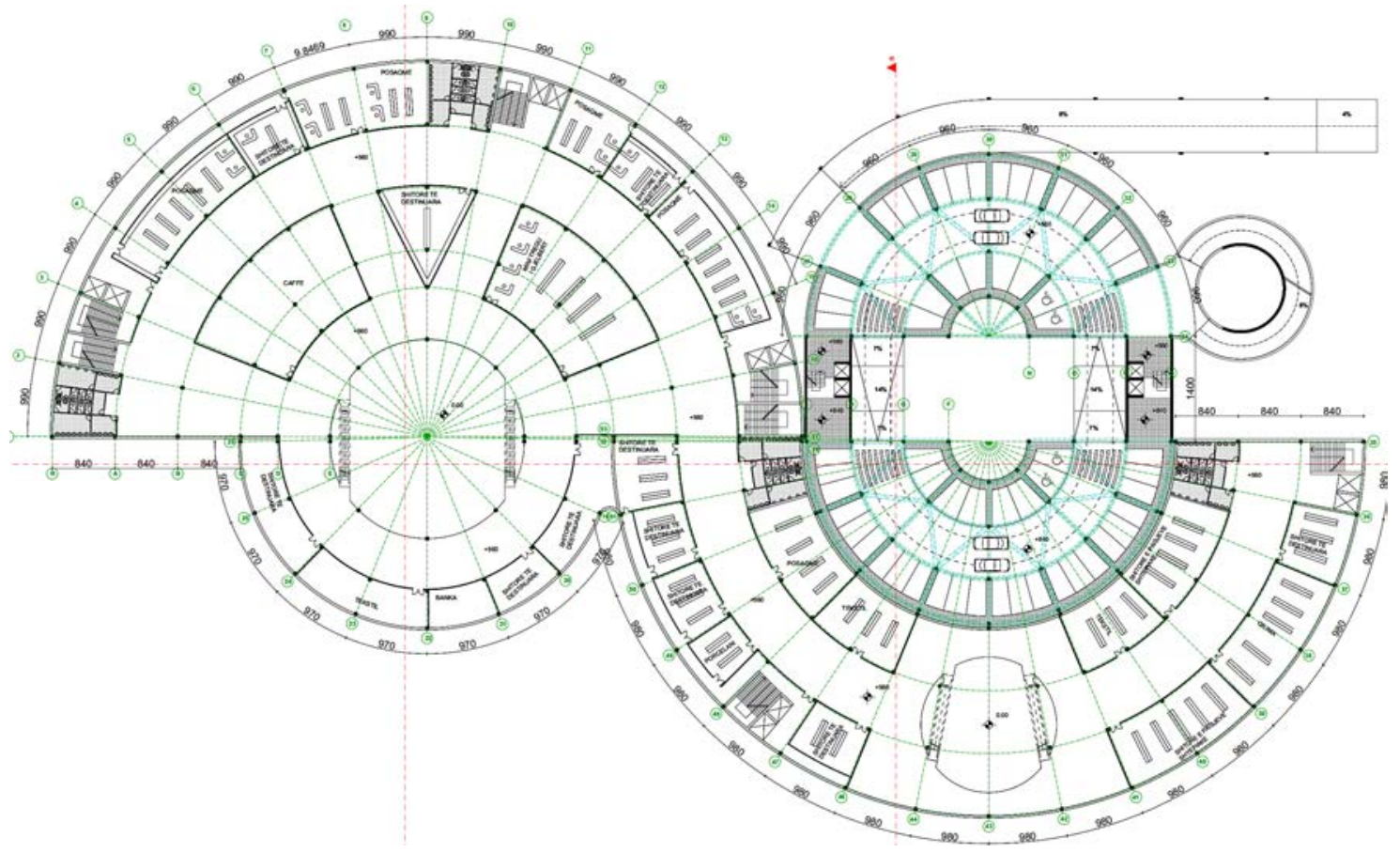

Figura 24. Baza e katit

(Burimi): Diella Shabani, Diellza Demiri, 2016 


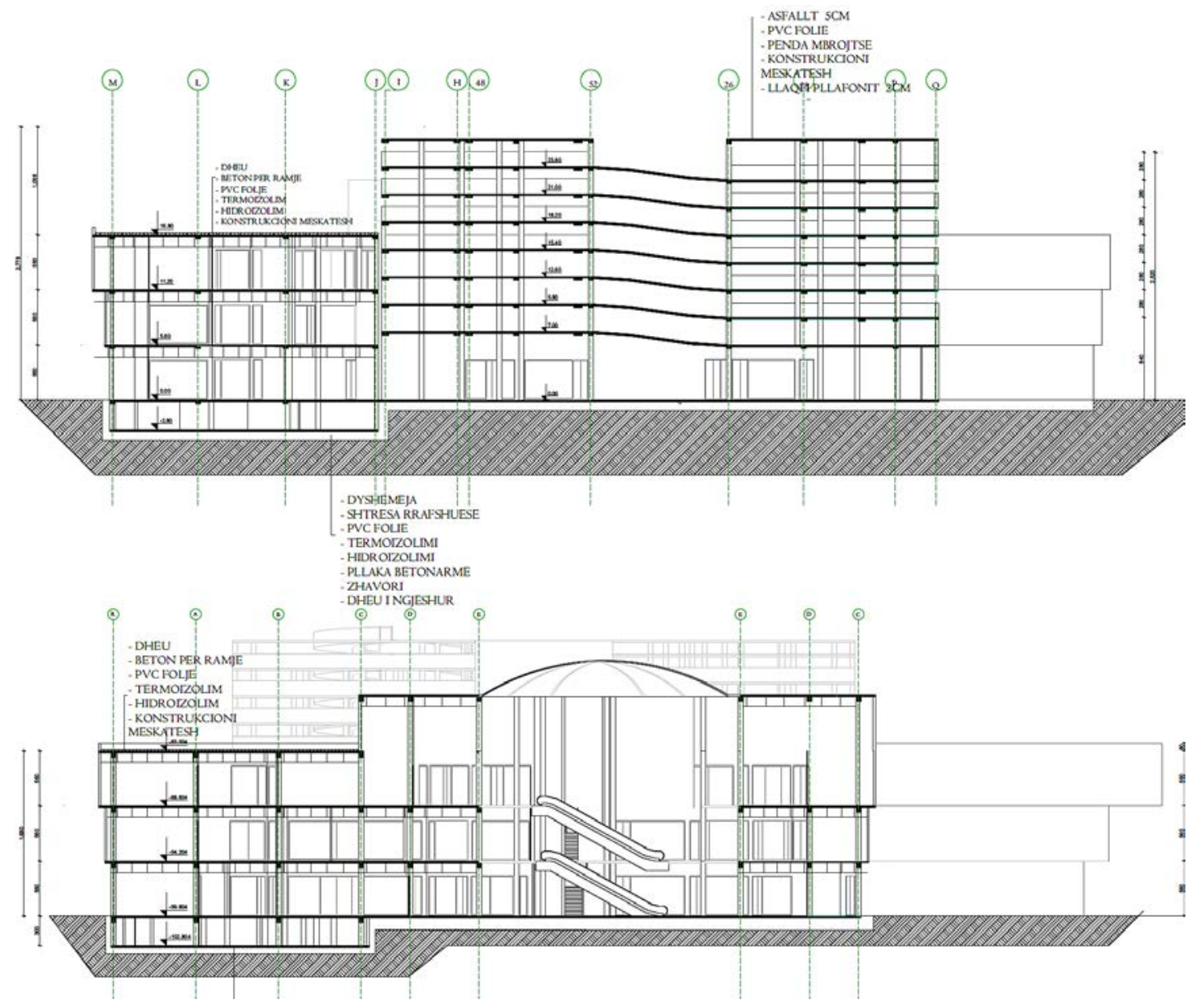

Figura 25. Prerjet

(Burimi): Diella Shabani, Diellza Demiri, 2016

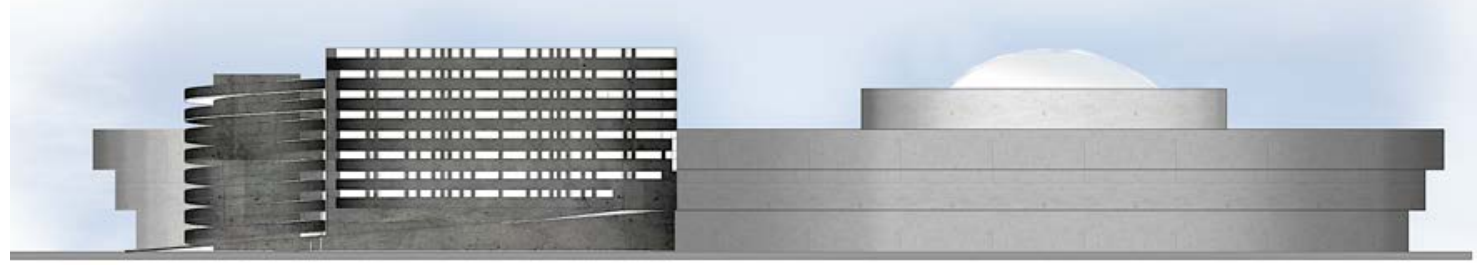

FASADA VERIORE

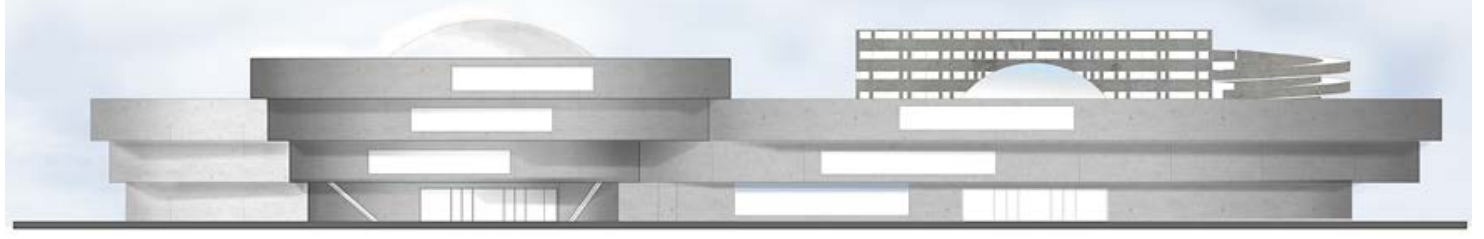

Figura 26. Pamjet

(Burimi): Diella Shabani, Diellza Demiri, 2016 


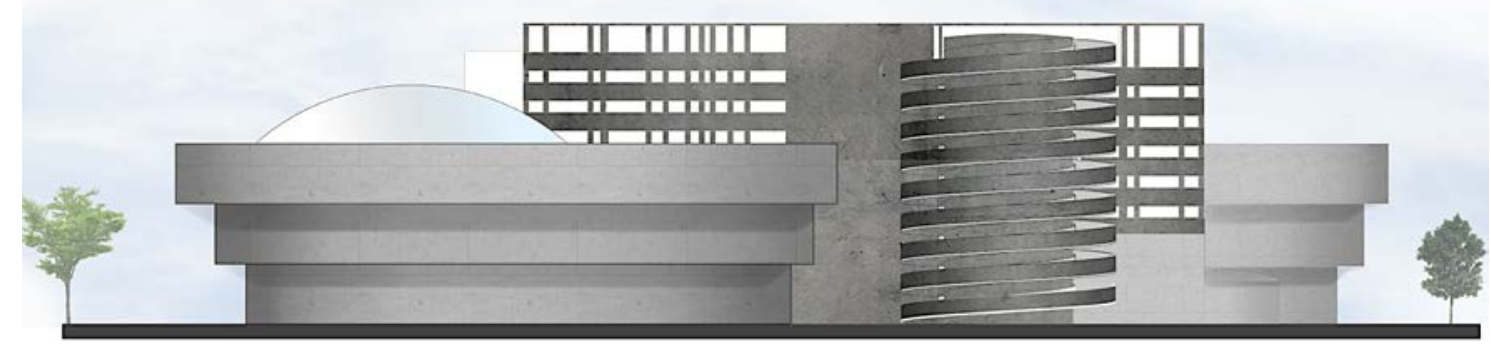

FASADA LINDORE



Figura 27. Pamjet

(Burimi): Diella Shabani, Diellza Demiri, 2016

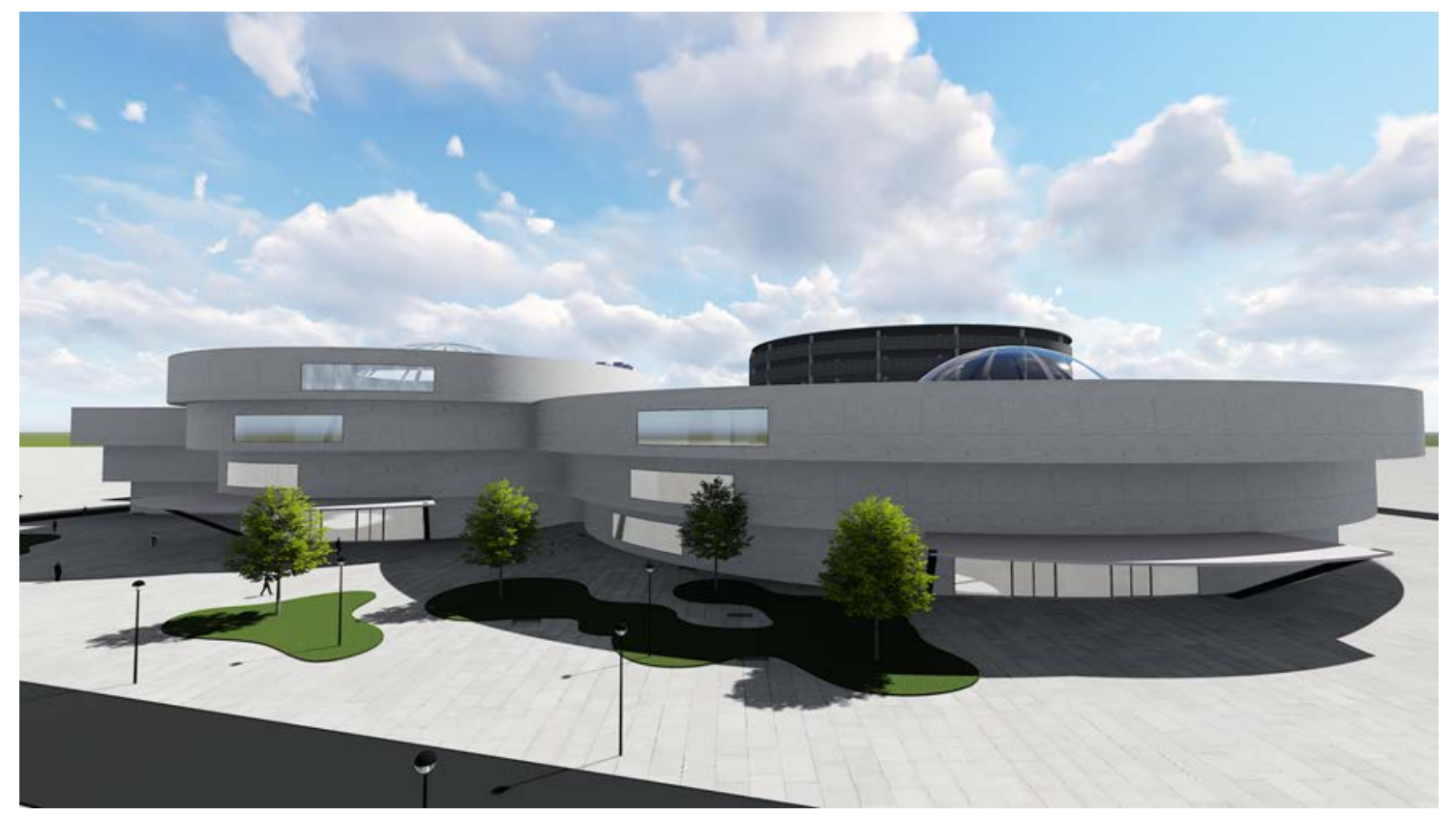

Figura 28. Perspektiva

(Burimi): Diella Shabani, Diellza Demiri, 2016 
Niveli Bachelor 2016/174. Fakulteti i Ndërtimtarisë dhe Arkitekturës, Universiteti i Prishtinës. Departamenti i Arkitekturës. Lënda: Projektim 4.

Studentët: Diell Sylhasi, Ledri Duraku.

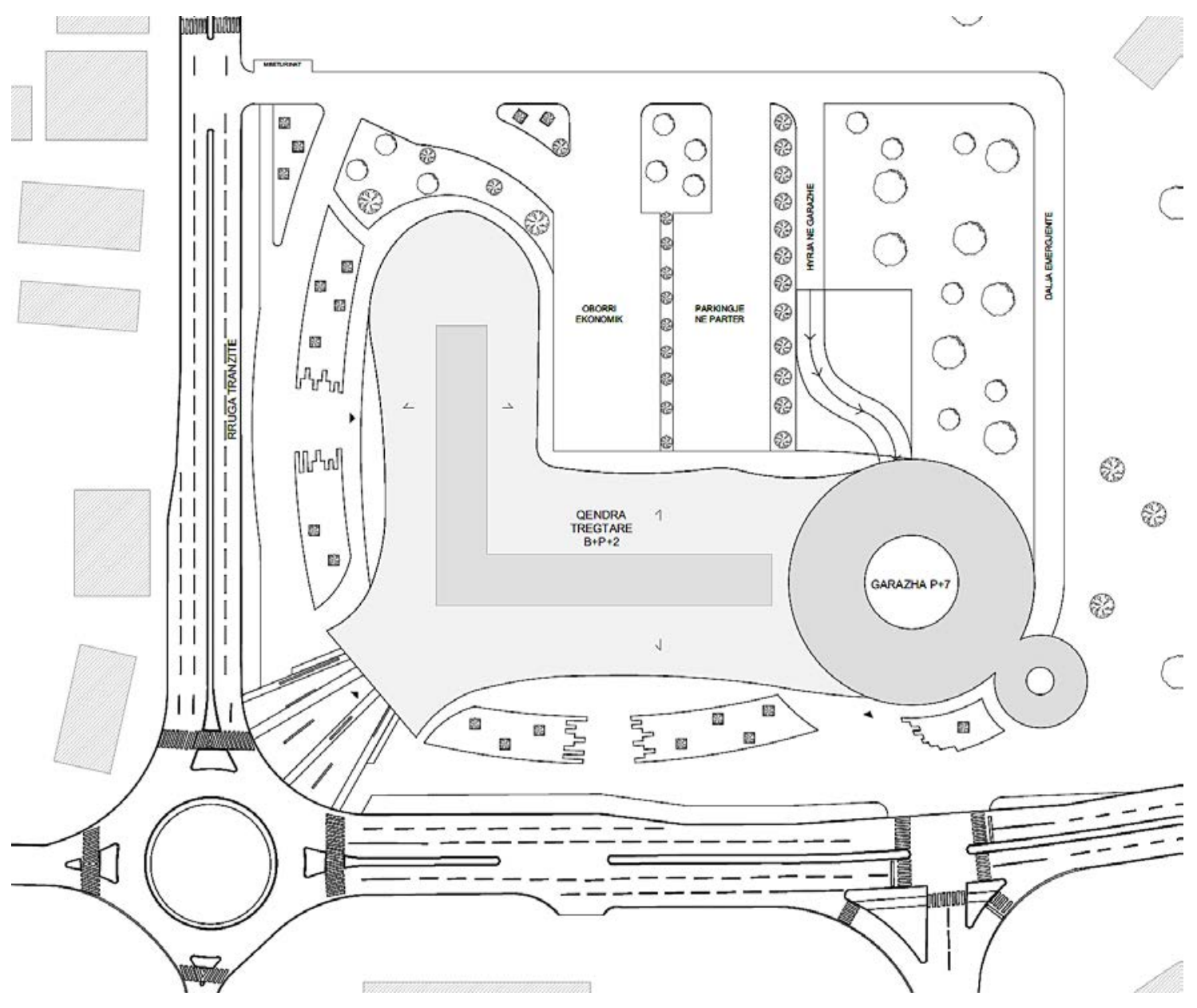

Figura 29. Situacioni

(Burimi): Diell Sylhasi, Ledri Duraku, 2016

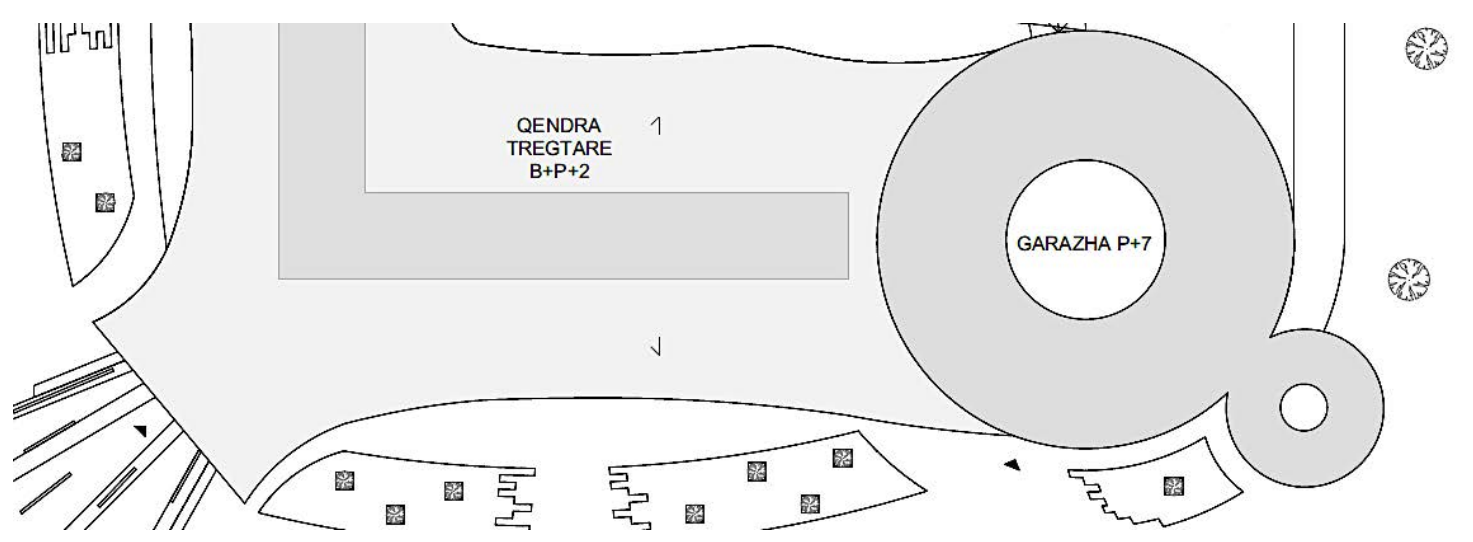

Figura 30. Situacioni

(Burimi): Diell Sylhasi, Ledri Duraku, 2016

${ }^{4}$ Diell Sylhasi, Ledri Duraku. Lënda: Projektim 4. Punimi i tërë sipas dorëzimit final. FNA, UP. 




Figura 31. Baza e përdhesës

(Burimi): Diell Sylhasi, Ledri Duraku, 2016

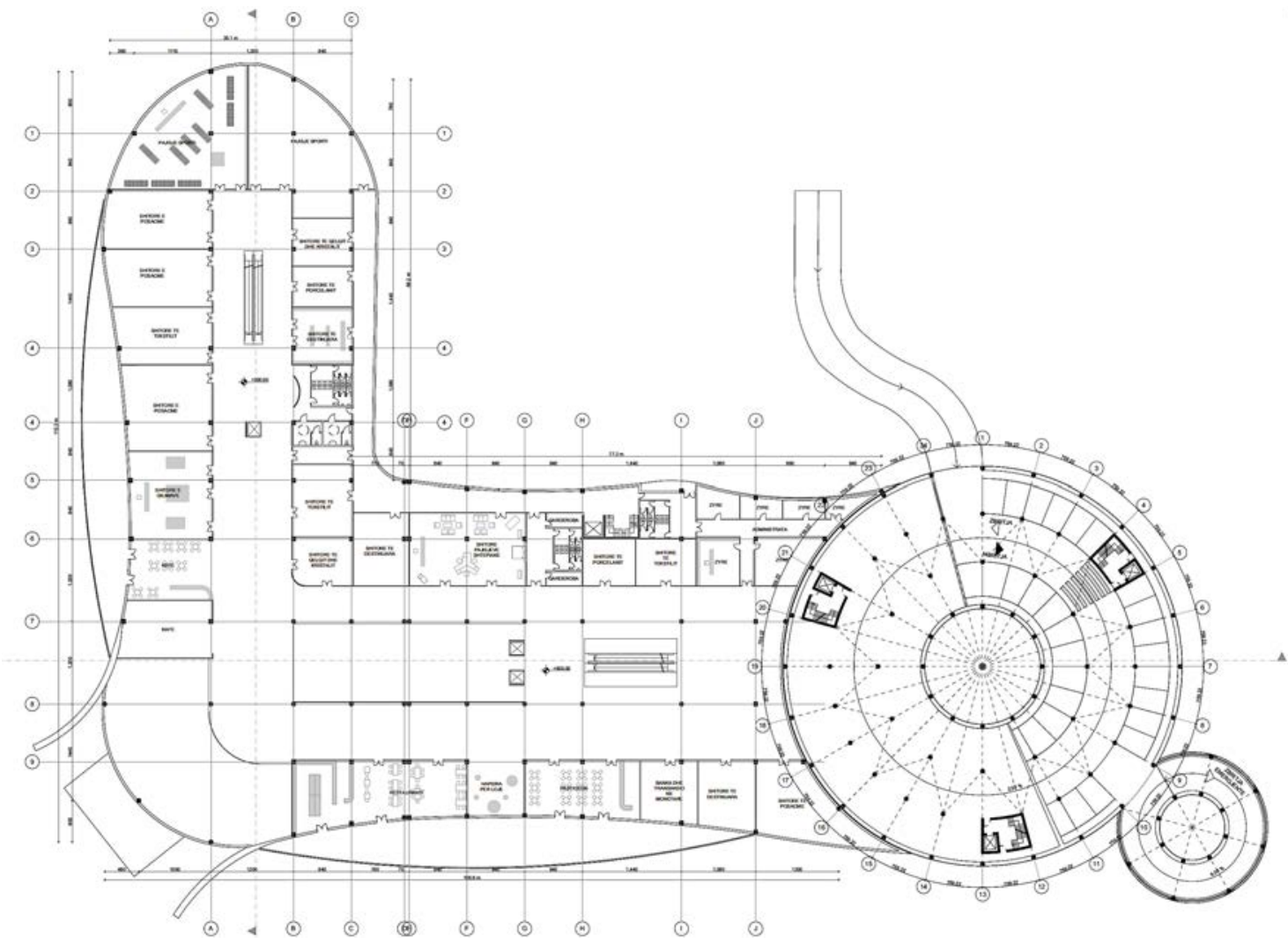

Figura 32. Baza e katit

(Burimi): Diell Sylhasi, Ledri Duraku, 2016 

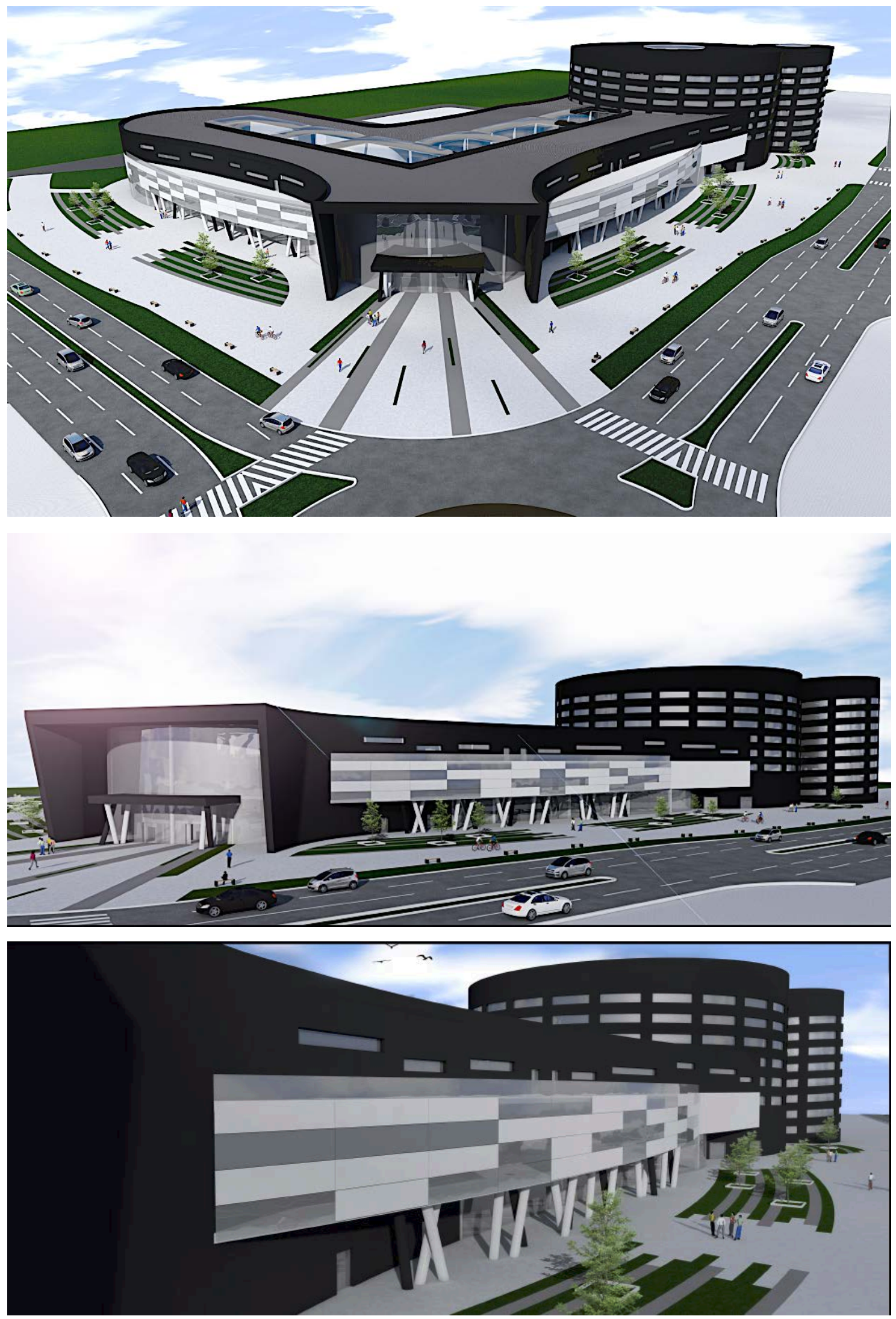

Figura 33. Perspektiva

(Burimi): Diell Sylhasi, Ledri Duraku, 2016 
Niveli Bachelor 2016/175 . Fakulteti i Ndërtimtarisë dhe Arkitekturës, Universiteti i Prishtinës. Departamenti i Arkitekturës. Lënda: Projektim 4. Studentët: Fjolla Januzi, Hana Ziberi.

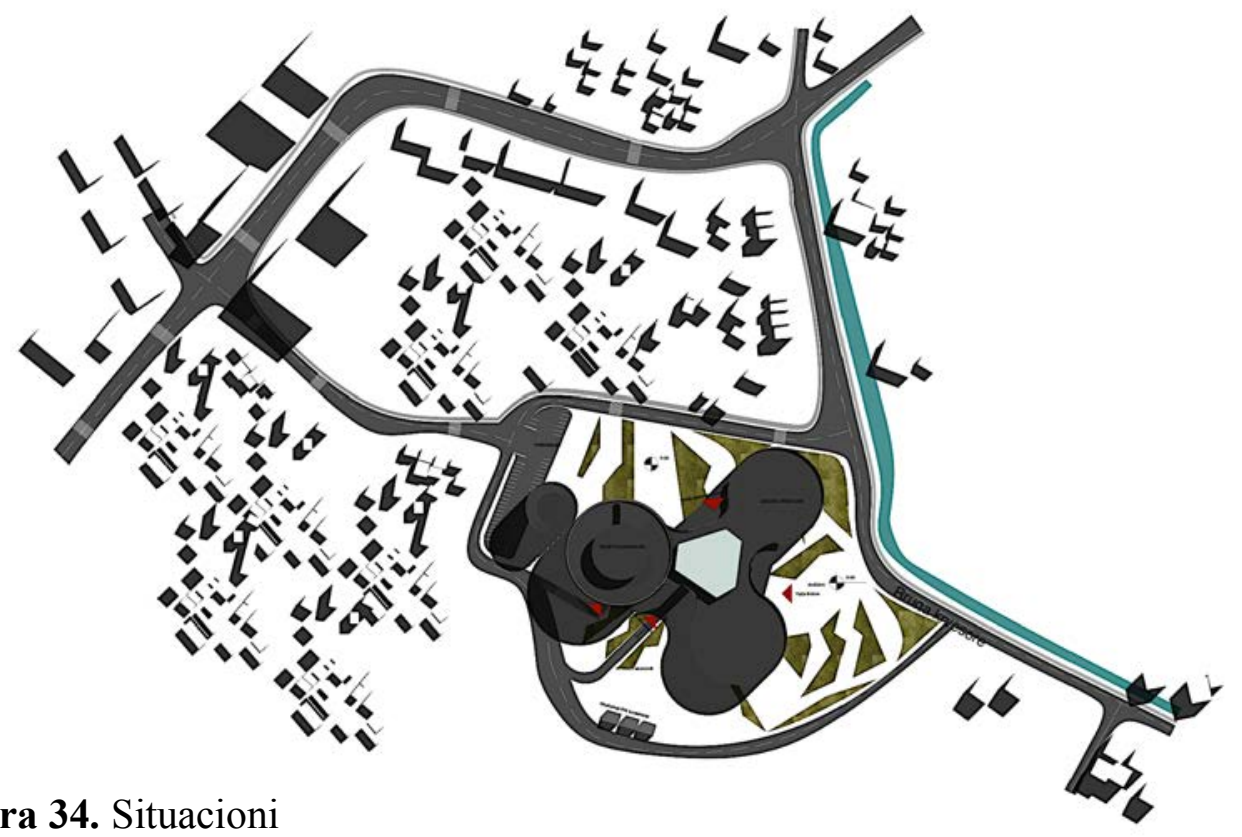

Figura 34. Situacioni

(Burimi): Fjolla Januzi, Hana Ziberi, 2016

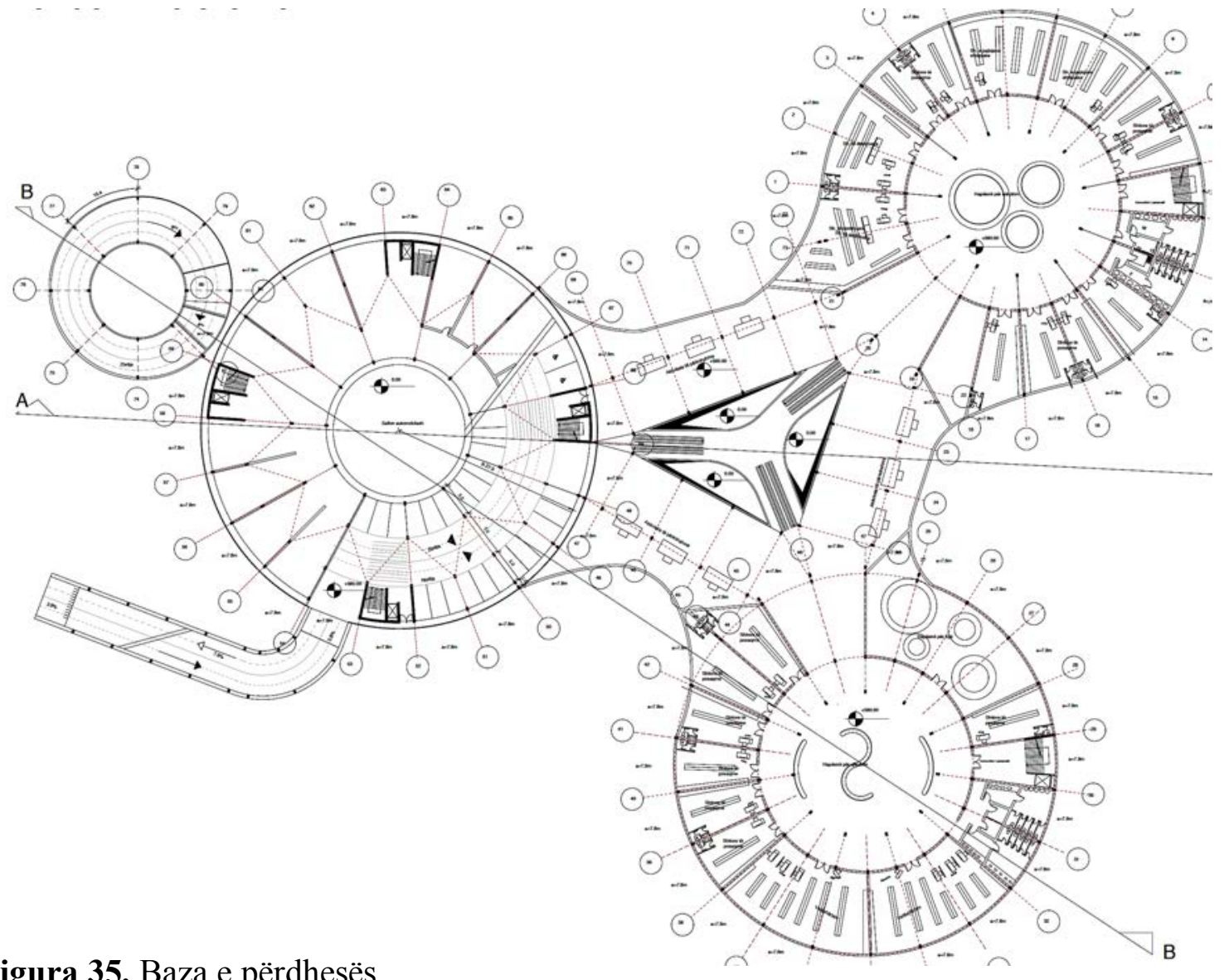

(Burimi): Fjolla Januzi, Hana Ziberi, 2016

5 Fjolla Januzi, Hana Ziberi. Lënda: Projektim 4. Punimi i tërë sipas dorëzimit final. FNA, UP. 




Figura 36. Baza e katit

(Burimi): Fjolla Januzi, Hana Ziberi, 2016

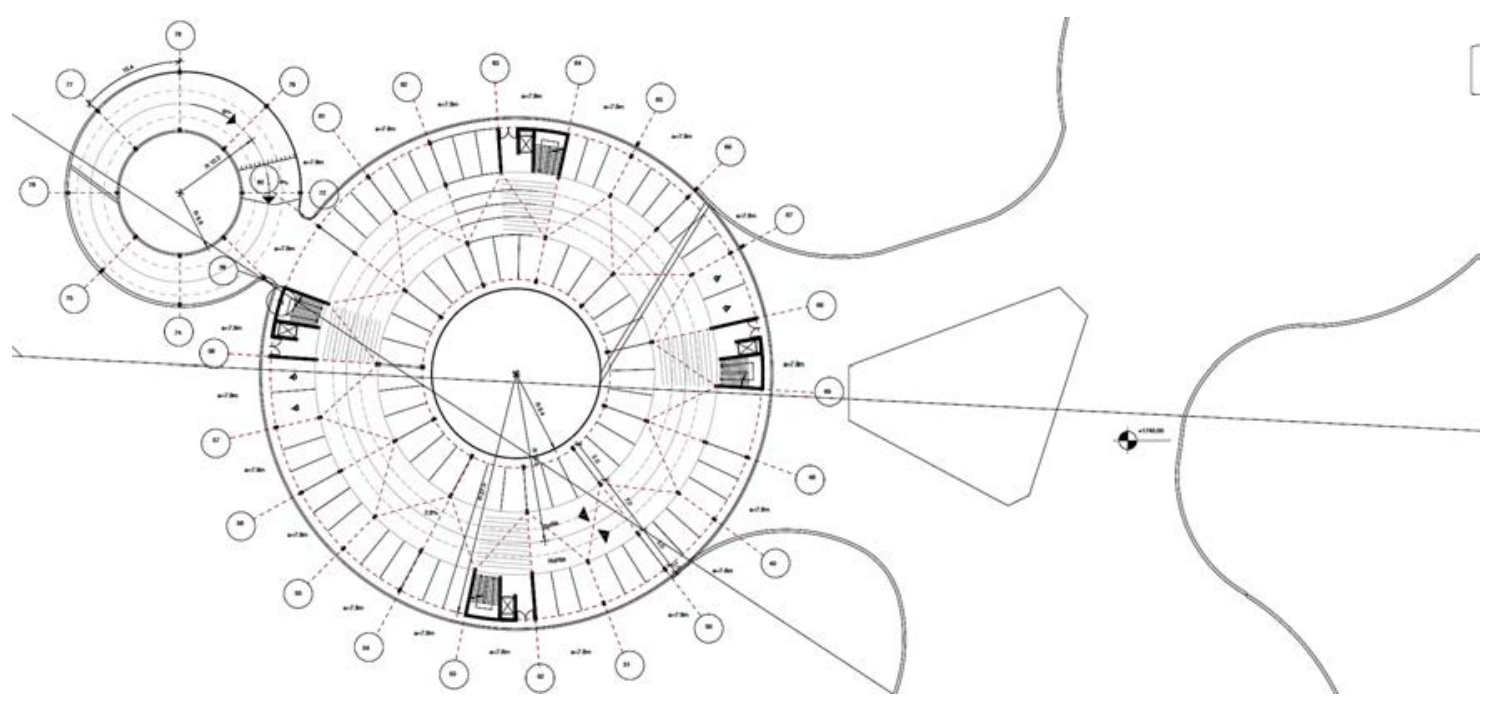

Figura 37. Baza e katit 4

(Burimi): Fjolla Januzi, Hana Ziberi, 2016 



Figura 38. Pamjet

(Burimi): Fjolla Januzi, Hana Ziberi, 2016



Figura 39. Perpektiva

(Burimi): Fjolla Januzi, Hana Ziberi, 2016 

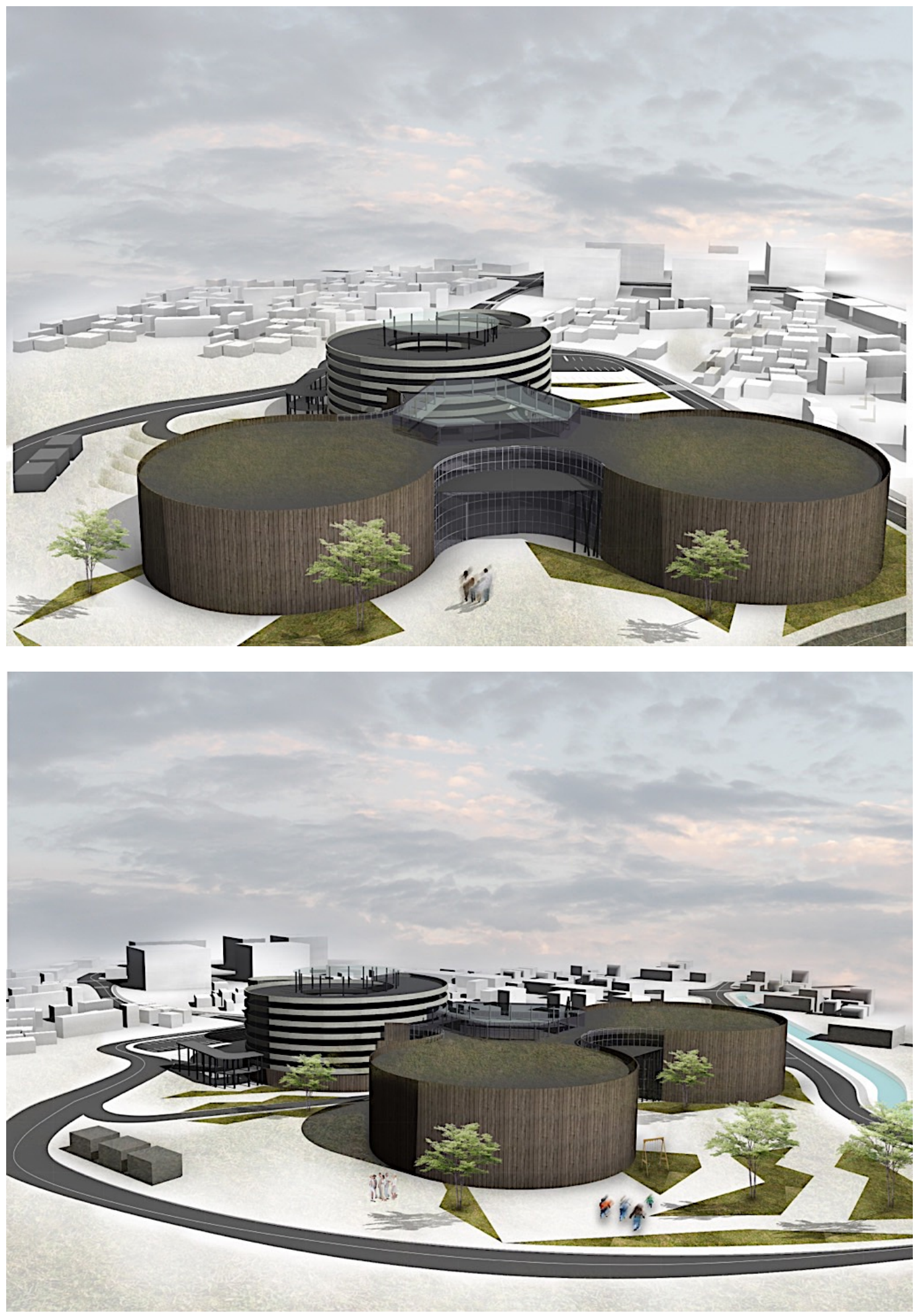

Figura 40. Perpektiva

(Burimi): Fjolla Januzi, Hana Ziberi, 2016 
Niveli Bachelor 2016/17 ${ }^{6}$. Fakulteti i Ndërtimtarisë dhe Arkitekturës, Universiteti i Prishtinës. Departamenti i Arkitekturës. Lënda: Projektim 4.

Studentët: Përparim Morina, Rina Kollqaku.

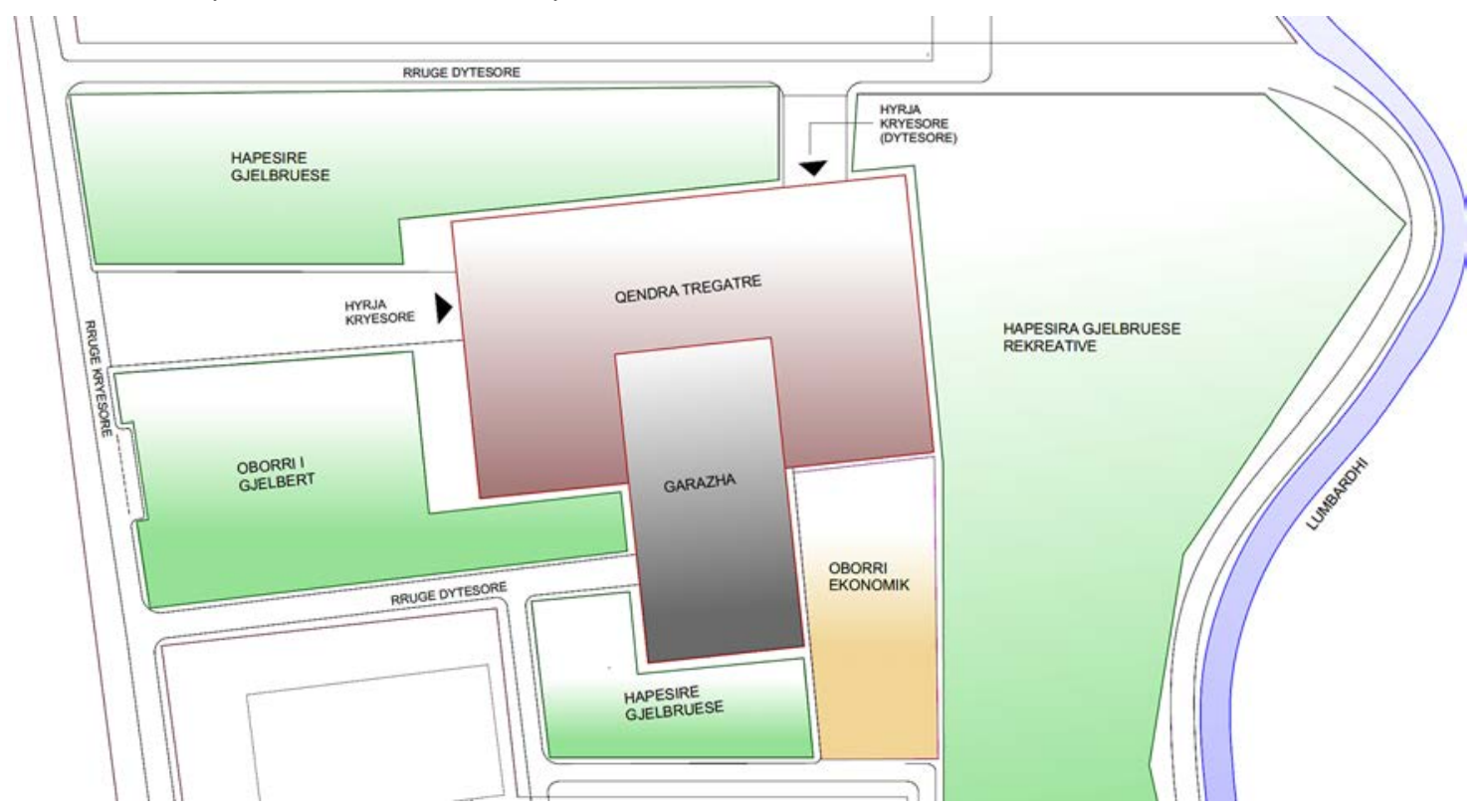

Figura 41. Kompozicioni funksional

(Burimi): Përparim Morina, Rina Kollqaku, 2016

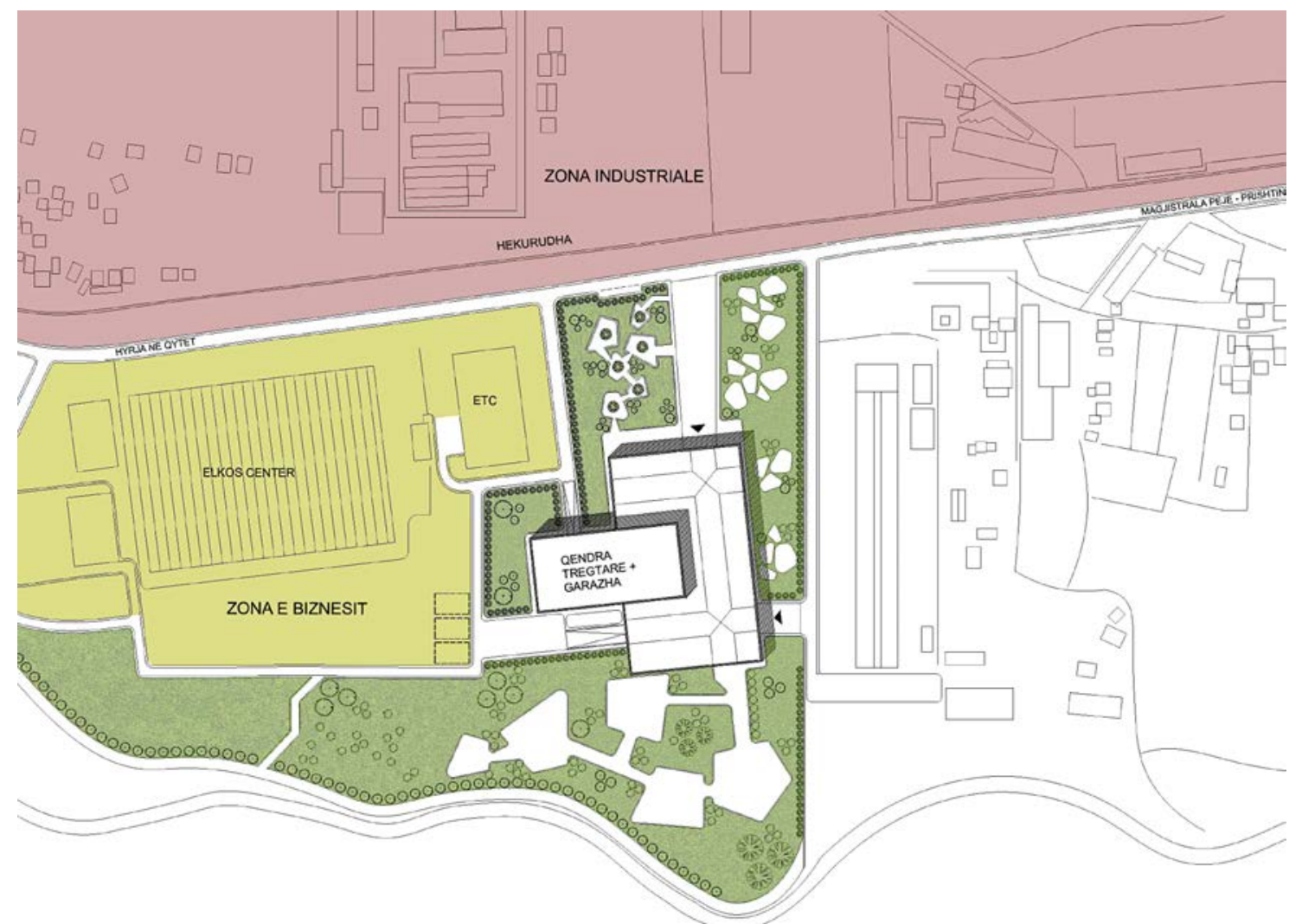

Figura 42. Situacioni

(Burimi): Përparim Morina, Rina Kollqaku, 2016

6 Përparim Morina, Rina Kollqaku. Lënda: Projektim 4. Punimi i tërë sipas dorëzimit final. FNA, UP. 


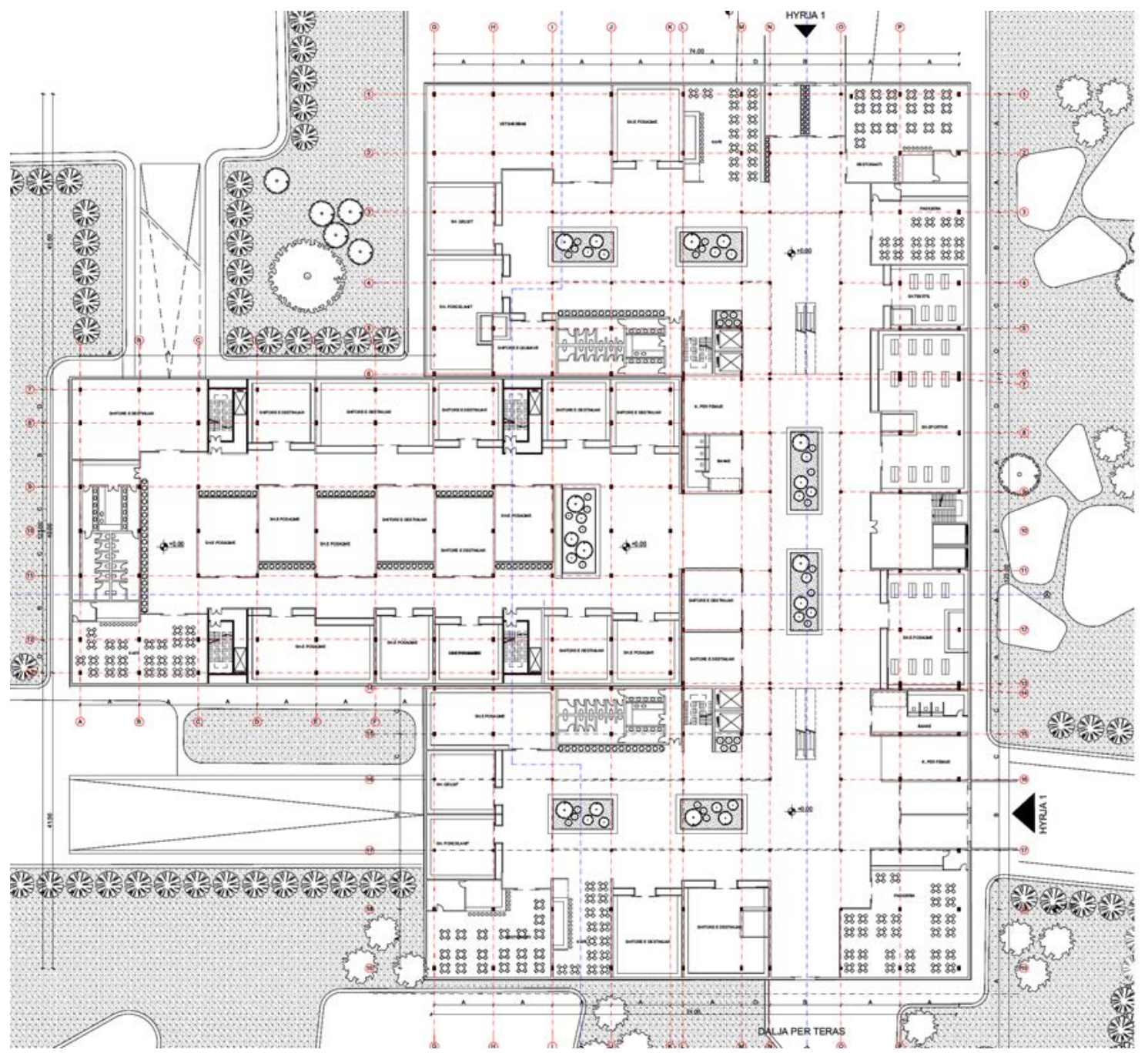

Figura 43. Baza e përdhesës

(Burimi): Përparim Morina, Rina Kollqaku, 2016



Figura 44. Prerja $C$

(Burimi): Përparim Morina, Rina Kollqaku, 2016 


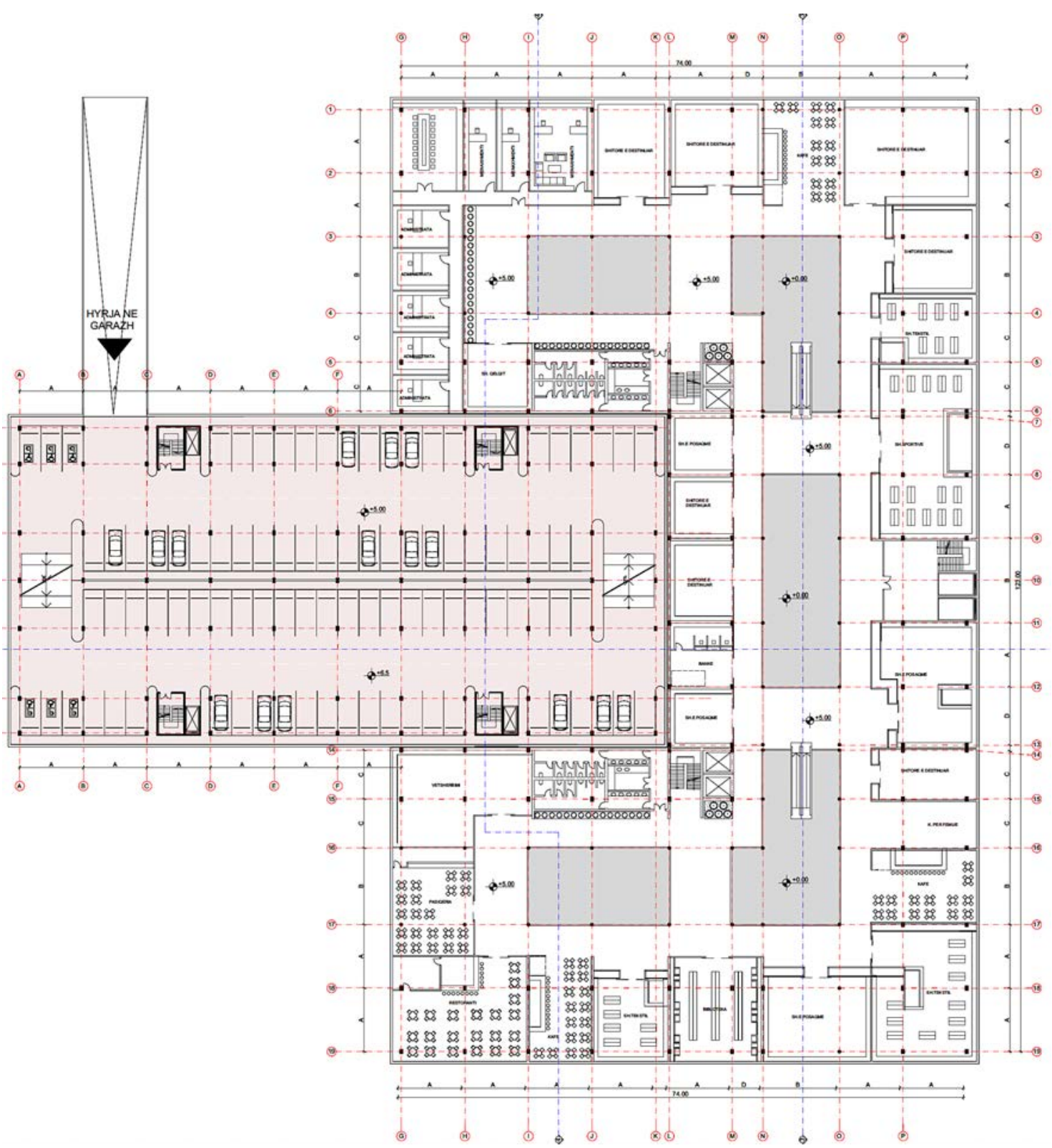

Figura 45. Baza e katit

(Burimi): Përparim Morina, Rina Kollqaku, 2016

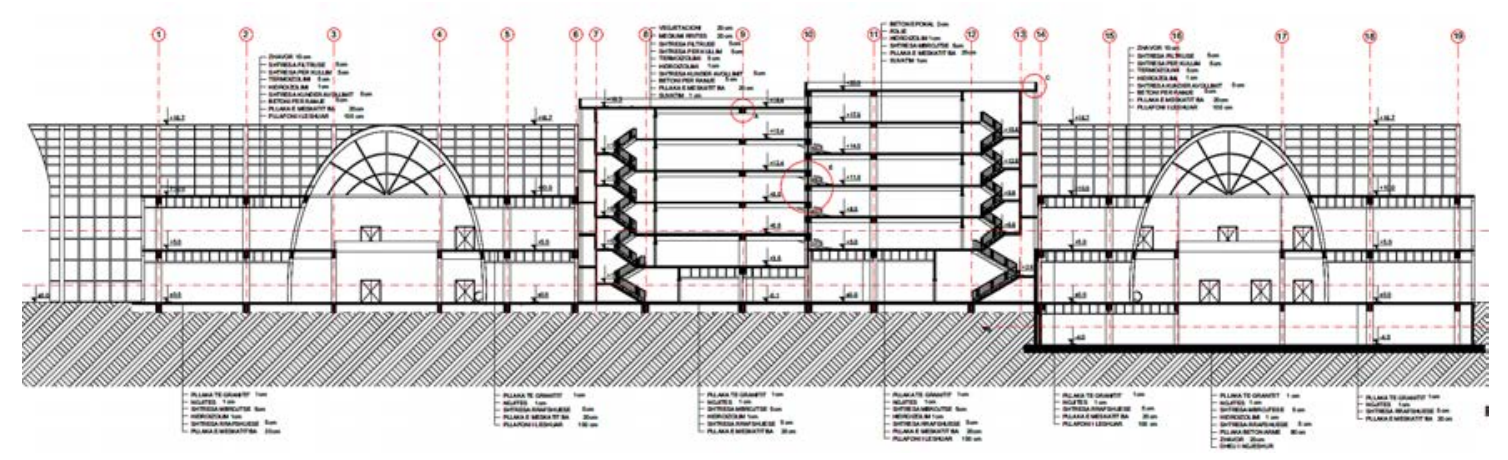

Figura 46. Prerja $B$

(Burimi): Përparim Morina, Rina Kollqaku, 2016 



Figura 47. Perspektiva

(Burimi): Përparim Morina, Rina Kollqaku, 2016 
Niveli Bachelor 2017/18 ${ }^{7}$. Fakulteti i Ndërtimtarisë dhe Arkitekturës, Universiteti i Prishtinës. Departamenti i Arkitekturës. Lënda: Projektim 4.

Studentët: Rinor Rushiti, Xhezide Vlashi
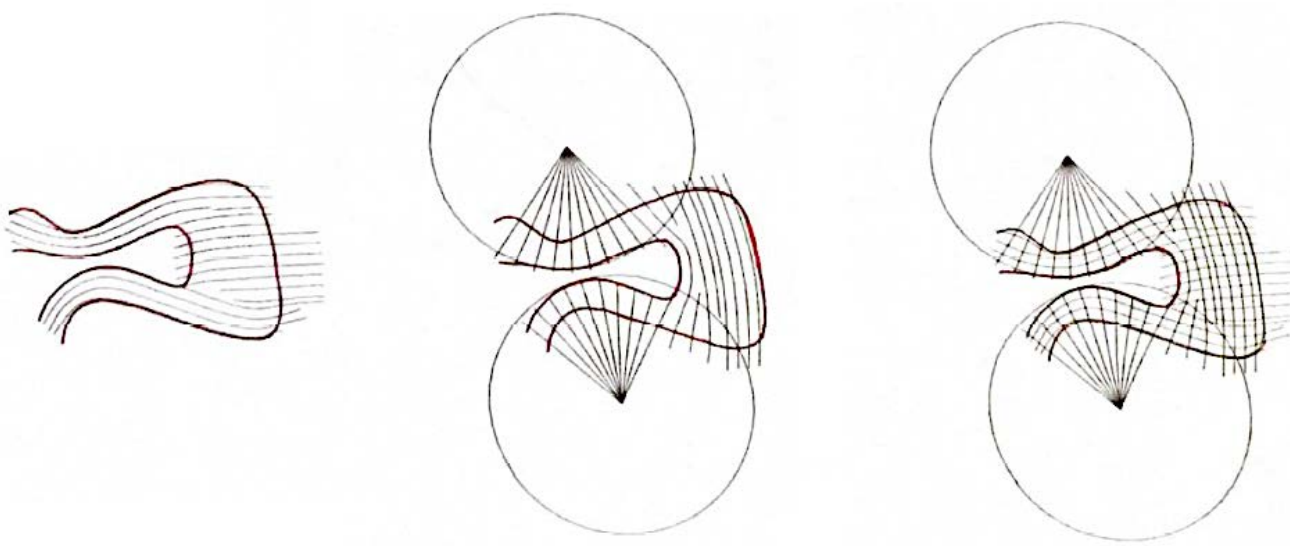

STRUKTURA

Figura 48. Analiza

(Burimi): Rinor Rushiti, Xhezide Vlashi, 2018

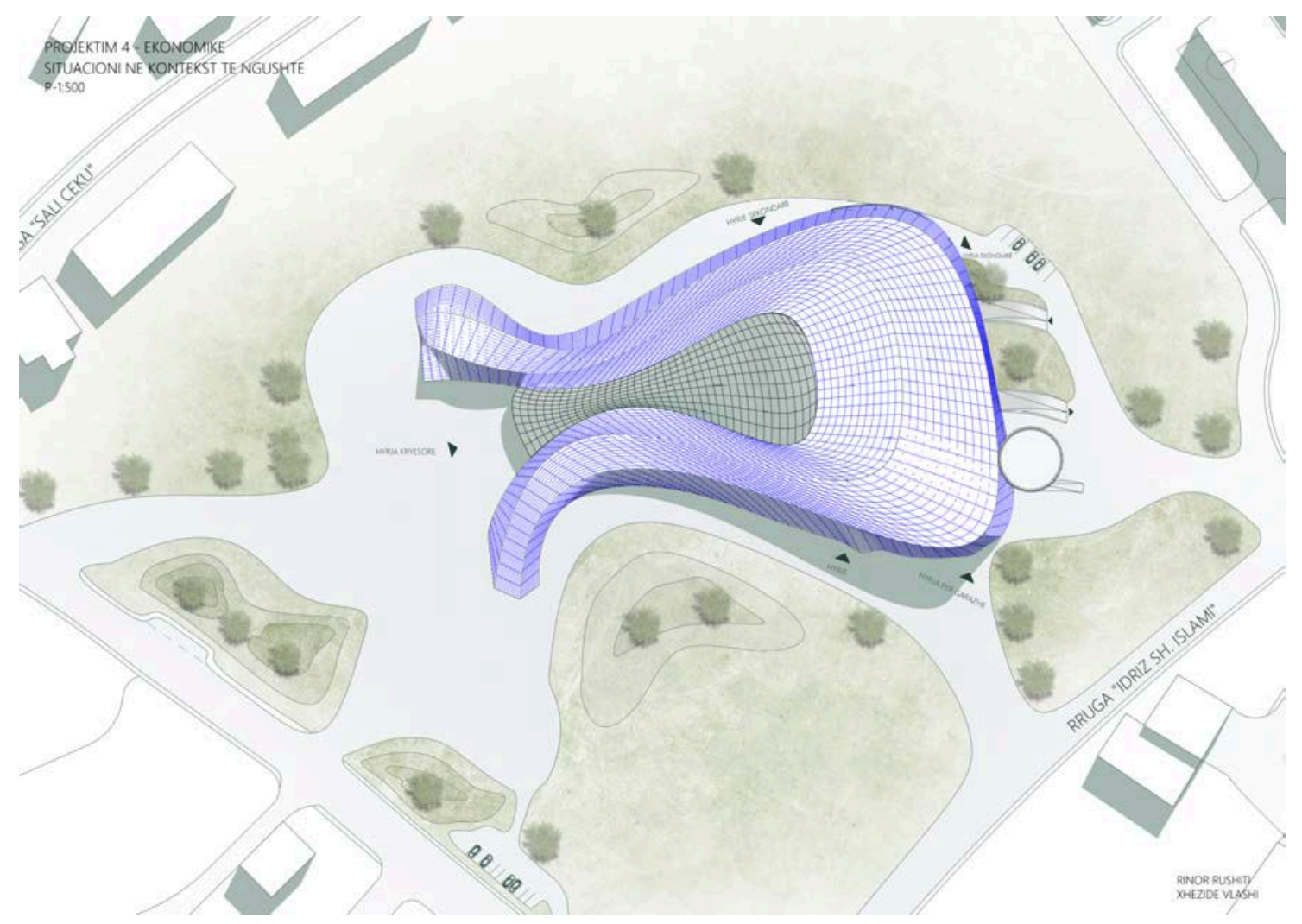

Figura 49. Situacioni

(Burimi): Rinor Rushiti, Xhezide Vlashi, 2018

7 Rinor Rushiti, Xhezide Vlashi. Lënda: Projektim 4. Punimi i tërë sipas dorëzimit final. FNA, UP. 


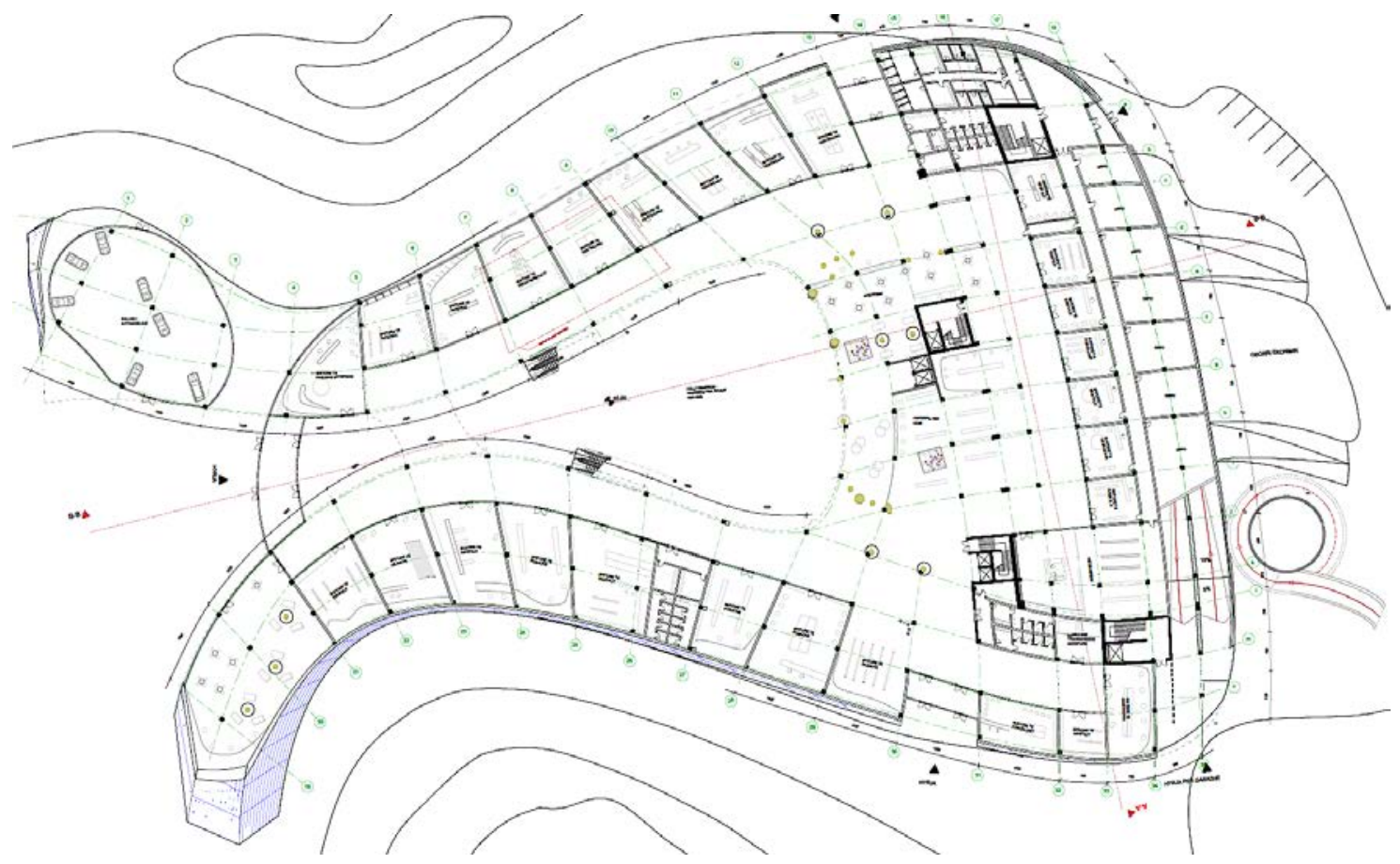

Figura 50. Baza e përdhesës

(Burimi): Rinor Rushiti, Xhezide Vlashi, 2018

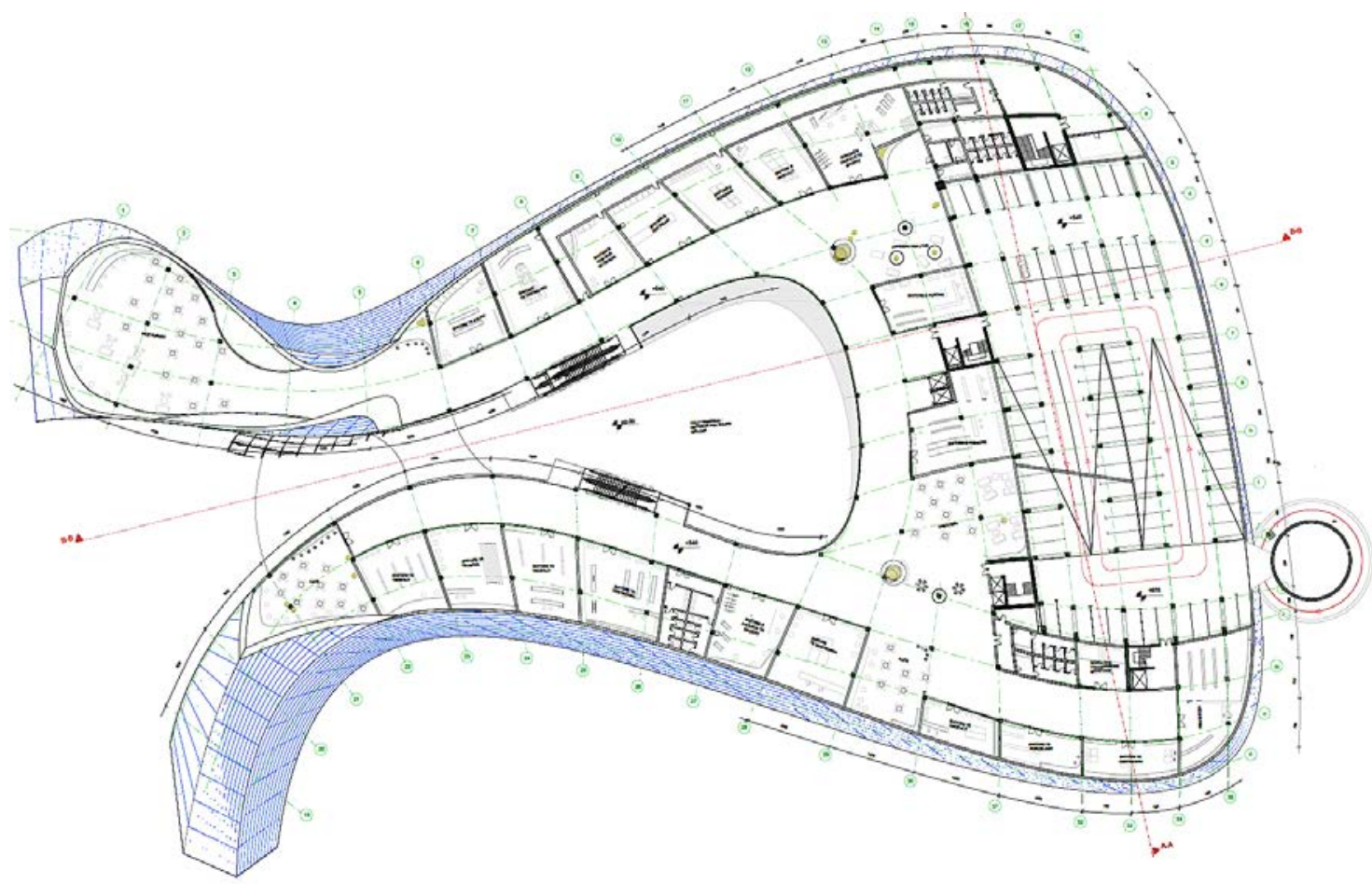

Figura 51. Baza e katit

(Burimi): Rinor Rushiti, Xhezide Vlashi, 2018 


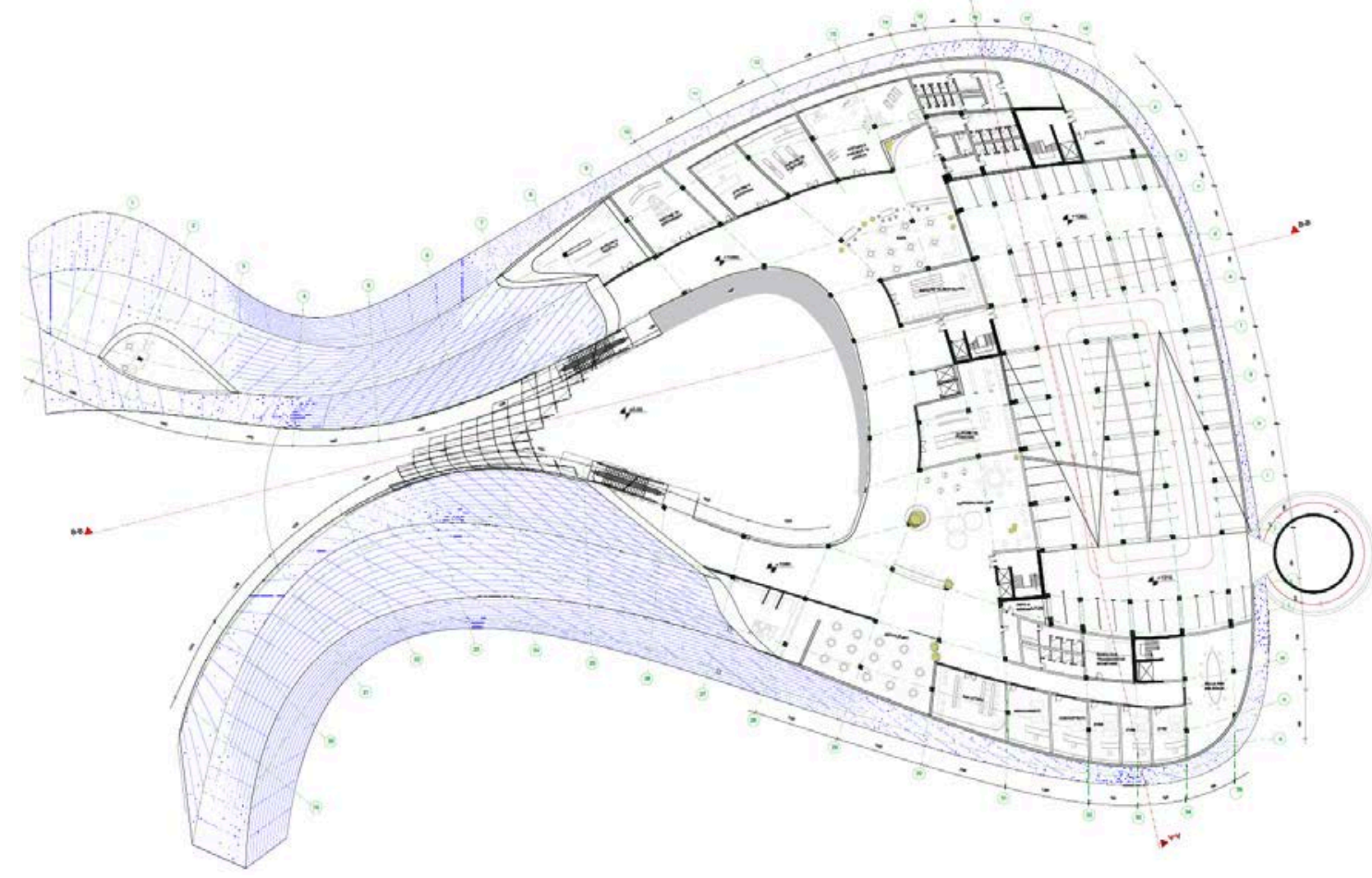

Figura 52. Baza e katit 2

(Burimi): Rinor Rushiti, Xhezide Vlashi, 2018

PRERJET A-A

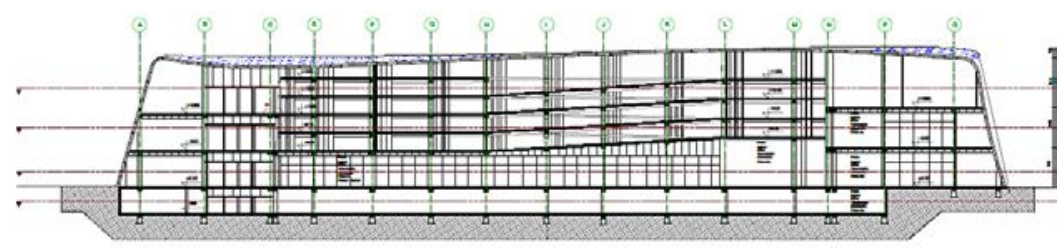

PRERJET B-B

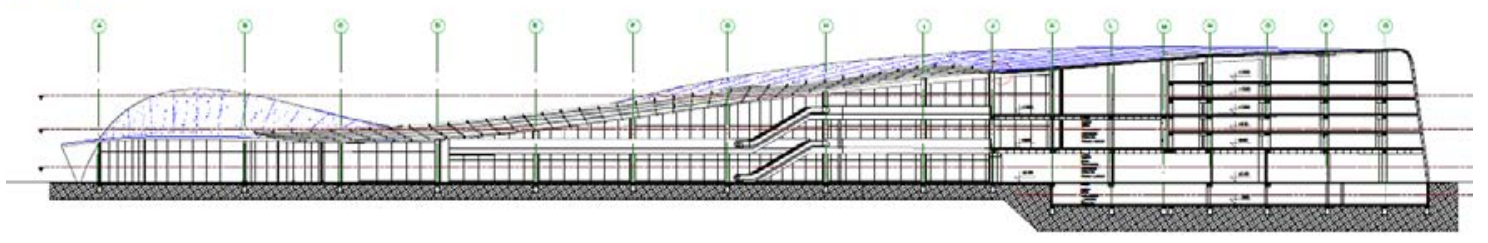

Figura 53. Prerjet

(Burimi): Rinor Rushiti, Xhezide Vlashi, 2018 


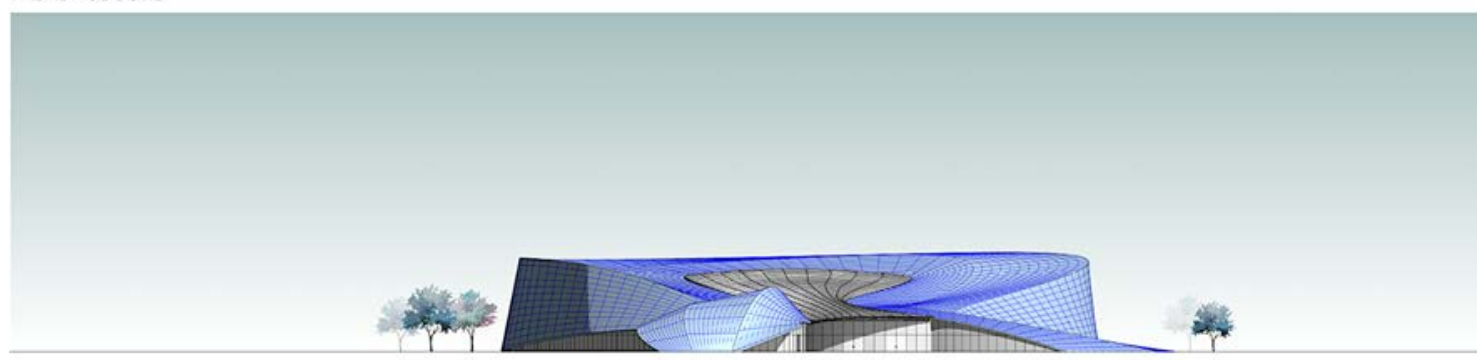

FASADA LINDORE

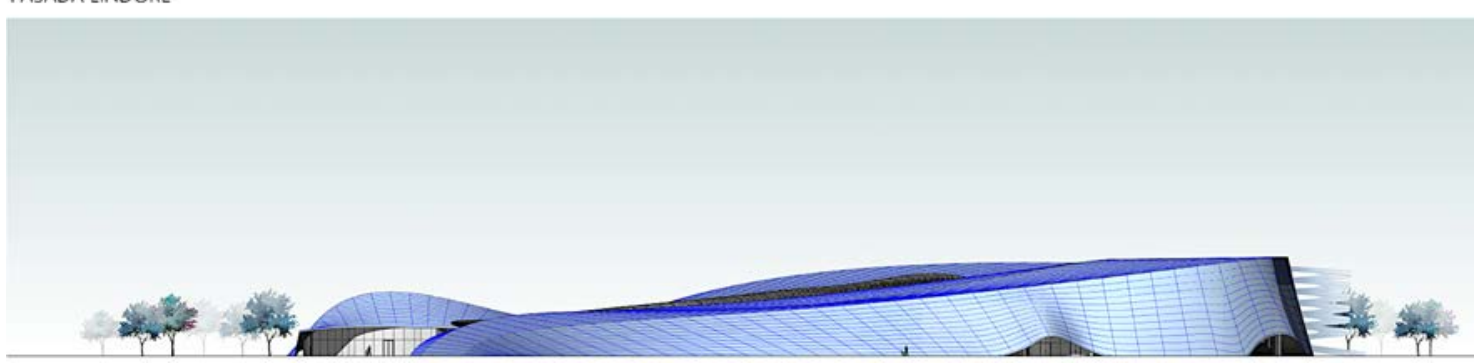

FASADA VERIORE

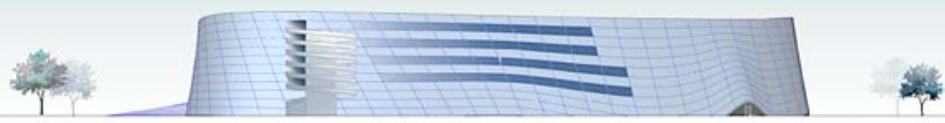

FASADA PERENDIMORE

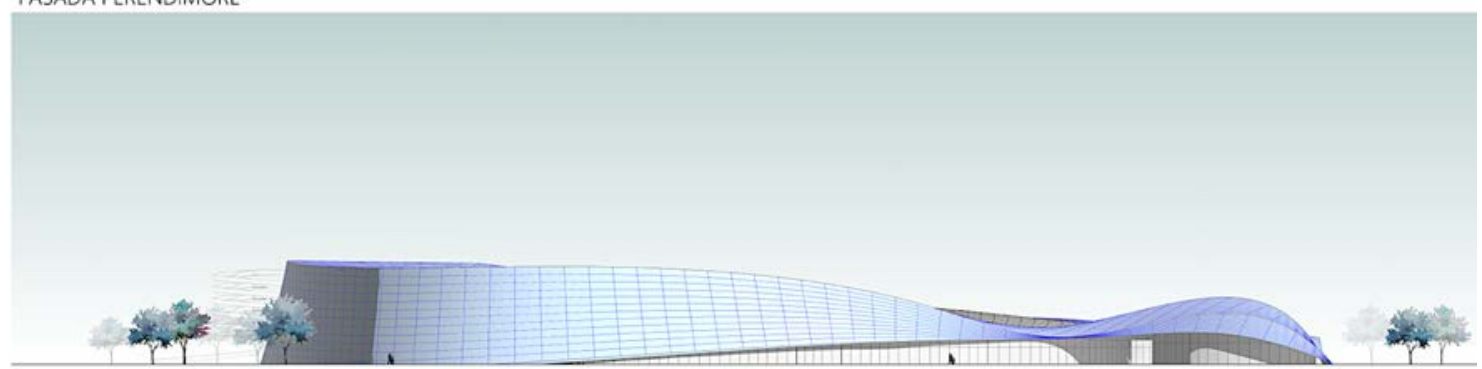

Figura 54. Pamjet

(Burimi): Rinor Rushiti, Xhezide Vlashi, 2018 


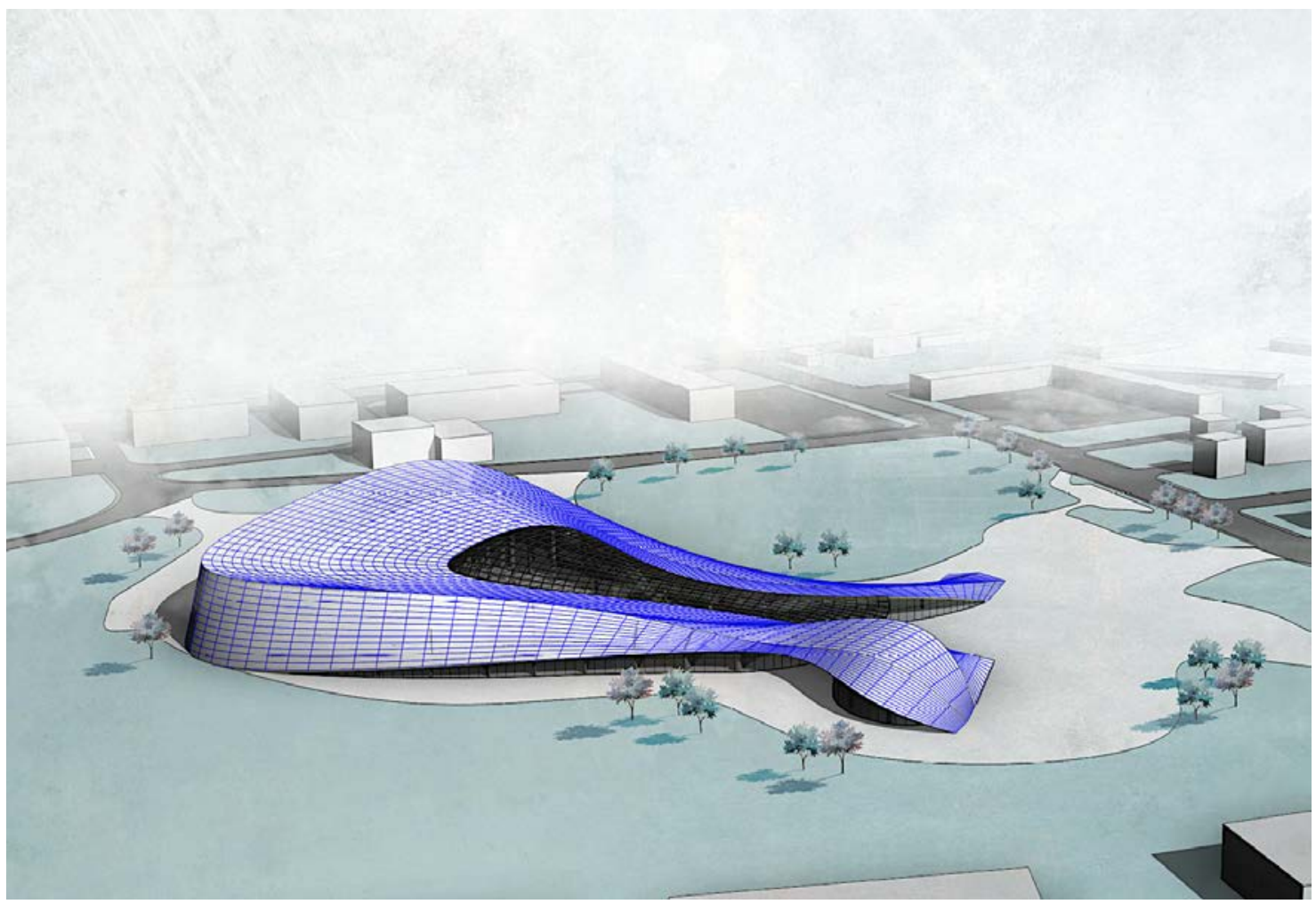

Figura 55. Perspektiva

(Burimi): Rinor Rushiti, Xhezide Vlashi, 2018



Figura 56. Perspektiva

(Burimi): Rinor Rushiti, Xhezide Vlashi, 2018 

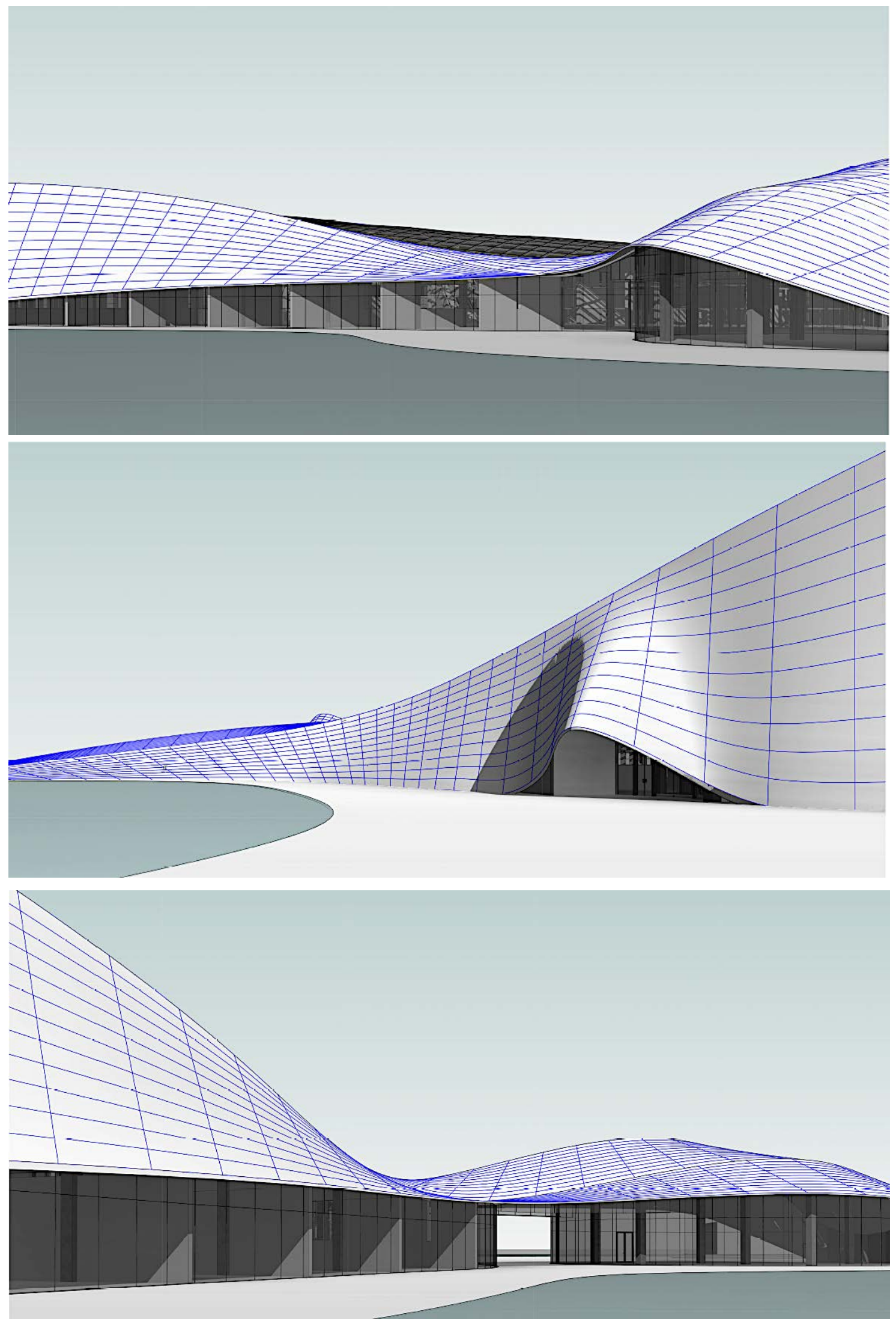

Figura 57. Perspektiva

(Burimi): Rinor Rushiti, Xhezide Vlashi, 2018 
Niveli Bachelor 2017/18 ${ }^{8}$. Fakulteti i Ndërtimtarisë dhe Arkitekturës, Universiteti i Prishtinës. Departamenti i Arkitekturës. Lënda: Projektim 4.

Studentët: Diellza Delija, Diellza Hajrizi


siperfagja totale $=25070.85 \mathrm{~m}^{2}$

Figura 58. Analizat

(Burimi): Diellza Delija, Diellza Hajrizi, 2018
Ky lokacion eshte i pershtatshem per objekt garazhues dhe qender tregtare per keto arsye:

*lokacioni mundeson kycjen dhe shkycjen e shpejte, * ka nje sperfaqe te mjaftueshme dhe nuk i pengon asnje objekti perreth keshtu qe etazhiteti nuk eshte i caktuar

ne baze te analizave kjo pozite per vendosjen e objektit garazhues e zvogelon tollovine ne brendesi te qytetit

8 Diellza Delija, Diellza Hajrizi. Lënda: Projektim 4. Punimi i tërë sipas dorëzimit final. FNA, UP. 


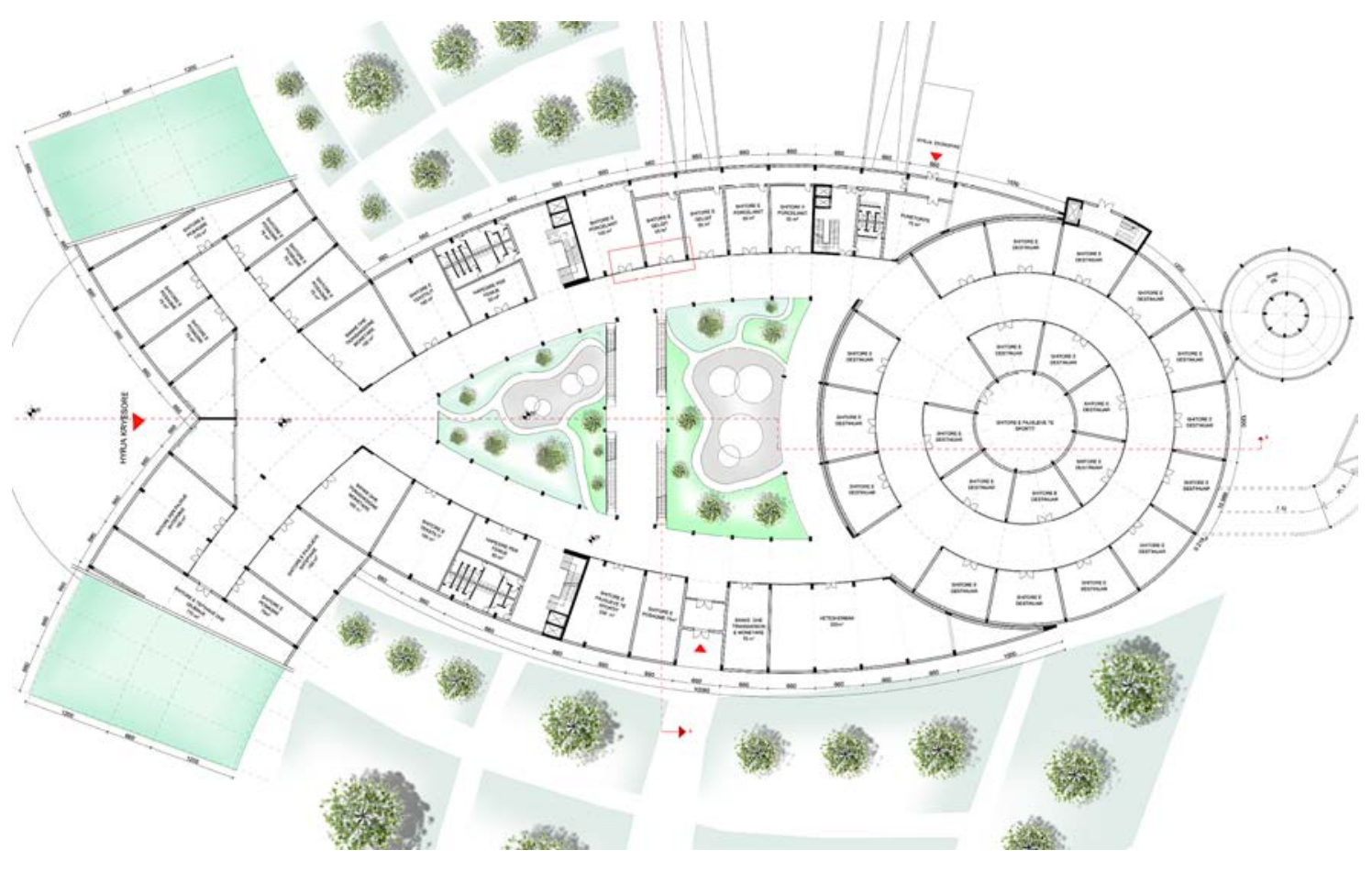

Figura 59. Baza e përdhesës

(Burimi): Diellza Delija, Diellza Hajrizi, 2018

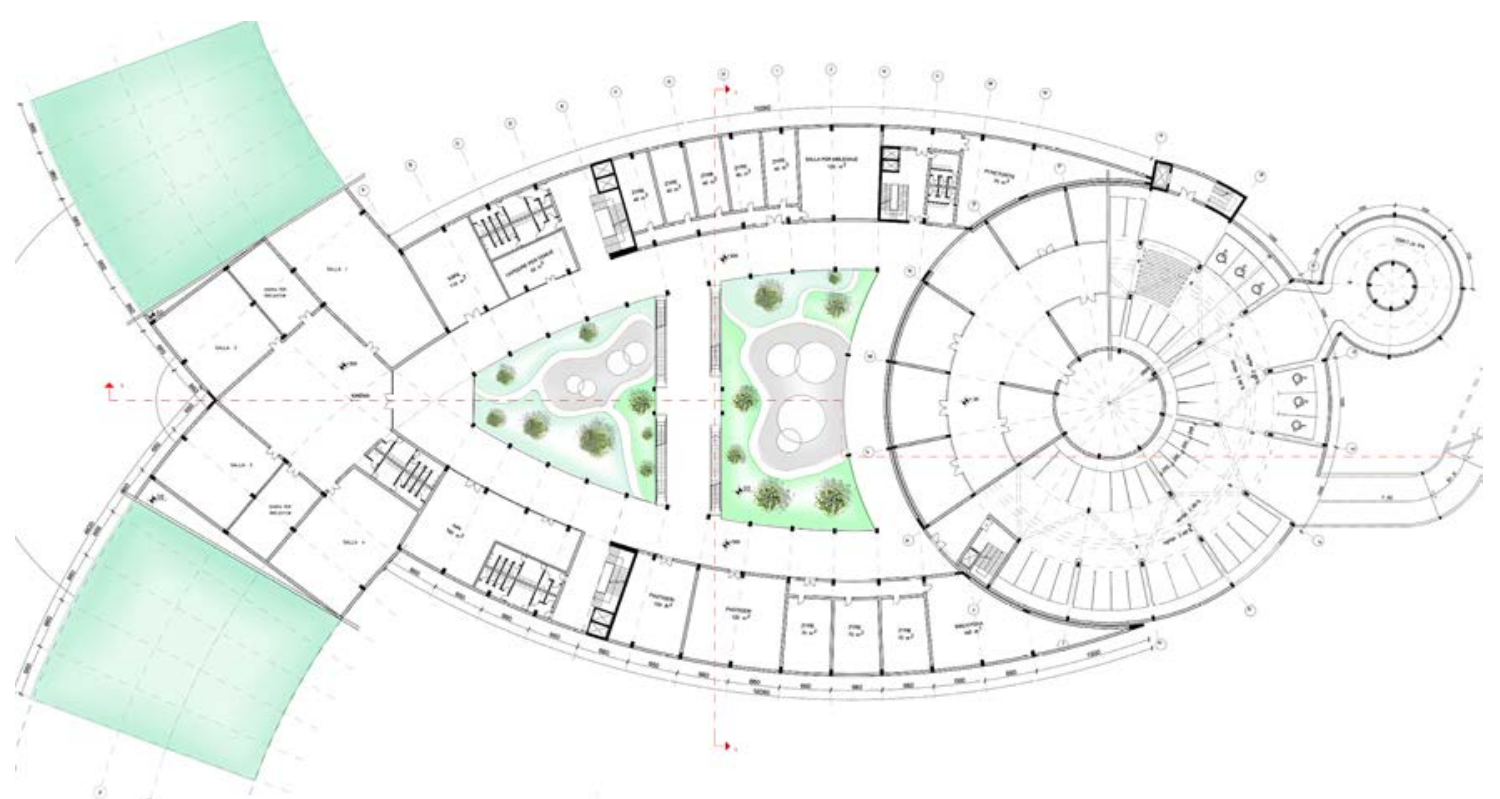

Figura 60. Baza e katit

(Burimi): Diellza Delija, Diellza Hajrizi, 2018 

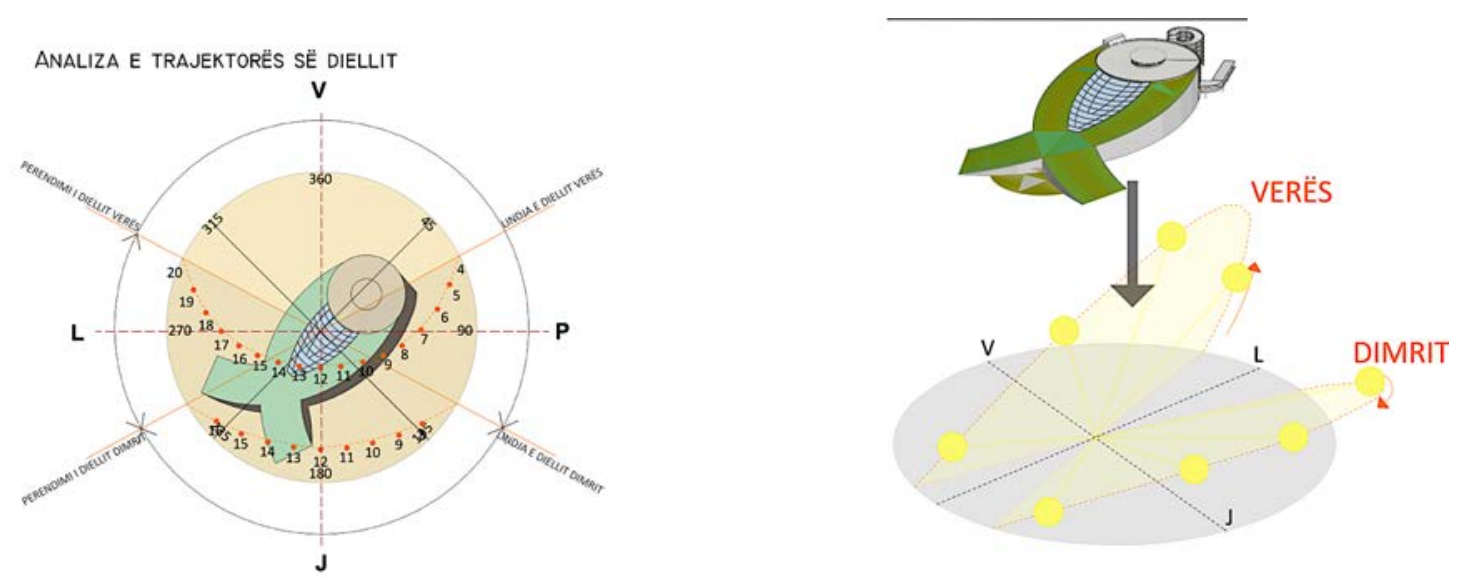

IALIZA E INSULIMIT GJATE DIMRIT DHE VERËS



Figura 61. Analizat

(Burimi): Diellza Delija, Diellza Hajrizi, 2018

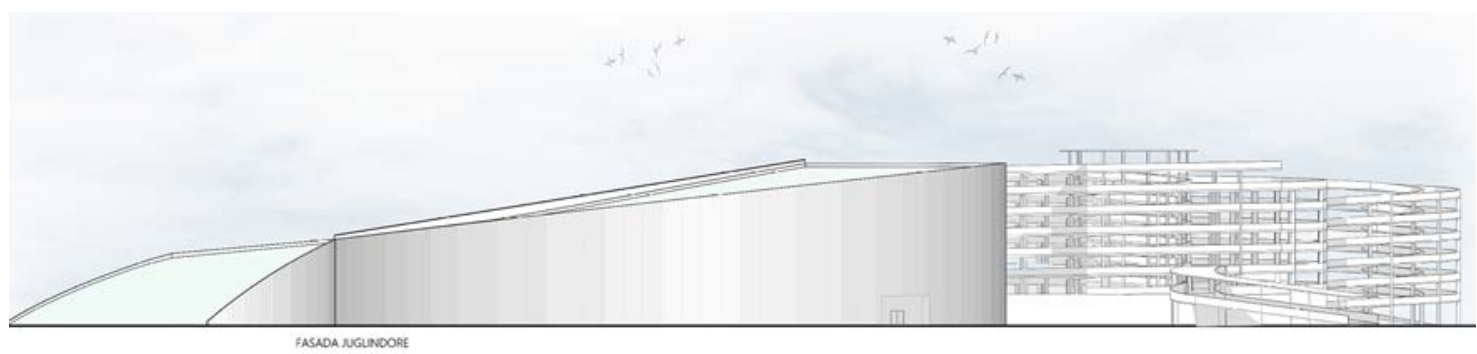

Figura 62. Pamjet

(Burimi): Diellza Delija, Diellza Hajrizi, 2018 


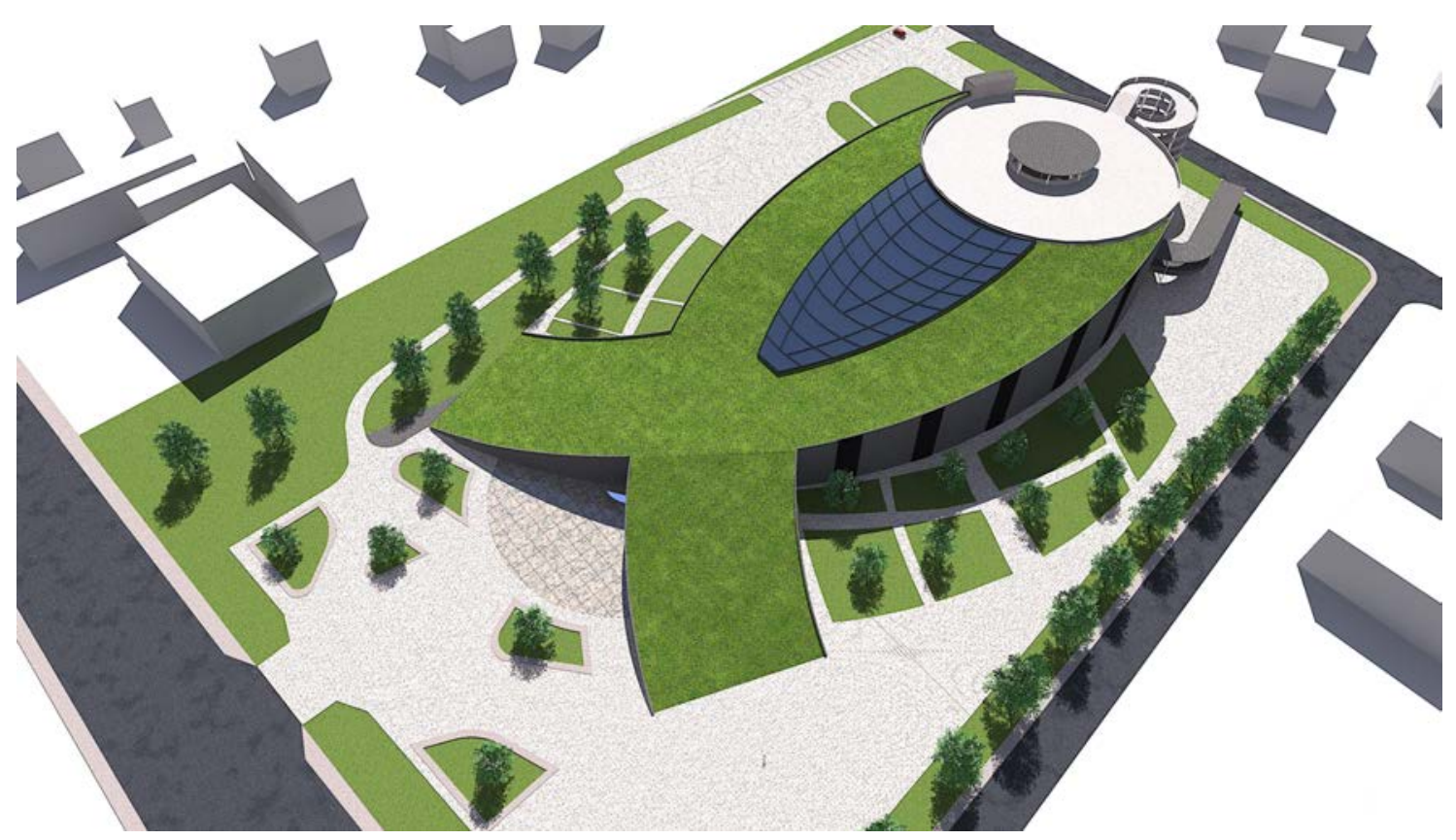

Figura 63. Perspektiva

(Burimi): Diellza Delija, Diellza Hajrizi, 2018



Figura 64. Perspektiva

(Burimi): Diellza Delija, Diellza Hajrizi, 2018 
Niveli Bachelor 2018/189 . Fakulteti i Ndërtimtarisë dhe Arkitekturës, Universiteti i Prishtinës. Departamenti i Arkitekturës. Lënda: Projektim 5.

Studentët: Dorarta Sallauka



Figura 65. Analizat

(Burimi): Dorarta Sallauka, 2018

9 Dorarta Sallauka. Lënda: Projektim 5. Punimi i tërë sipas dorëzimit final. FNA, UP. 


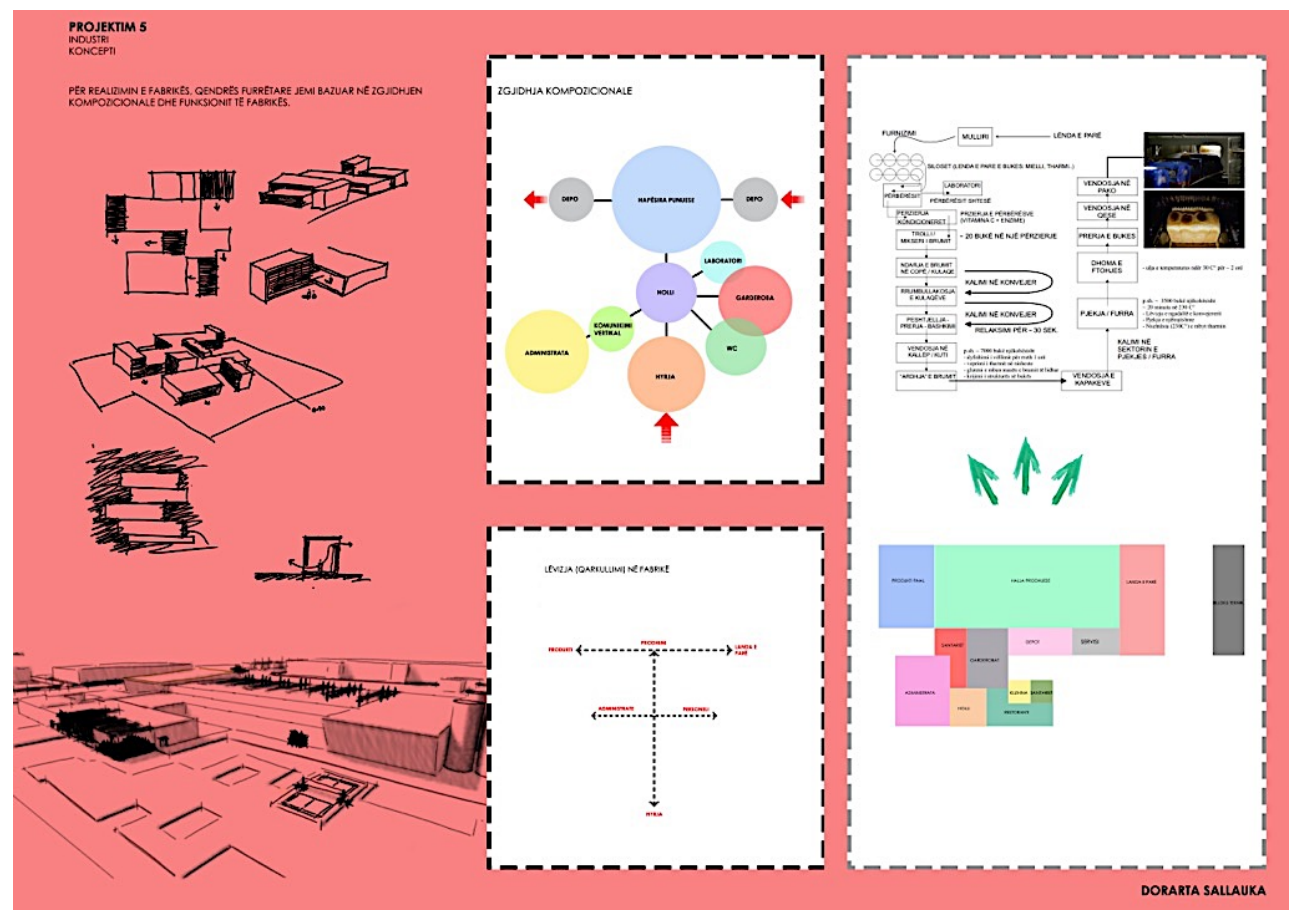

Figura 66. Analizat - Kompozicioni funksional (Burimi): Dorarta Sallauka, 2018



Figura 67. Baza e përdhesës (Burimi): Dorarta Sallauka, 2018 

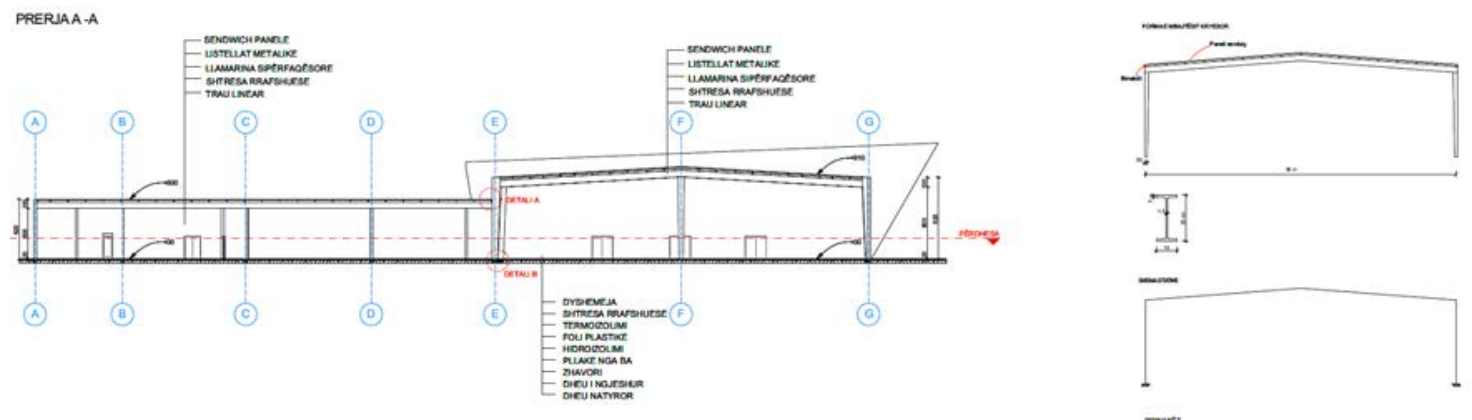

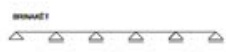

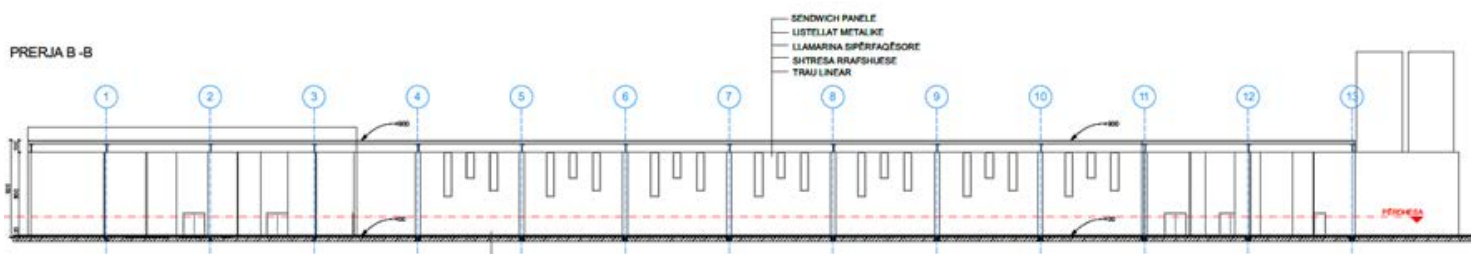

Figura 68. Prerjet

(Burimi): Dorarta Sallauka, 2018



DORARTA SALLAUKa

Figura 69. Pamjet

(Burimi): Dorarta Sallauka, 2018 
PROJEKTIM 5

PROJEKTIM 5
INDUSTRI
FASADAT P.1:200

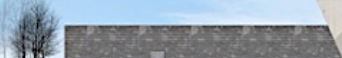

FASADA LINDORE

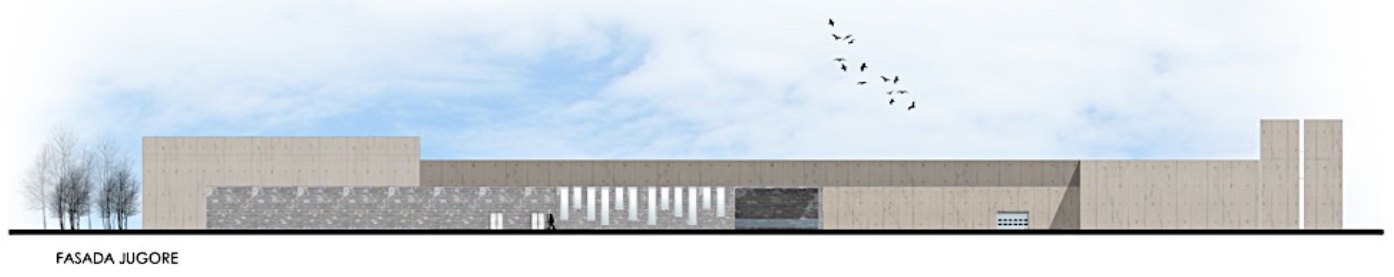

Figura 70. Pamjet

(Burimi): Dorarta Sallauka, 2018

DORARTA SALLAUKA

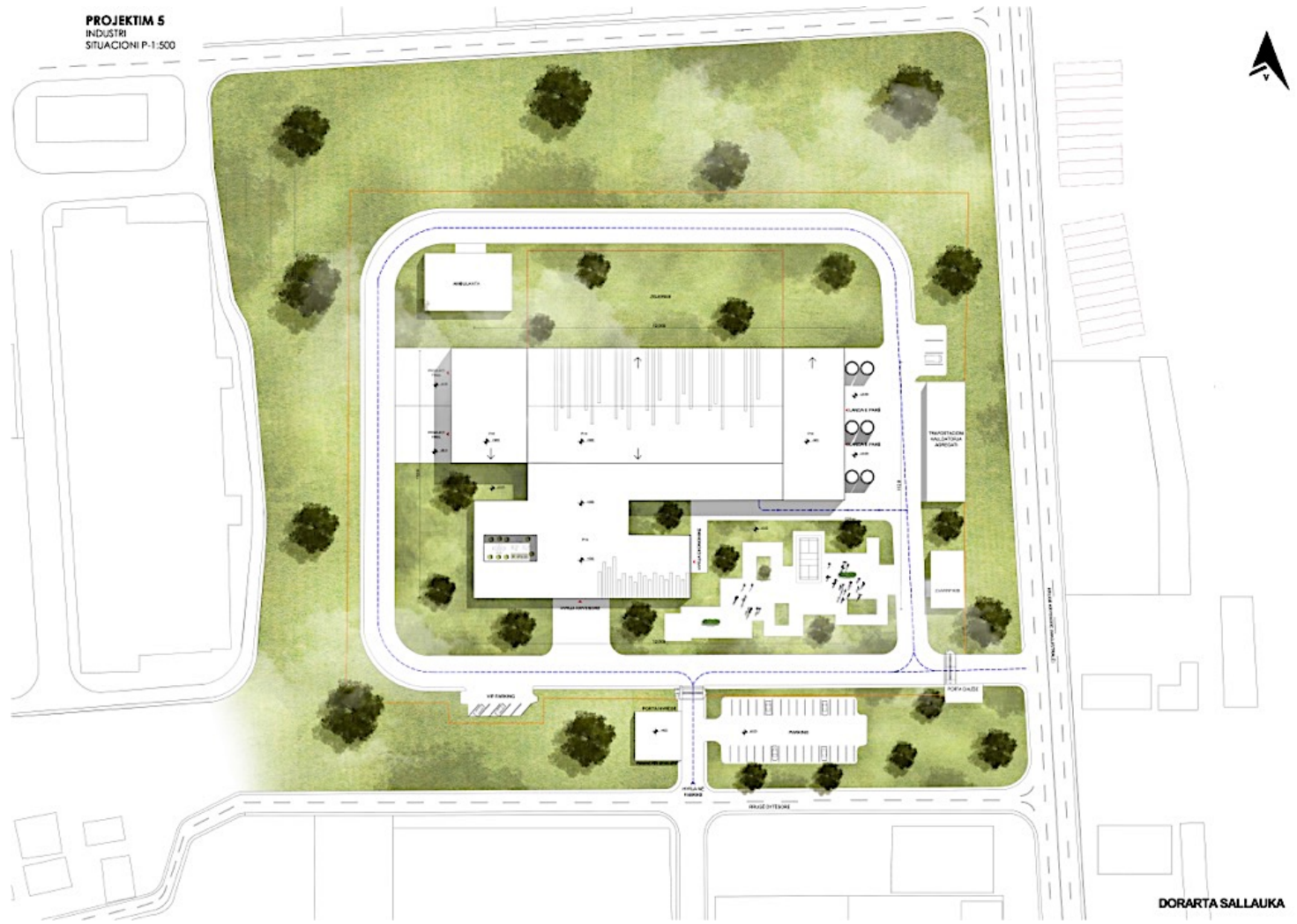

Figura 71. Situacioni

(Burimi): Dorarta Sallauka, 2018 

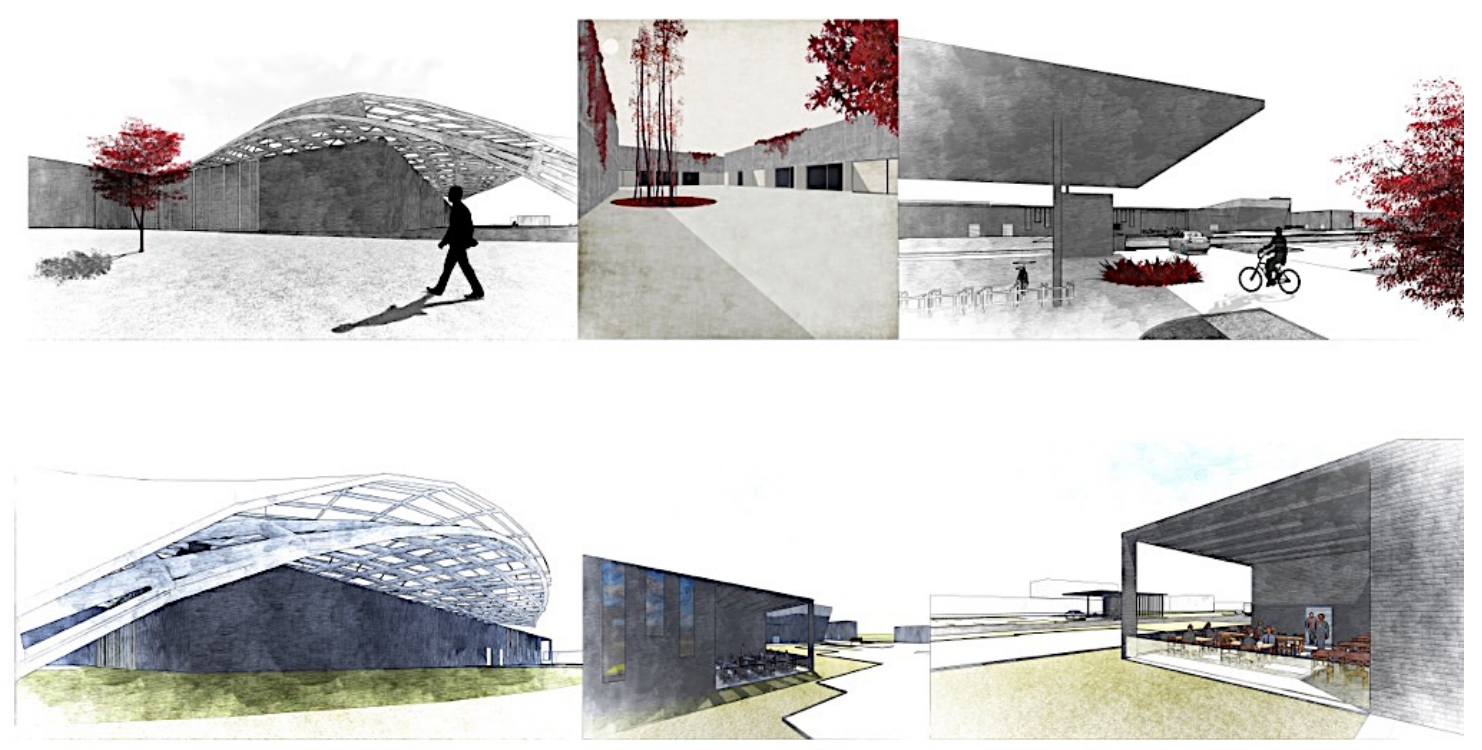

dorarta sallauka

Figura 72. Perspektiva

(Burimi): Dorarta Sallauka, 2018

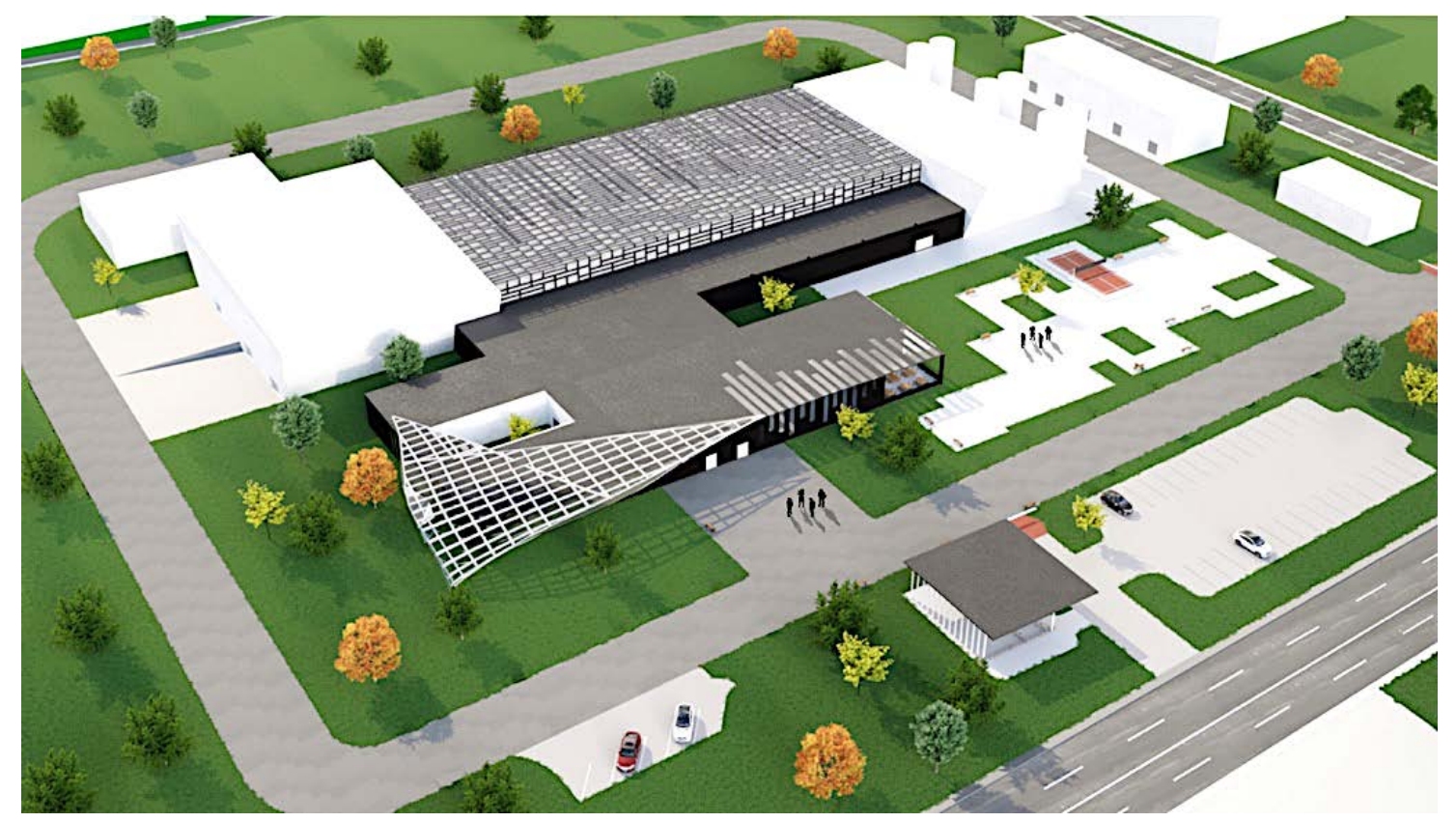

Figura 73. Perspektiva

(Burimi): Dorarta Sallauka, 2018 
Niveli Bachelor 2017/18 ${ }^{10}$. Fakulteti i Ndërtimtarisë dhe Arkitekturës, Universiteti i Prishtinës. Departamenti i Arkitekturës. Lënda: Projektim 5.

Studentët: Diana Deda

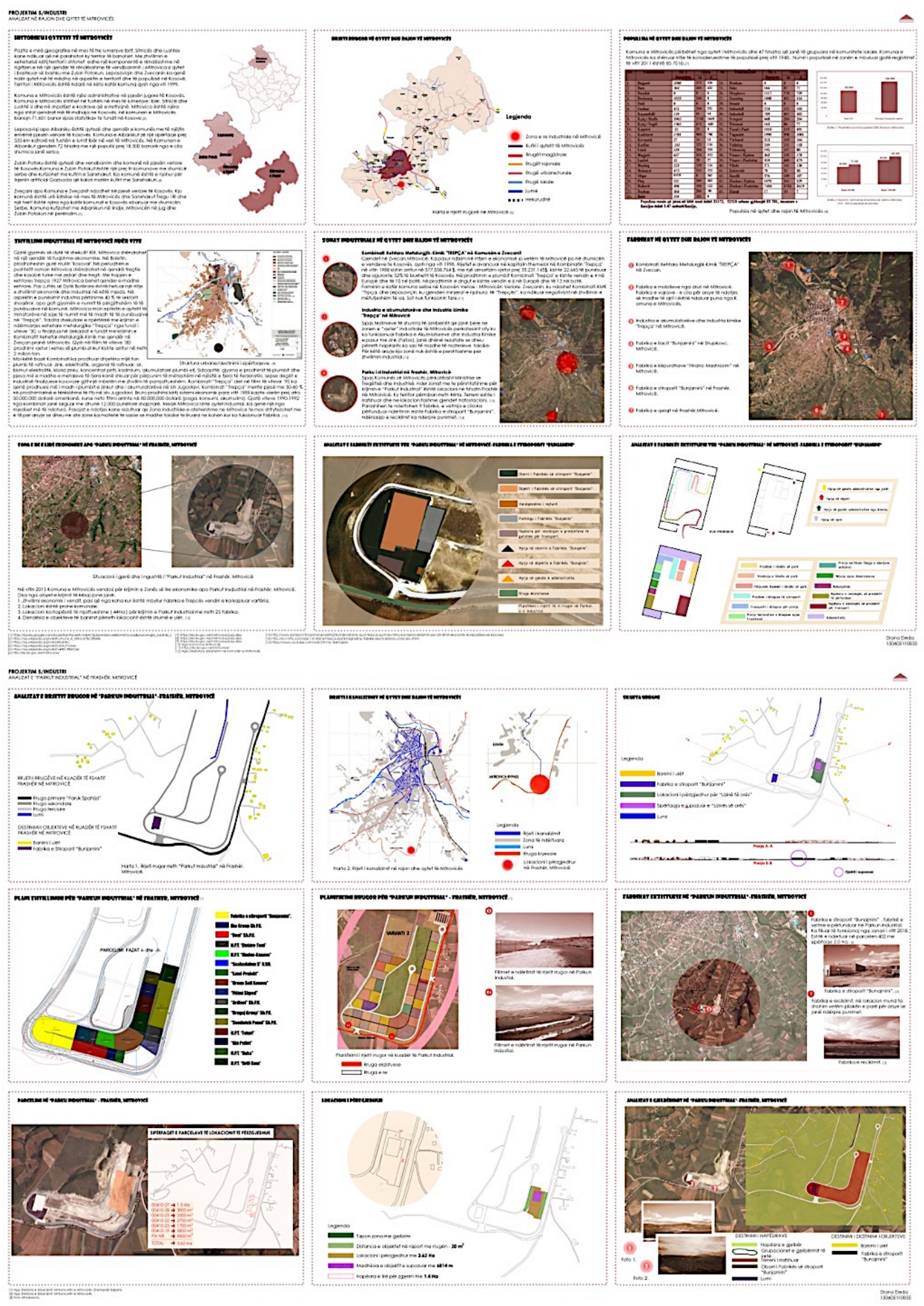

Figura 74. Analizat

(Burimi): Diana Deda, 2018

10 Diana Deda. Lënda: Projektim 5. Punimi i tërë sipas dorëzimit final. FNA, UP. 


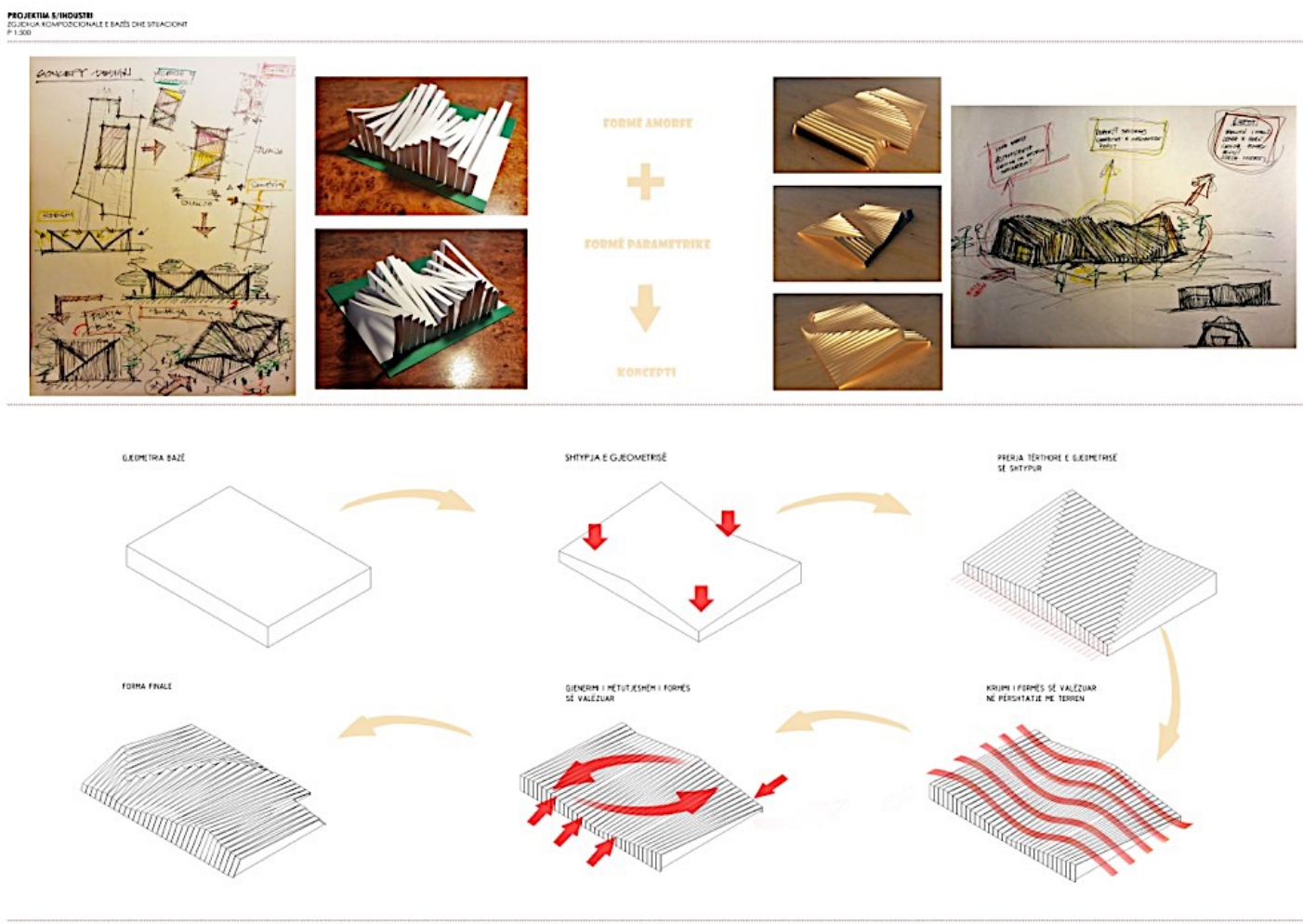

Figura 75. Koncepti

(Burimi): Diana Deda, 2018

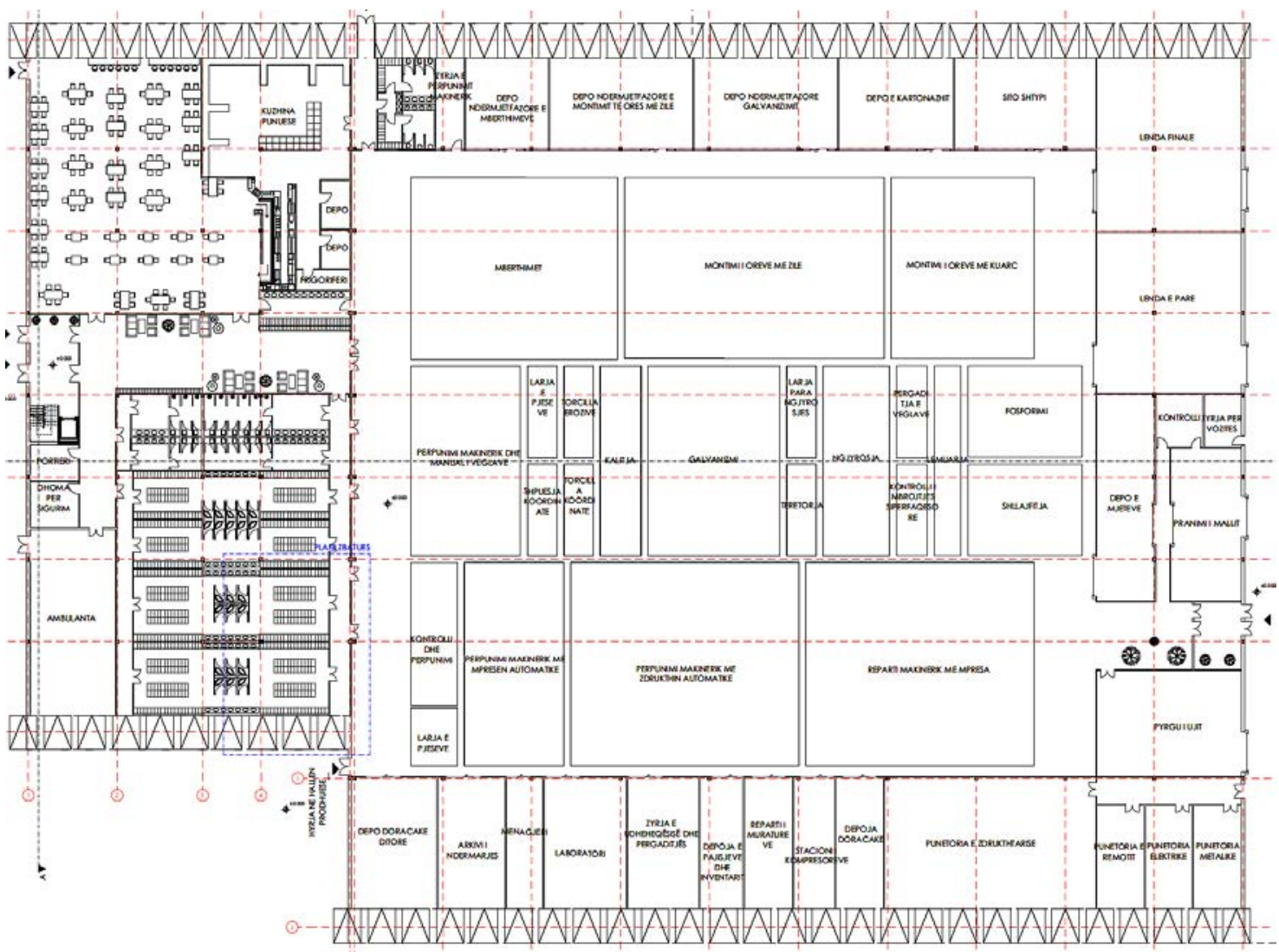

Figura 76. Baza e përdhesës (Burimi): Diana Deda, 2018 

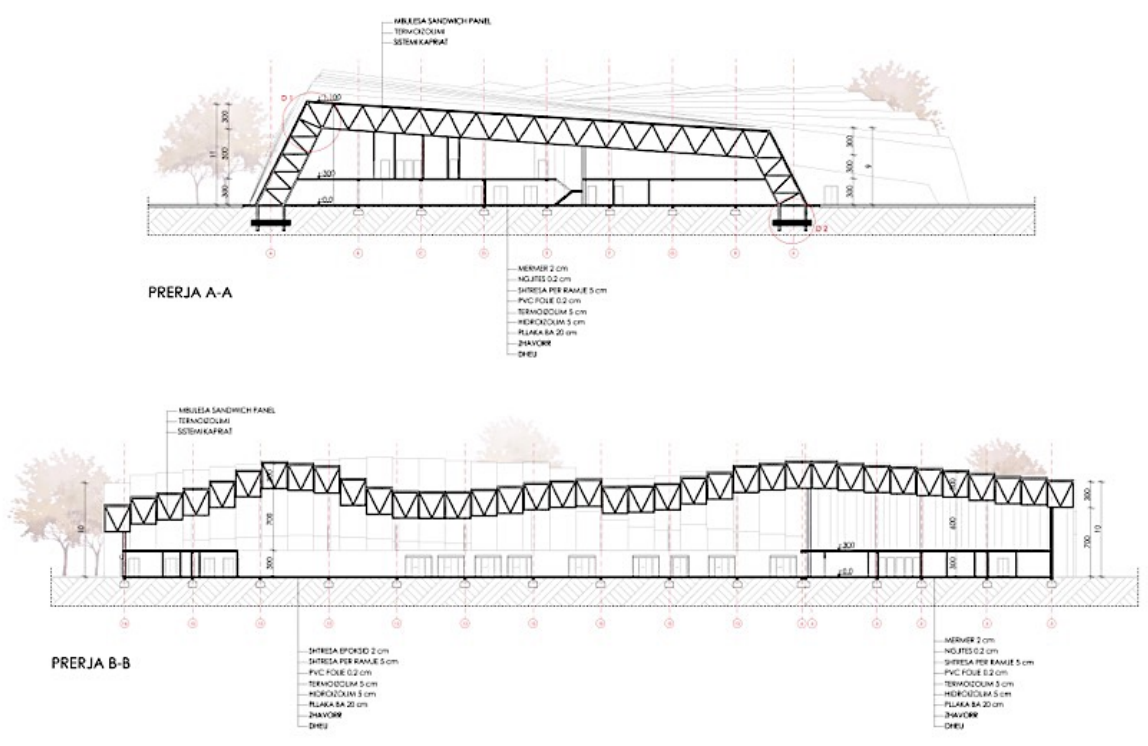

Figura 77. Prerjet

(Burimi): Diana Deda, 2018

PrOJEKTIM S/INDUSTRI
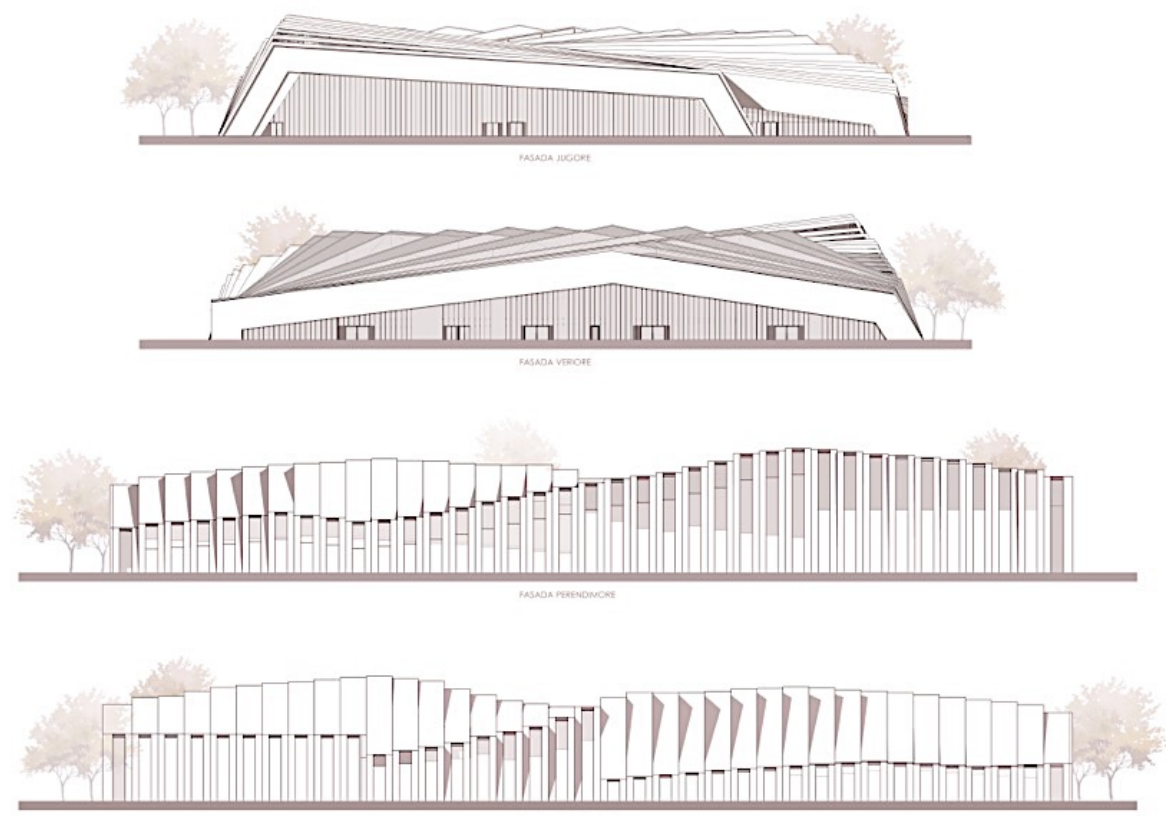

Figura 78. Pamjet

(Burimi): Diana Deda, 2018 

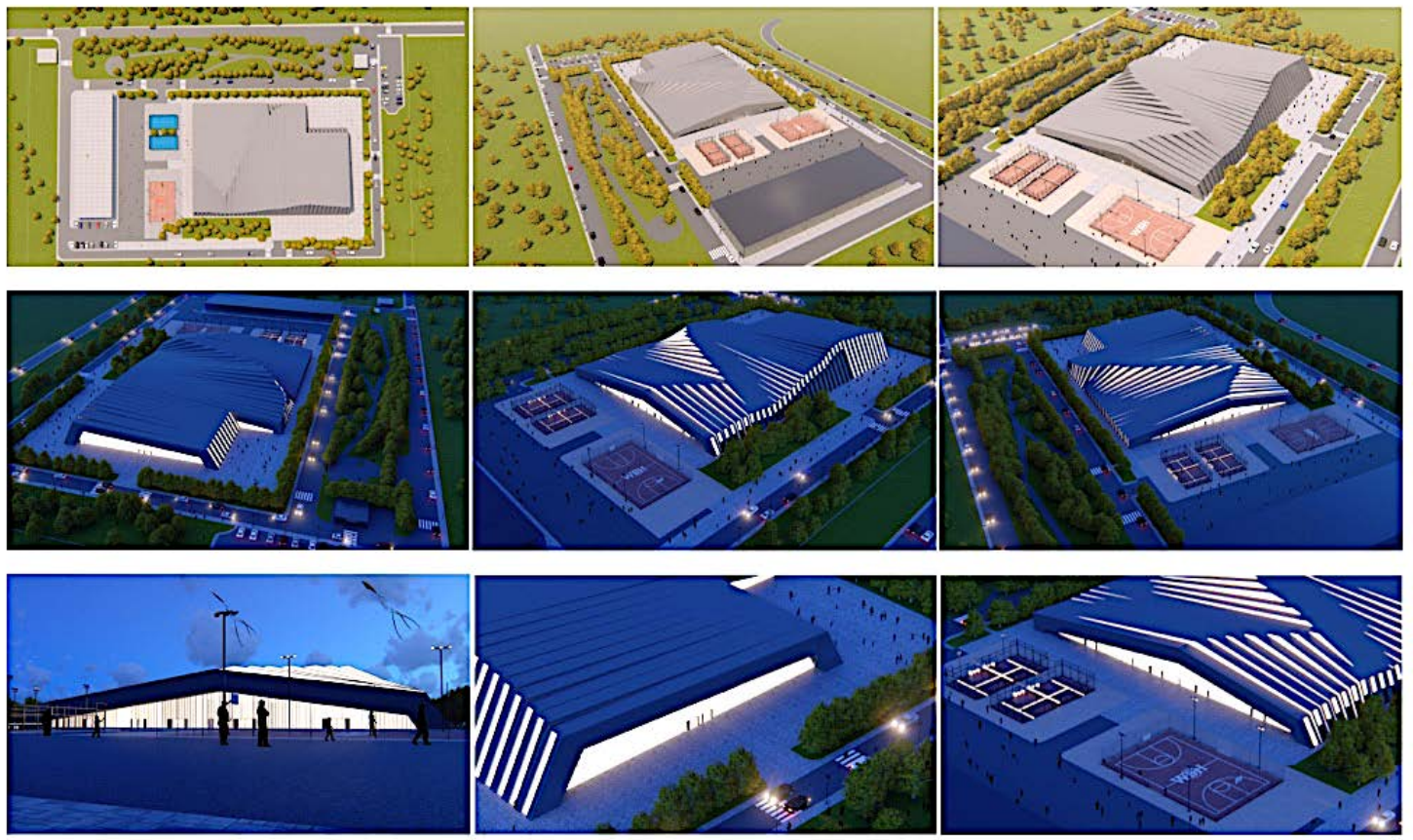

Figura 79. Perspektiva

(Burimi): Diana Deda, 2018

PROJEKTIM 5/INOUSTRI


Figura 80. Perspektiva

(Burimi): Diana Deda, 2018 
Niveli Bachelor 2017/18 ${ }^{11}$. Fakulteti i Ndërtimtarisë dhe Arkitekturës, Universiteti i Prishtinës. Departamenti i Arkitekturës. Lënda: Projektim 5.

Studentët: Dhuratë Krasniqi

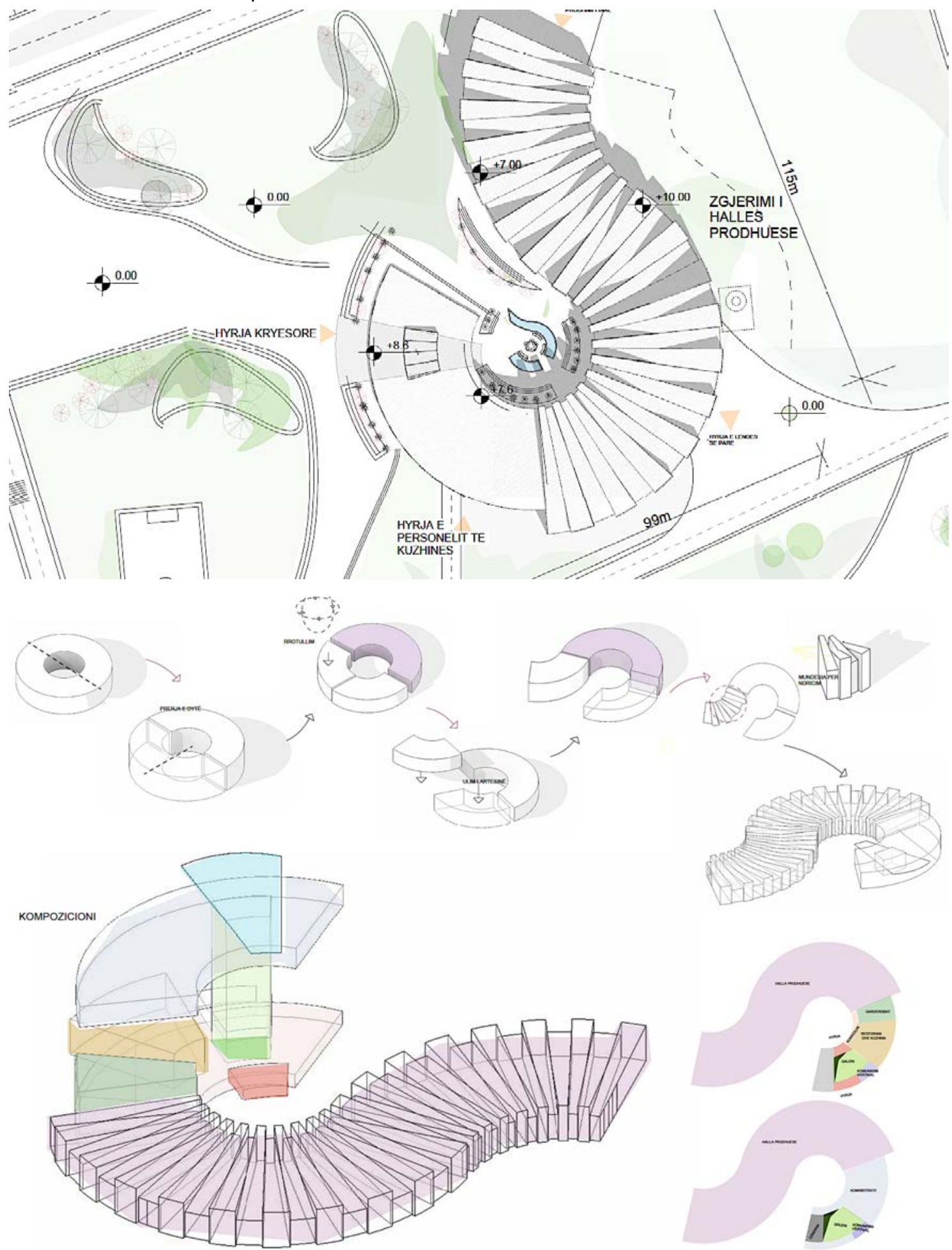

Figura 81. Situacioni - Kompozicioni funksional (Burimi): Dhuratë Krasniqi, 2018

11 Dhuratë Krasniqi. Lënda: Projektim 5. Punimi i tërë sipas dorëzimit final. FNA, UP. 


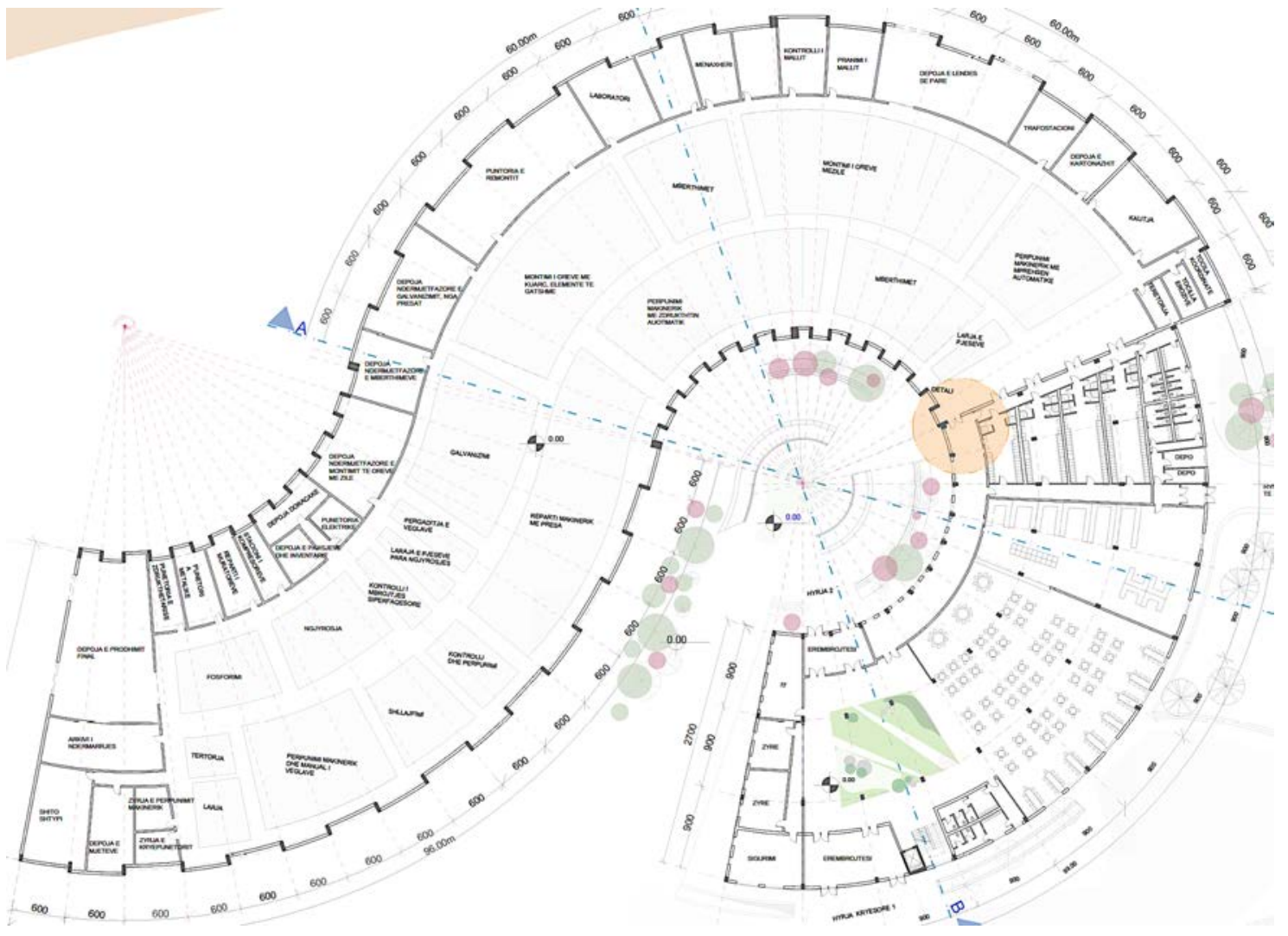

Figura 82. Baza e përdhesës (Burimi): Dhuratë Krasniqi, 2018

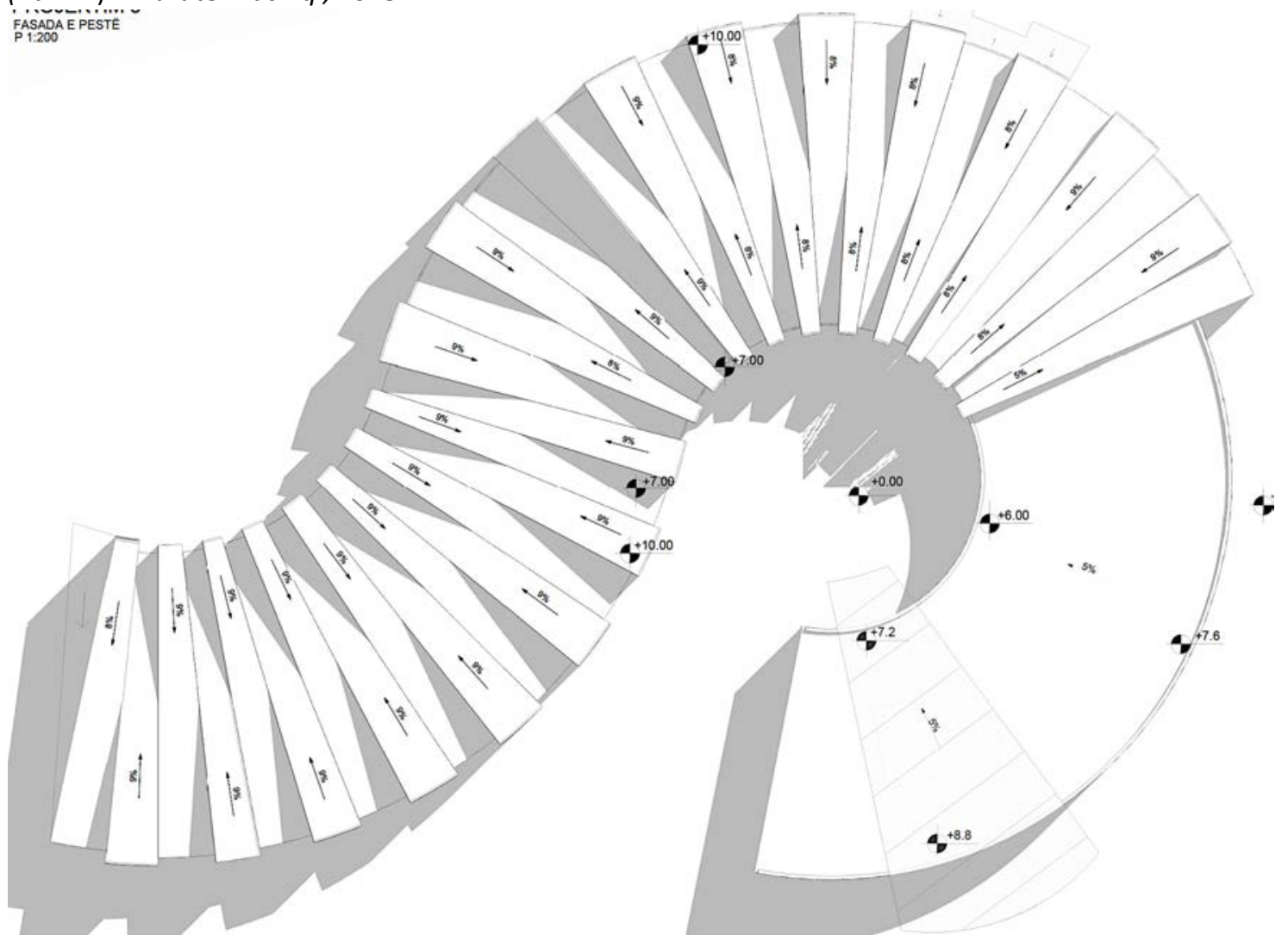

Figura 83. Pamja nga lartë (Burimi): Dhuratë Krasniqi, 2018 

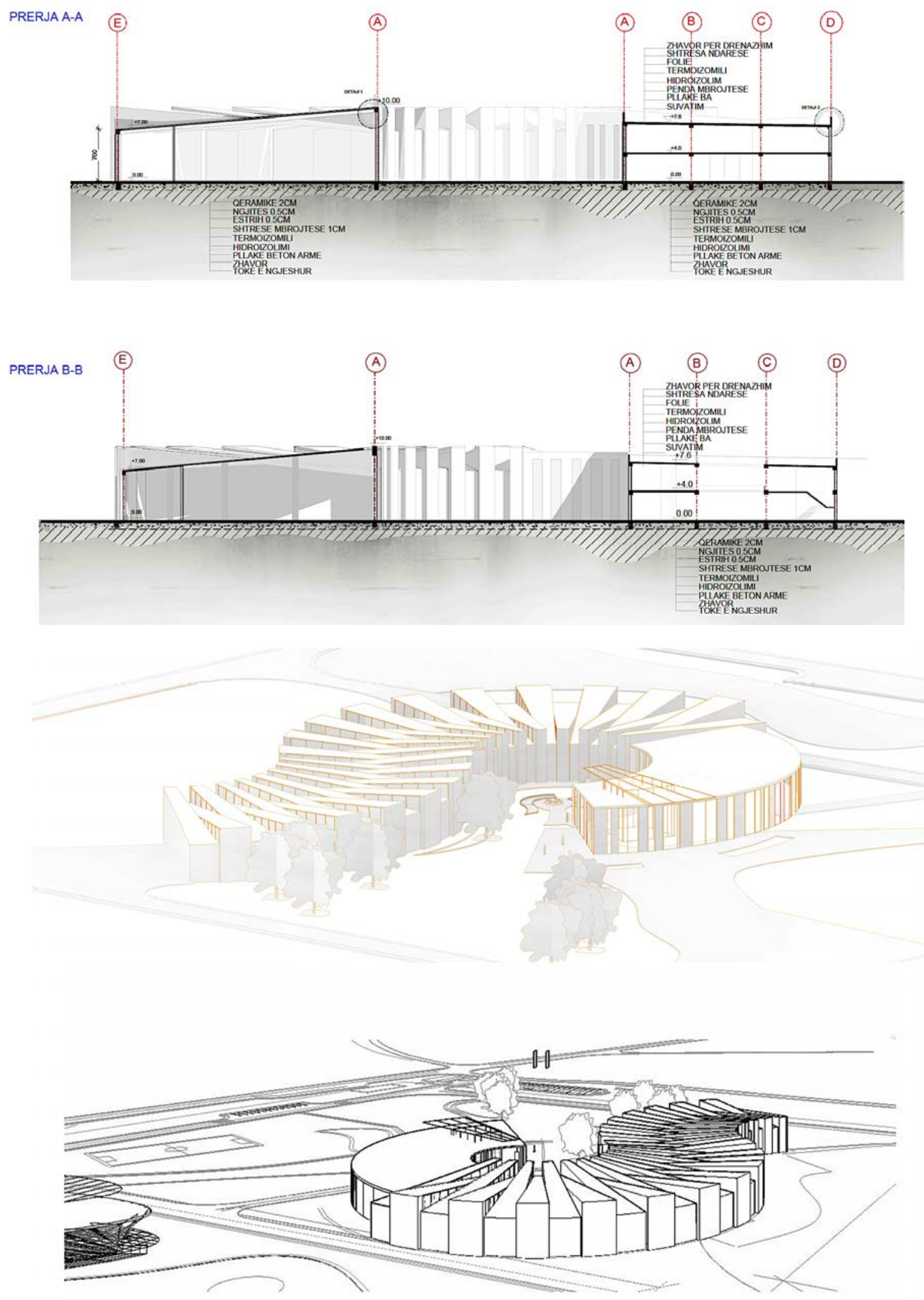

Figura 84. Prerjet - Perspektiva

(Burimi): Dhuratë Krasniqi, 2018 


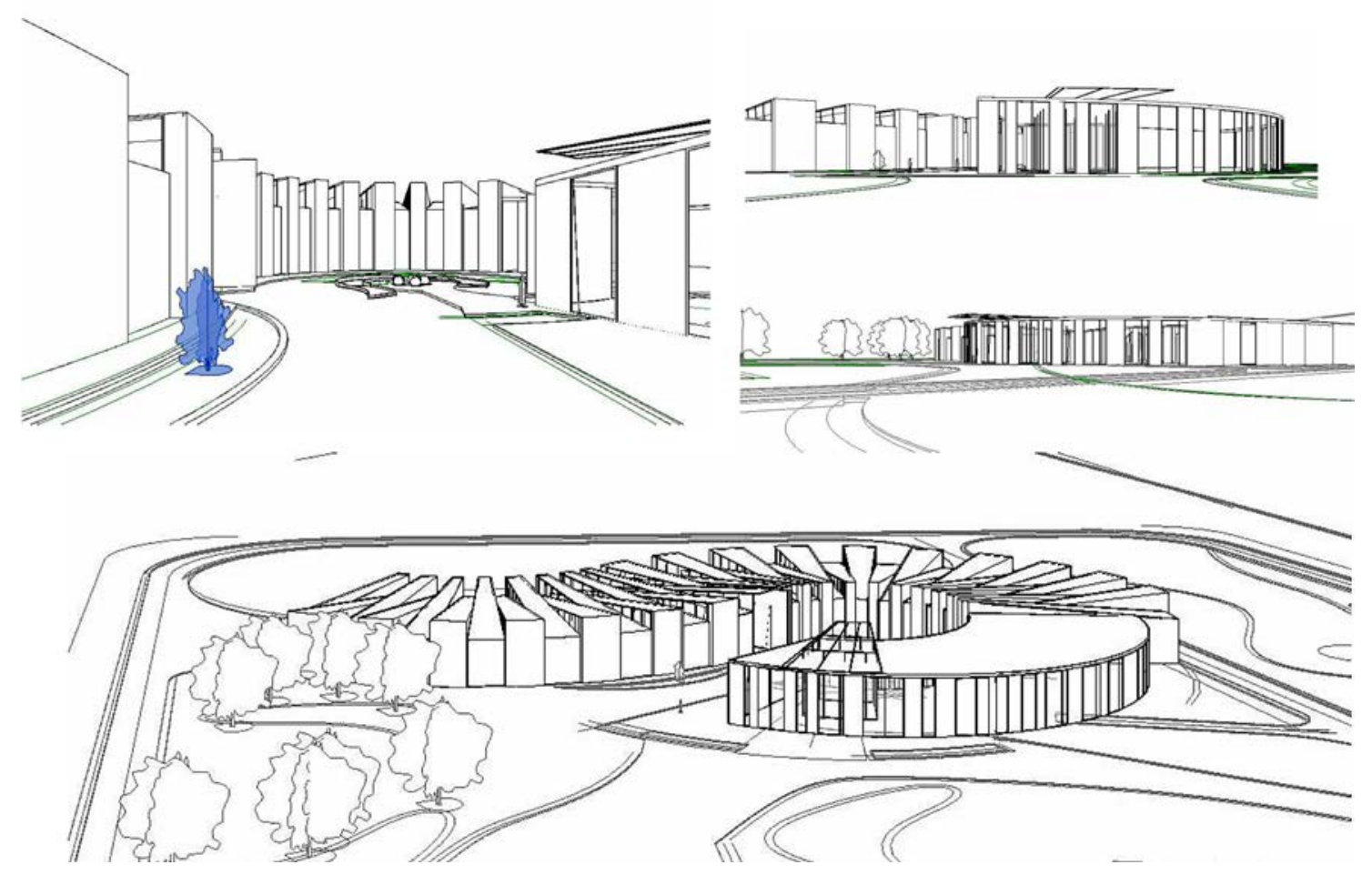

Figura 85. Perspektiva

(Burimi): Dhuratë Krasniqi, 2018

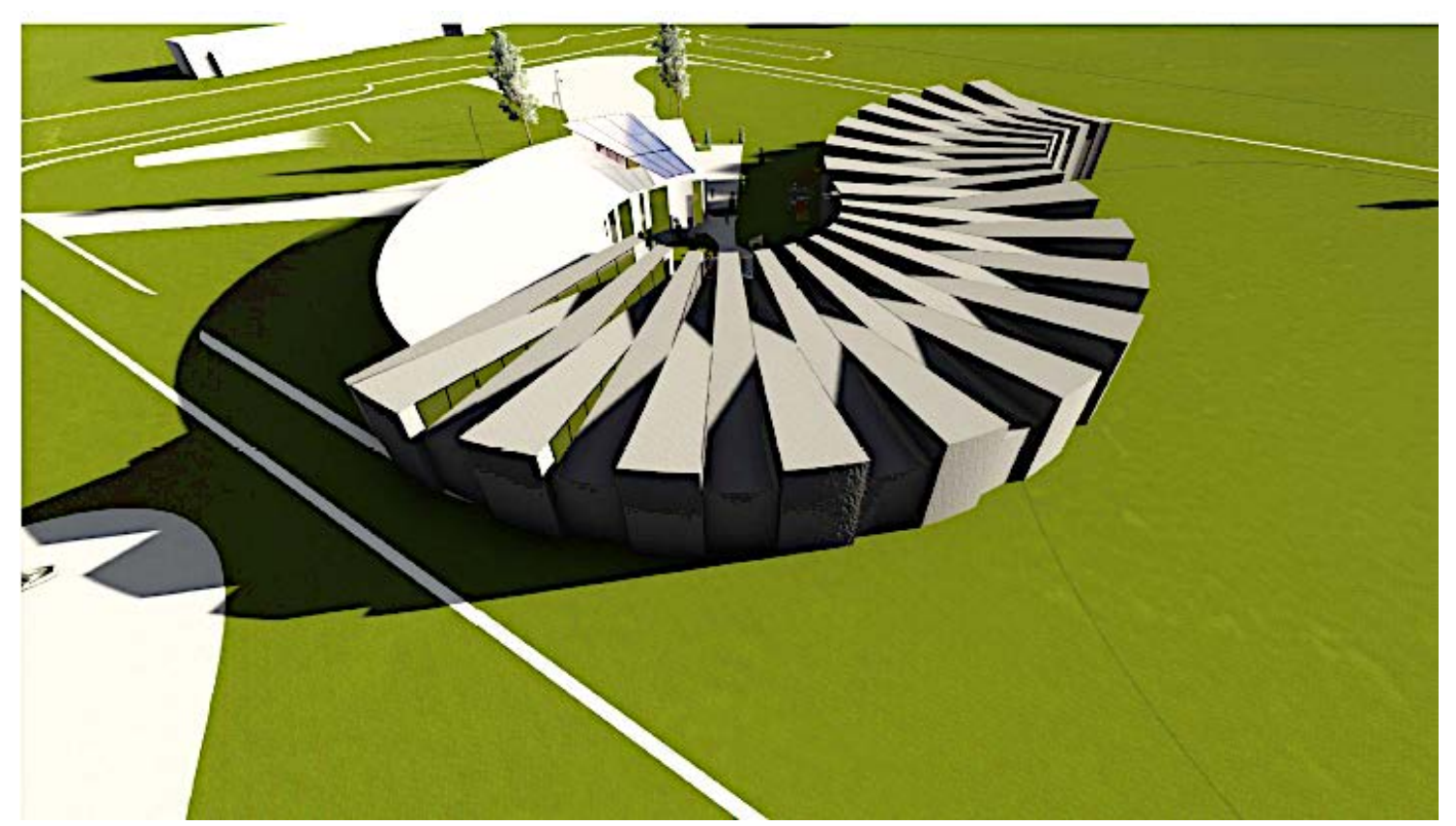

Figura 86. Perspektiva

(Burimi): Dhuratë Krasniqi, 2018 
Niveli Bachelor 2017/18 ${ }^{12}$. Fakulteti i Ndërtimtarisë dhe Arkitekturës, Universiteti i Prishtinës. Departamenti i Arkitekturës. Lënda: Projektim 5.

Studentët: Safete Dauti

$$
\begin{aligned}
& \text { PROJEKTIM } 5 \\
& \text { ANALIZA E LOKACIONIT- GJILAN }
\end{aligned}
$$
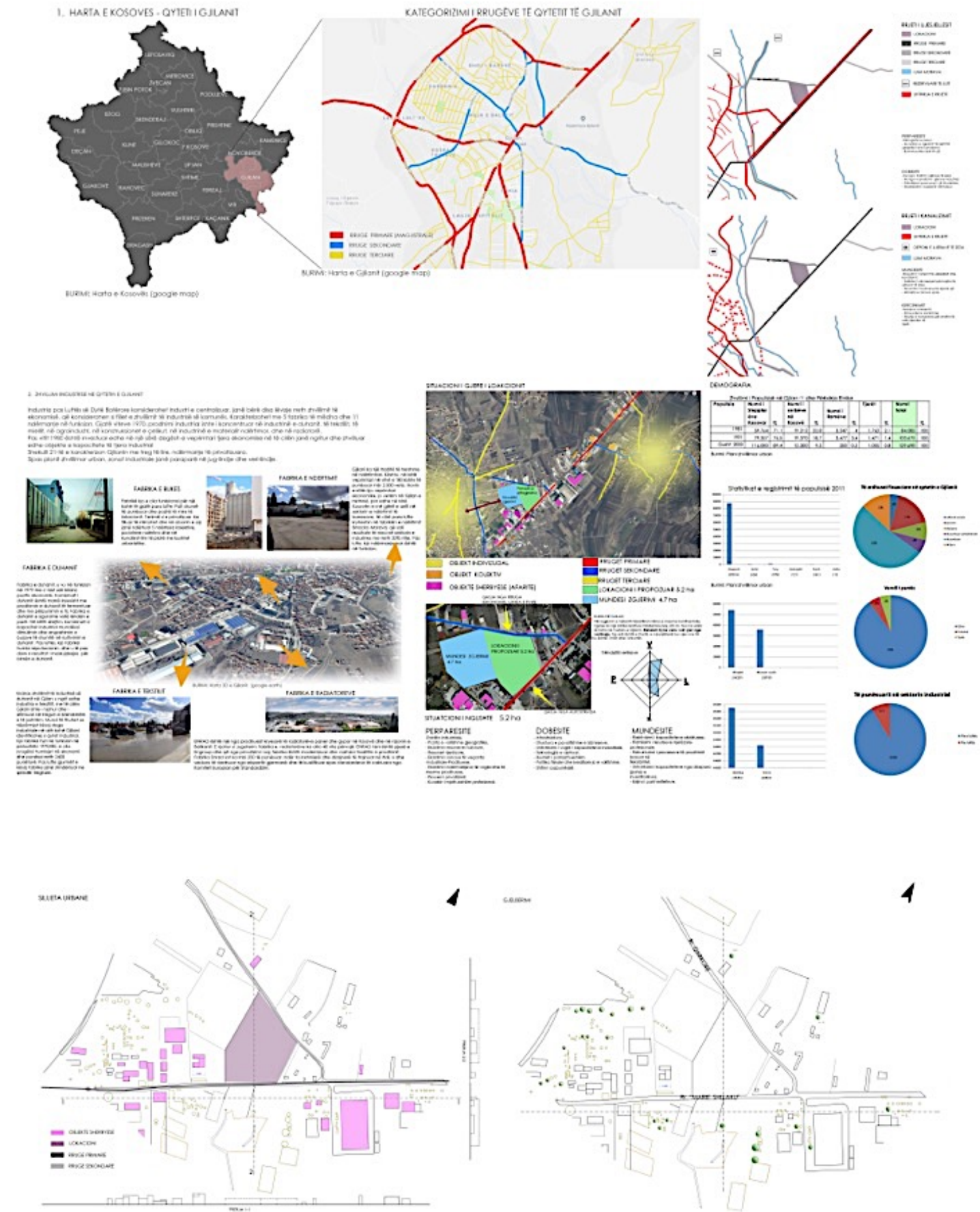

Figura 87. Analizat

(Burimi): Safete Dauti, 2018

SAFETE DAUTI

Prof. As. Dr. Bujar BAJÇINOVCI As. Mr. sc. Vlora ALIU

12 Safete Dauti. Lënda: Projektim 5. Punimi i tërë sipas dorëzimit final. FNA, UP. 


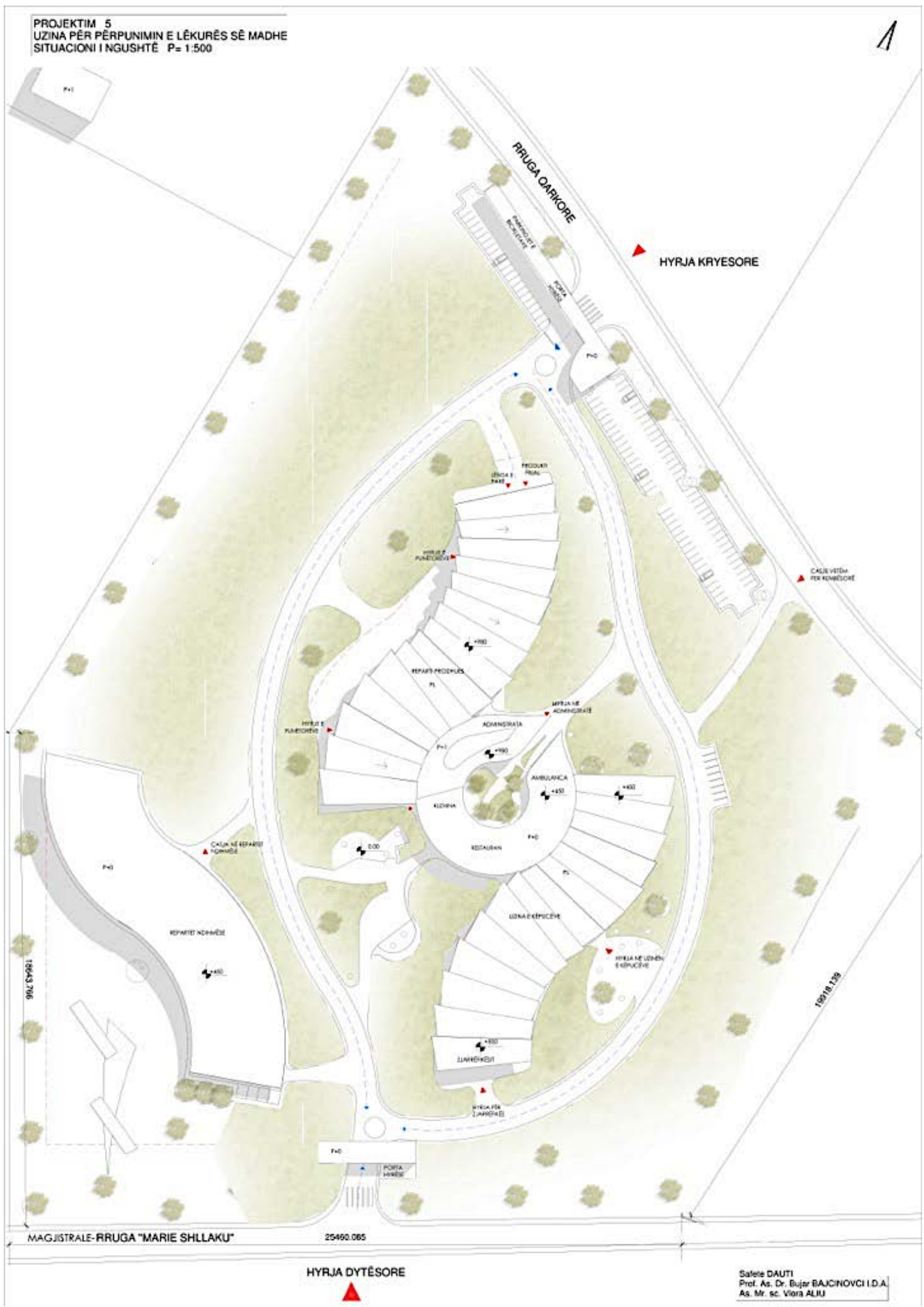

Figura 88. Situacioni

(Burimi): Safete Dauti, 2018 


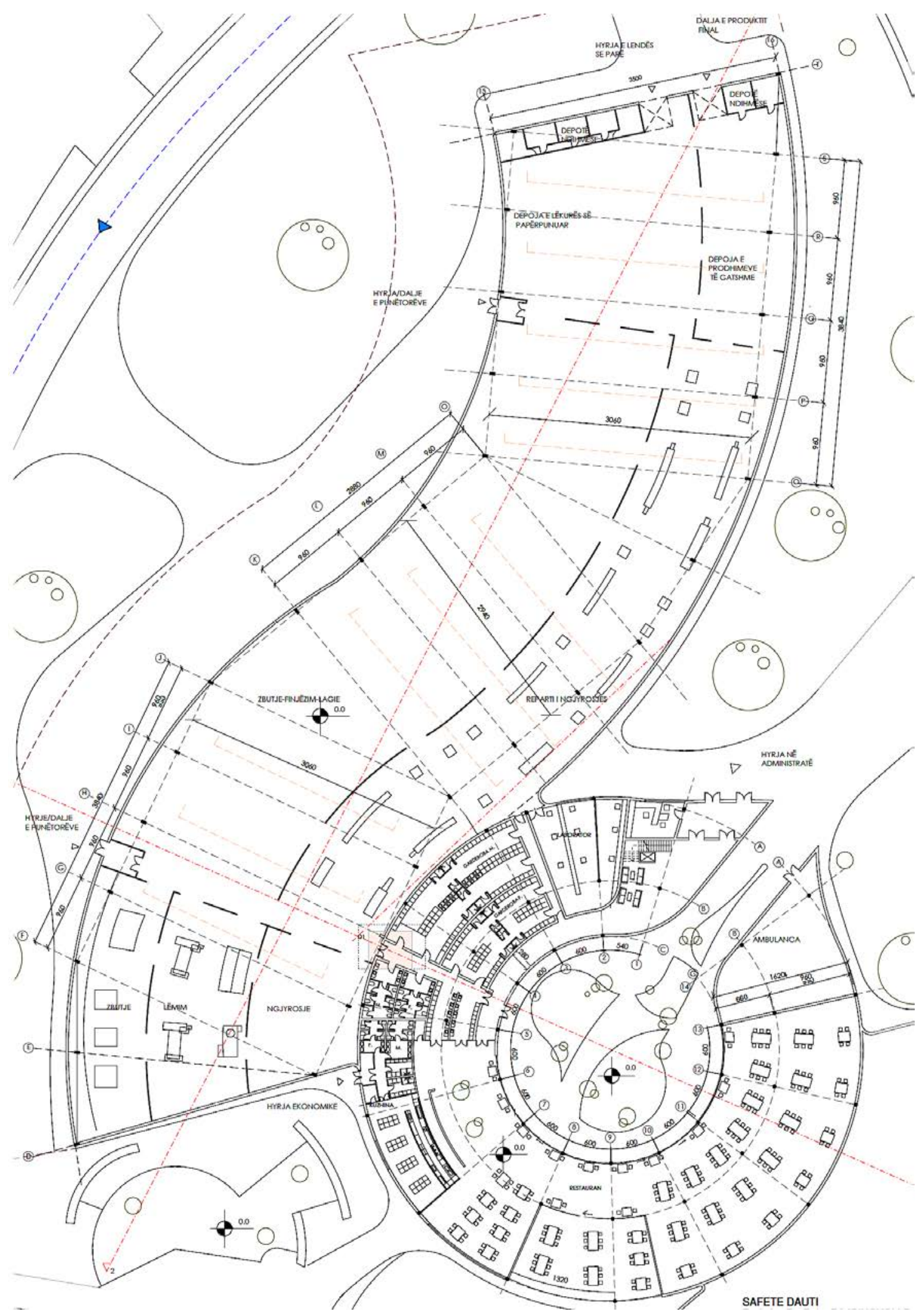

Figura 89. Baza e përdhesës

(Burimi): Safete Dauti, 2018 

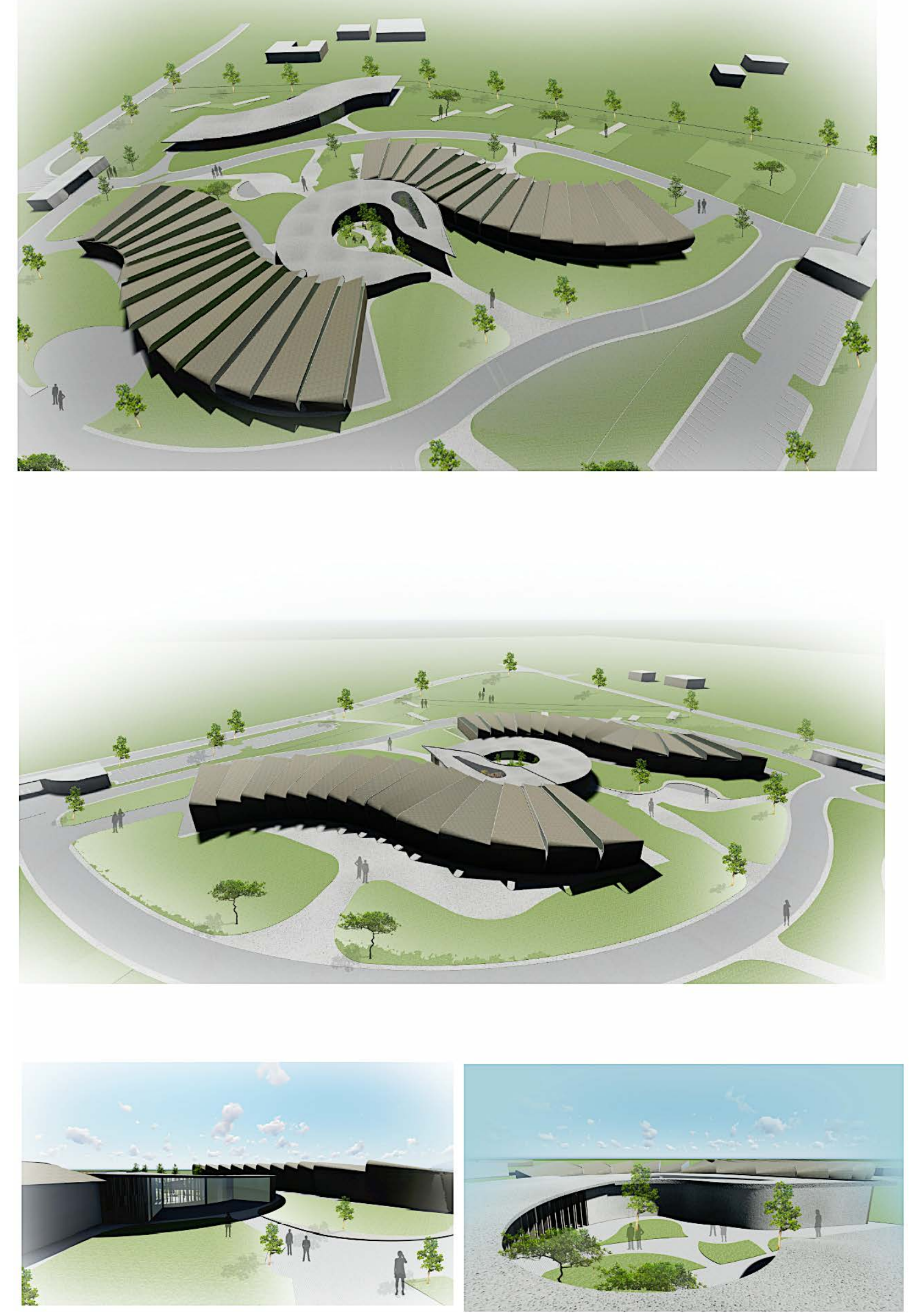

Figura 90. Perspektiva

(Burimi): Safete Dauti, 2018 
Niveli Bachelor 2017/18 ${ }^{13}$. Fakulteti i Ndërtimtarisë dhe Arkitekturës, Universiteti i Prishtinës. Departamenti i Arkitekturës. Lënda: Projektim 5.

Studentët: Gentianë Thaçi

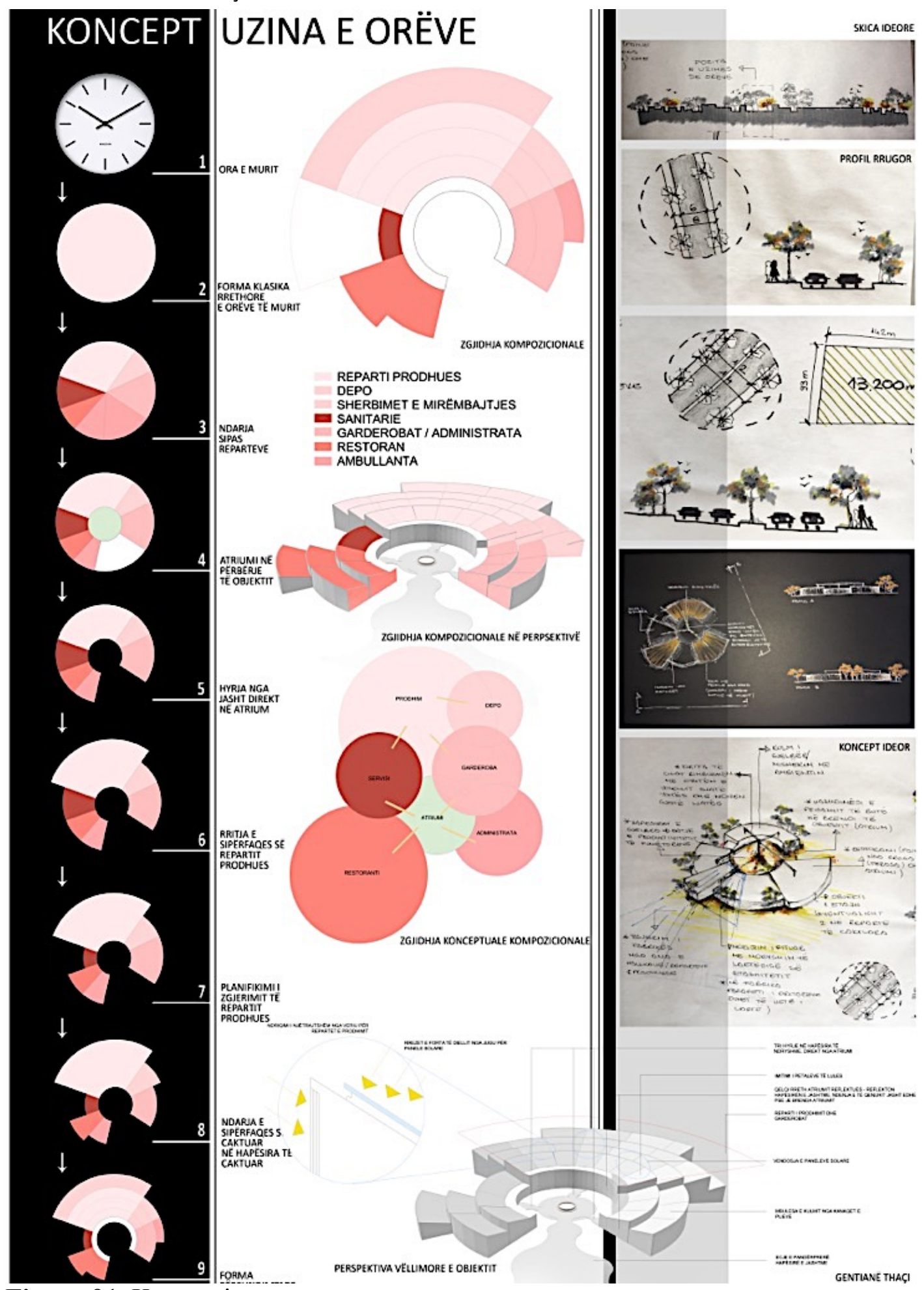

Figura 91. Koncepti

(Burimi): Gentianë Thaçi, 2018

13 Gentianë Thaçi. Lënda: Projektim 5. Punimi i tërë sipas dorëzimit final. FNA, UP. 


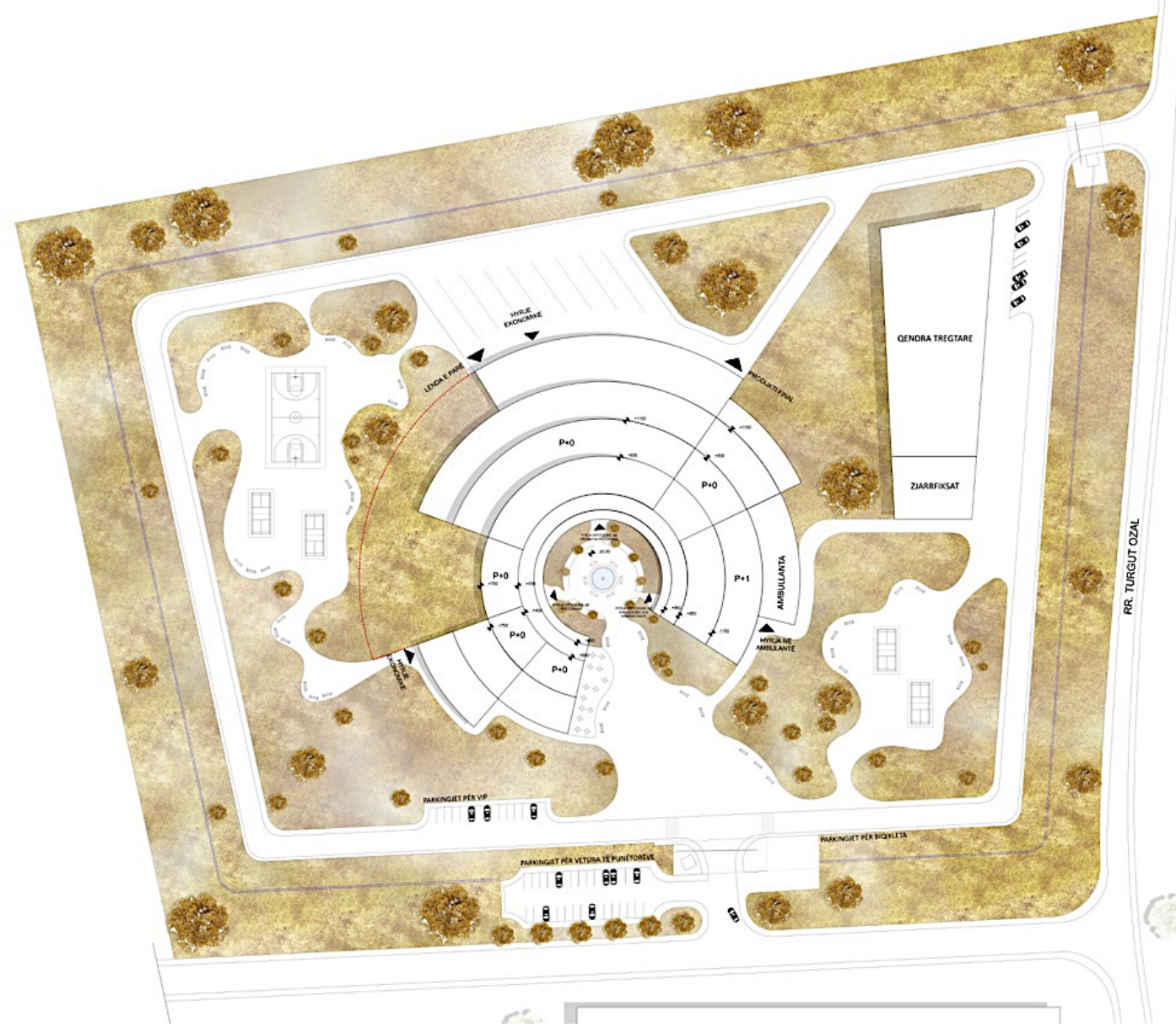

Figura 92. Situacioni

(Burimi): Gentianë Thaçi, 2018
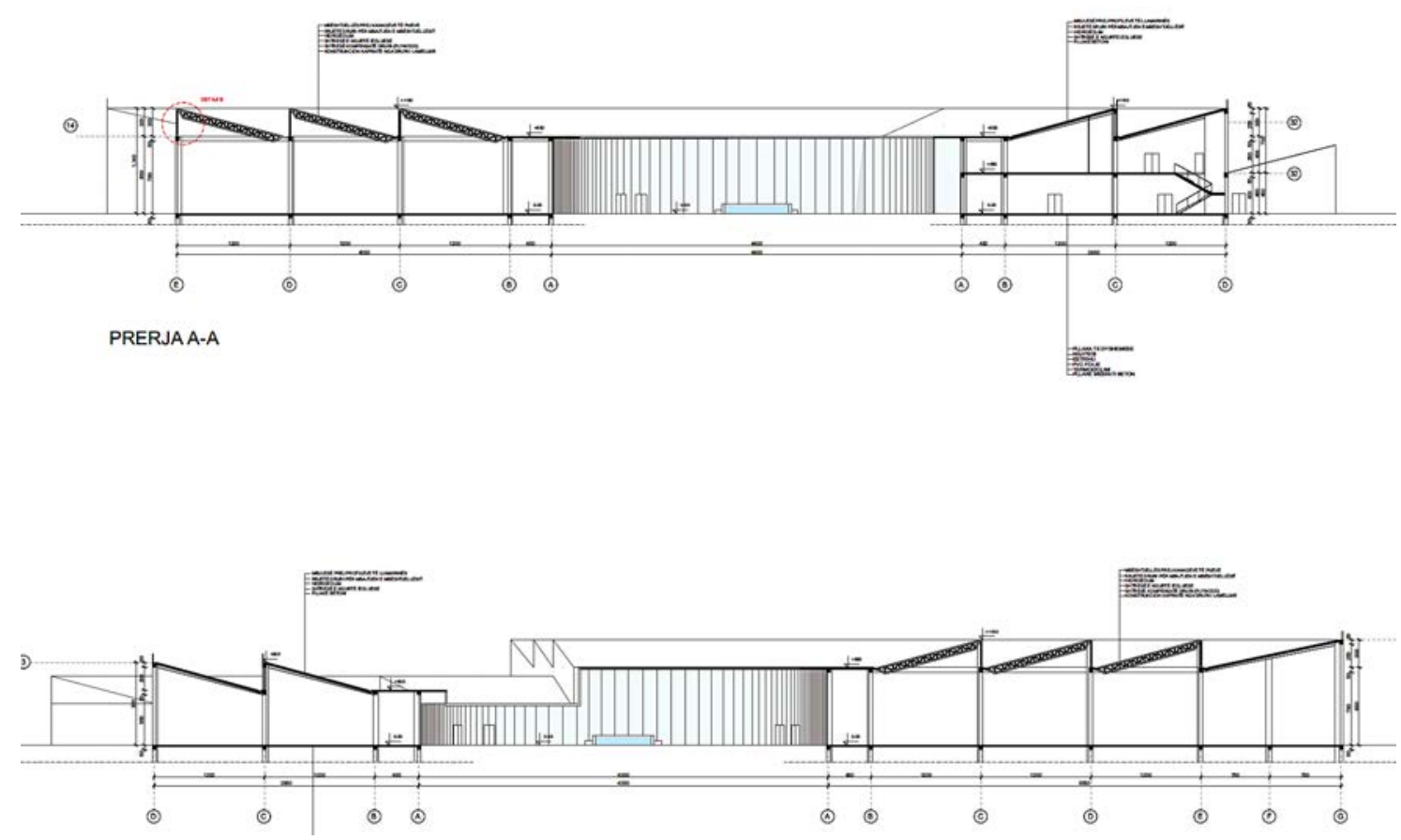

Figura 93. Prerjet

(Burimi): Gentianë Thaçi, 2018 

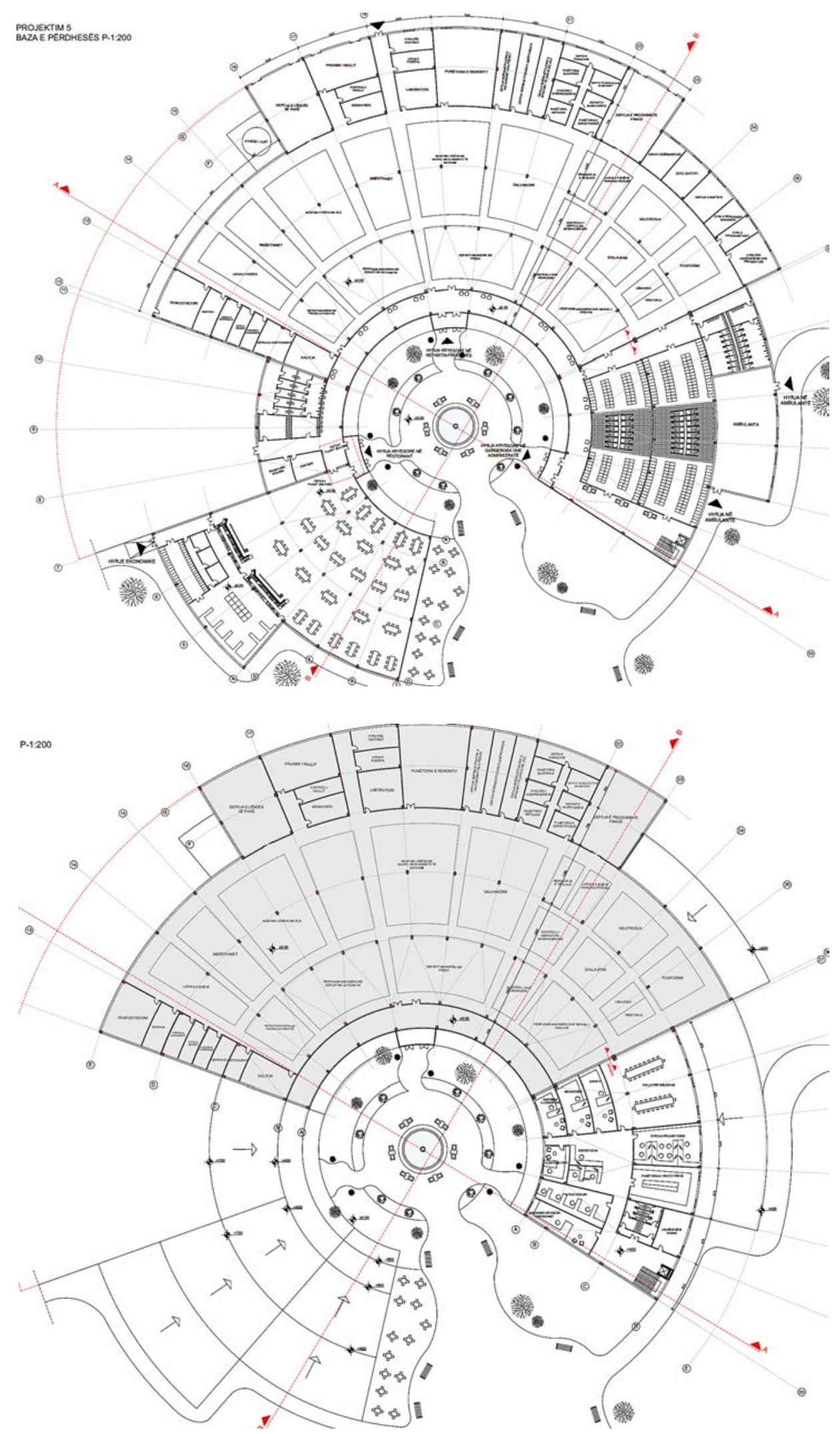

Figura 94. Baza e përdhesës dhe katit (Burimi): Gentianë Thaçi, 2018 




FASADA JUGORE

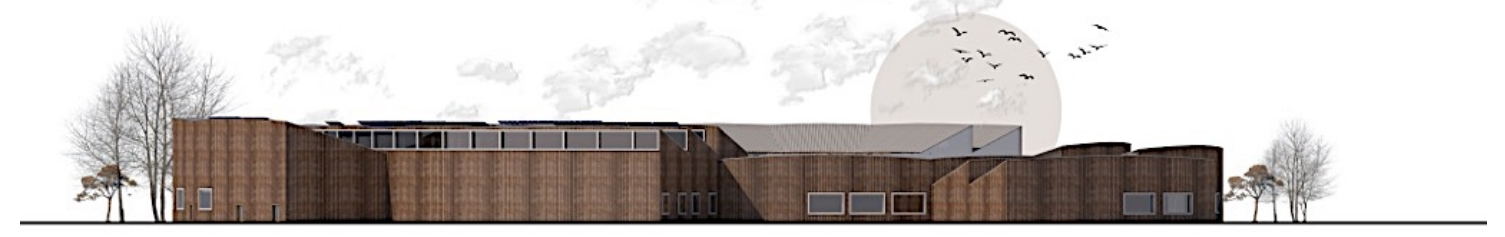

FASADA PERENDIMORE

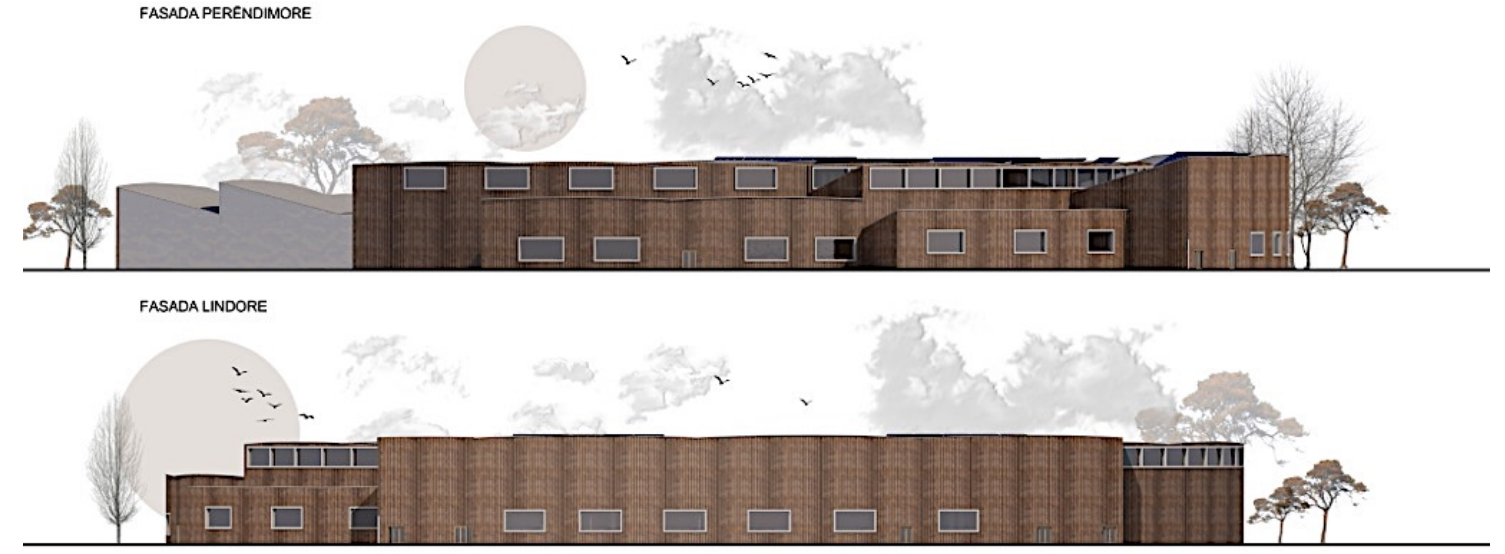

Figura 95. Pamjet

(Burimi): Gentianë Thaçi, 2018

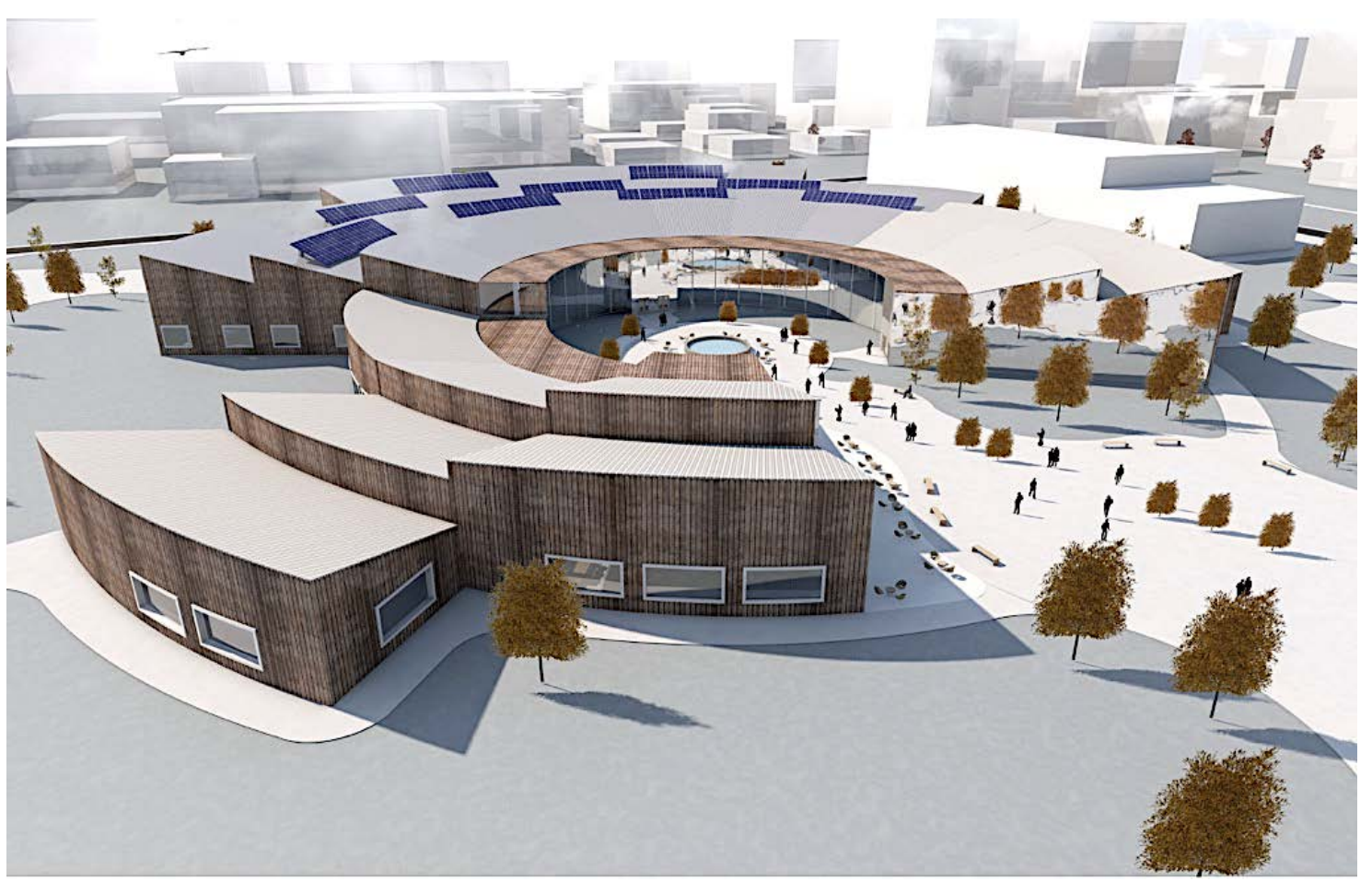

Figura 96. Perspektiva

(Burimi): Gentianë Thaçi, 2018 

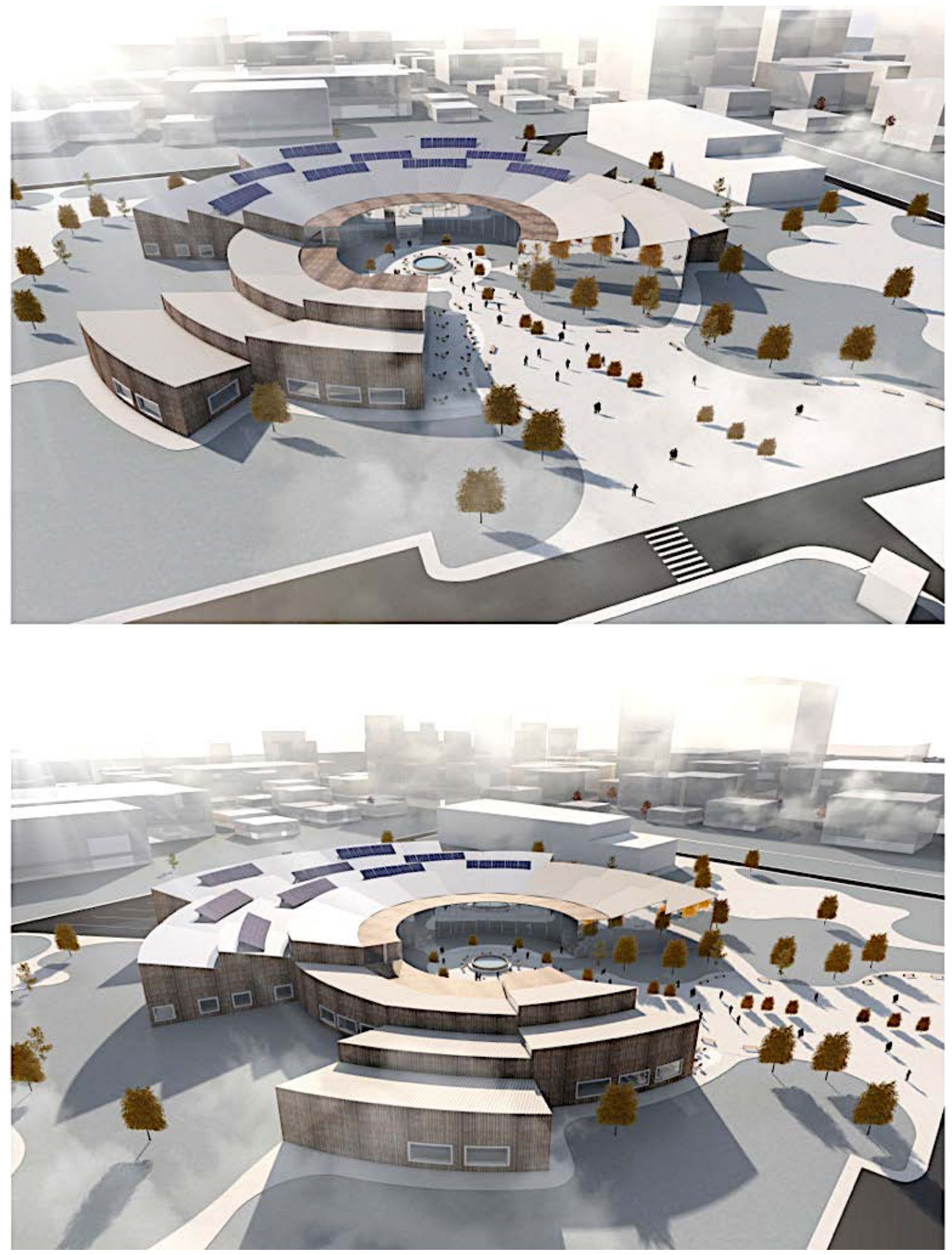

Figura 97. Perspektiva

(Burimi): Gentianë Thaçi, 2018 
Niveli Bachelor 2017/18 ${ }^{14}$. Fakulteti i Ndërtimtarisë dhe Arkitekturës, Universiteti i Prishtinës. Departamenti i Arkitekturës. Lënda: Projektim 5.

Studentet: Diellza Delija, Diellza Hajrizi

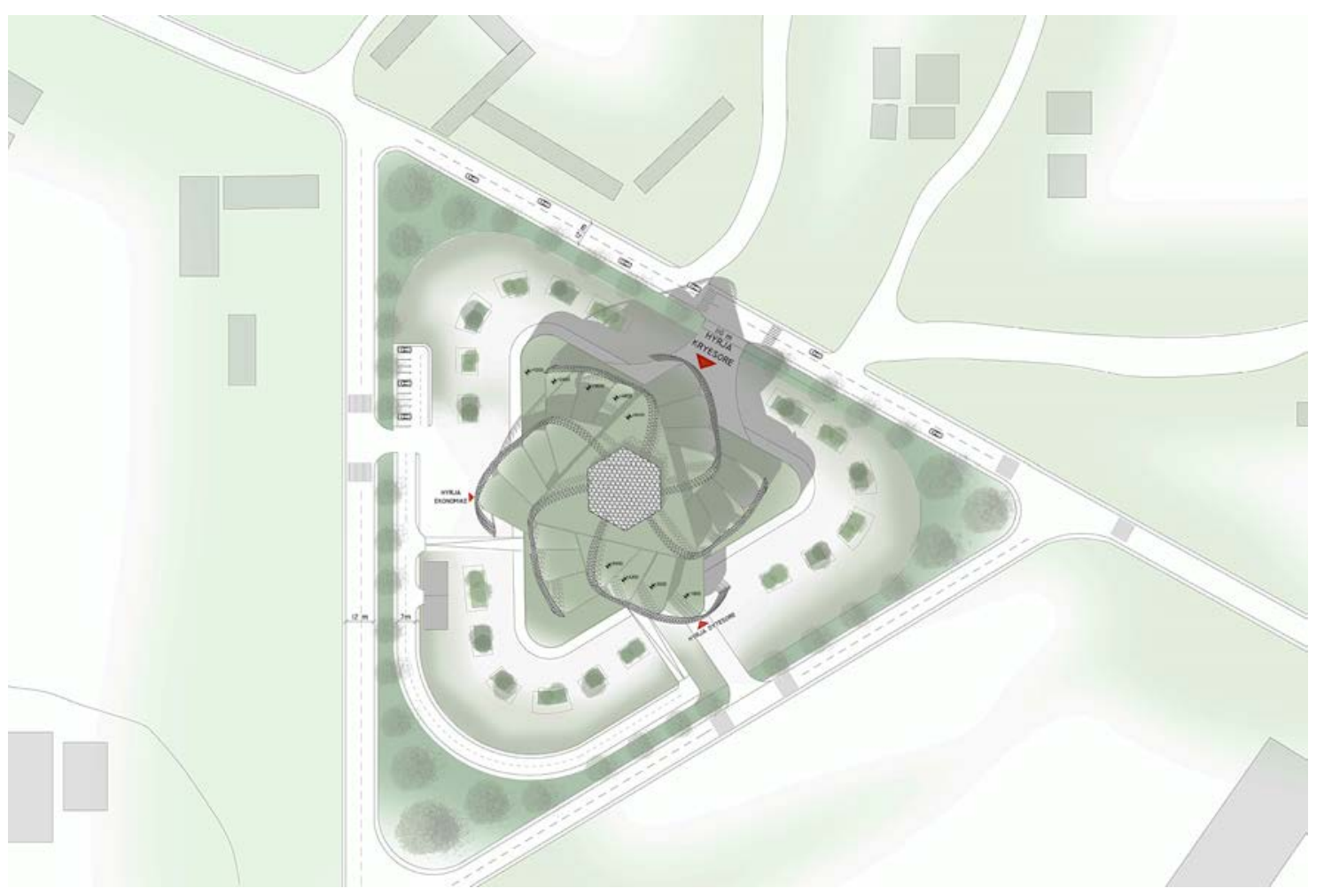

Figura 98. Situacioni

(Burimi): Diellza Delija, Diellza Hajrizi, 2018.



Figura 99. Analizat e Situacionit

(Burimi): Diellza Delija, Diellza Hajrizi, 2018.

14 Diellza Delija, Diellza Hajrizi. Lënda: Projektim 5. Punimi i tërë sipas dorëzimit final. FNA, UP. 



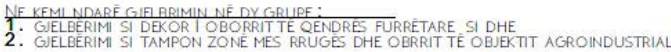

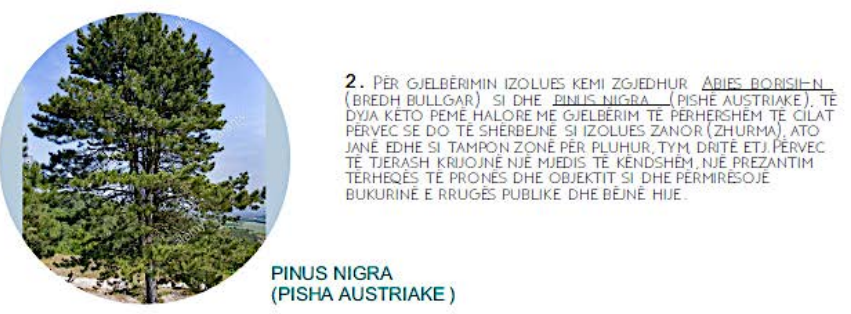

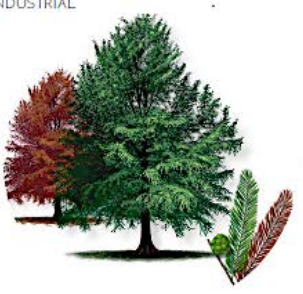

BALD CYPRESS

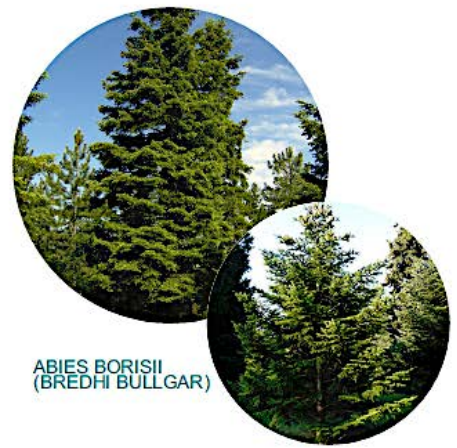

Figura 100. Analizat e bimësisë

(Burimi): Diellza Delija, Diellza Hajrizi, 2018.

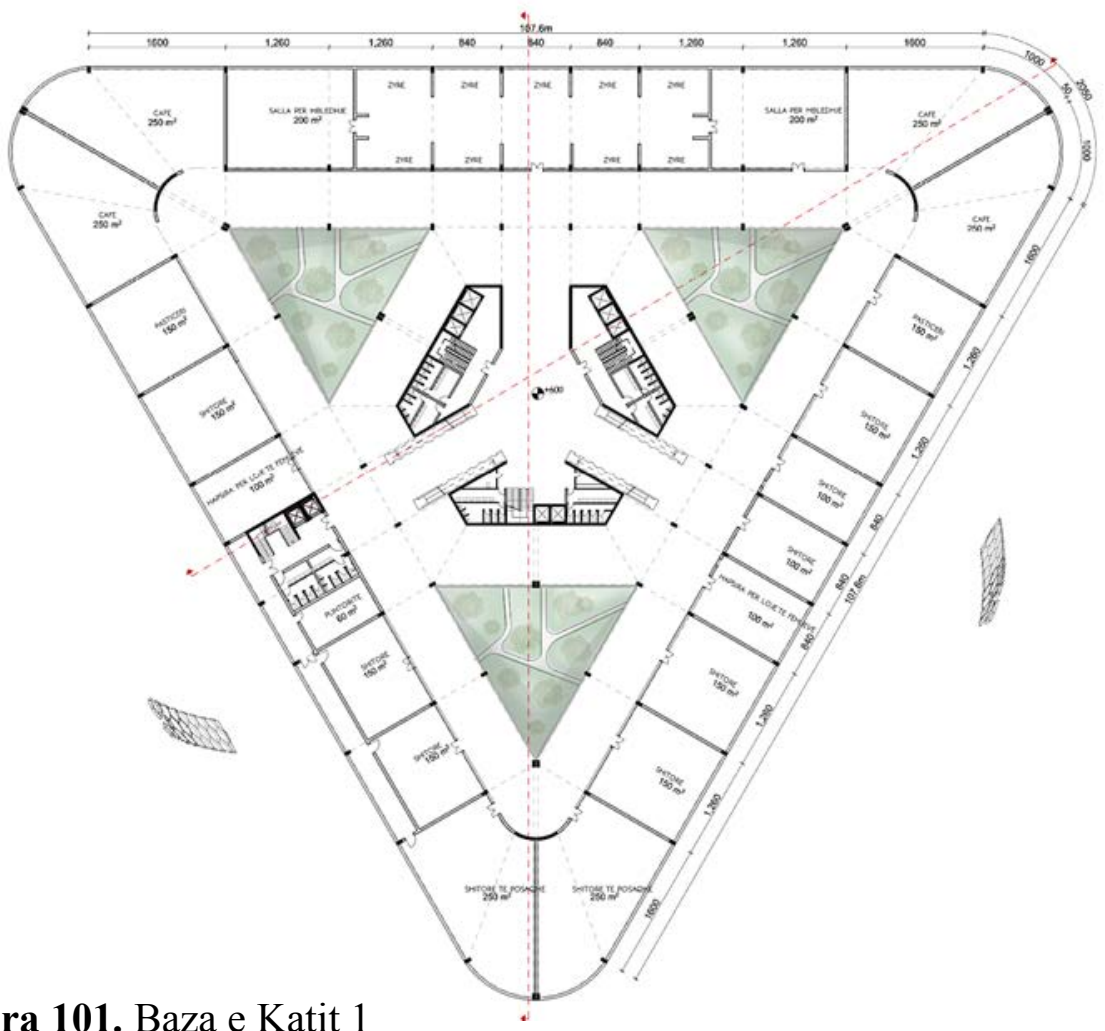

Figura 101. Baza e Katit 1

(Burimi): Diellza Delija, Diellza Hajrizi, 2018. 


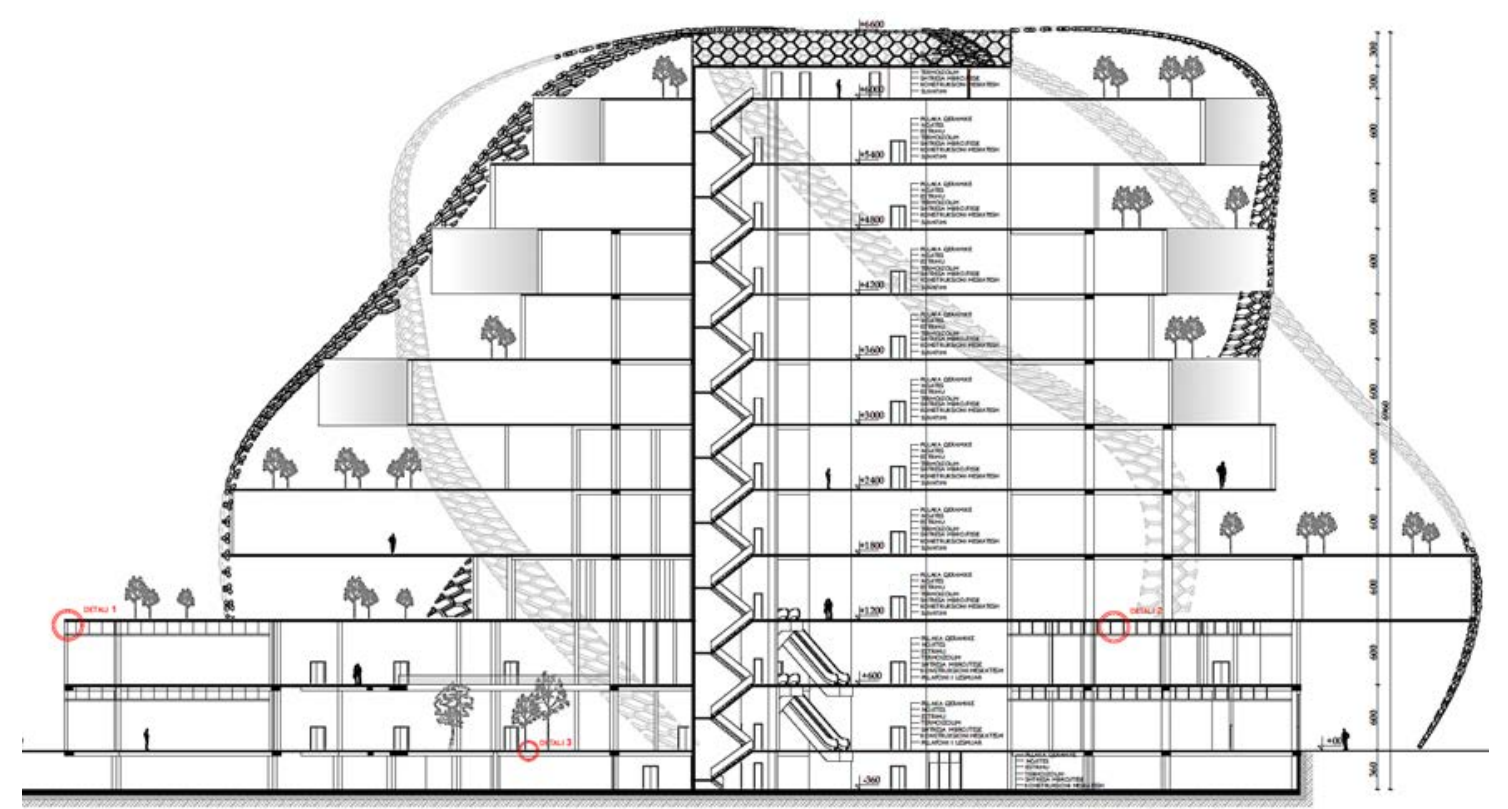

Figura 102. Prerja

(Burimi): Diellza Delija, Diellza Hajrizi, 2018.

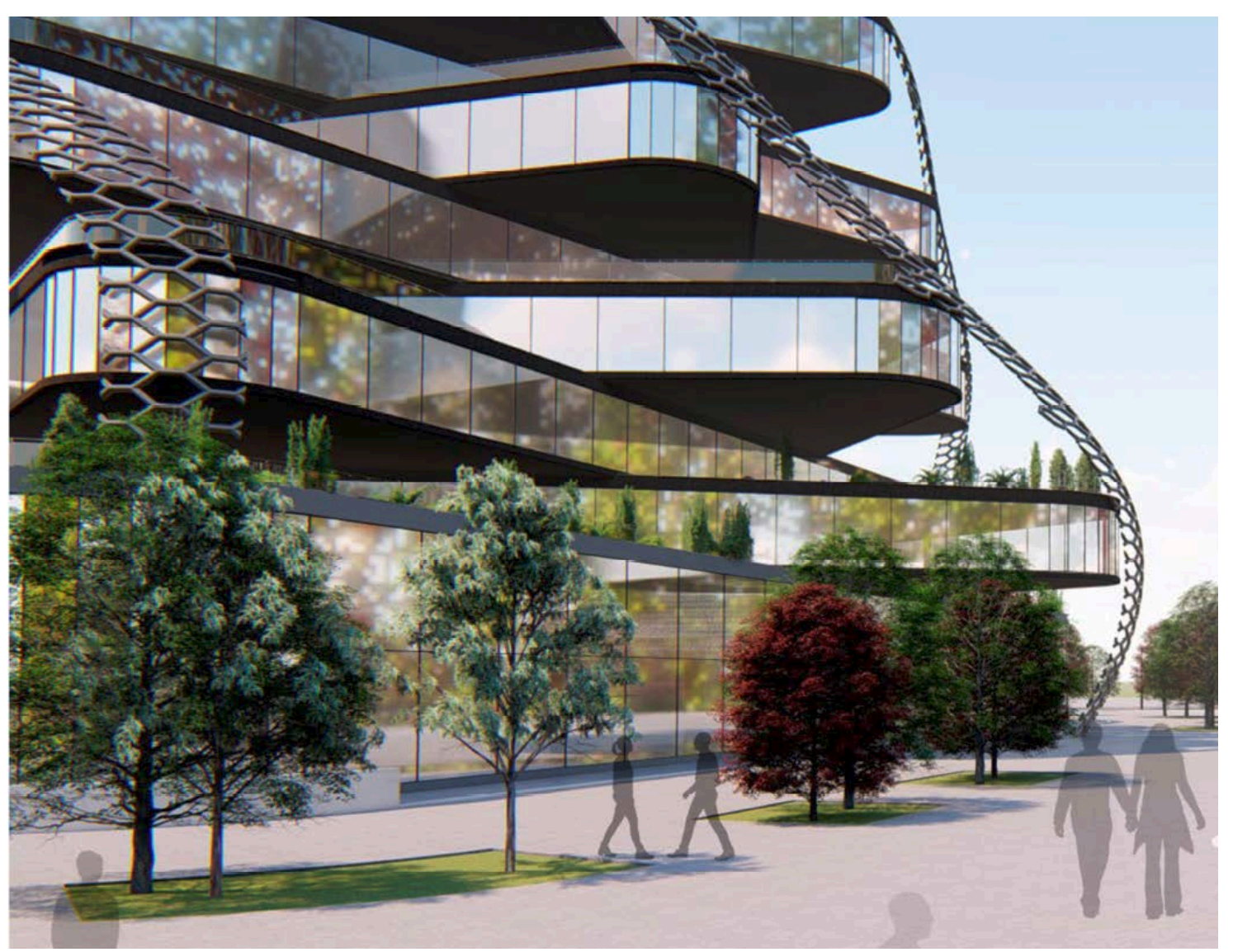

Figura 103. Perspektiva

(Burimi): Diellza Delija, Diellza Hajrizi, 2018. 

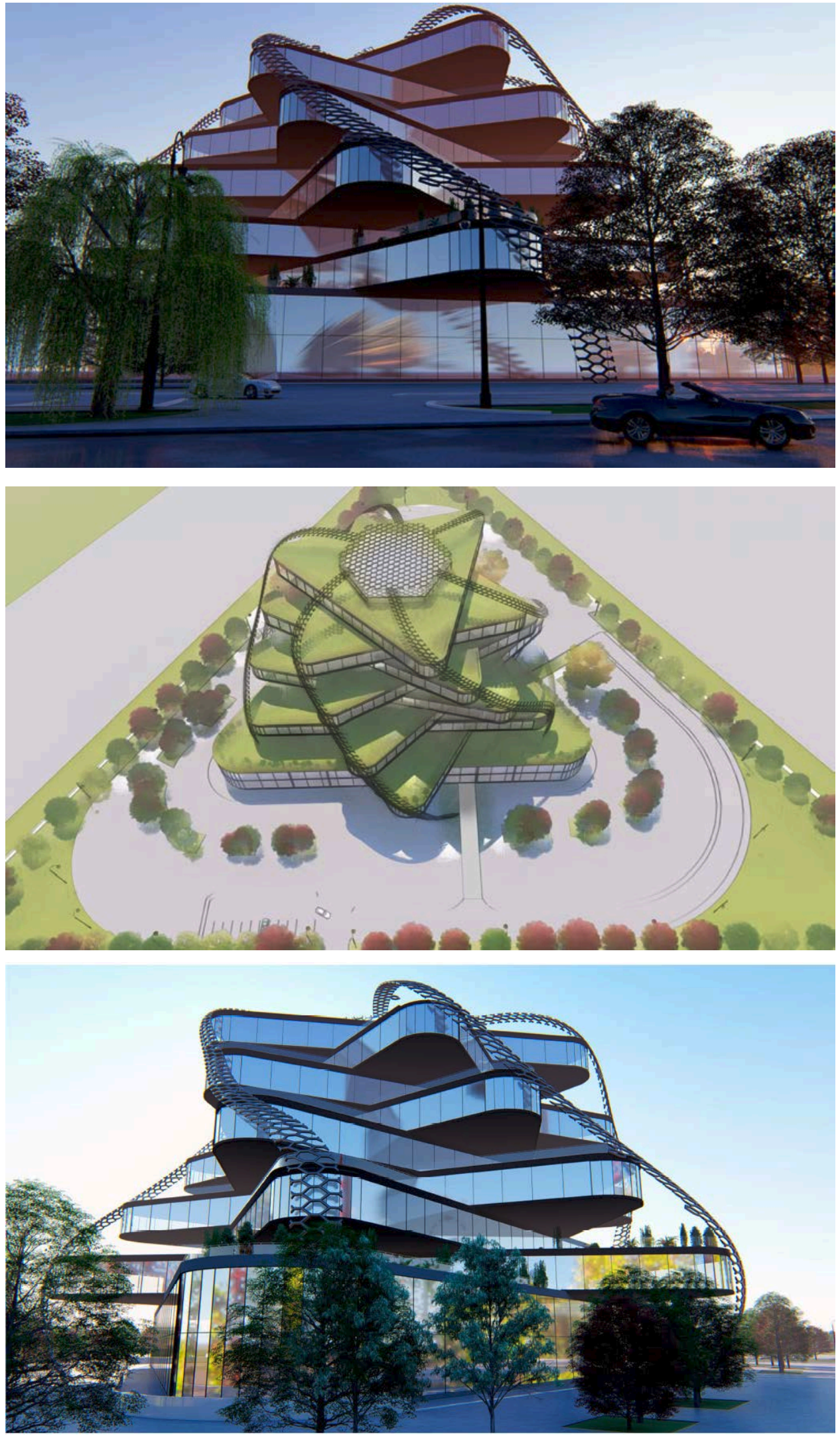

Figura 104. Perspektivat

(Burimi): Diellza Delija, Diellza Hajrizi, 2018. 
Niveli Bachelor 2017/18 ${ }^{15}$. Fakulteti i Ndërtimtarisë dhe Arkitekturës, Universiteti i Prishtinës. Departamenti i Arkitekturës. Lënda: Projektim 5.

Studentet: Nita Hasimja, Nita Llonçari

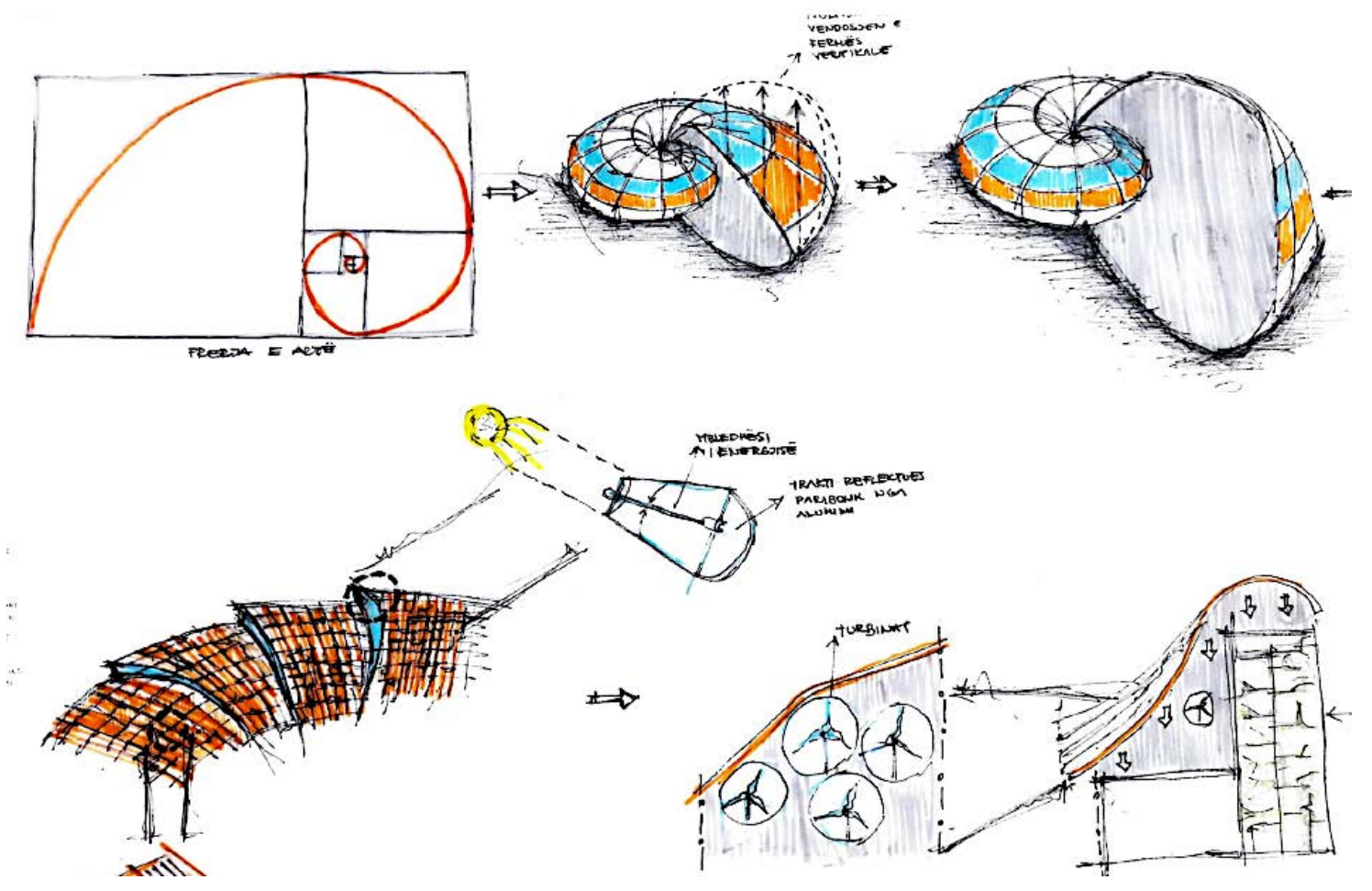

Figura 105. Analizat

(Burimi): Nita Hasimja, Nita Llonçari, 2018.

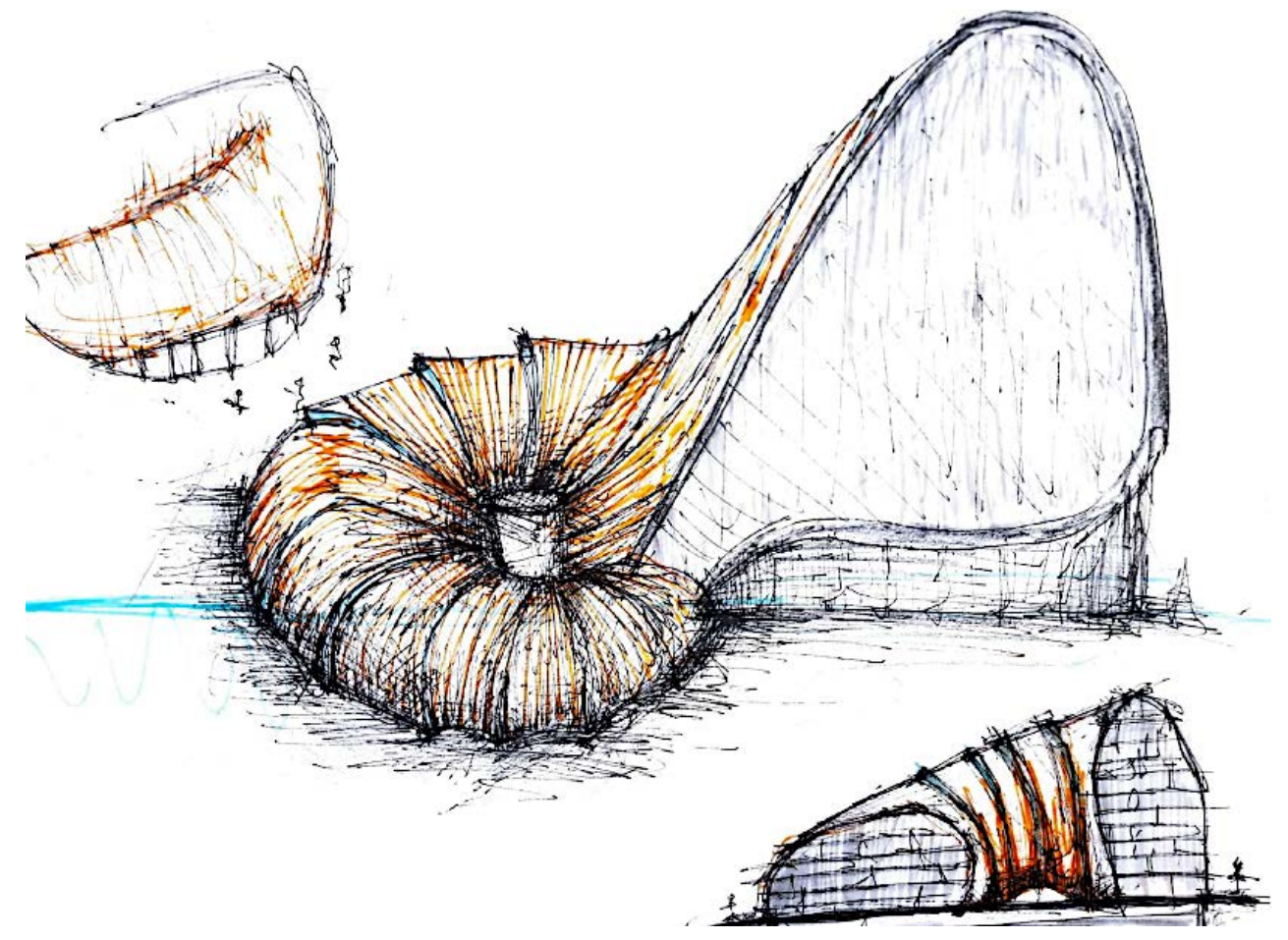

Figura 106. Analizat

(Burimi): Nita Hasimja, Nita Llonçari, 2018.

15 Nita Hasimja, Nita Llonçari. Lënda: Projektim 5. Punimi i tërë sipas dorëzimit final. FNA, UP. 


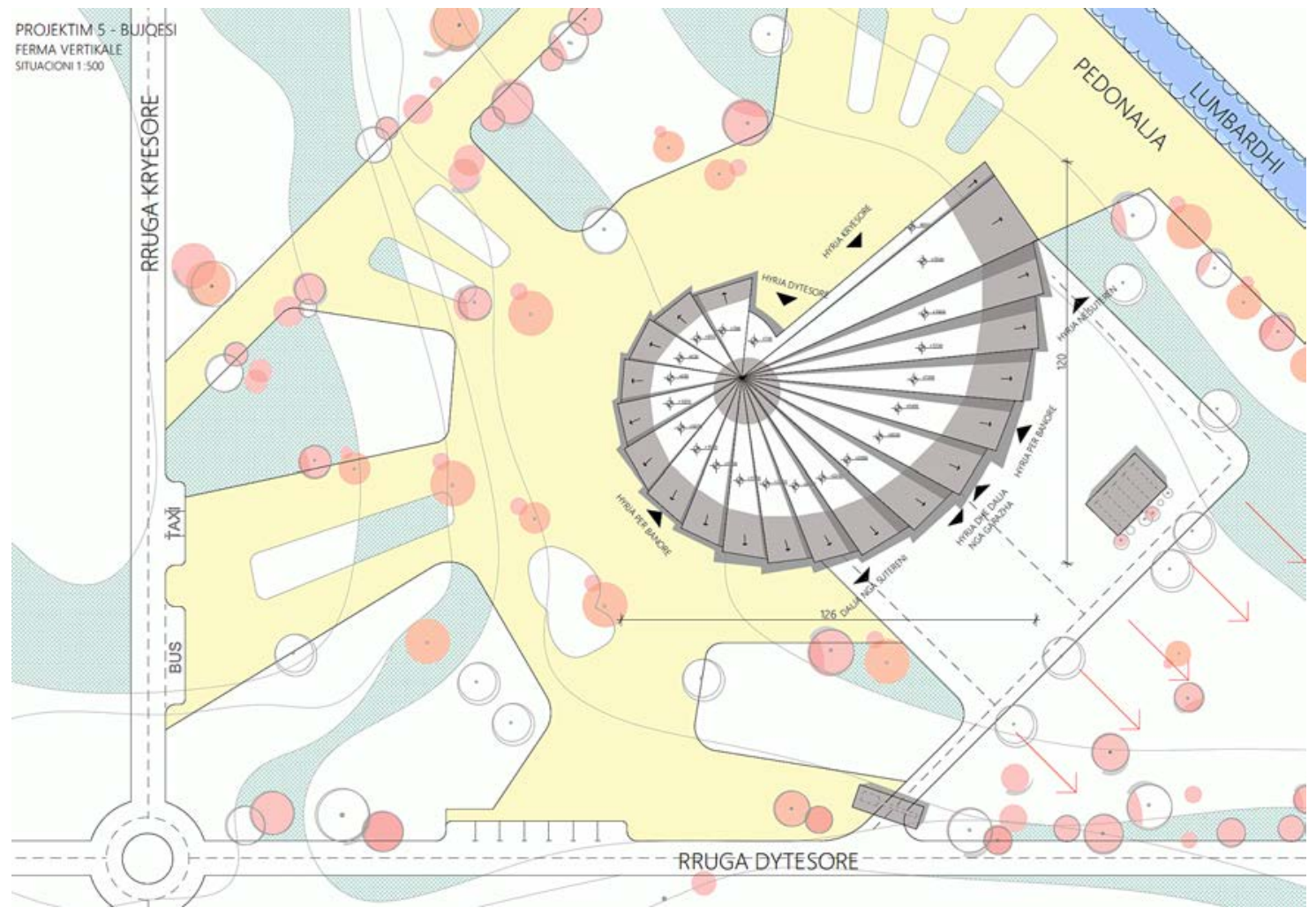

Figura 107. Situacioni

(Burimi): Nita Hasimja, Nita Llonçari, 2018.

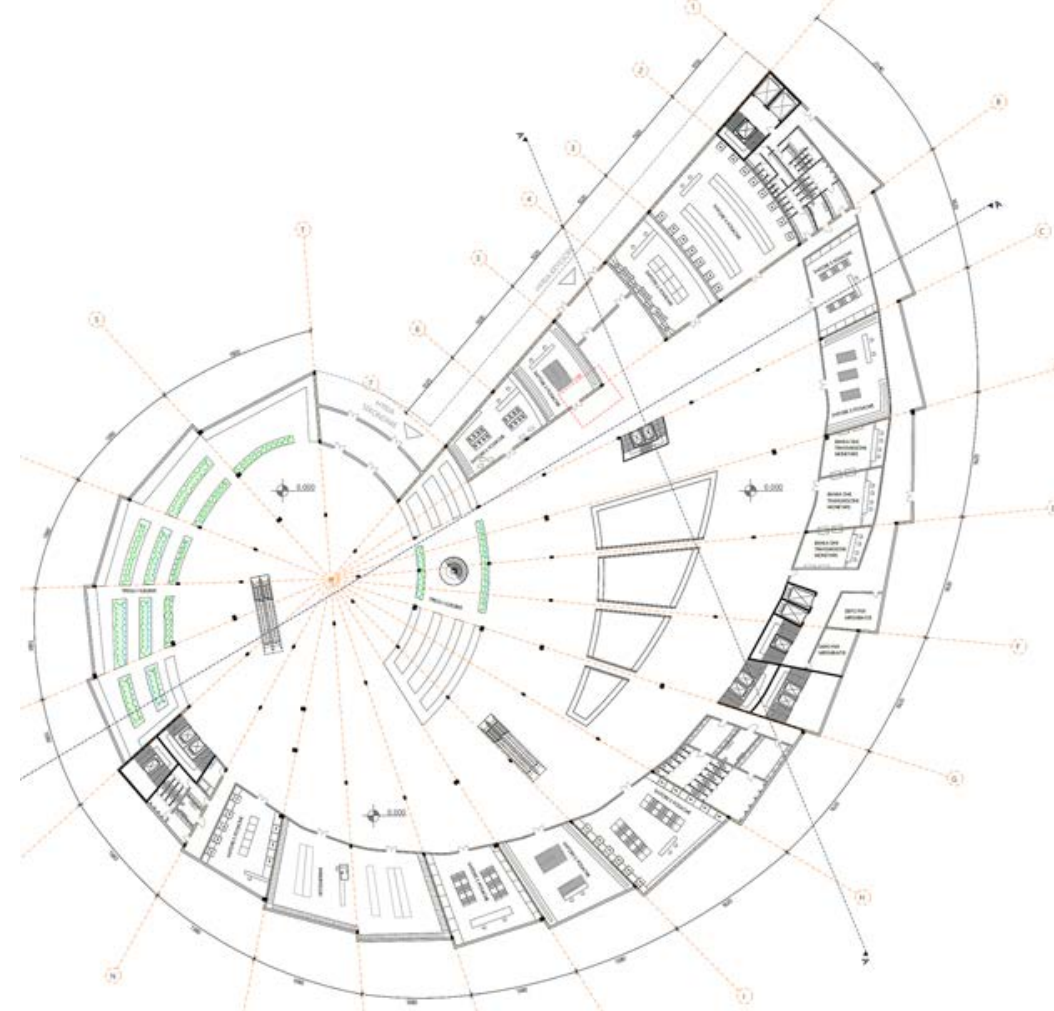

Figura 108. Baza e Përdhesës

(Burimi): Nita Hasimja, Nita Llonçari, 2018. 


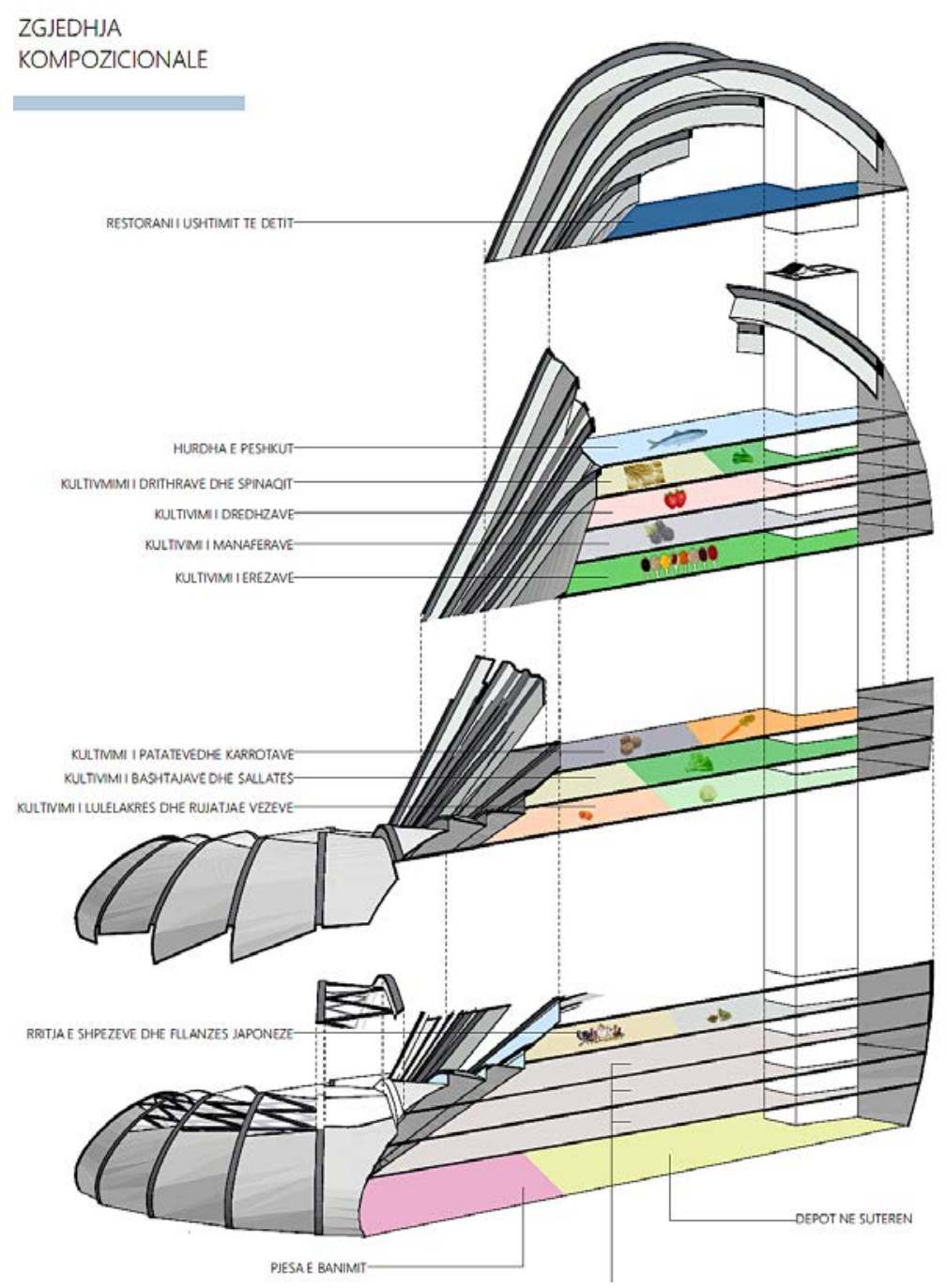

Figura 109. Zgjedhja Kompozicionale (Burimi): Nita Hasimja, Nita Llonçari, 2018.

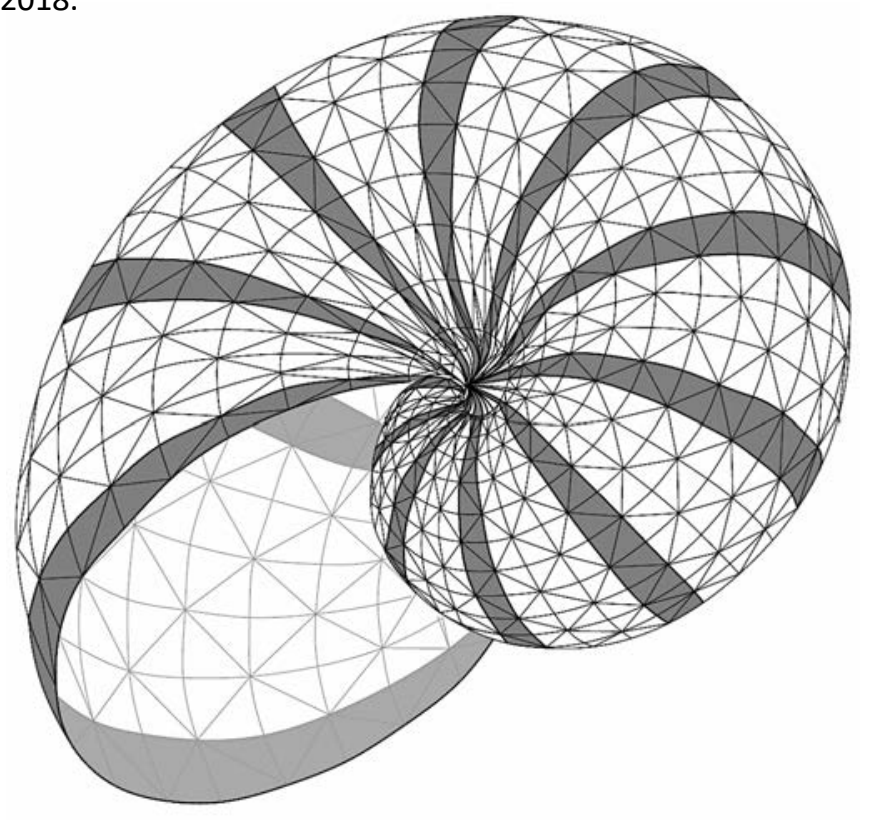

Figura 110. Mbështjellësi

(Burimi): Nita Hasimja, Nita Llonçari, 2018. 




Figura 111. Prerja

(Burimi): Nita Hasimja, Nita Llonçari, 2018.


Figura 112.

Perspektivat

(Burimi):

NitaHasimja,

Nita Llonçari,

2018. 


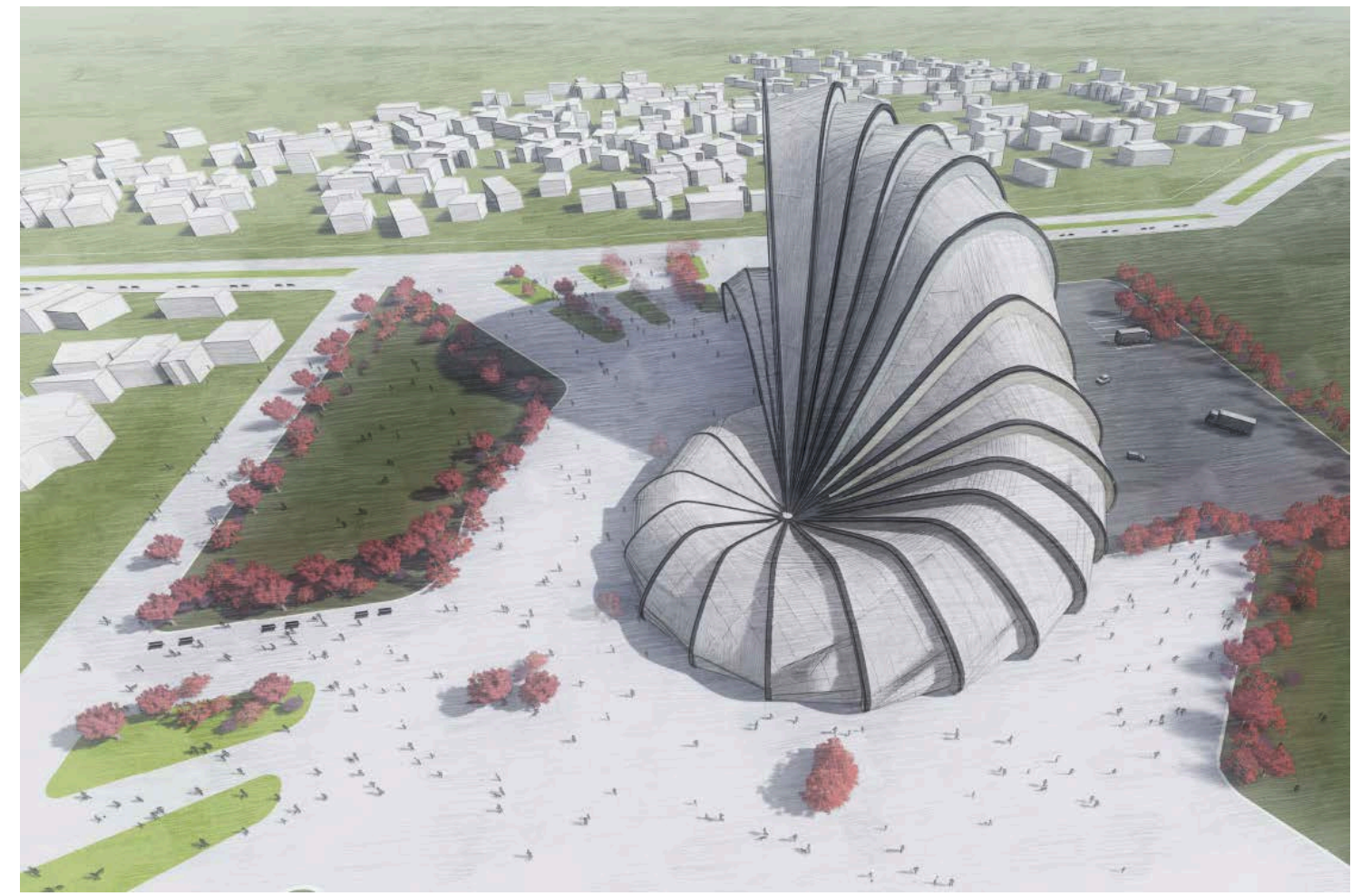

Figura 113. Perspektiva

(Burimi): Nita Hasimja, Nita Llonçari, 2018.



Figura 114. Perspektiva

(Burimi): Nita Hasimja, Nita Llonçari, 2018. 
Niveli Bachelor 2017/18 ${ }^{16}$. Fakulteti i Ndërtimtarisë dhe Arkitekturës, Universiteti i Prishtinës. Departamenti i Arkitekturës. Lënda: Projektim 5.

Studentet: Gentianë Thaçi, Hana Mikullovci



Figura 115. Analizat

(Burimi): Gentianë Thaçi, Hana Mikullovci, 2018.

16 Gentianë Thaçi, Hana Mikullovci. Lënda: Projektim 5. Punimi i tërë sipas dorëzimit final. FNA, UP. 


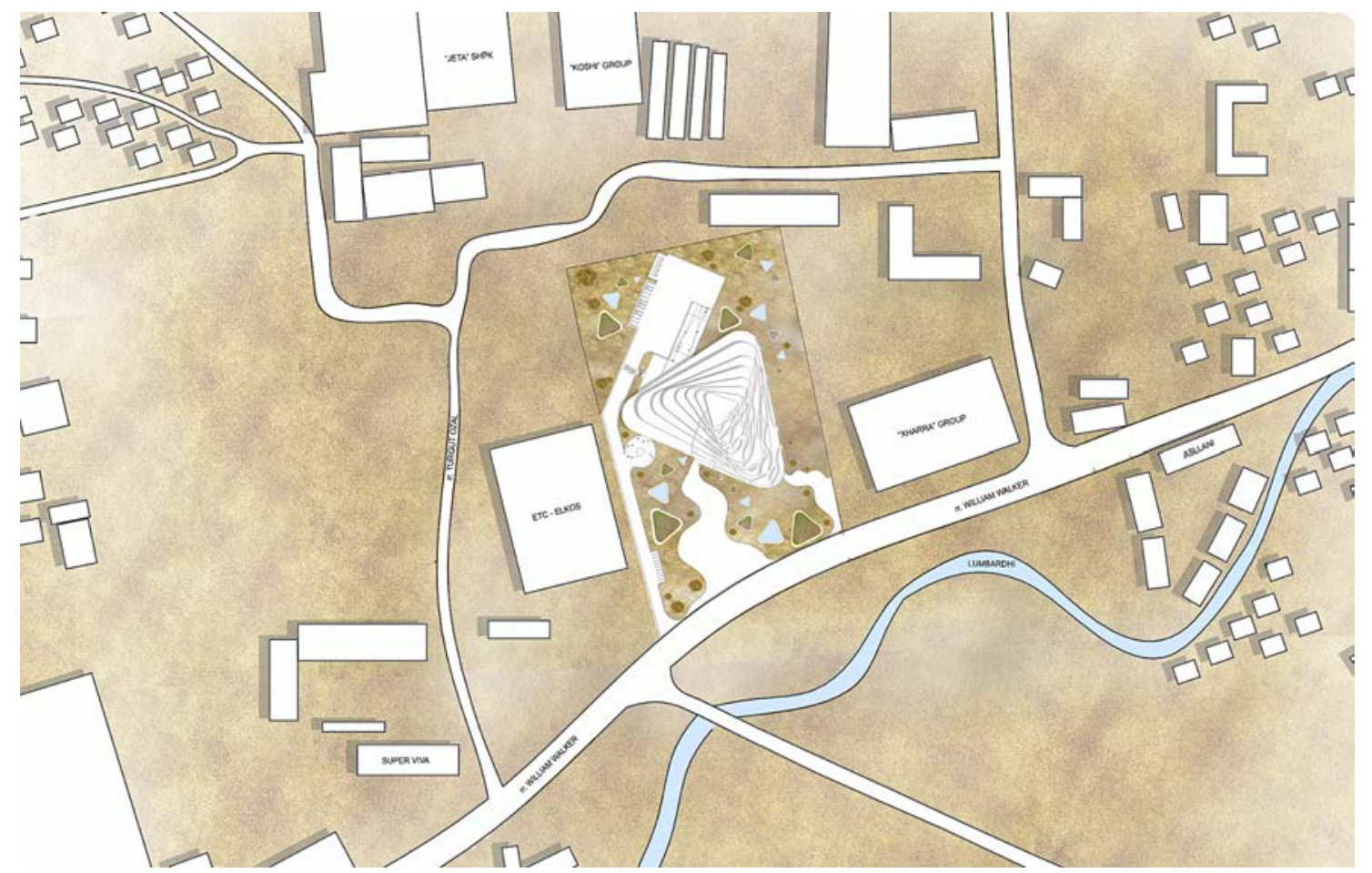

Figura 116. Situacioni

(Burimi): Gentianë Thaçi, Hana Mikullovci, 2018.

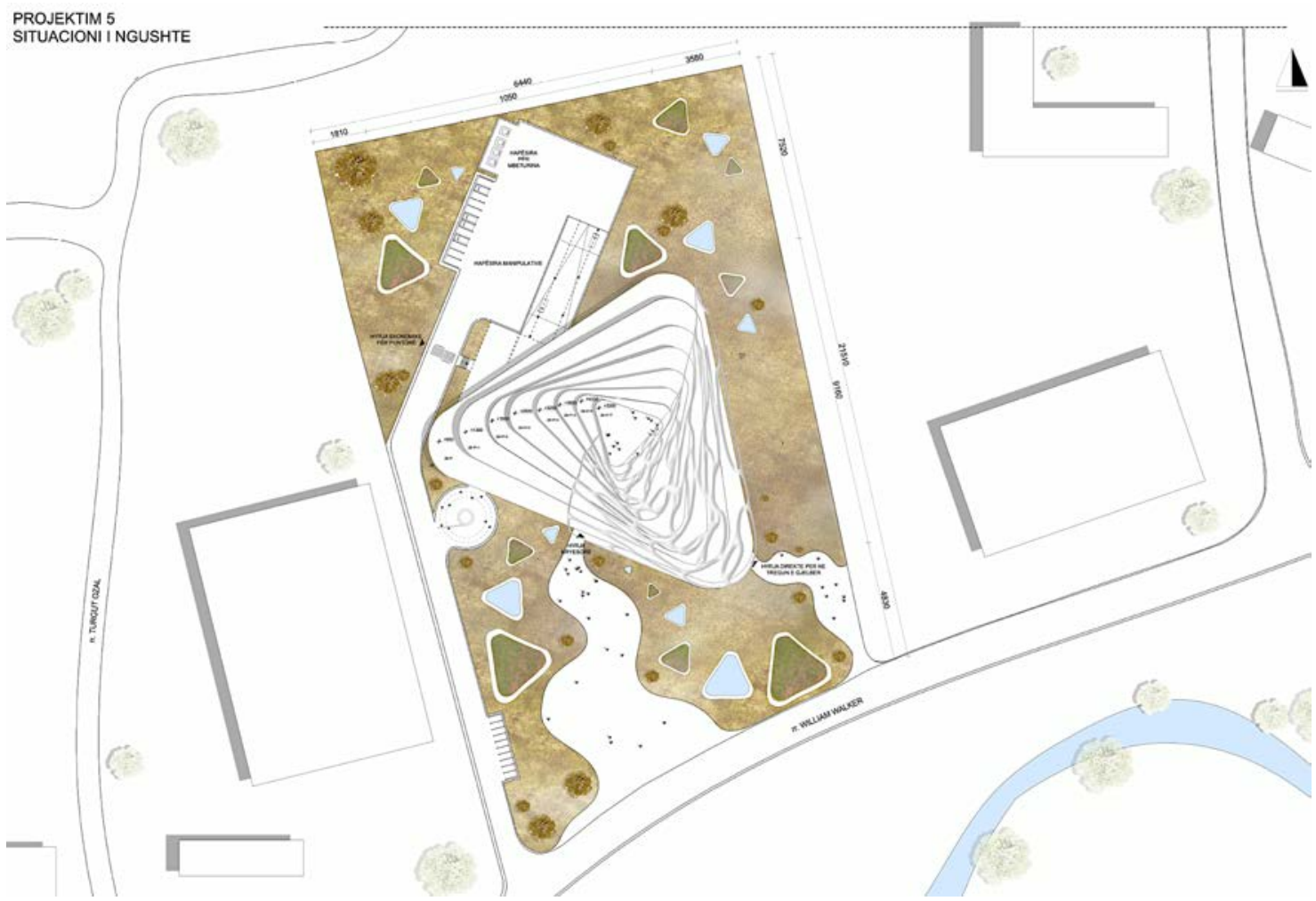

Figura 117. Situacioni i ngushtë

(Burimi): Gentianë Thaçi, Hana Mikullovci, 2018. 


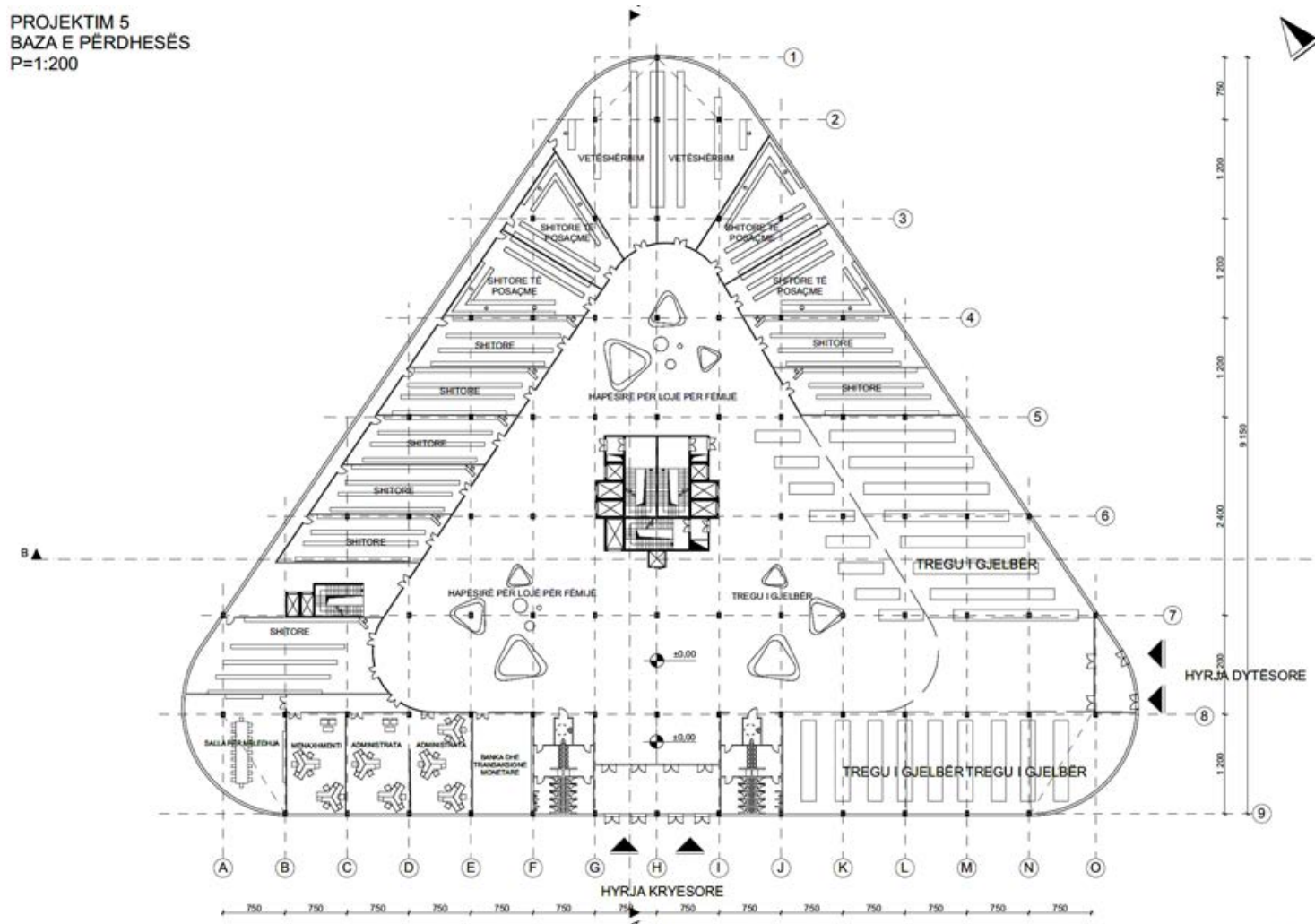

Figura 118. Baza e Përdhesës

(Burimi): Gentianë Thaçi, Hana Mikullovci, 2018.

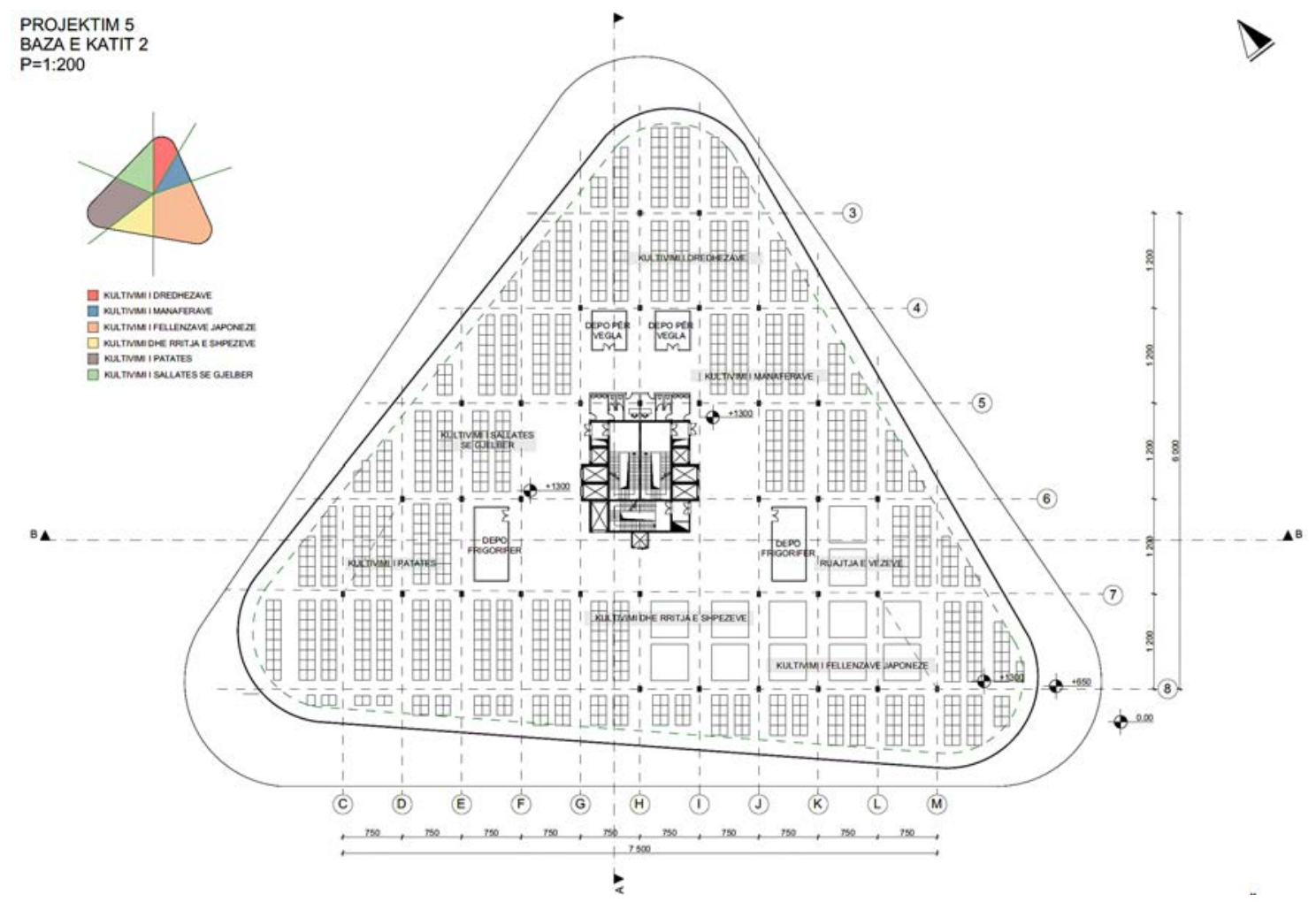

Figura 119. Baza e Katit 2

(Burimi): Gentianë Thaçi, Hana Mikullovci, 2018. 




Figura 120. Prerja $A$

(Burimi): Gentianë Thaçi, Hana Mikullovci, 2018

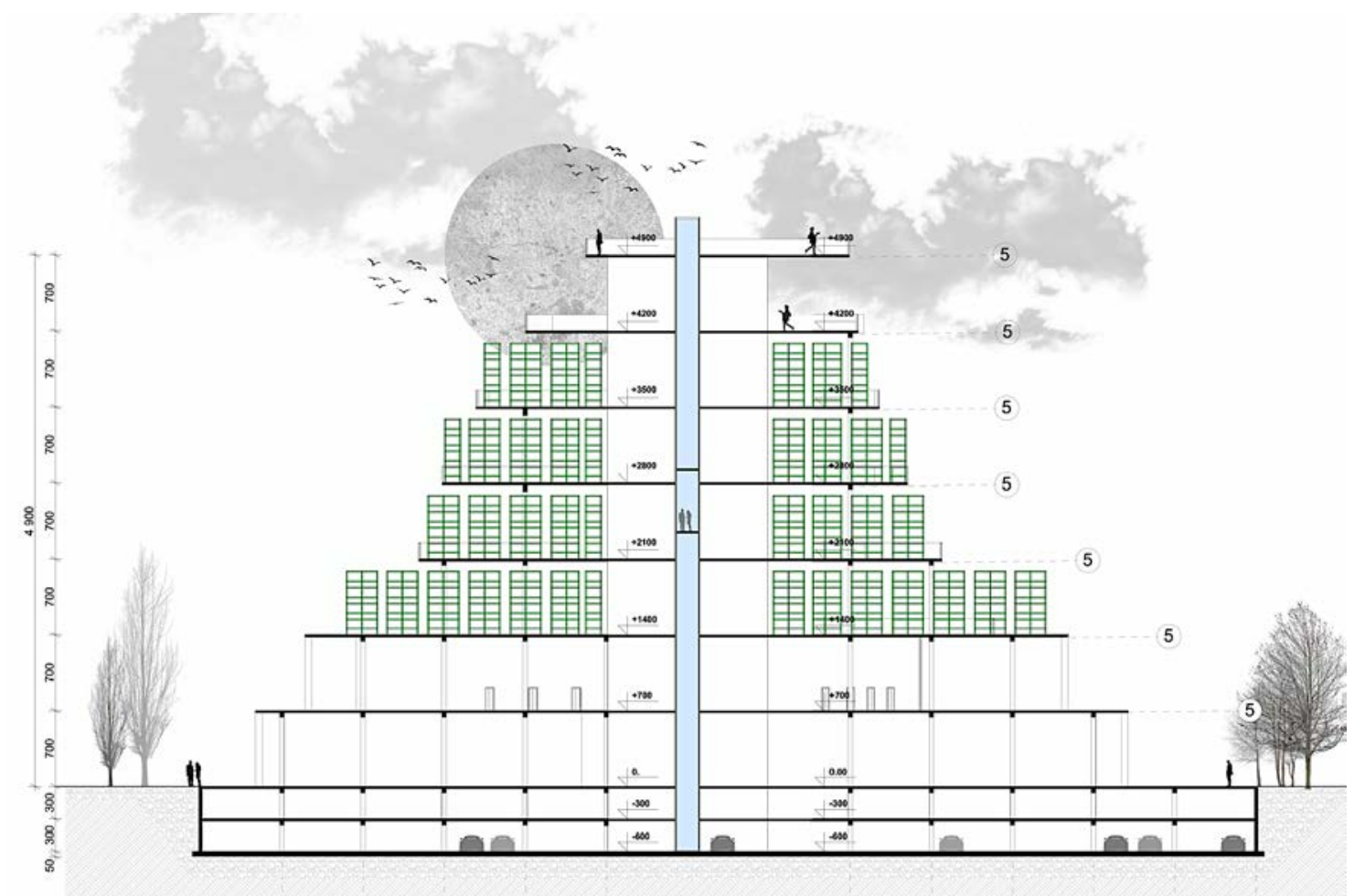

Figura 121. Prerja $B$

(Burimi): Gentianë Thaçi, Hana Mikullovci, 2018 


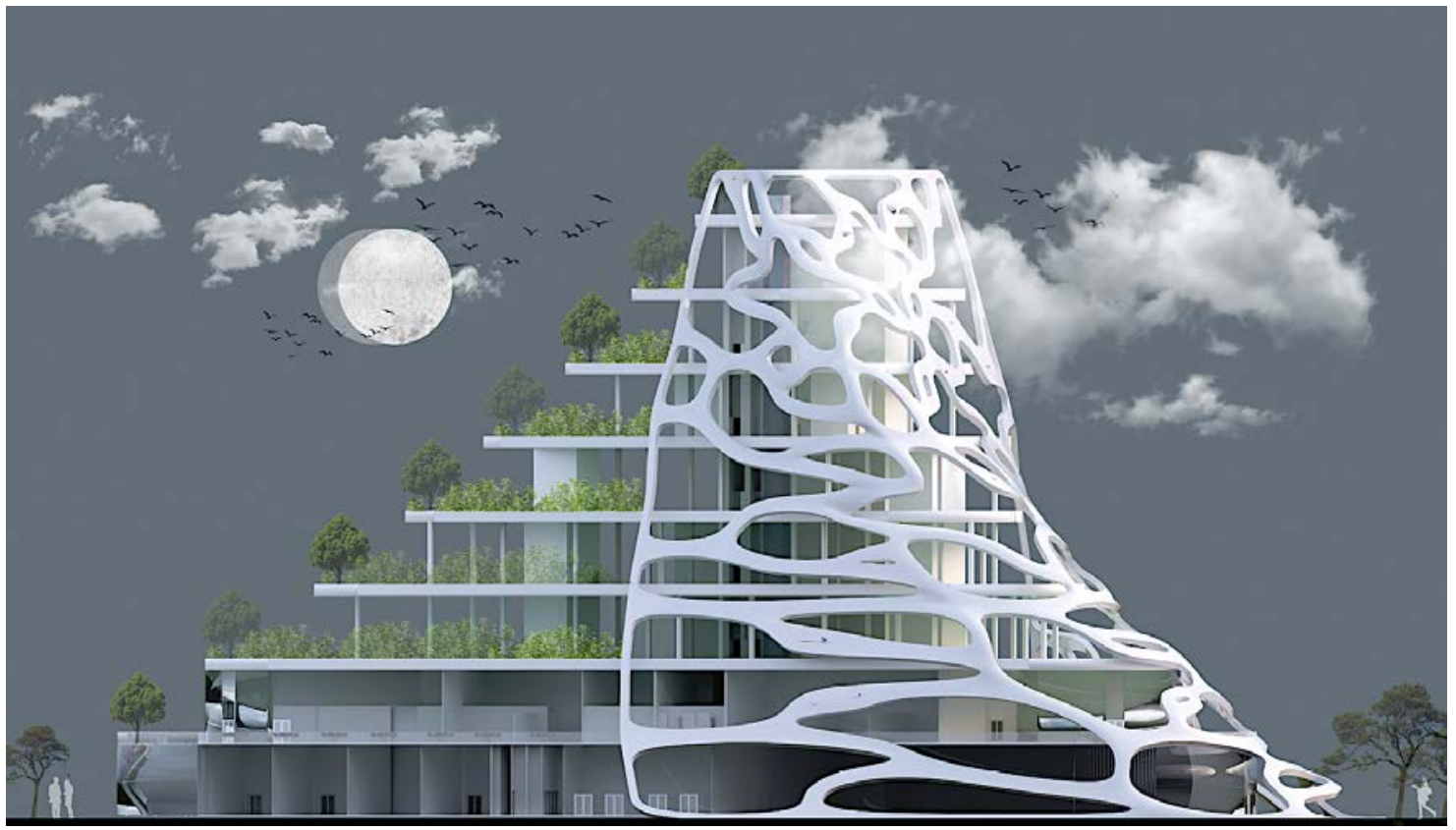

Figura 122. Pamja

(Burimi): Gentianë Thaçi, Hana Mikullovci, 2018

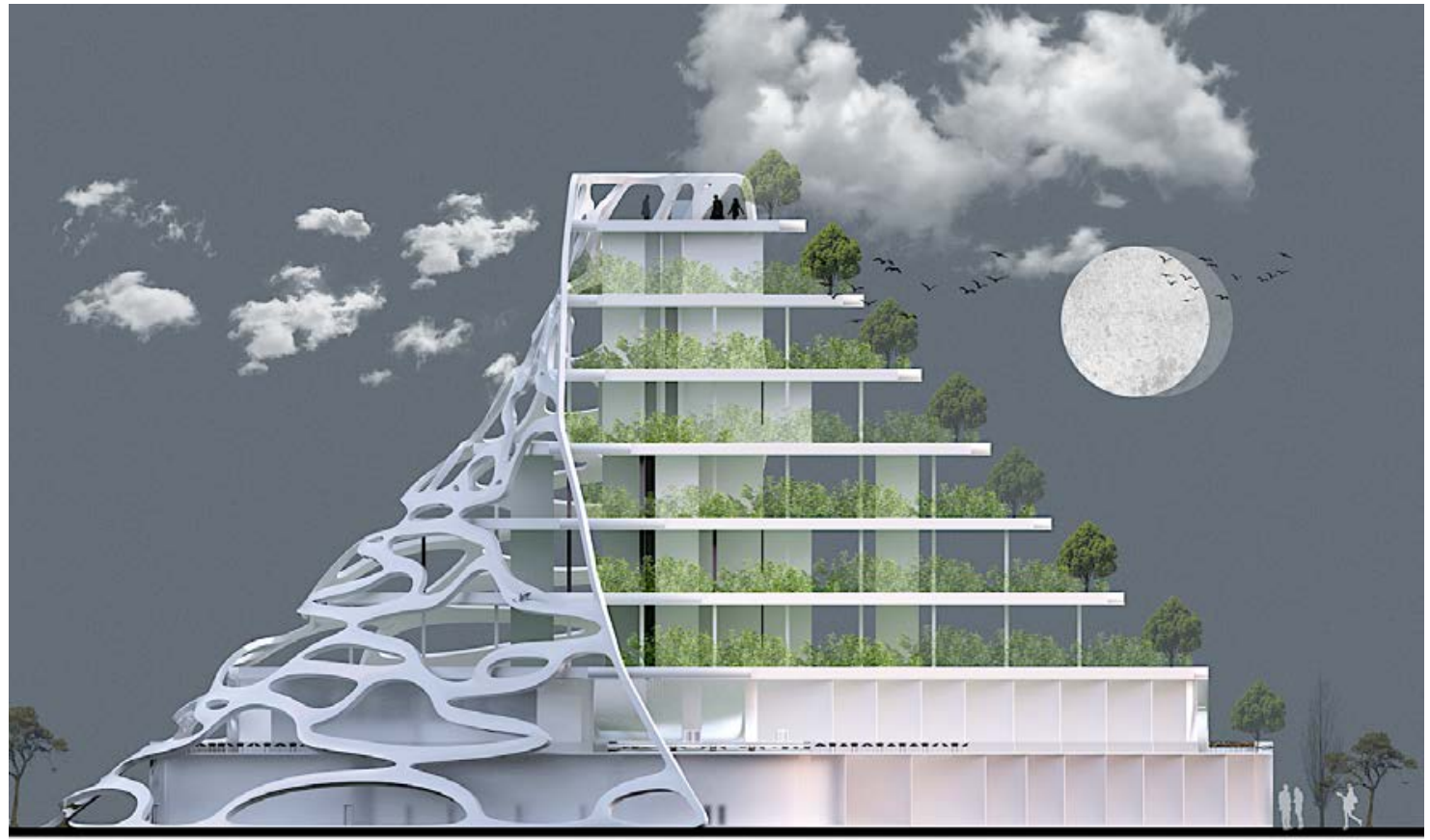

Figura 123. Pamja

(Burimi): Gentianë Thaçi, Hana Mikullovci, 2018 


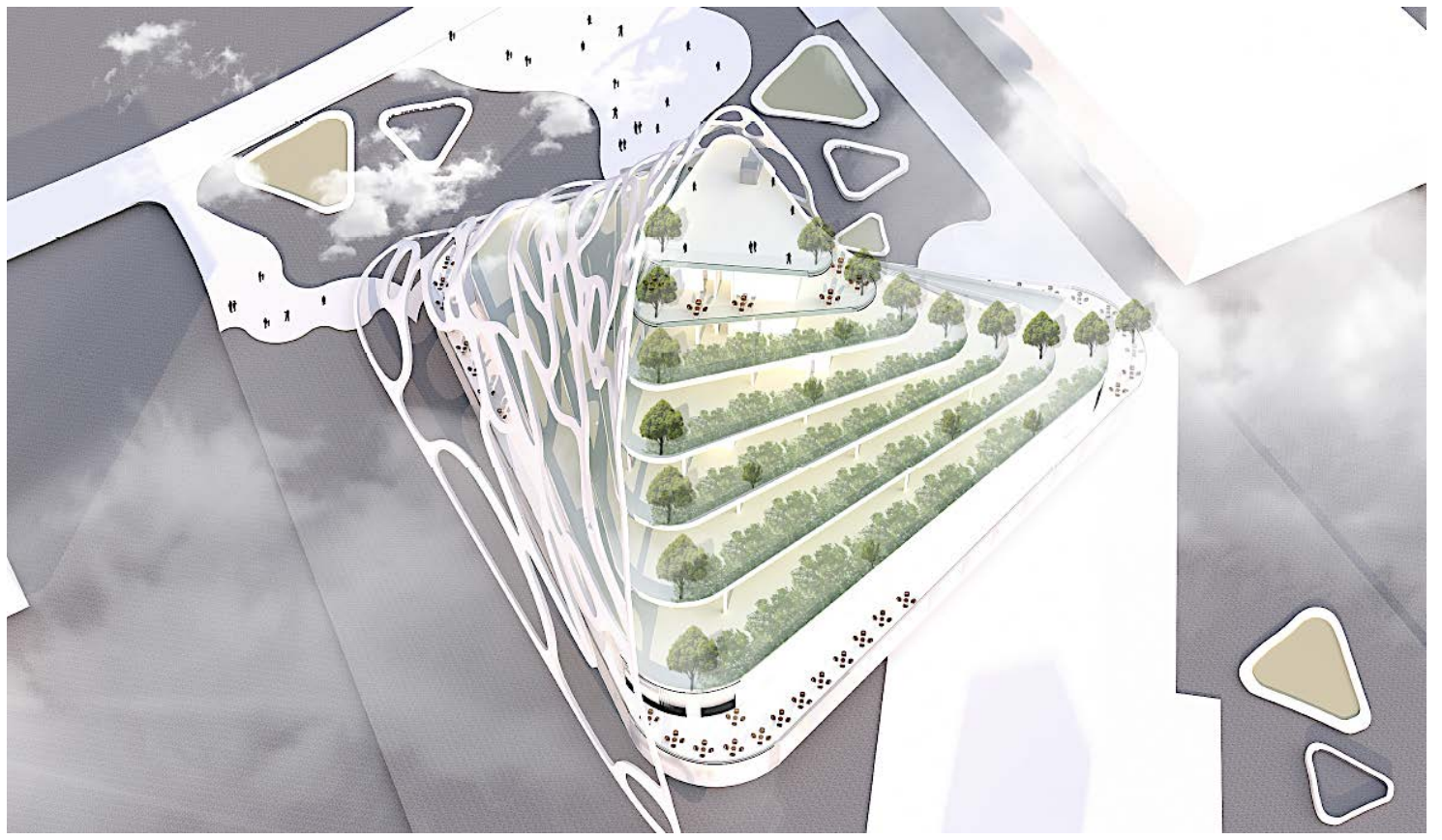

Figura 124. Perspektiva

(Burimi): Gentianë Thaçi, Hana Mikullovci, 2018



Figura 125. Perspektiva

(Burimi): Gentianë Thaçi, Hana Mikullovci, 2018 

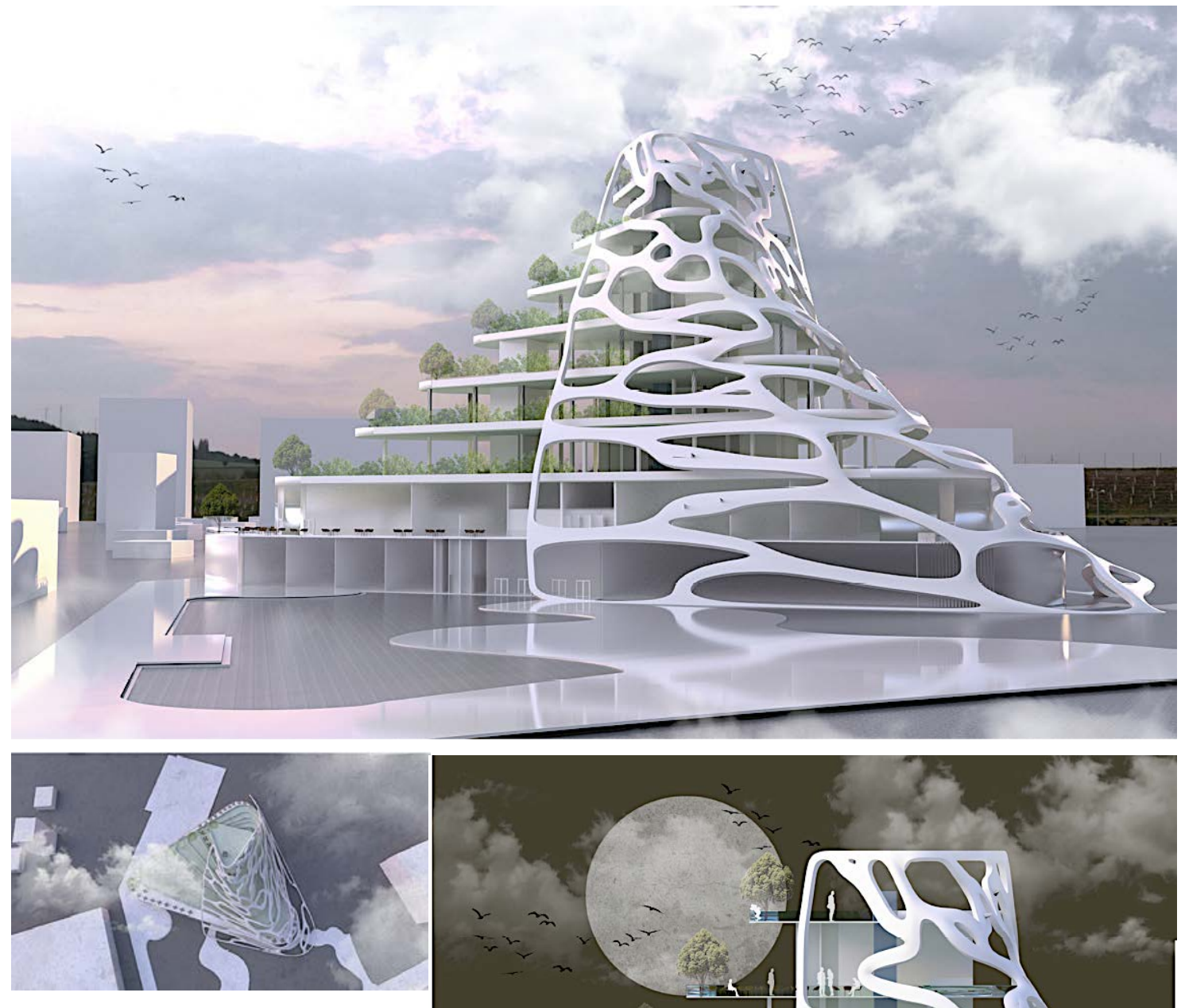

Figura 126. Perspektiva

(Burimi): Gentianë Thaçi, Hana Mikullovci, 2018
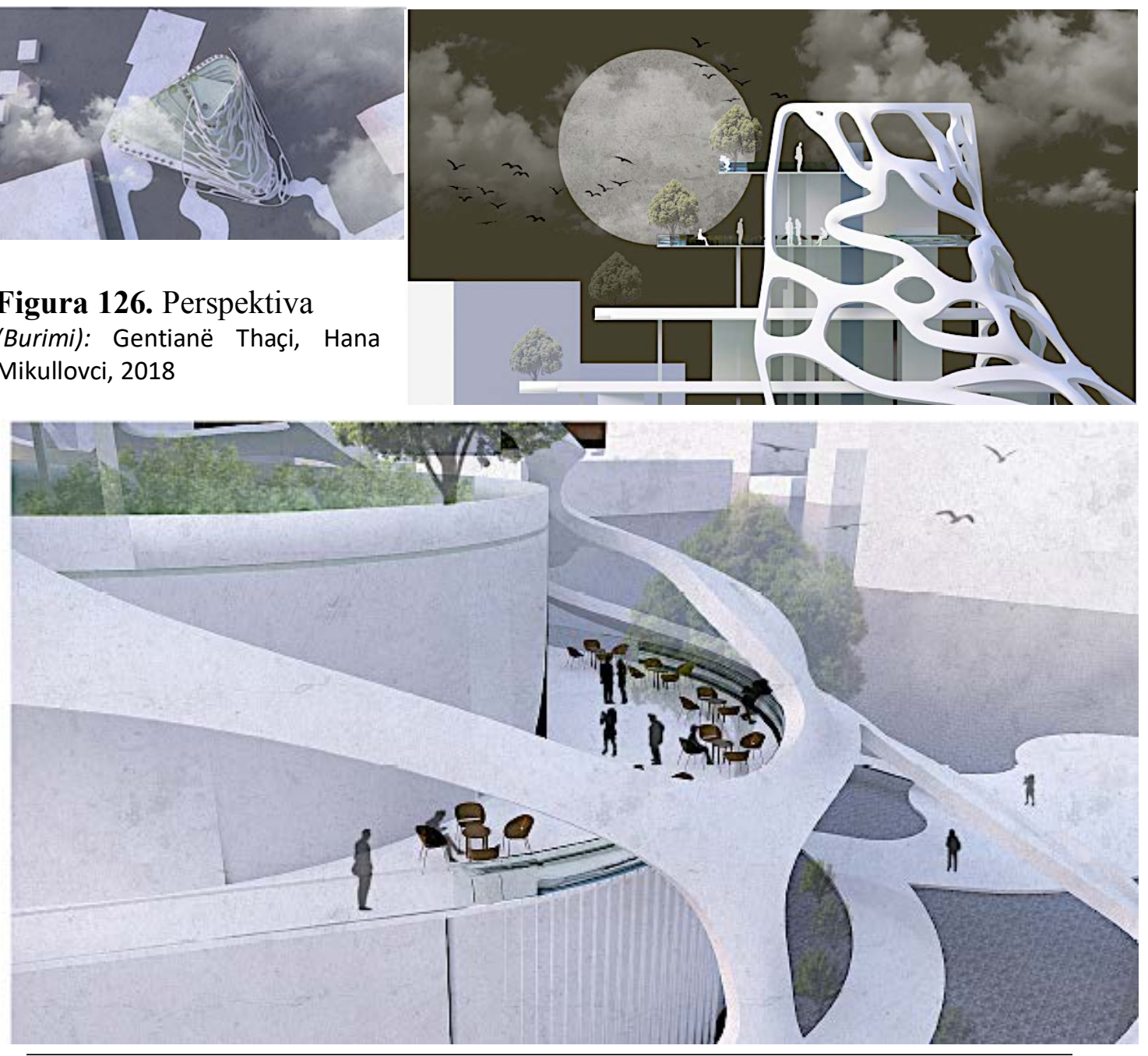
Niveli Bachelor 2017/18 ${ }^{17}$. Fakulteti i Ndërtimtarisë dhe Arkitekturës, Universiteti i Prishtinës. Departamenti i Arkitekturës. Lënda: Projektim 5.

Studentet: Albertina Likaj, Dhuratë Krasniqi

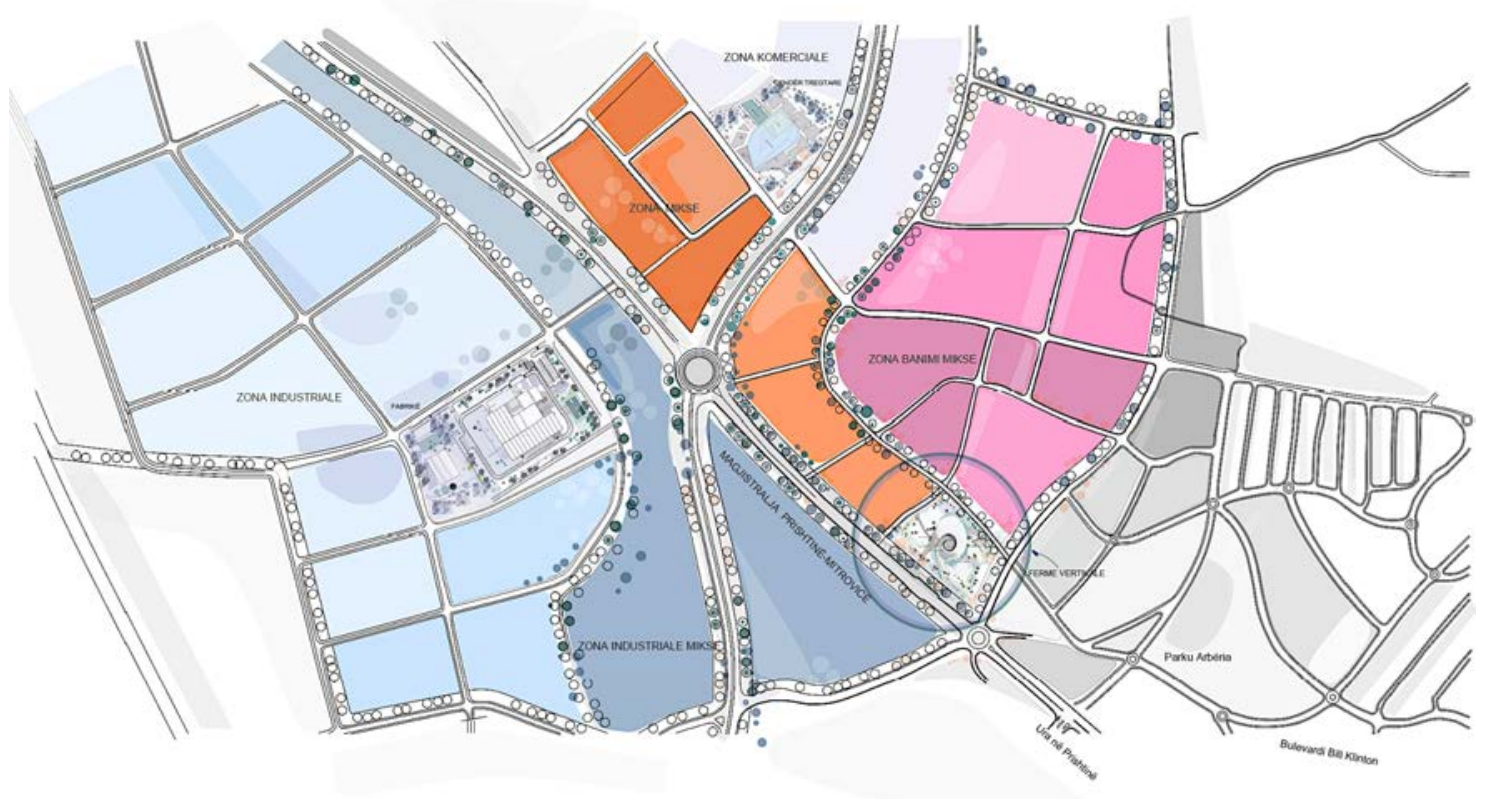

Figura 127. Situacioni

(Burimi): Albertina Likaj, Dhuratë Krasniqi, 2018

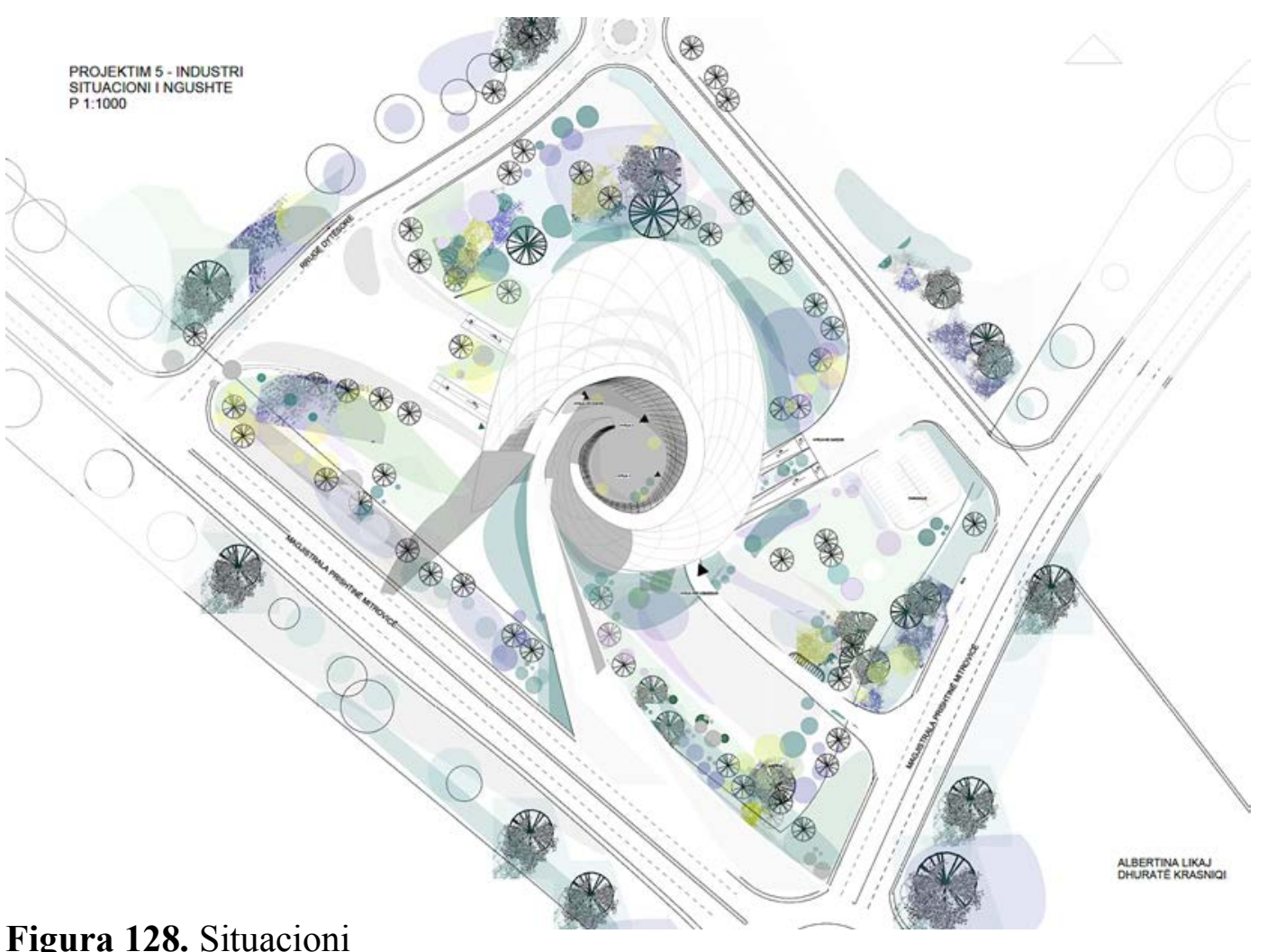

Figura 128. Situacioni

(Burimi): Albertina Likaj, Dhuratë Krasniqi, 2018

17 Albertina Likaj, Dhuratë Krasniqi. Lënda: Projektim 5. Punimi i tërë sipas dorëzimit final. FNA, UP. 

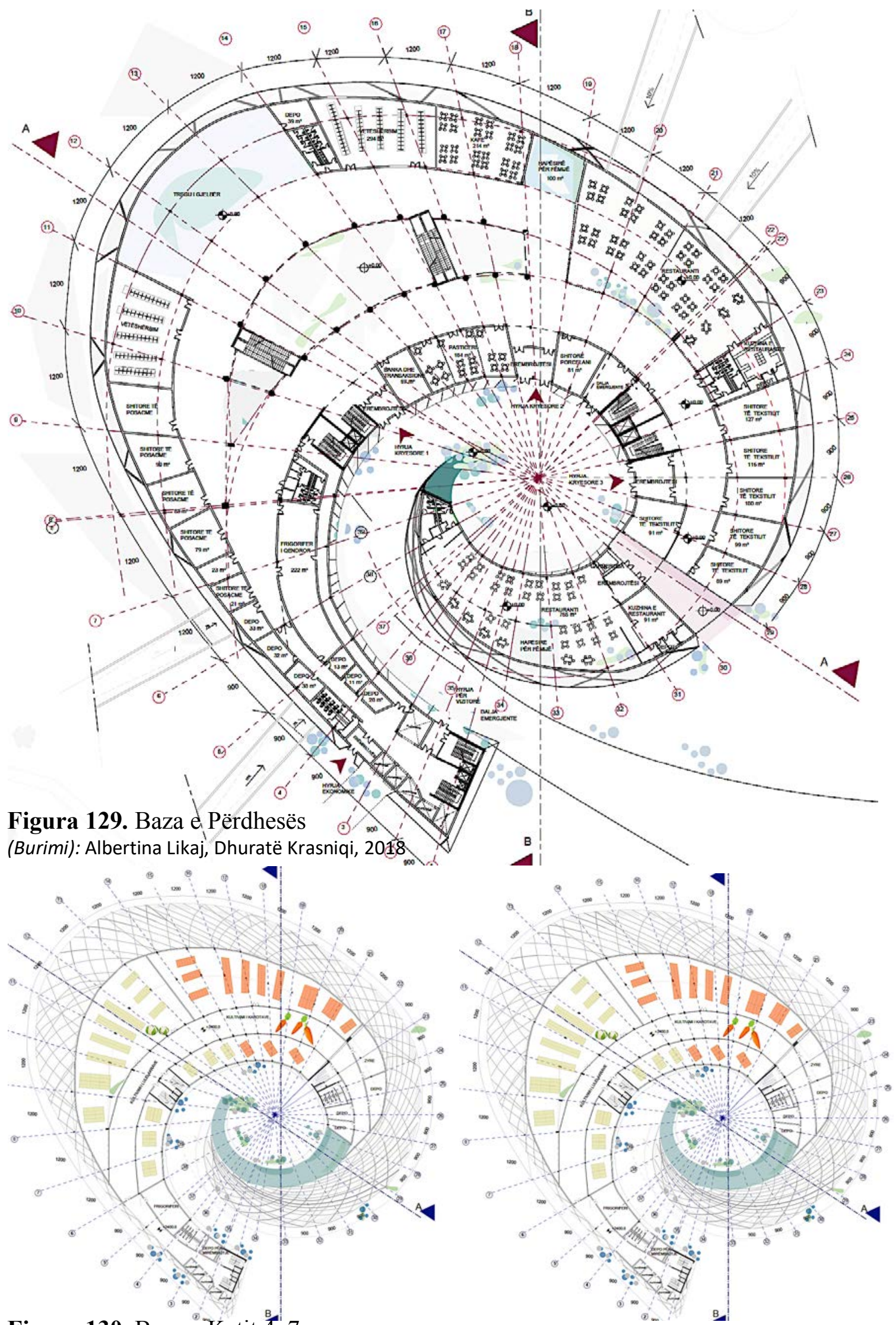

Figura 130. Baza e Katit $\frac{8}{4}, 7$

(Burimi): Albertina Likaj, Dhuratë Krasniqi, 2018 


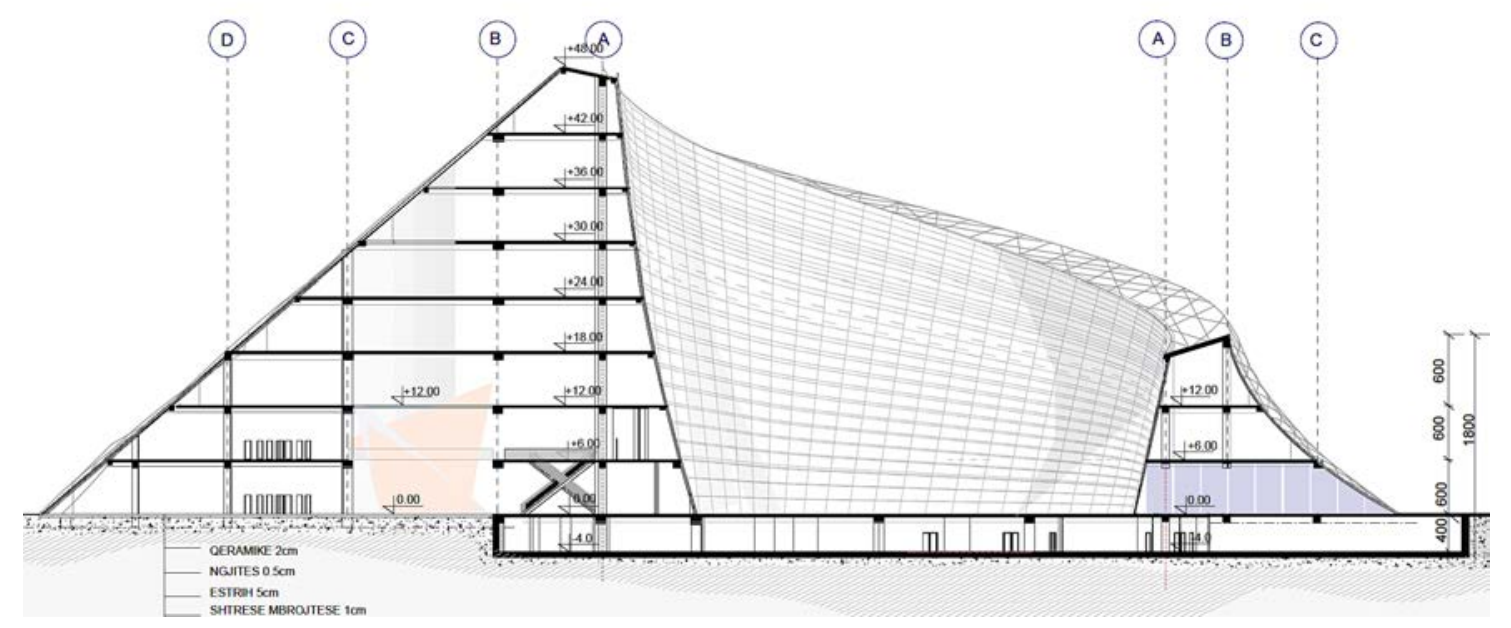

Figura 131. Prerja A

(Burimi): Albertina Likaj, Dhuratë Krasniqi, 2018

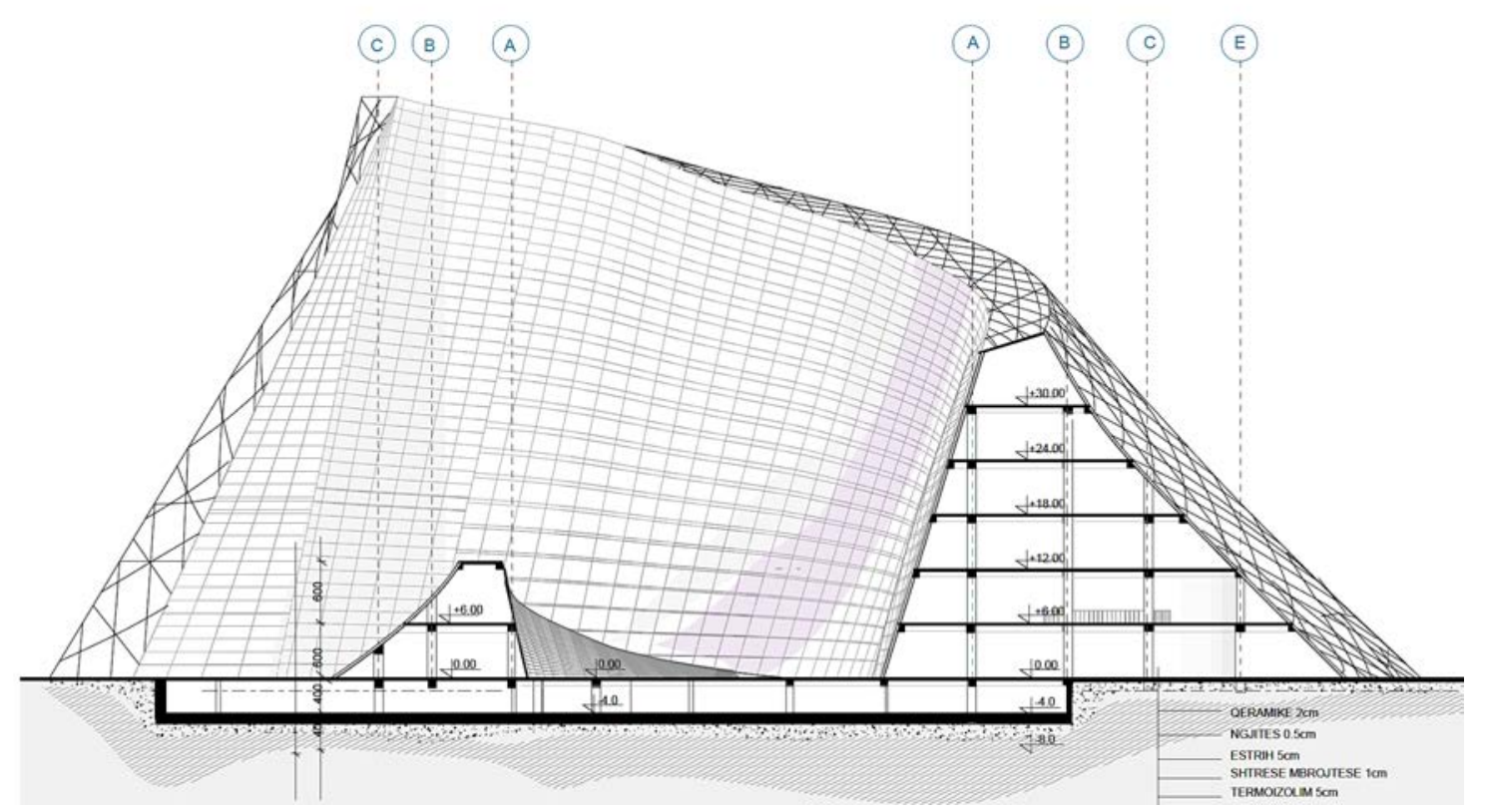

Figura 132. Prerja $B$

(Burimi): Albertina Likaj, Dhuratë Krasniqi, 2018 


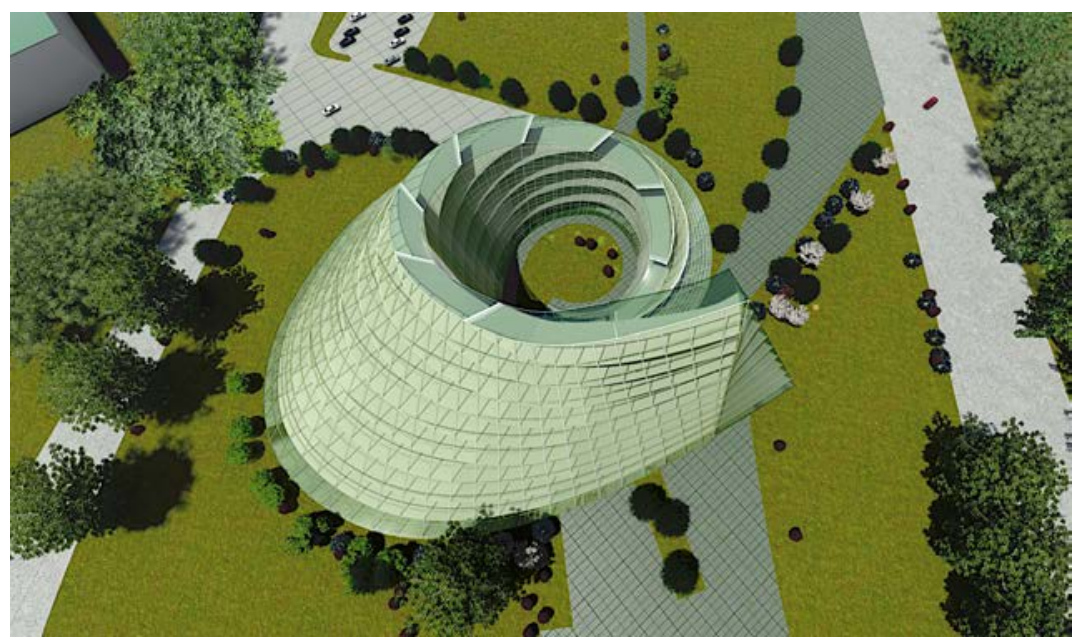

Figura 133.

Perspektivat

(Burimi): Albertina Likaj,

Dhuratë Krasniqi, 2018
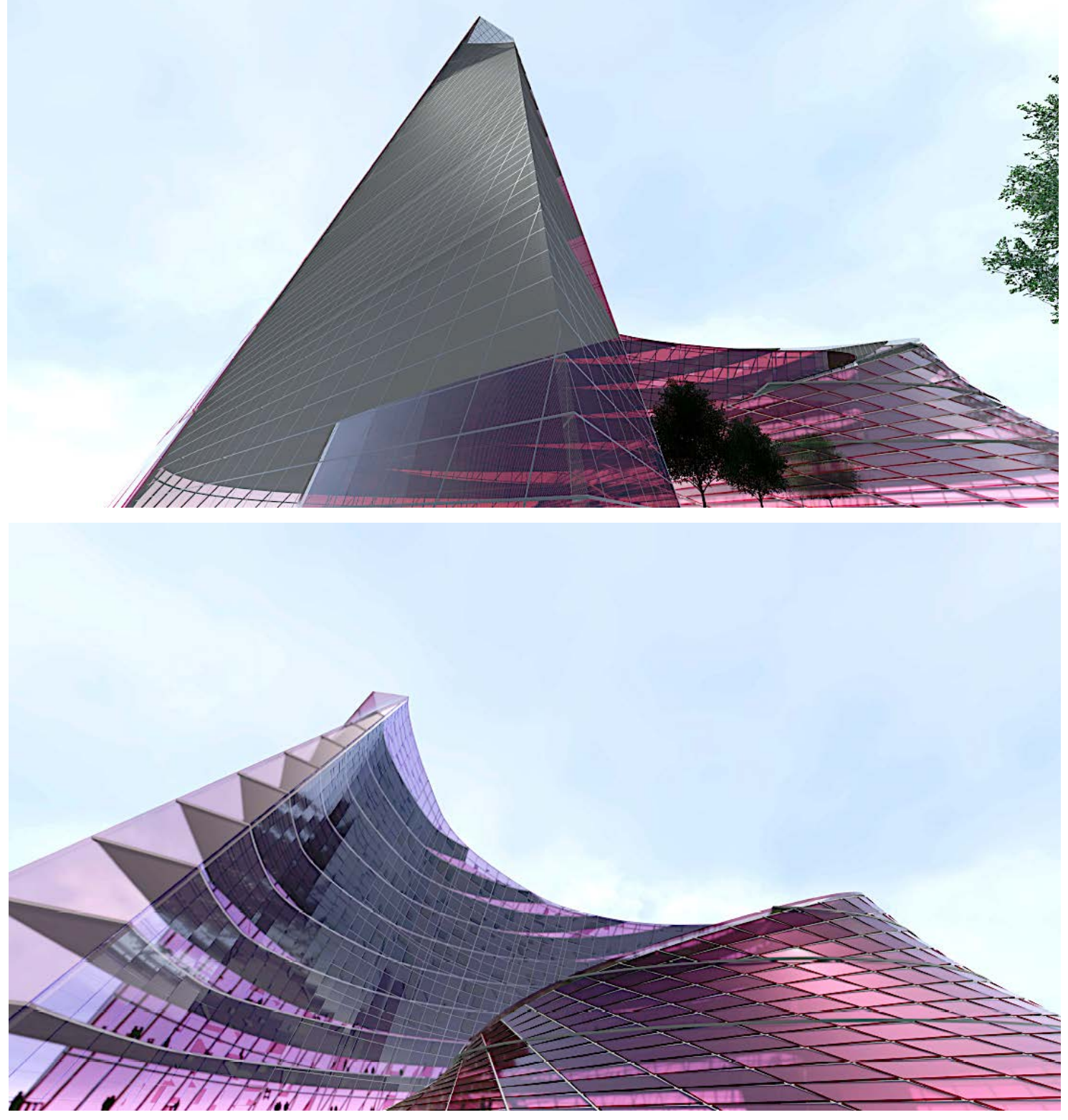
Niveli Master 2017/18 ${ }^{18}$. Fakulteti i Ndërtimtarisë dhe Arkitekturës, Universiteti i Prishtinës. Departamenti i Arkitekturës. Lënda: Studio.

Studentet: Ardiana Zullufi, Blerina Boshnjaku
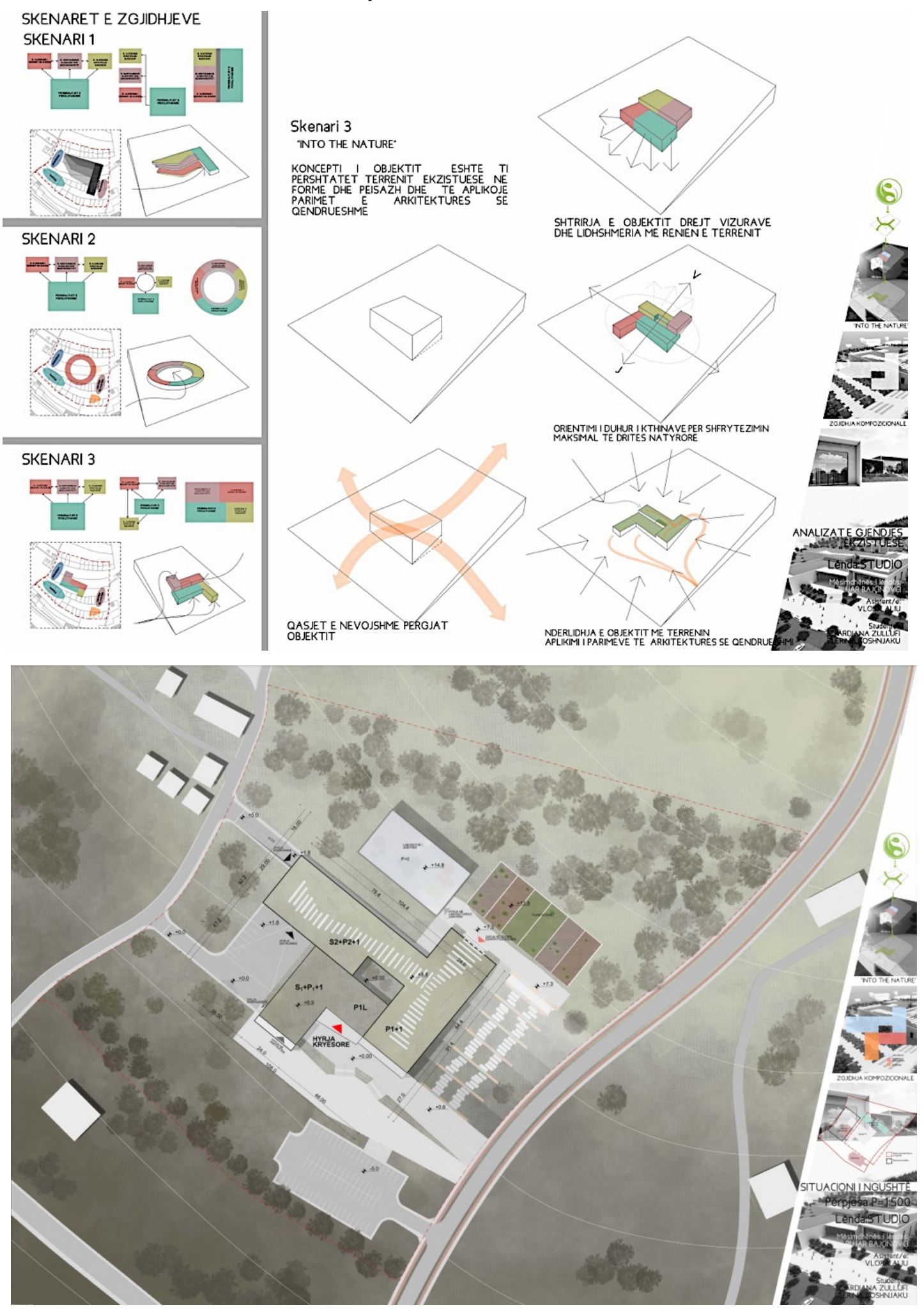

Figura 134. Analizat dhe Situacioni

(Burimi): Ardiana Zullufi, Blerina Boshnjaku, 2018

18 Ardiana Zullufi, Blerina Boshnjaku. Lënda: Studio Design. Punimi i tërë sipas dorëzimit final. FNA, UP. 


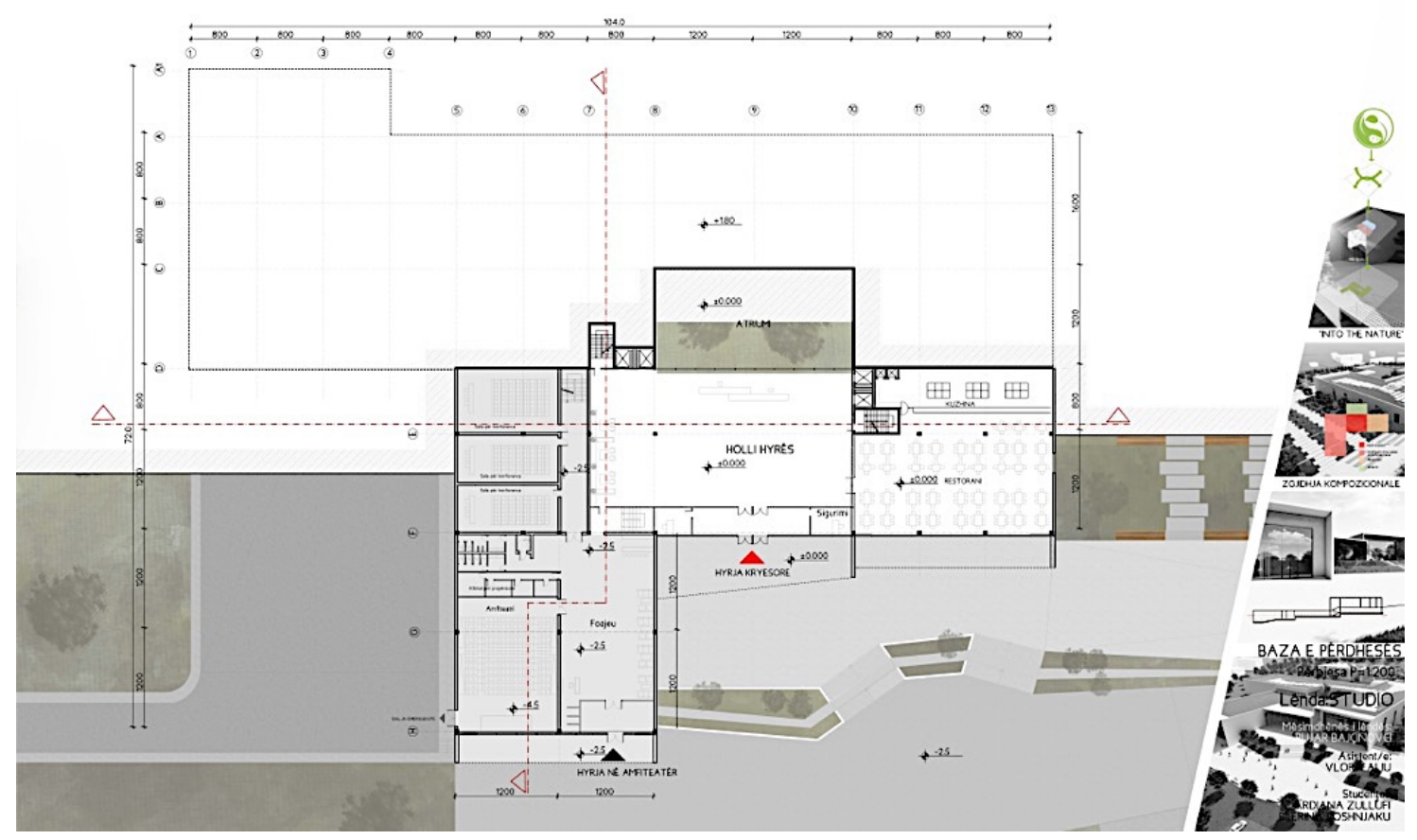

Figura 135. Baza e përdhesës

(Burimi): Ardiana Zullufi, Blerina Boshnjaku, 2018

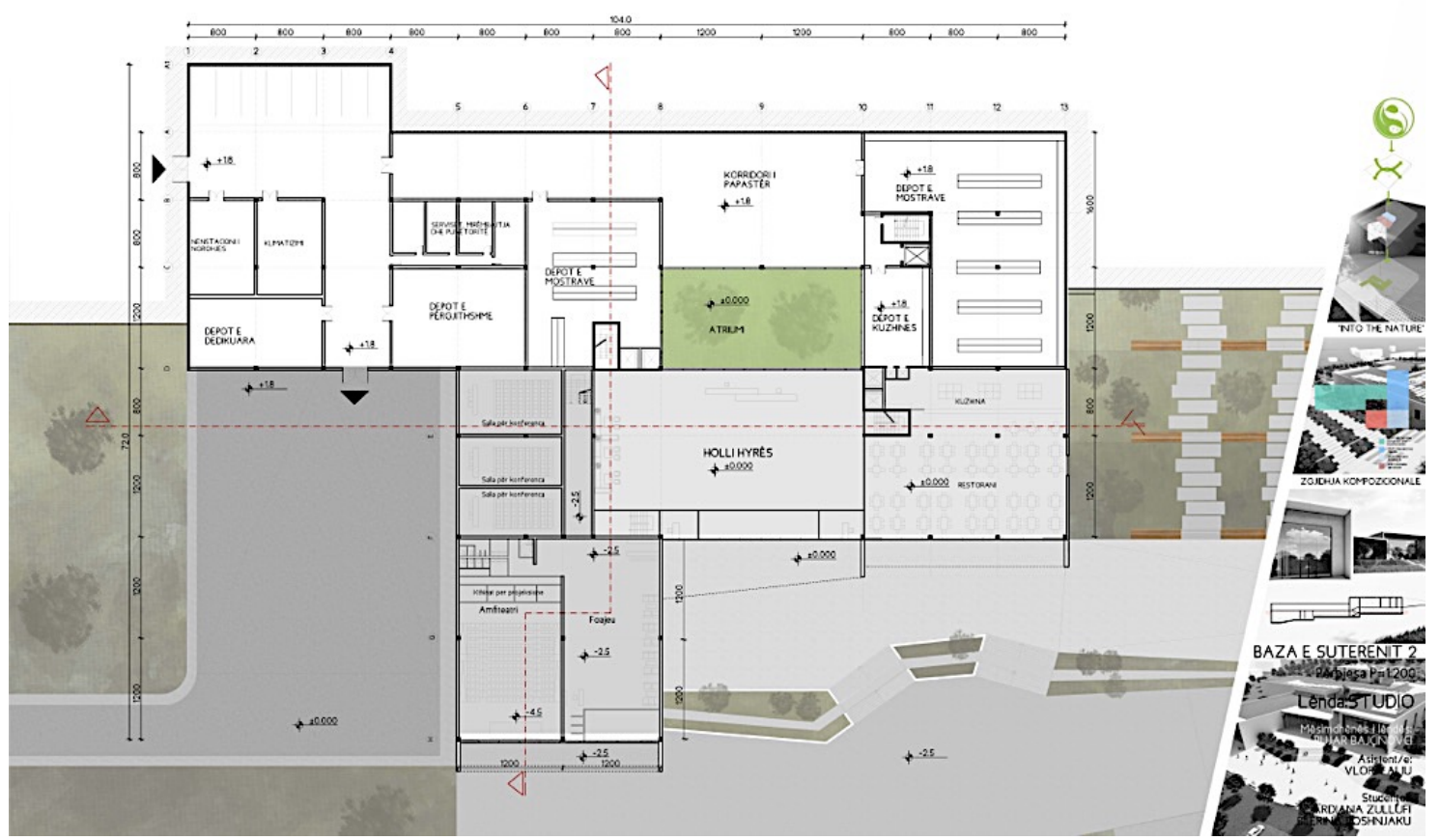

Figura 136. Baza e suterenit

(Burimi): Ardiana Zullufi, Blerina Boshnjaku, 2018 


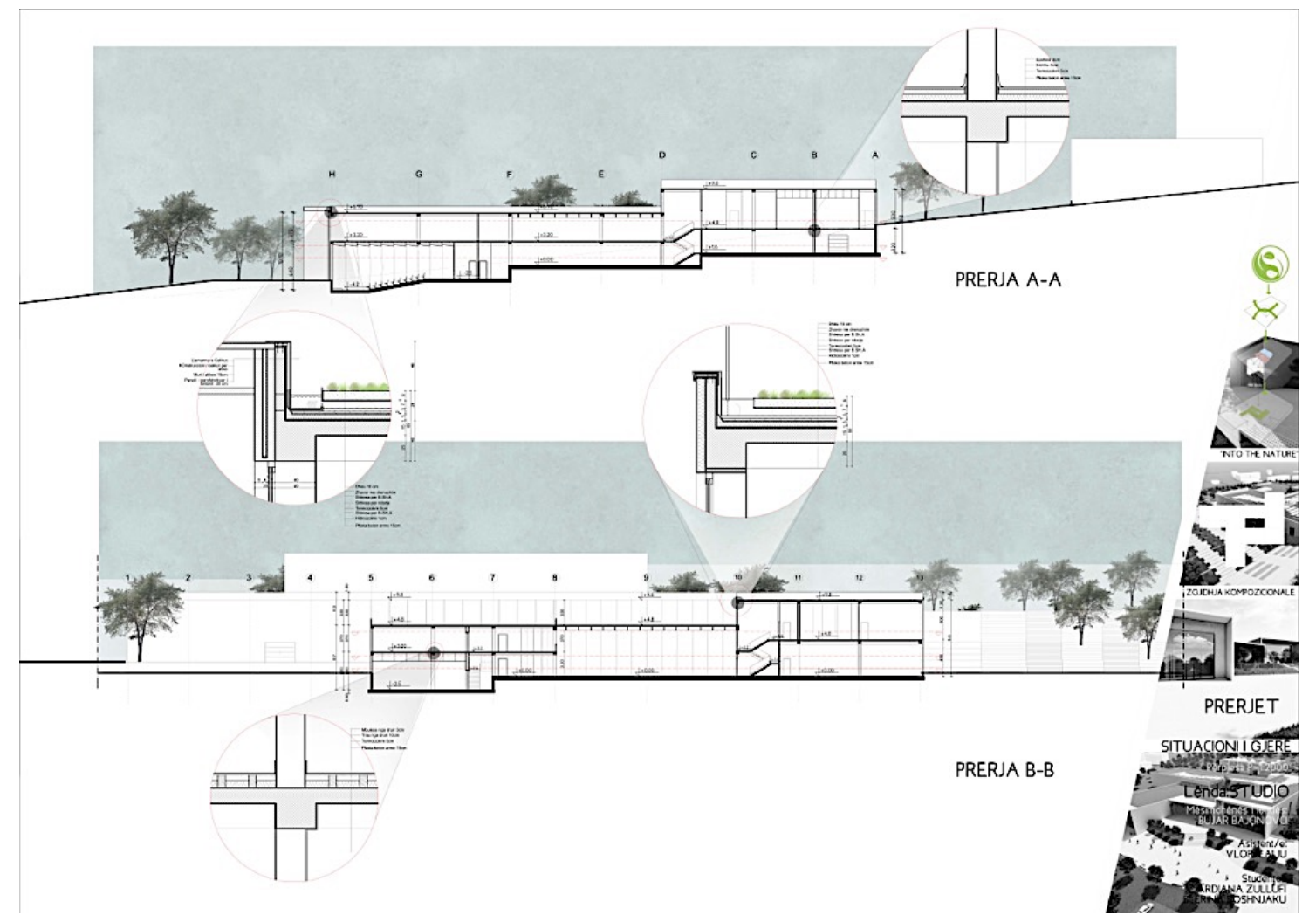

Figura 137. Prerjet

(Burimi): Ardiana Zullufi, Blerina Boshnjaku, 2018

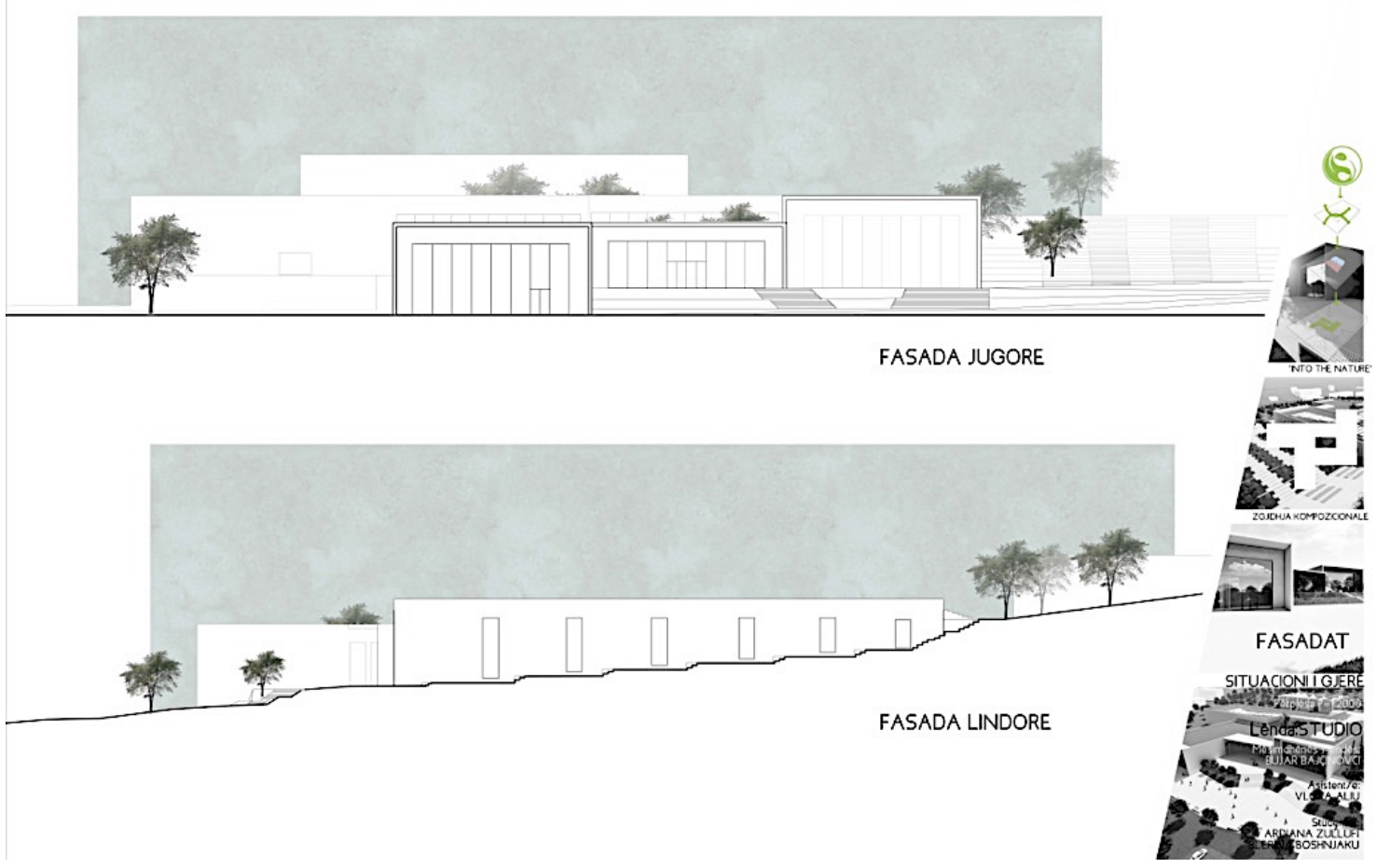

Figura 138. Pamjet

(Burimi): Ardiana Zullufi, Blerina Boshnjaku, 2018 

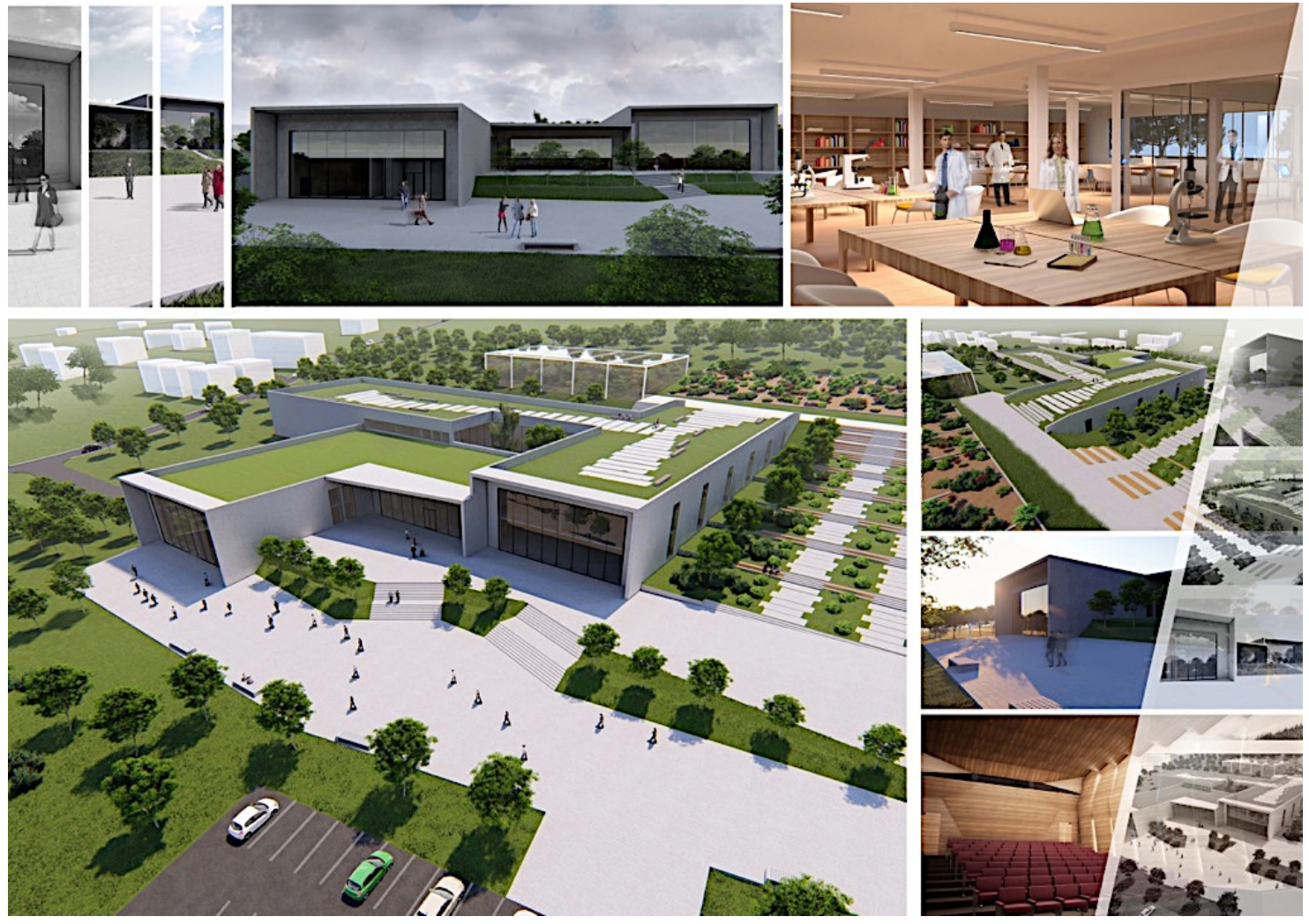

Figura 139. Perspektivat

(Burimi): Ardiana Zullufi, Blerina Boshnjaku, 2018



Figura 140. Struktura

(Burimi): Ardiana Zullufi, Blerina Boshnjaku, 2018 
Niveli Master 2017/18 ${ }^{19}$. Fakulteti i Ndërtimtarisë dhe Arkitekturës, Universiteti i Prishtinës. Departamenti i Arkitekturës. Lënda: Studio.

Studentet: Aulona Blakaj, Shpend Jashari
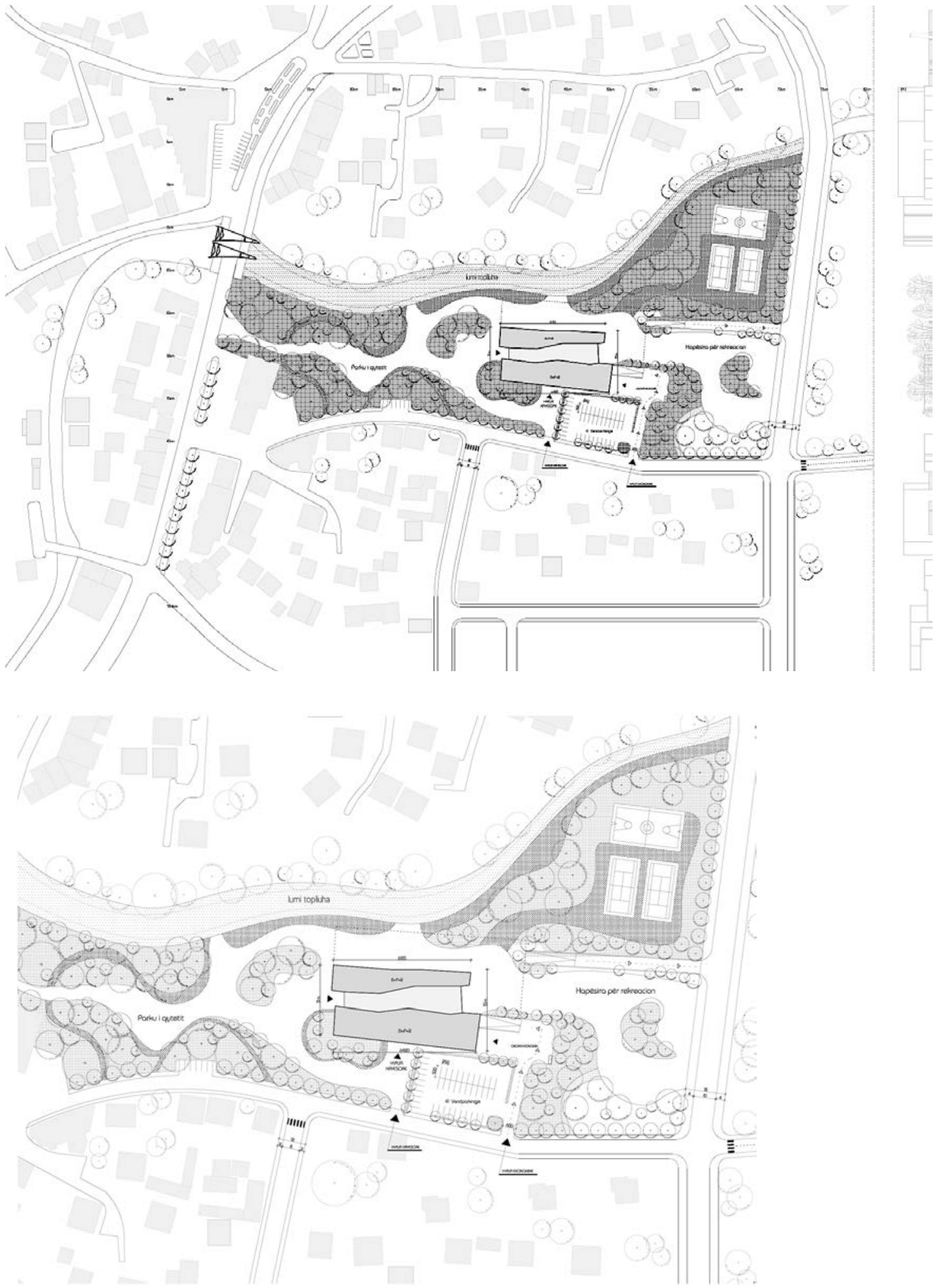

Figura 141. Situacioni

(Burimi): Aulona Blakaj, Shpend Jashari, 2018

19 Aulona Blakaj, Shpend Jashari. Lënda: Studio Design. Punimi i tërë sipas dorëzimit final. FNA, UP. 




Figura 142. Baza e Përdhesës

(Burimi): Aulona Blakaj, Shpend Jashari, 2018

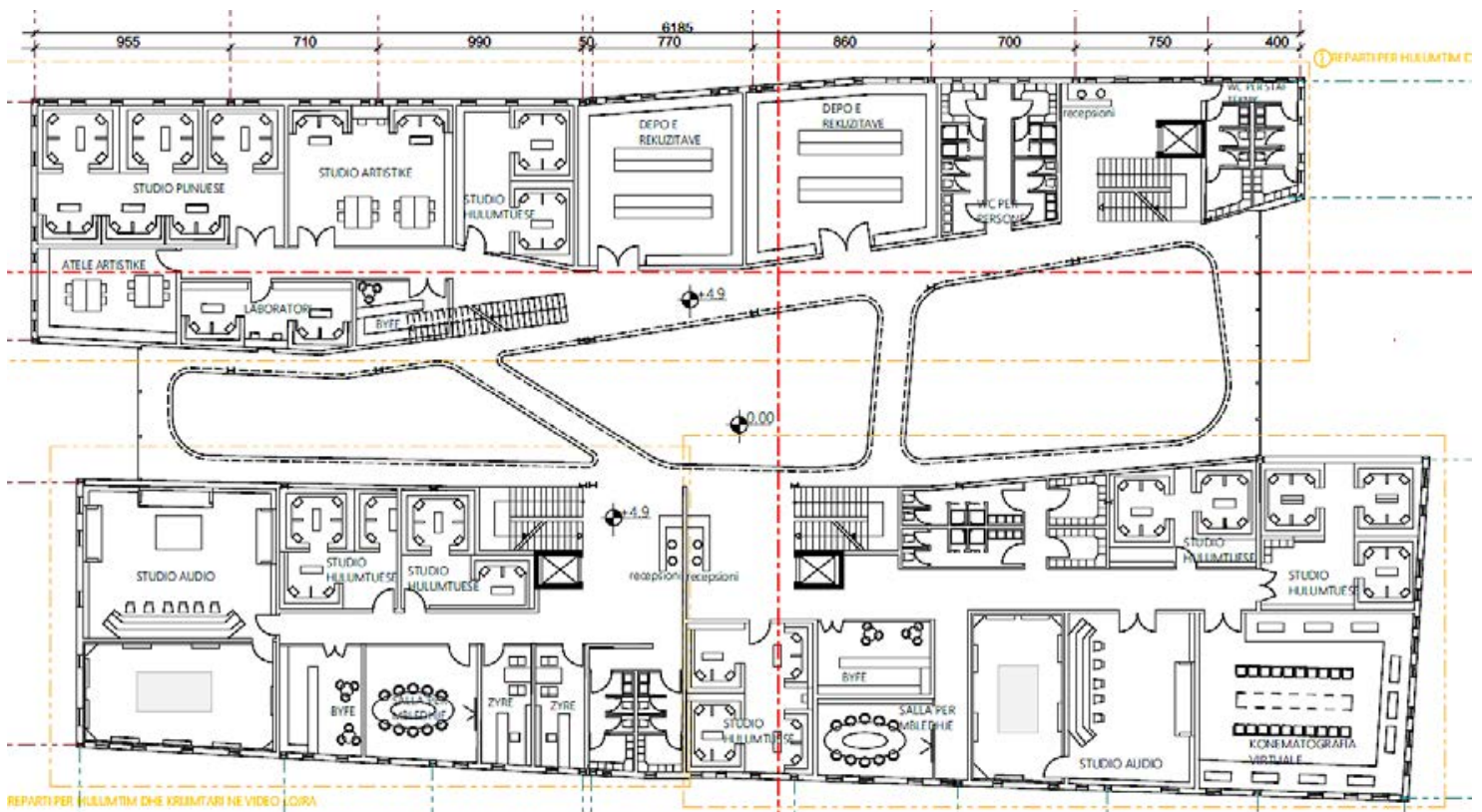

Figura 143. Baza e katit

(Burimi): Aulona Blakaj, Shpend Jashari, 2018 

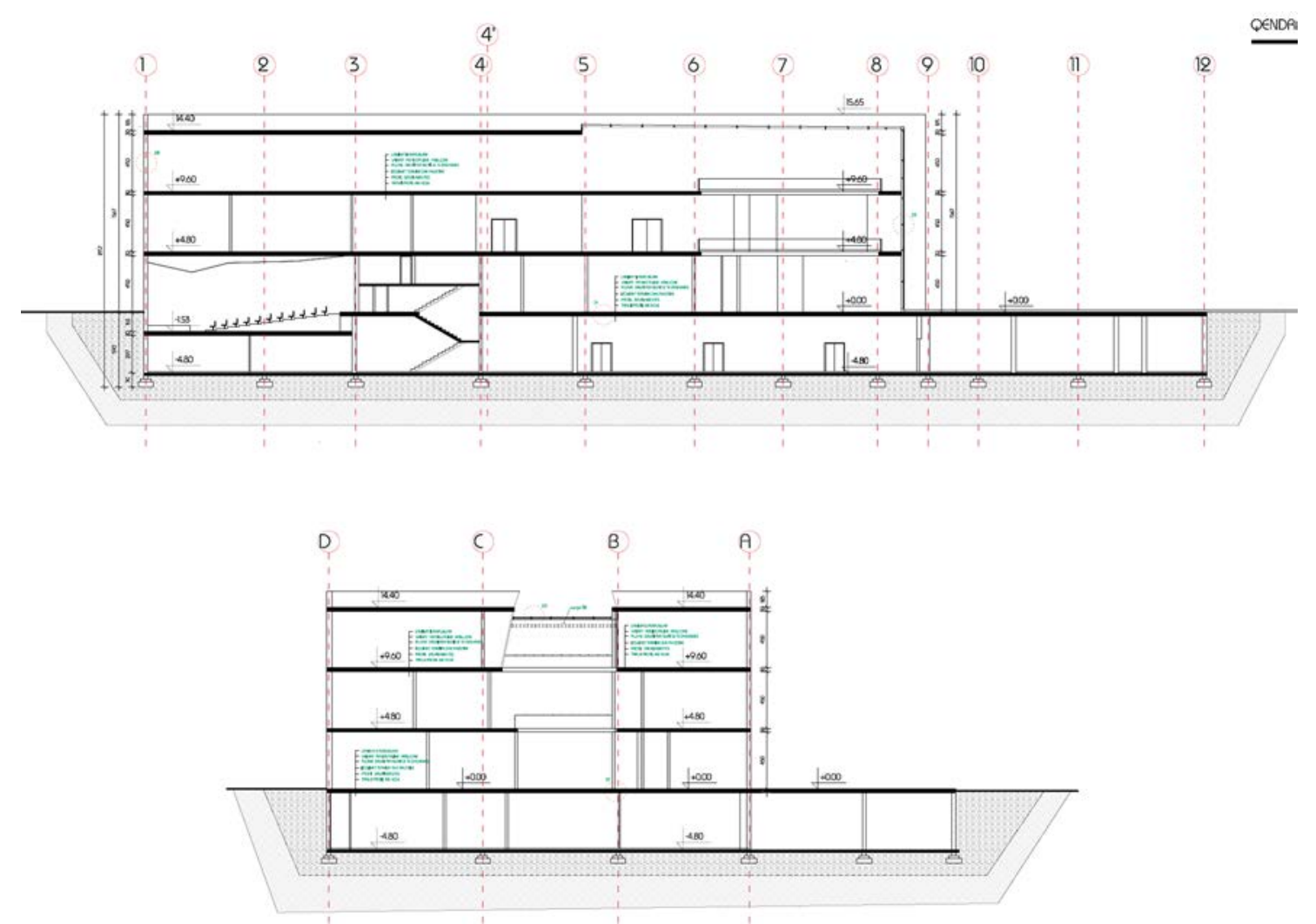

Figura 144. Prerjet

(Burimi): Aulona Blakaj, Shpend Jashari, 2018
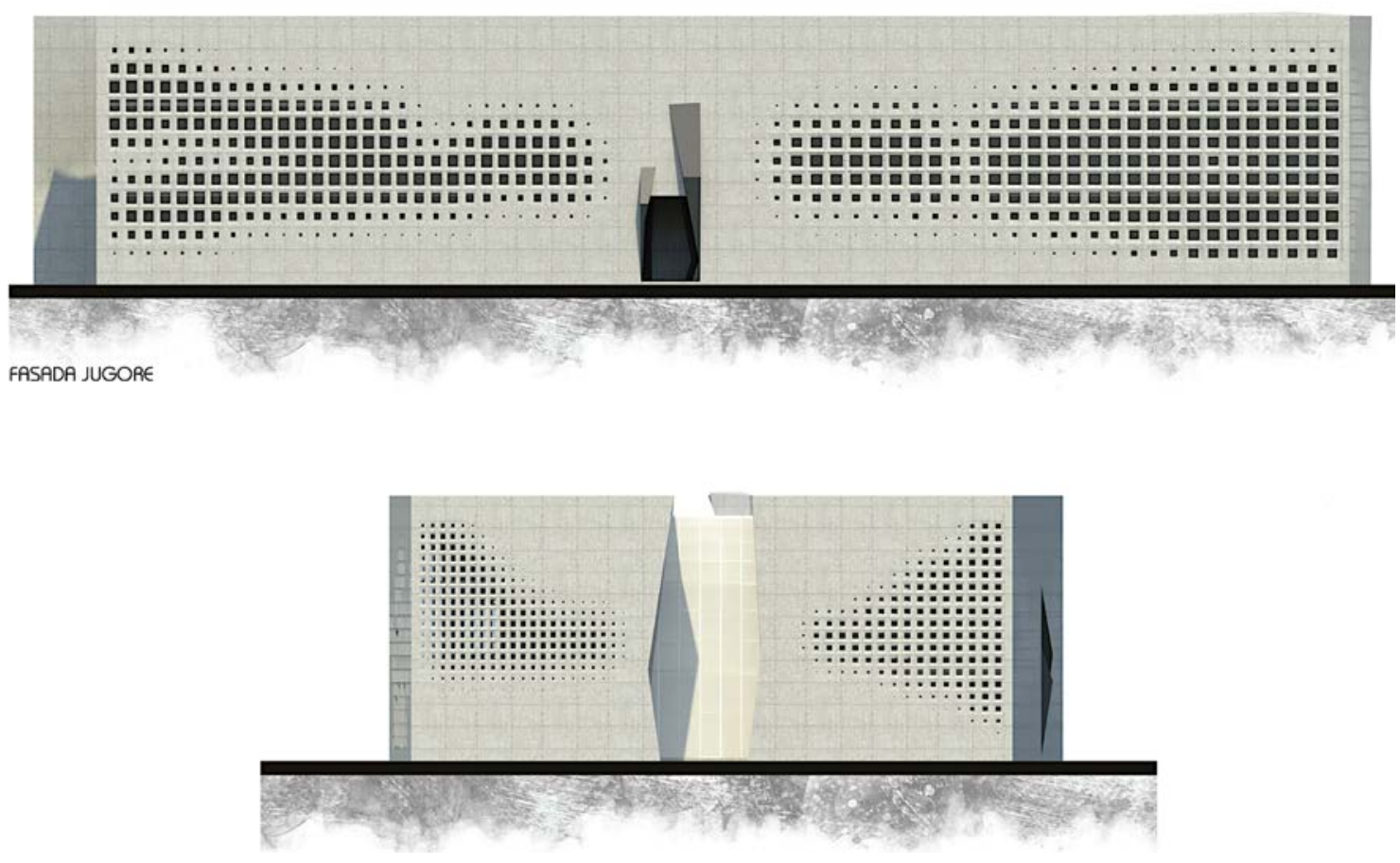

Figura 145. Pamjet

(Burimi): Aulona Blakaj, Shpend Jashari, 2018 



Figura 146. Perpektiva

(Burimi): Aulona Blakaj, Shpend Jashari, 2018 



Figura 147. Perpektiva

(Burimi): Aulona Blakaj, Shpend Jashari, 2018 
Niveli Master 2017/18 ${ }^{20}$. Fakulteti i Ndërtimtarisë dhe Arkitekturës, Universiteti i Prishtinës.

Departamenti i Arkitekturës. Lënda: Studio.

Studentet: Benjamin Komani, Kushtrim Thaqi
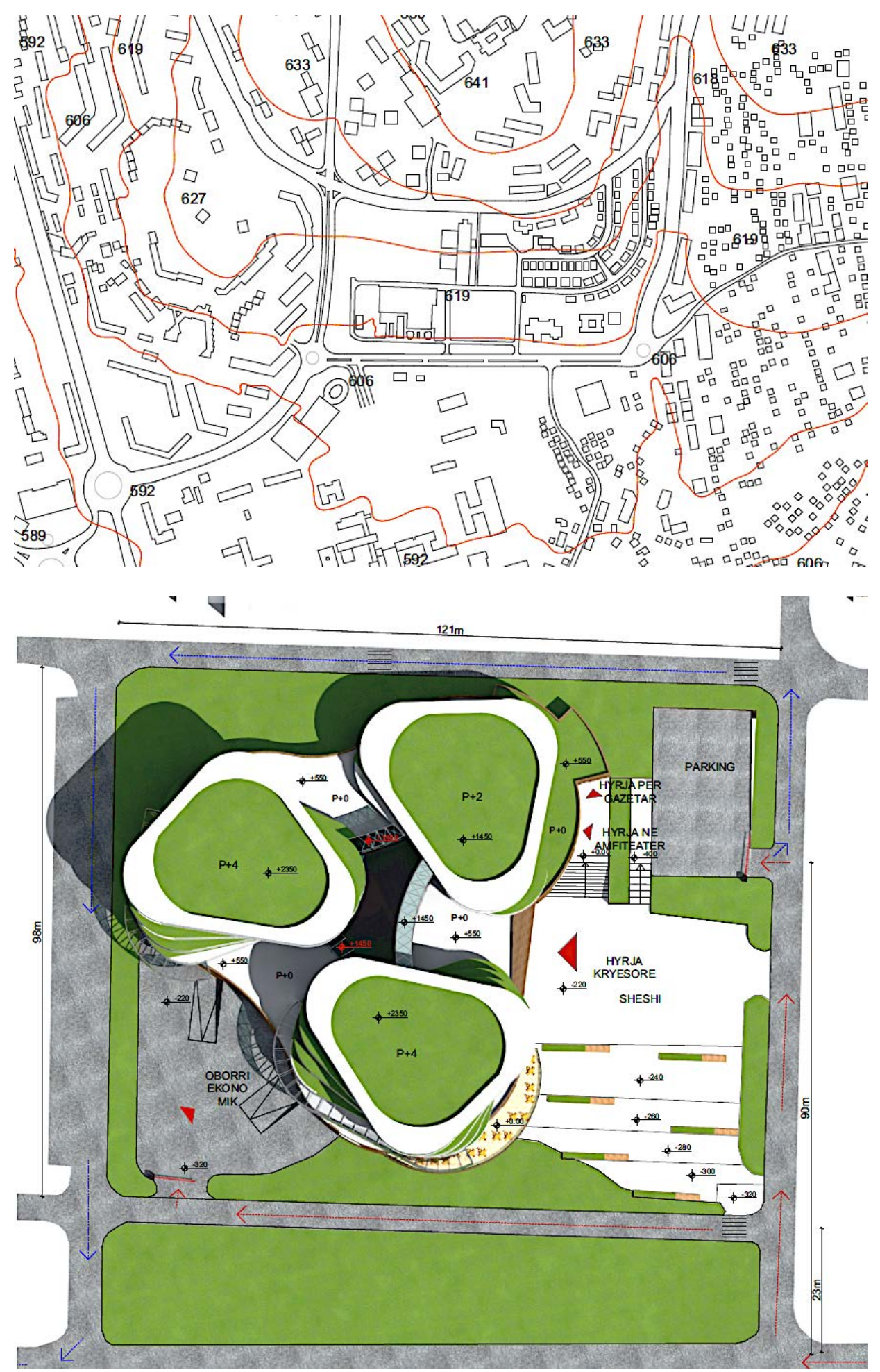

Figura 148. Situacioni

(Burimi): Benjamin Komani, Kushtrim Thaqi, 2018

20 Benjamin Komani, Kushtrim Thaqi. Lënda: Studio Design. Punimi i tërë sipas dorëzimit final. FNA, UP. 


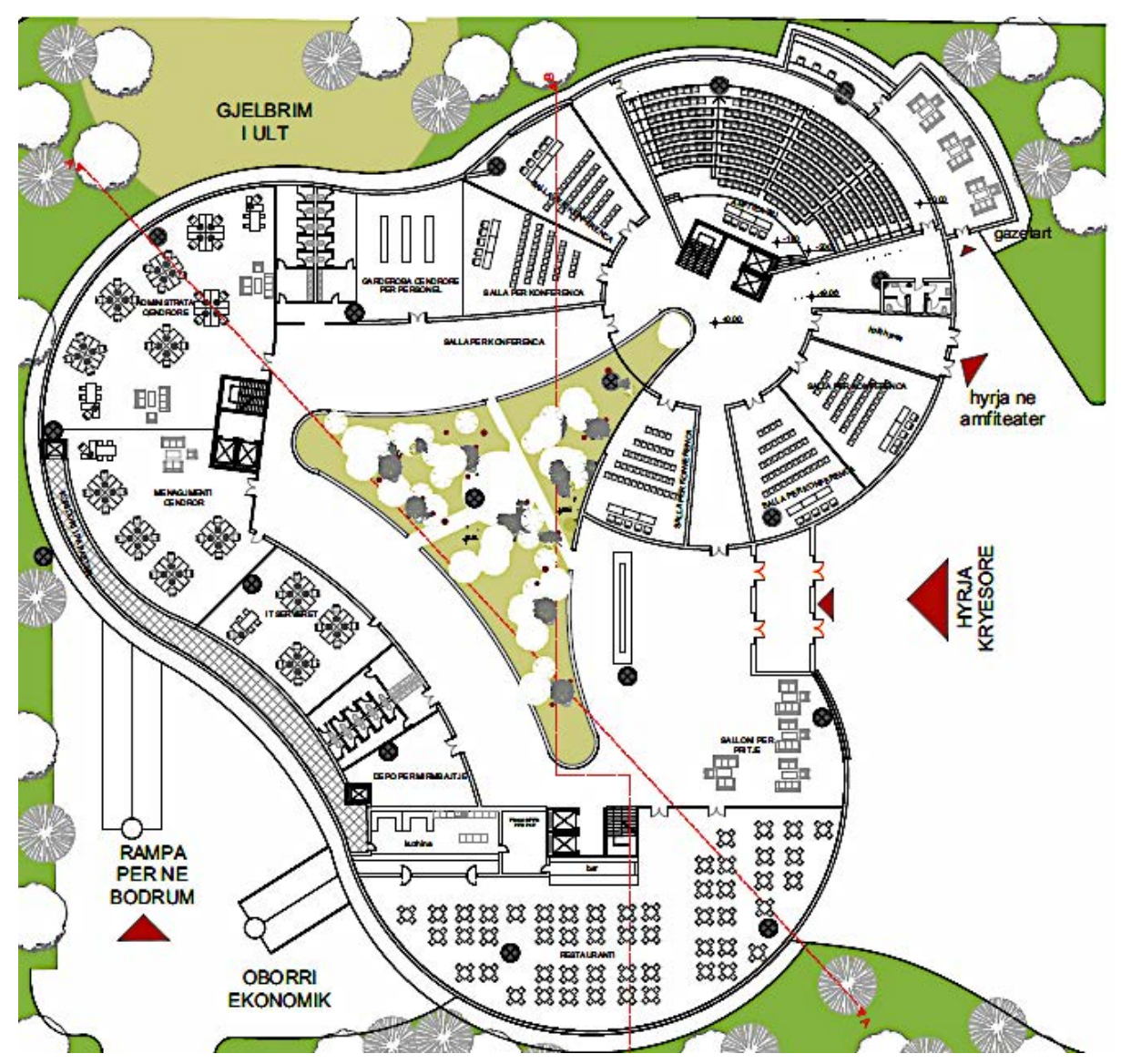

Figura 149. Baza e përdhesës

(Burimi): Benjamin Komani, Kushtrim Thaqi, 2018

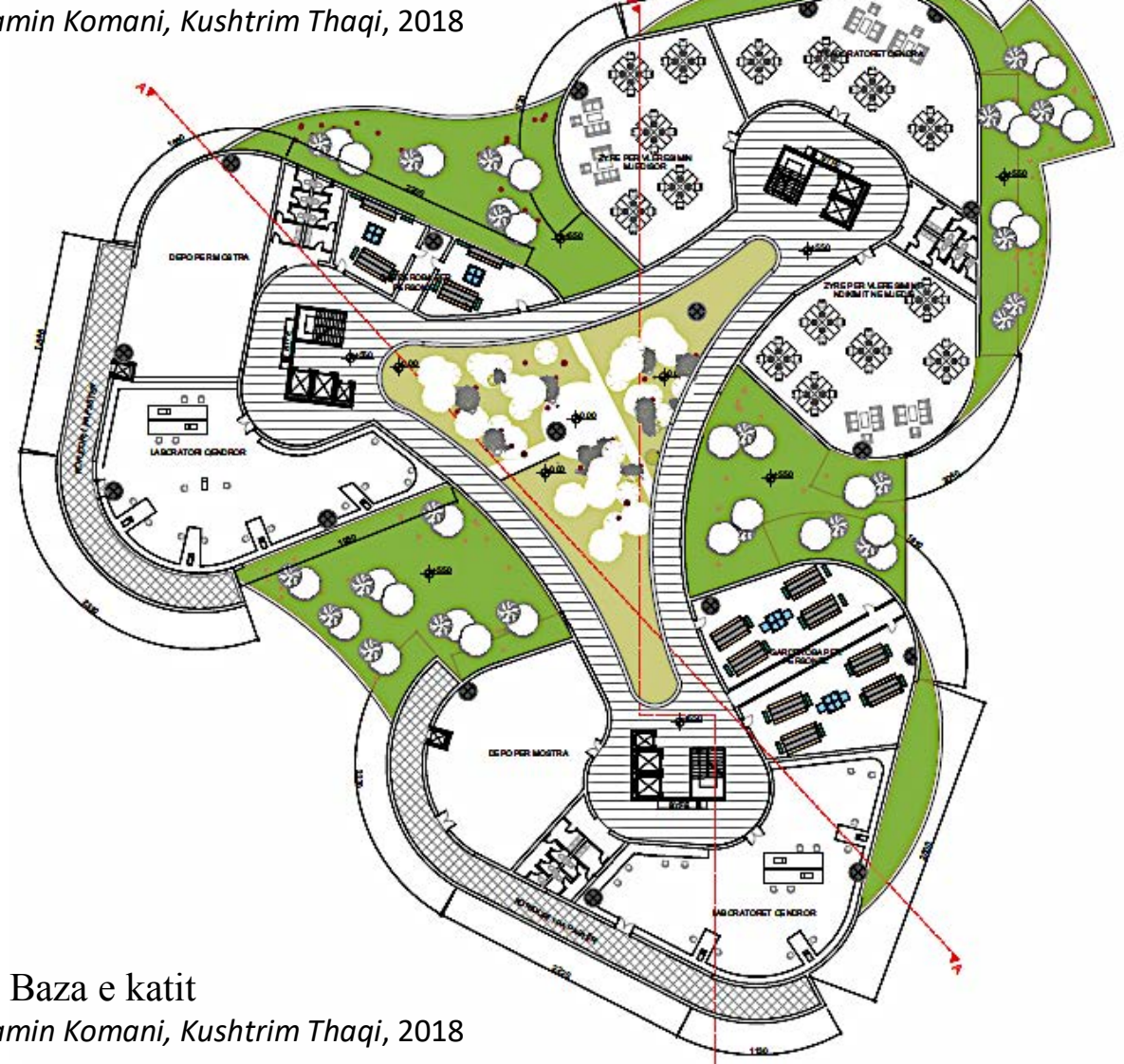

Figura 150. Baza e katit

(Burimi): Benjamin Komani, Kushtrim Thaqi, 2018 

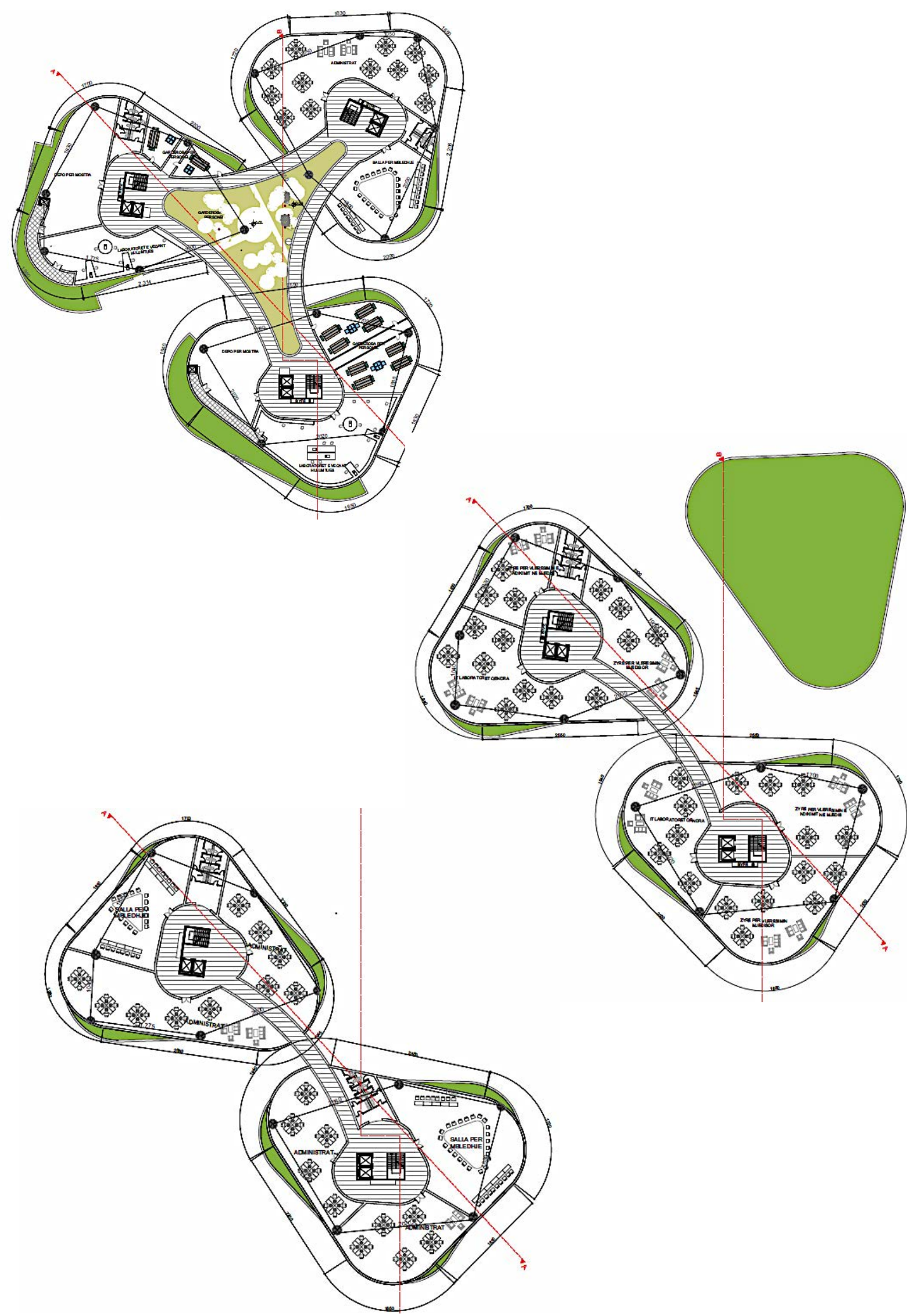

Figura 151. Baza e sipërme

(Burimi): Benjamin Komani, Kushtrim Thaqi, 2018 

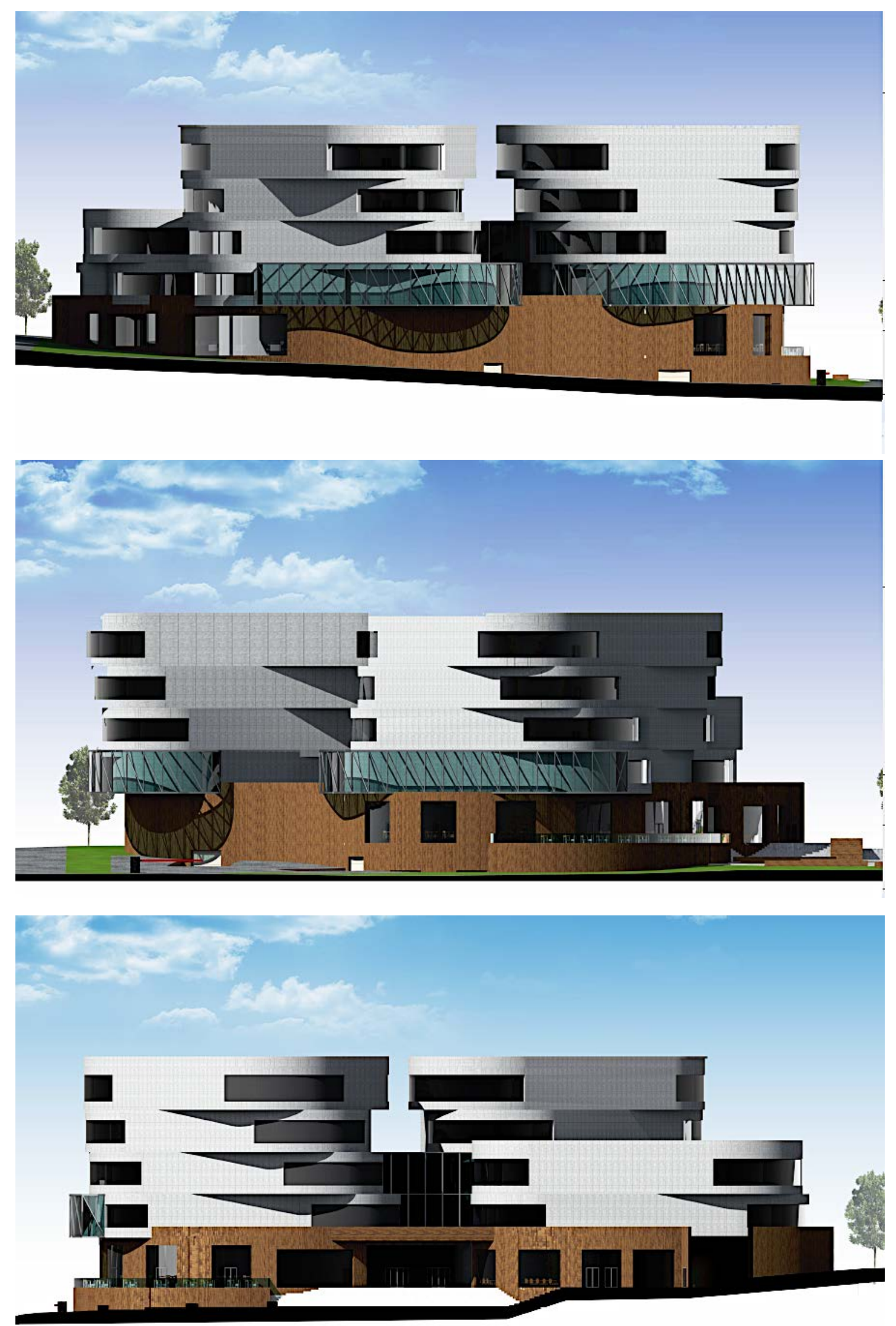

Figura 152. Pamjet

(Burimi): Benjamin Komani, Kushtrim Thaqi, 2018 



Figura 153. Perspektiva

(Burimi): Benjamin Komani, Kushtrim Thaqi, 2018 
Niveli Master 2017/18 ${ }^{21}$. Fakulteti i Ndërtimtarisë dhe Arkitekturës, Universiteti i Prishtinës. Departamenti i Arkitekturës. Lënda: Studio.

Studentet: Nerimane Merovci, Rajmonda Jetullahu
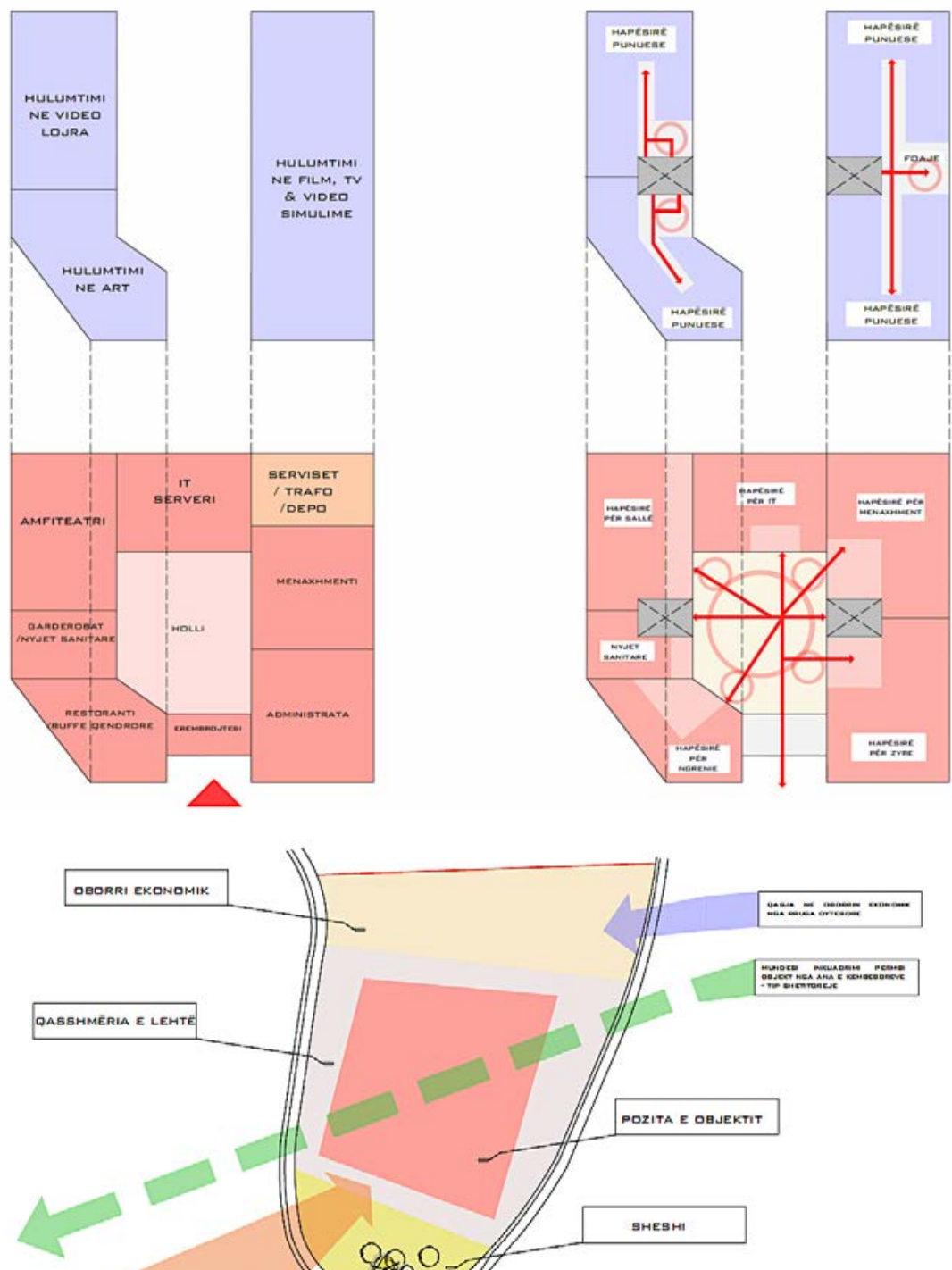

Figura 154. Analizat

(Burimi): Nerimane Merovci, Rajmonda Jetullahu, 2018

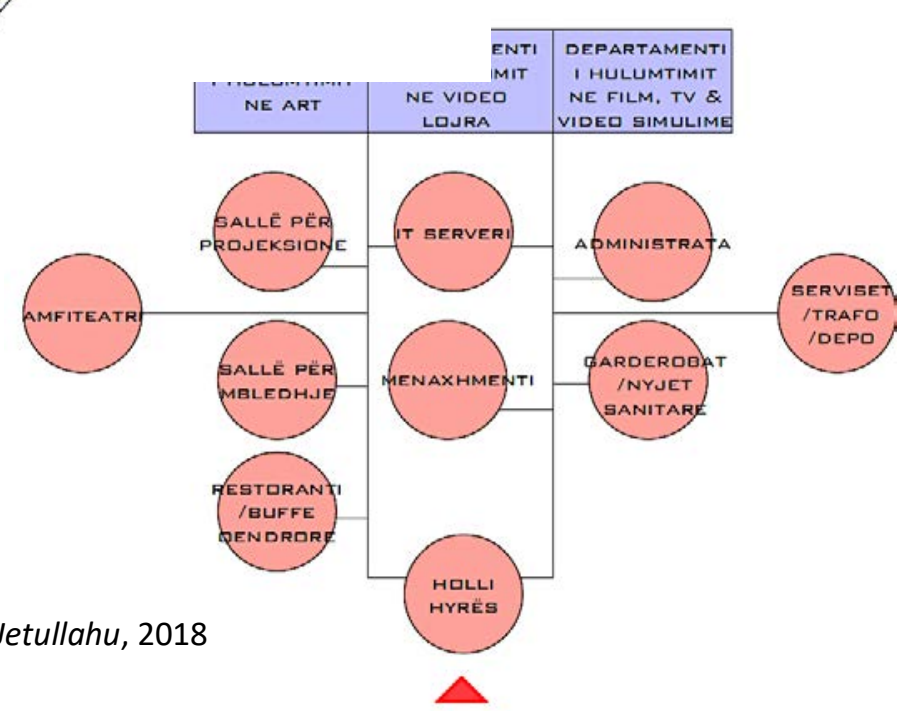

21 Nerimane Merovci, Rajmonda Jetullahu. Studio Design. Punimi i tërë sipas dorëzimit final. FNA, UP. 




Figura 155. Analizat - Situacioni

(Burimi): Nerimane Merovci, Rajmonda Jetullahu, 2018 




Figura 156. Situacioni

(Burimi): Nerimane Merovci, Rajmonda Jetullahu, 2018



Figura 157. Baza e përdhesës

(Burimi): Nerimane Merovci, Rajmonda Jetullahu, 2018 




Figura 158. Baza e katit

(Burimi): Nerimane Merovci, Rajmonda Jetullahu, 2018



Figura 159. Baza e katit 2

(Burimi): Nerimane Merovci, Rajmonda Jetullahu, 2018 


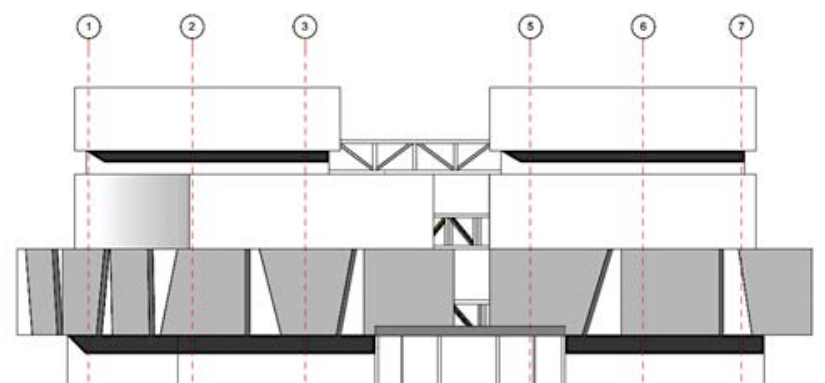

FASADA JUGORE

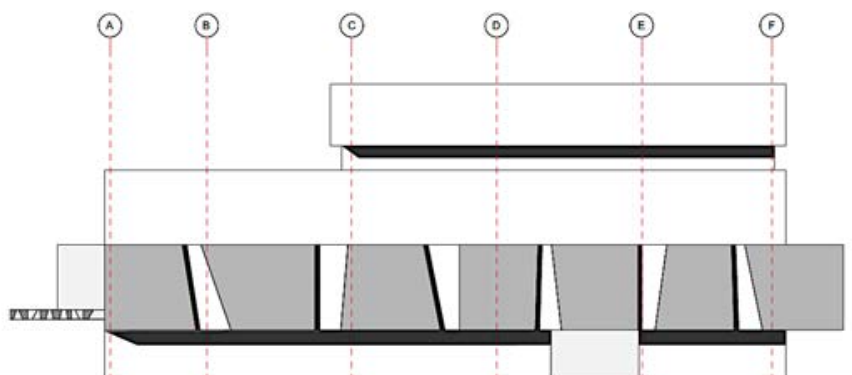

Figura 160. Pamjet

(Burimi): Nerimane Merovci, Rajmonda Jetullahu, 2018

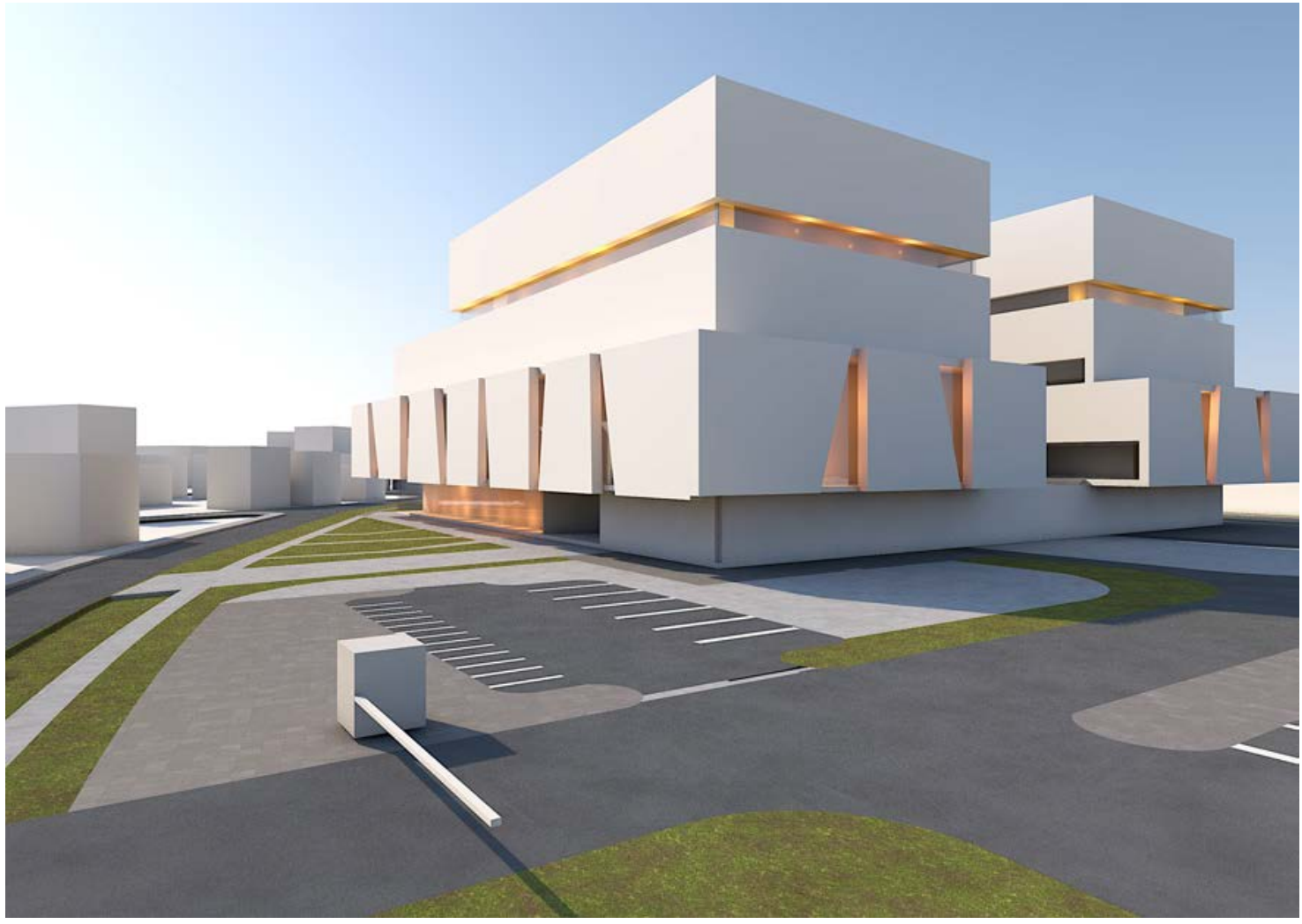

Figura 161. Perspektiva

(Burimi): Nerimane Merovci, Rajmonda Jetullahu, 2018 

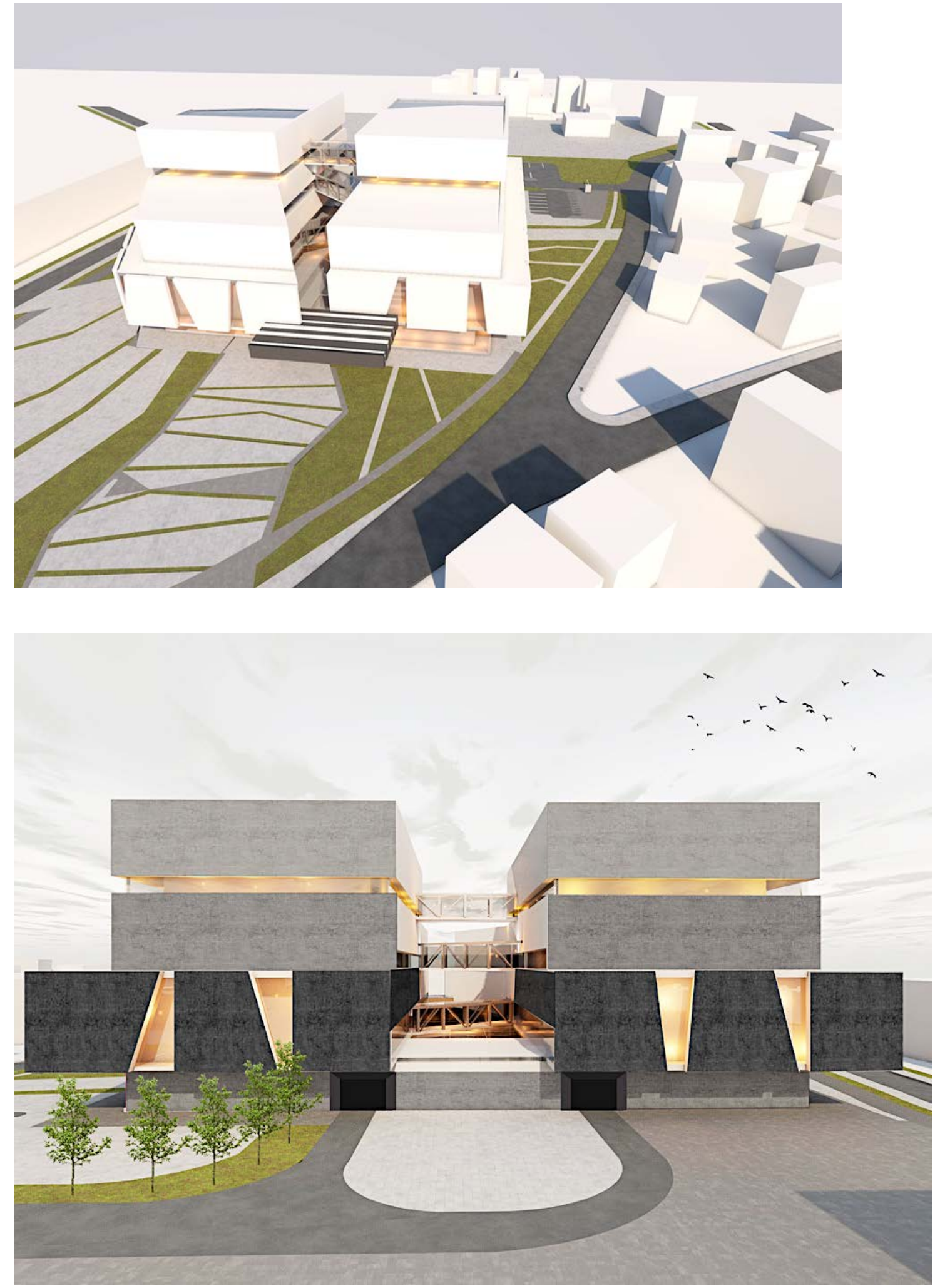

Figura 162. Perspektiva

(Burimi): Nerimane Merovci, Rajmonda Jetullahu, 2018 



Figura 163. Perspektiva

(Burimi): Nerimane Merovci, Rajmonda Jetullahu, 2018 
Niveli Master 2017/18 ${ }^{22}$. Fakulteti i Ndërtimtarisë dhe Arkitekturës, Universiteti i Prishtinës. Departamenti i Arkitekturës. Lënda: Studio.

Studentet: Nertila Kabashaj, Njomza Tahiri


Figura 164. Situacioni

(Burimi): Nertila Kabashaj, Njomza Tahiri, 2018

22 Nertila Kabashaj, Njomza Tahiri. Lënda: Studio Design. Punimi i tërë sipas dorëzimit final. FNA, UP. 


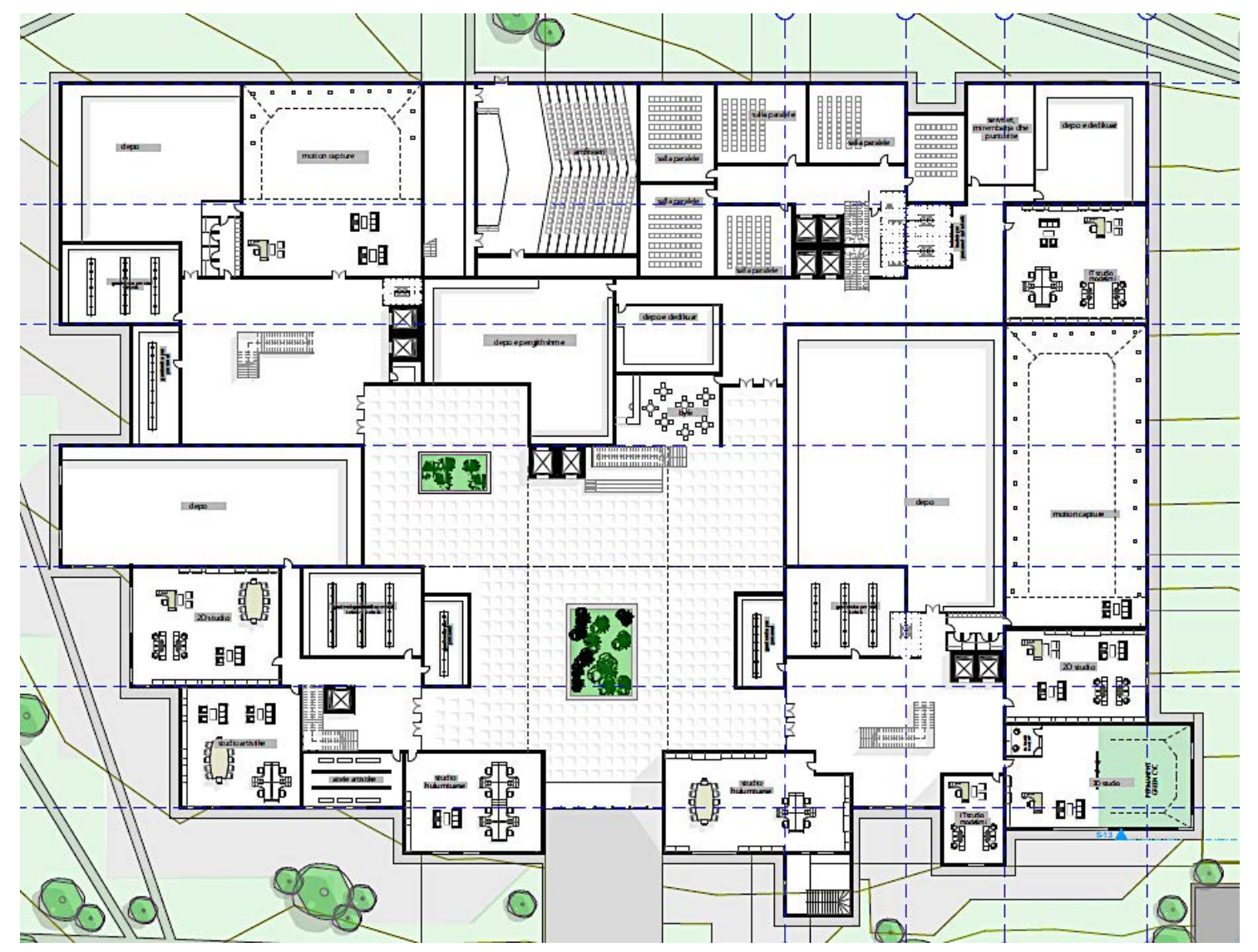

Figura 165. Baza e përdhesës

(Burimi): Nertila Kabashaj, Njomza Tahiri, 2018



Figura 166. Baza e katit

(Burimi): Nertila Kabashaj, Njomza Tahiri, 2018 


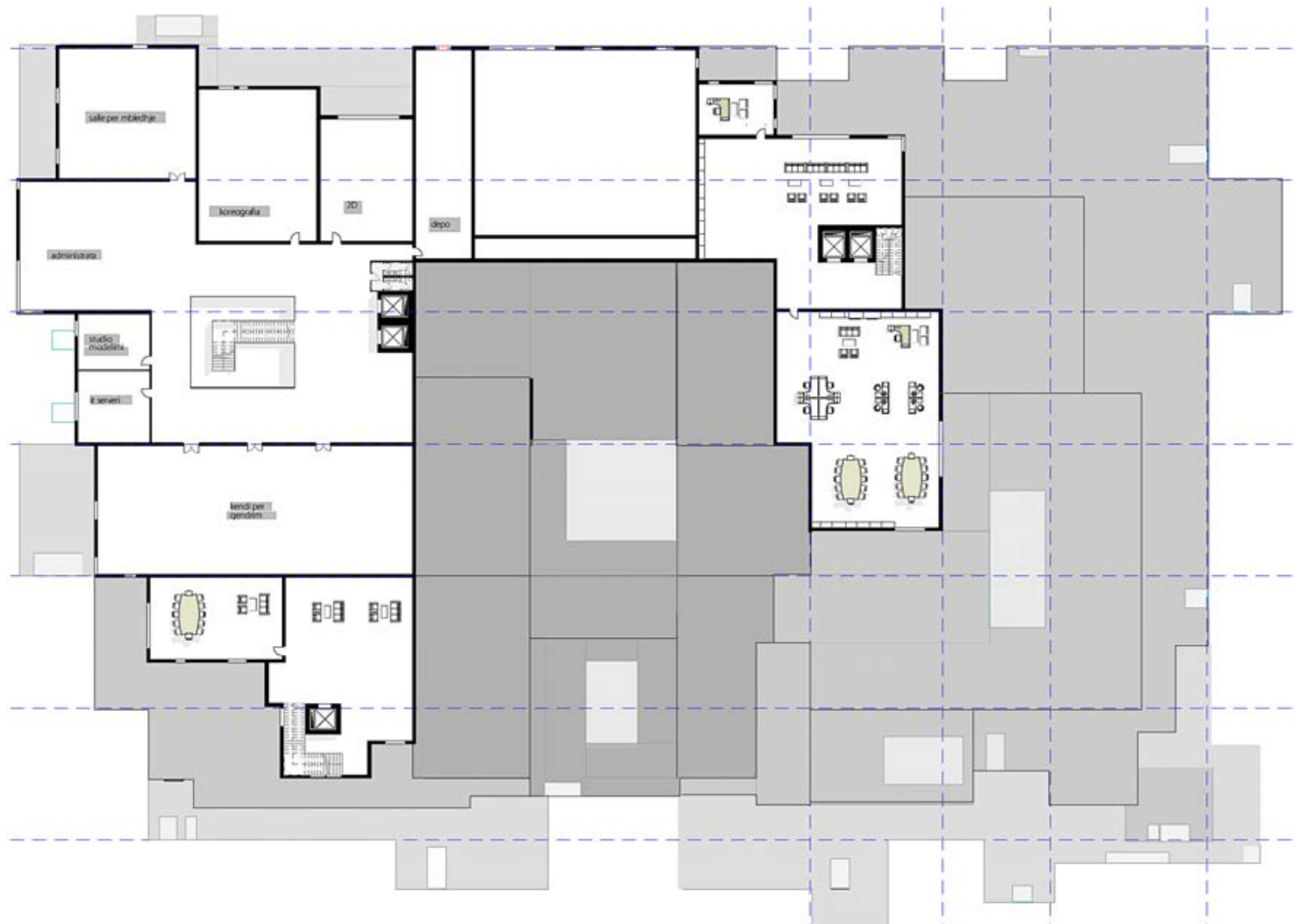

Figura 167. Baza e katit 2

(Burimi): Nertila Kabashaj, Njomza Tahiri, 2018

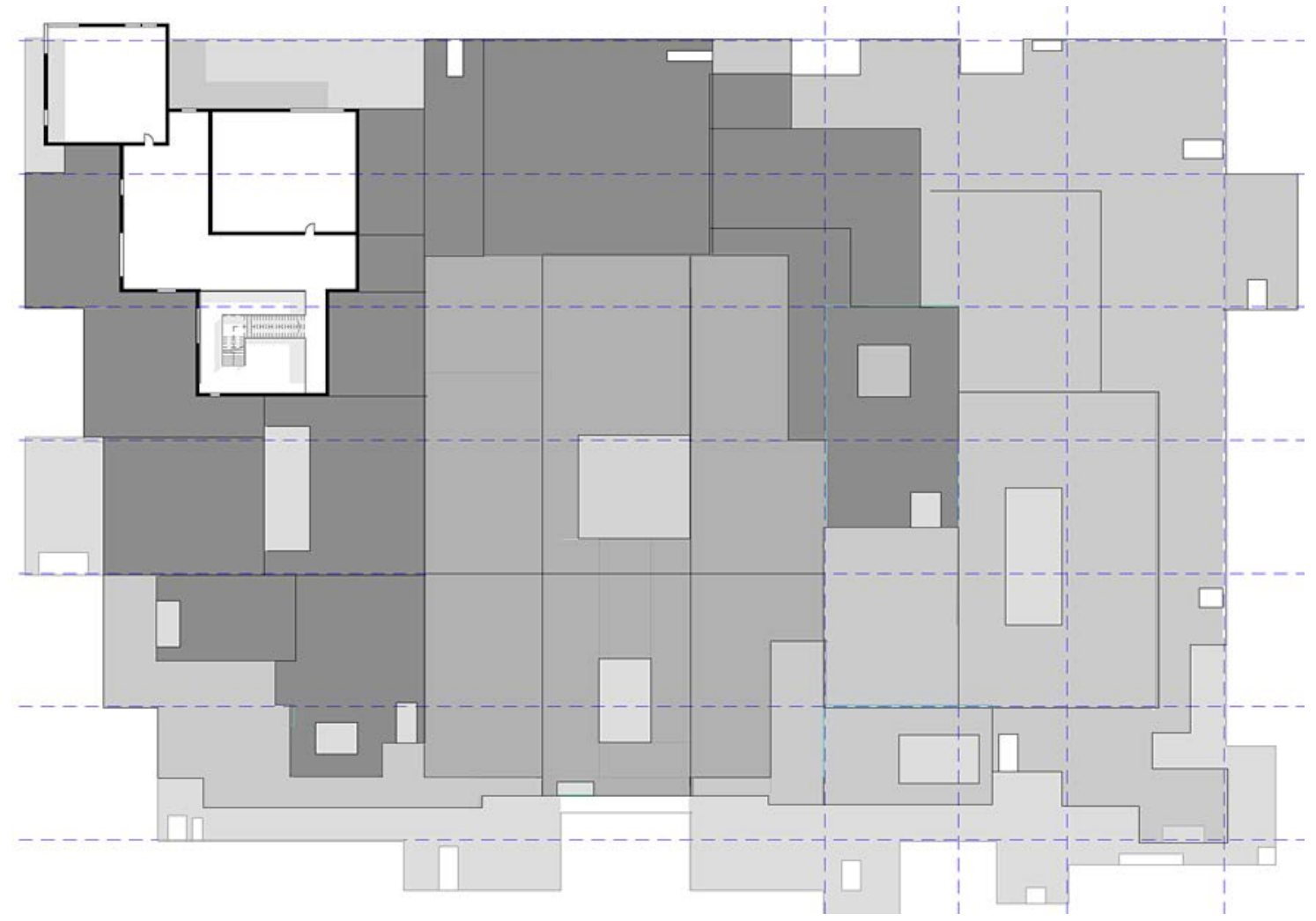

Figura 168. Baza e katit 3

(Burimi): Nertila Kabashaj, Njomza Tahiri, 2018 



Figura 169. Prerjet

(Burimi): Nertila Kabashaj, Njomza Tahiri, 2018

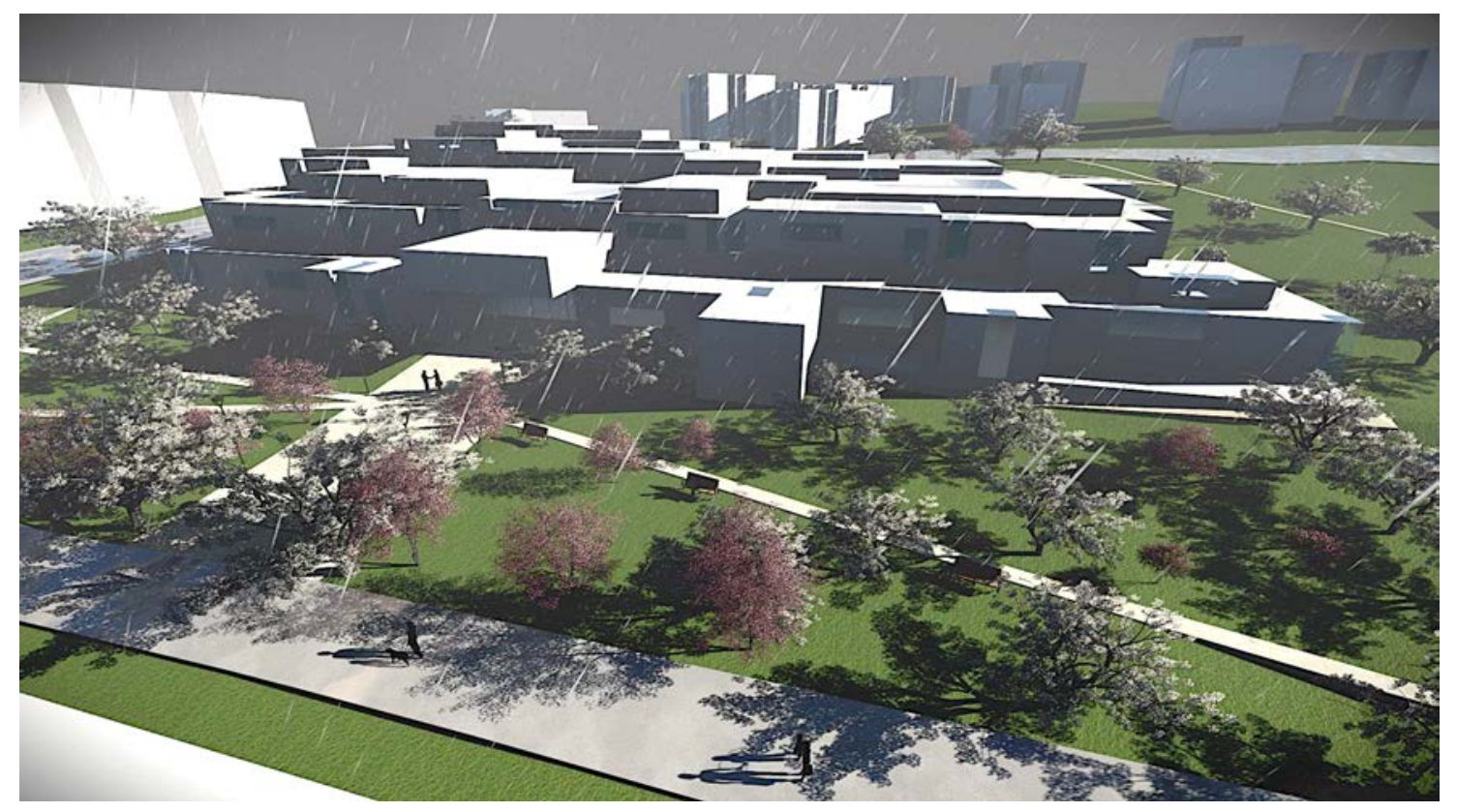

Figura 170. Perspektiva

(Burimi): Nertila Kabashaj, Njomza Tahiri, 2018 
KJO FAQE ËSHTË LËNË QËLLIMISHT E ZBRAZËT! 


\section{INDEKSI I FOTOGRAFIVE - TABELAVE}

\section{FOTOGRAFITË:}

Figura 1. Analizat e Situacionit

(Burimi): Alen Ajdarpasic, Fjollëza Bunjaku, 2016.

Figura 2. Baza e përdhesës

(Burimi): Alen Ajdarpasic, Fjollëza Bunjaku, 2016.

Figura 3. Baza e katit

(Burimi): Alen Ajdarpasic, Fjollëza Bunjaku, 2016.

Figura 4. Prerjet

(Burimi): Alen Ajdarpasic, Fjollëza Bunjaku, 2016.

Figura 5. Perspektiva

(Burimi): Alen Ajdarpasic, Fjollëza Bunjaku, 2016.

Figura 6. Perspektiva

(Burimi): Alen Ajdarpasic, Fjollëza Bunjaku, 2016.

Figura 7. Perspektiva

(Burimi): Alen Ajdarpasic, Fjollëza Bunjaku, 2016.

Figura 8. Perspektiva

(Burimi): Alen Ajdarpasic, Fjollëza Bunjaku, 2016.

Figura 9. Baza e bodrumit

(Burimi): Alen Ajdarpasic, Fjollëza Bunjaku, 2016.

Figura 10. Analizat, kompozicioni

(Burimi): Festim Haliti, Uran Sadikaj, 2016.

Figura 11. Baza e përdhesës

(Burimi): Festim Haliti, Uran Sadikaj, 2016.

Figura 12. Baza e katit dhe bodrumit (Burimi): Festim Haliti, Uran Sadikaj, 2016.

Figura 13. Prerja A

(Burimi): Festim Haliti, Uran Sadikaj, 2016. 
Figura 14. Situacioni

(Burimi): Festim Haliti, Uran Sadikaj, 2016.

Figura 15. Perspektiva

(Burimi): Festim Haliti, Uran Sadikaj, 2016

Figura 16. Perspektiva

(Burimi): Festim Haliti, Uran Sadikaj, 2016

Figura 17. Perspektiva

(Burimi): Festim Haliti, Uran Sadikaj, 2016

Figura 18. Perspektiva

(Burimi): Festim Haliti, Uran Sadikaj, 2016

Figura 19. Perspektiva

(Burimi): Festim Haliti, Uran Sadikaj, 2016

Figura 20. Perspektiva

(Burimi): Festim Haliti, Uran Sadikaj, 2016

Figura 21. Situacioni

(Burimi): Diella Shabani, Diellza Demiri, 2016

Figura 22. Situacioni

(Burimi): Diella Shabani, Diellza Demiri, 2016

Figura 23. Baza e përdhesës

(Burimi): Diella Shabani, Diellza Demiri, 2016

Figura 24. Baza e katit

(Burimi): Diella Shabani, Diellza Demiri, 2016

Figura 25. Prerjet

(Burimi): Diella Shabani, Diellza Demiri, 2016

Figura 26. Pamjet

(Burimi): Diella Shabani, Diellza Demiri, 2016

Figura 27. Pamjet

(Burimi): Diella Shabani, Diellza Demiri, 2016

Figura 28. Perspektiva

(Burimi): Diella Shabani, Diellza Demiri, 2016

Figura 29. Situacioni

(Burimi): Diell Sylhasi, Ledri Duraku, 2016

Figura 30. Situacioni

(Burimi): Diell Sylhasi, Ledri Duraku, 2016

Figura 31. Baza e përdhesës

(Burimi): Diell Sylhasi, Ledri Duraku, 2016 
Figura 32. Baza e katit

(Burimi): Diell Sylhasi, Ledri Duraku, 2016

Figura 33. Perspektiva

(Burimi): Diell Sylhasi, Ledri Duraku, 2016

Figura 34. Situacioni

(Burimi): Fjolla Januzi, Hana Ziberi, 2016

Figura 35. Baza e përdhesës

(Burimi): Fjolla Januzi, Hana Ziberi, 2016

Figura 36. Baza e katit

(Burimi): Fjolla Januzi, Hana Ziberi, 2016

Figura 37. Baza e katit 4

(Burimi): Fjolla Januzi, Hana Ziberi, 2016

Figura 38. Pamjet

(Burimi): Fjolla Januzi, Hana Ziberi, 2016

Figura 39. Perpektiva

(Burimi): Fjolla Januzi, Hana Ziberi, 2016

Figura 40. Perpektiva

(Burimi): Fjolla Januzi, Hana Ziberi, 2016

Figura 41. Kompozicioni funksional

(Burimi): Përparim Morina, Rina Kollqaku, 2016

Figura 42. Situacioni

(Burimi): Përparim Morina, Rina Kollqaku, 2016

Figura 43. Baza e përdhesës

(Burimi): Përparim Morina, Rina Kollqaku, 2016

Figura 44. Prerja $C$

(Burimi): Përparim Morina, Rina Kollqaku, 2016

Figura 45. Baza e katit

(Burimi): Përparim Morina, Rina Kollqaku, 2016

Figura 46. Prerja $B$

(Burimi): Përparim Morina, Rina Kollqaku, 2016

Figura 47. Perspektiva

(Burimi): Përparim Morina, Rina Kollqaku, 2016

Figura 48. Analiza

(Burimi): Rinor Rushiti, Xhezide Vlashi, 2018

Figura 49. Situacioni

(Burimi): Rinor Rushiti, Xhezide Vlashi, 2018 
Figura 50. Baza e përdhesës

(Burimi): Rinor Rushiti, Xhezide Vlashi, 2018

Figura 51. Baza e katit

(Burimi): Rinor Rushiti, Xhezide Vlashi, 2018

Figura 52. Baza e katit 2

(Burimi): Rinor Rushiti, Xhezide Vlashi, 2018

Figura 53. Prerjet

(Burimi): Rinor Rushiti, Xhezide Vlashi, 2018

Figura 54. Pamjet

(Burimi): Rinor Rushiti, Xhezide Vlashi, 2018

Figura 55. Perspektiva

(Burimi): Rinor Rushiti, Xhezide Vlashi, 2018

Figura 56. Perspektiva

(Burimi): Rinor Rushiti, Xhezide Vlashi, 2018

Figura 57. Perspektiva

(Burimi): Rinor Rushiti, Xhezide Vlashi, 2018

Figura 58. Analizat

(Burimi): Diellza Delija, Diellza Hajrizi, 2018

Figura 59. Baza e përdhesës

(Burimi): Diellza Delija, Diellza Hajrizi, 2018

Figura 60. Baza e katit

(Burimi): Diellza Delija, Diellza Hajrizi, 2018

Figura 61. Analizat

(Burimi): Diellza Delija, Diellza Hajrizi, 2018

Figura 62. Pamjet

(Burimi): Diellza Delija, Diellza Hajrizi, 2018

Figura 63. Perspektiva

(Burimi): Diellza Delija, Diellza Hajrizi, 2018

Figura 64. Perspektiva

(Burimi): Diellza Delija, Diellza Hajrizi, 2018

Figura 65. Analizat

(Burimi): Dorarta Sallauka, 2018

Figura 66. Analizat - Kompozicioni funksional (Burimi): Dorarta Sallauka, 2018

Figura 67. Baza e përdhesës (Burimi): Dorarta Sallauka, 2018 
Figura 68. Prerjet

(Burimi): Dorarta Sallauka, 2018

Figura 69. Pamjet

(Burimi): Dorarta Sallauka, 2018

Figura 70. Pamjet

(Burimi): Dorarta Sallauka, 2018

Figura 71. Situacioni

(Burimi): Dorarta Sallauka, 2018

Figura 72. Perspektiva

(Burimi): Dorarta Sallauka, 2018

Figura 73. Perspektiva

(Burimi): Dorarta Sallauka, 2018

Figura 74. Analizat

(Burimi): Diana Deda, 2018

Figura 75. Koncepti

(Burimi): Diana Deda, 2018

Figura 76. Baza e përdhesës

(Burimi): Diana Deda, 2018

Figura 77. Prerjet

(Burimi): Diana Deda, 2018

Figura 78. Pamjet

(Burimi): Diana Deda, 2018

Figura 79. Perspektiva

(Burimi): Diana Deda, 2018

Figura 80. Perspektiva

(Burimi): Diana Deda, 2018

Figura 81. Situacioni - Kompozicioni funksional (Burimi): Dhuratë Krasniqi, 2018

Figura 82. Baza e përdhesës

(Burimi): Dhuratë Krasniqi, 2018

Figura 83. Pamja nga lartë

(Burimi): Dhuratë Krasniqi, 2018

Figura 84. Prerjet - Perspektiva

(Burimi): Dhuratë Krasniqi, 2018

Figura 85. Perspektiva

(Burimi): Dhuratë Krasniqi, 2018 
Figura 86. Perspektiva

(Burimi): Dhuratë Krasniqi, 2018

Figura 87. Analizat

(Burimi): Safete Dauti, 2018

Figura 88. Situacioni

(Burimi): Safete Dauti, 2018

Figura 89. Baza e përdhesës

(Burimi): Safete Dauti, 2018

Figura 90. Perspektiva

(Burimi): Safete Dauti, 2018

Figura 91. Koncepti

(Burimi): Gentianë Thaçi, 2018

Figura 92. Situacioni

(Burimi): Gentianë Thaçi, 2018

Figura 93. Prerjet

(Burimi): Gentianë Thaçi, 2018

Figura 94. Baza e përdhesës dhe katit (Burimi): Gentianë Thaçi, 2018

Figura 95. Pamjet

(Burimi): Gentianë Thaçi, 2018

Figura 96. Perspektiva

(Burimi): Gentianë Thaçi, 2018

Figura 97. Perspektiva

(Burimi): Gentianë Thaçi, 2018

Figura 98. Situacioni

(Burimi): Diellza Delija, Diellza Hajrizi, 2018.

Figura 99. Analizat e Situacionit

(Burimi): Diellza Delija, Diellza Hajrizi, 2018.

Figura 100. Analizat e bimësisë

(Burimi): Diellza Delija, Diellza Hajrizi, 2018.

Figura 101. Baza e Katit 1

(Burimi): Diellza Delija, Diellza Hajrizi, 2018.

Figura 102. Prerja

(Burimi): Diellza Delija, Diellza Hajrizi, 2018.

Figura 103. Perspektiva

(Burimi): Diellza Delija, Diellza Hajrizi, 2018. 
Figura 104. Perspektivat

(Burimi): Diellza Delija, Diellza Hajrizi, 2018.

Figura 105. Analizat

(Burimi): Nita Hasimja, Nita Llonçari, 2018.

Figura 106. Analizat

(Burimi): Nita Hasimja, Nita Llonçari, 2018.

Figura 107. Situacioni

(Burimi): Nita Hasimja, Nita Llonçari, 2018.

Figura 108. Baza e Përdhesës

(Burimi): Nita Hasimja, Nita Llonçari, 2018.

Figura 109. Zgjedhja Kompozicionale (Burimi): Nita Hasimja, Nita Llonçari, 2018.

Figura 110. Mbështjellësi

(Burimi): Nita Hasimja, Nita Llonçari, 2018.

Figura 111. Prerja

(Burimi): Nita Hasimja, Nita Llonçari, 2018.

Figura 112. Perspektivat

(Burimi): NitaHasimja, Nita Llonçari, 2018.

Figura 113. Perspektiva

(Burimi): Nita Hasimja, Nita Llonçari, 2018.

Figura 114. Perspektiva

(Burimi): Nita Hasimja, Nita Llonçari, 2018.

Figura 115. Analizat

(Burimi): Gentianë Thaçi, Hana Mikullovci, 2018.

Figura 116. Situacioni

(Burimi): Gentianë Thaçi, Hana Mikullovci, 2018.

Figura 117. Situacioni i ngushtë

(Burimi): Gentianë Thaçi, Hana Mikullovci, 2018.

Figura 118. Baza e Përdhesës

(Burimi): Gentianë Thaçi, Hana Mikullovci, 2018.

Figura 119. Baza e Katit 2

(Burimi): Gentianë Thaçi, Hana Mikullovci, 2018.

Figura 120. Prerja A

(Burimi): Gentianë Thaçi, Hana Mikullovci, 2018

Figura 121. Prerja B

(Burimi): Gentianë Thaçi, Hana Mikullovci, 2018 
Figura 122. Pamja

(Burimi): Gentianë Thaçi, Hana Mikullovci, 2018

Figura 123. Pamja

(Burimi): Gentianë Thaçi, Hana Mikullovci, 2018

Figura 124. Perspektiva

(Burimi): Gentianë Thaçi, Hana Mikullovci, 2018

Figura 125. Perspektiva

(Burimi): Gentianë Thaçi, Hana Mikullovci, 2018

Figura 126. Perspektiva

(Burimi): Gentianë Thaçi, Hana Mikullovci, 2018

Figura 127. Situacioni

(Burimi): Albertina Likaj, Dhuratë Krasniqi, 2018

Figura 128. Situacioni

(Burimi): Albertina Likaj, Dhuratë Krasniqi, 2018

Figura 129. Baza e Përdhesës

(Burimi): Albertina Likaj, Dhuratë Krasniqi, 2018

Figura 130. Baza e Katit 4, 7

(Burimi): Albertina Likaj, Dhuratë Krasniqi, 2018

Figura 131. Prerja A

(Burimi): Albertina Likaj, Dhuratë Krasniqi, 2018

Figura 132. Prerja $B$

(Burimi): Albertina Likaj, Dhuratë Krasniqi, 2018

Figura 133. Perspektivat

(Burimi): Albertina Likaj, Dhuratë Krasniqi, 2018

Figura 134. Analizat dhe Situacioni

(Burimi): Ardiana Zullufi, Blerina Boshnjaku, 2018

Figura 135. Baza e përdhesës

(Burimi): Ardiana Zullufi, Blerina Boshnjaku, 2018

Figura 136. Baza e suterenit

(Burimi): Ardiana Zullufi, Blerina Boshnjaku, 2018

Figura 137. Prerjet

(Burimi): Ardiana Zullufi, Blerina Boshnjaku, 2018

Figura 138. Pamjet

(Burimi): Ardiana Zullufi, Blerina Boshnjaku, 2018 
Figura 139. Perspektivat

(Burimi): Ardiana Zullufi, Blerina Boshnjaku, 2018

Figura 140. Struktura

(Burimi): Ardiana Zullufi, Blerina Boshnjaku, 2018

Figura 141. Situacioni

(Burimi): Aulona Blakaj, Shpend Jashari, 2018

Figura 142. Baza e Përdhesës

(Burimi): Aulona Blakaj, Shpend Jashari, 2018

Figura 143. Baza e katit

(Burimi): Aulona Blakaj, Shpend Jashari, 2018

Figura 144. Prerjet

(Burimi): Aulona Blakaj, Shpend Jashari, 2018

Figura 145. Pamjet

(Burimi): Aulona Blakaj, Shpend Jashari, 2018

Figura 146. Perpektiva

(Burimi): Aulona Blakaj, Shpend Jashari, 2018

Figura 147. Perpektiva

(Burimi): Aulona Blakaj, Shpend Jashari, 2018

Figura 148. Situacioni

(Burimi): Benjamin Komani, Kushtrim Thaqi, 2018

Figura 149. Baza e përdhesës

(Burimi): Benjamin Komani, Kushtrim Thaqi, 2018

Figura 150. Baza e katit

(Burimi): Benjamin Komani, Kushtrim Thaqi, 2018

Figura 151. Baza e sipërme

(Burimi): Benjamin Komani, Kushtrim Thaqi, 2018

Figura 152. Pamjet

(Burimi): Benjamin Komani, Kushtrim Thaqi, 2018

Figura 153. Perspektiva

(Burimi): Benjamin Komani, Kushtrim Thaqi, 2018

Figura 154. Analizat

(Burimi): Nerimane Merovci, Rajmonda Jetullahu, 2018

Figura 155. Analizat - Situacioni

(Burimi): Nerimane Merovci, Rajmonda Jetullahu, 2018

Figura 156. Situacioni

(Burimi): Nerimane Merovci, Rajmonda Jetullahu, 2018 
Figura 157. Baza e përdhesës

(Burimi): Nerimane Merovci, Rajmonda Jetullahu, 2018

Figura 158. Baza e katit

(Burimi): Nerimane Merovci, Rajmonda Jetullahu, 2018

Figura 159. Baza e katit 2

(Burimi): Nerimane Merovci, Rajmonda Jetullahu, 2018

Figura 160. Pamjet

(Burimi): Nerimane Merovci, Rajmonda Jetullahu, 2018

Figura 161. Perspektiva

(Burimi): Nerimane Merovci, Rajmonda Jetullahu, 2018

Figura 162. Perspektiva

(Burimi): Nerimane Merovci, Rajmonda Jetullahu, 2018

Figura 163. Perspektiva

(Burimi): Nerimane Merovci, Rajmonda Jetullahu, 2018

Figura 164. Situacioni

(Burimi): Nertila Kabashaj, Njomza Tahiri, 2018

Figura 165. Baza e përdhesës

(Burimi): Nertila Kabashaj, Njomza Tahiri, 2018

Figura 166. Baza e katit

(Burimi): Nertila Kabashaj, Njomza Tahiri, 2018

Figura 167. Baza e katit 2

(Burimi): Nertila Kabashaj, Njomza Tahiri, 2018

Figura 168. Baza e katit 3

(Burimi): Nertila Kabashaj, Njomza Tahiri, 2018

Figura 169. Prerjet

(Burimi): Nertila Kabashaj, Njomza Tahiri, 2018

Figura 170. Perspektiva

(Burimi): Nertila Kabashaj, Njomza Tahiri, 2018 
KJO FAQE ËSHTË LËNË QËLLIMISHT E ZBRAZËT! 


\section{LITERATURA}

1. Abel, C.(2004). Architecture,Technology and Process. Oxford, UK: Elsevier

2. ACRP, report 130. (2015). Guidebook for Airport Terminal Restroom Planning and Design. Federal Aviation Administration, (C) National Academy of Sciences. USA.

3. Alfeld, E, L. (1995). Urban dynamics-The first fifty years. System Dynamics ReviewVol. 11, no. 3: 199-217. John Wiley \& Sons, ltd.

4. Agjencia e Statistikave të Kosovës. Popullsia e Kosovës 2014. 2015.

5. Audi, R. (2011). Epistemology. London, UK. New York. USA : Routledge. Tailor \& Francis Group.

6. Asociacioni i Komunave të Kosovës. Deklaratë parimore: Planifikimi urban dhe rural. 2010.

7. ASK. (2018). Statistikat e transportit dhe telekomunikacionit TM $1-2016$. Ministria e Punëve të Brendshme

8. Asistenca evropiane $128976 / \mathrm{C} / \mathrm{SER} / \mathrm{KOS}$

9. Averill, A.B; Eldredge, P. (2012). Principles of General Chemistry

10. Batty, M., Torrens M.P. (2005). Modelling and prediction in a complex world. London, UK. Salt Lake City, USA : Elsevier.

11. Bajçinovci, B., Thaçi, K. (2016). Heritage and Artistic Boon: Valuing Prizren Castle. Journal of Science, Humanities and Arts. JOSHA. ISSN: 2364-0626. Vol. (3), Is. 5. 2016. DOI: 10.17160/josha.3.5.228

12. Bajçinovci, B., Jerliu, F. (2016). Integrated Design as an Evolutive Transdisciplinary Strategy. European Journal of Technology and Design, Vol. (13), Is. 3: pp. 90-98. 2016. DOI: 10.13187/ejtd.2016.13.90

13. Bajçinovci, B. (2016). Challenges of Architectural Design in relation to Environment and Air Pollution. A Case study: Prishtina's first public parking Garage. Journal of Science, Humanities and Arts. JOSHA. ISSN: 2364-0626. Vol. (3), Is. 7. 2016. DOI: 10.17160/josha.3.7.254

14. Bajçinovci, B. (2016). Hybrid Structures as a Symbiotic Bond of Art and science. Journal of Science, Humanities and Arts. JOSHA. ISSN: 2364-0626. Vol. (3), Is. 5. 2016. DOI: 10.17160/josha.3.5.233

15. Bajçinovci, B., Jerliu, F. (2016). Urban Resettlements and Environmental Engineering as a Context for Human Development. A Case Study: Hade. Journal of Applied Engineering Sciences, Vol. 6(19), Is. 2/2016, Art. No. 203, pp. 7-14. 2016. DOI: 10.1515/jaes-2016-0011

16. Bajçinovci, B. (2016). Architectural Conceptual Design - the Sustainable Shopping Malls Structures. European Journal of Technology and Design, Vol. (14), Is. 4: pp. 136-143. 2016. DOI: 10.13187/ejtd.2016.14.136

17. Bajçinovci, B., Jerliu, F. (2016). Achieving Energy Efficiency in Accordance with Bioclimatic Architecture Principles. Environmental and Climate Technologies. Vol. (18), pp. 54-63. 2016. DOI: 10.1515/rtuect-2016-0013 
18. Bajçinovci, B., Thaçi, K., B. Q. Bajçinovci (2016). Architectural Reflection on Italo Calvino's Invisible Cities. Journal of Science, Humanities and Arts. JOSHA. Vol. (4), Is. 1. 2018. DOI: 10.17160/josha.4.1.261

19. Bajçinovci, B., Jerliu, F. (2016). Complexity of Iterative Model - Architectural Integrated Design as an Evolutive Transdisciplinary Strategy. Case Study: A City Without a River. Journal of Science, Humanities and Arts. JOSHA. ISSN: 2364-0626. Vol. (4), Is. 1. 2018. DOI: 10.17160/josha.4.1.264

20. Bajçinovci, B. (2018). Ecological Factors Regarding to the Site Selection and Architectural Design of Parking Garages. European Journal of Technology and Design, Vol. (5), Is. 1. 2018. DOI: 10.13187/ejtd.2018.1

21. Bajçinovci, B., Jerliu, F. (2016). The Concept of "Modelarium" and its Impact on Creativity and Artistic Education. Review of Artistic Education, Vol. (14), Is. 1. 2018. DOI: $10.1515 / \mathrm{rae}-2018-0030$

22. Bajçinovci, B., Jerliu, F. (2018). Impact on pollution and Urban liveabilityAbandoned Quarries. Pollution Research, Vol. (36), Is.1: 23-28.

23. Bajçinovci, B., Bajçinovci, U., B. Q. Bajçinovci. (2018). Aloft Metabolism: A Juncture of Architecture Future Design. European Journal of Technology and Design, Vol. (5), Is. 1: 14-19. DOI: 10.13187/ejtd.2018.1.14

24. Bajçinovci, B. (2018). Sustainable Architectural Design - Principles - in the Albanian Language. JOSHA, Journal of Science, Humanities and Arts. Volume: 4 Issue: 3, Freiburg Germany. DOI: 10.17160/josha.4.3.306

25. Bajçinovci, B. (2018). Airports - Planning and Design- in the Albanian Language. JOSHA, Journal of Science, Humanities and Arts. Volume: 4 Issue: 3, Freiburg Germany. DOI: 10.17160/josha.4.3.309

26. Bajçinovci, B. (2018). Commercial Hybrid Buildings - Planning and Design- in the Albanian Language. JOSHA, Journal of Science, Humanities and Arts. Volume: 4 Issue: 3, Freiburg Germany. DOI: 10.17160/josha.4.3.307

27. Bajçinovci, B. (2018). Hotels - Design Principles - in the Albanian Language. JOSHA, Journal of Science, Humanities and Arts. Volume: 4 Issue: 3, Freiburg Germany. DOI: 10.17160/josha.4.3.312

28. Bajçinovci, B. (2018). Industrial Complexes - part 1, Planning and Design - in the Albanian Language. Unpublished, part of the Project: Industrial Complexes - Planning and Design - in the Albanian Language. ResearchGate, DOI: 10.13140/RG.2.2.23049.13923, DOI: $10.13140 /$ RG.2.2.29969.74082, DOI: 10.13140/RG.2.2.33639.75686 DOI: 10.13140/RG.2.2.14293.52965, DOI: 10.13140/RG.2.2.27805.41441

29. Bajçinovci, B. (2018). Industrial Complexes - part 2, Planning and Design - in the Albanian Language. Unpublished, part of the Project: Industrial Complexes - in the Albanian Language. ResearchGate, DOI: $10.13140 /$ RG.2.2.15086.10564

30. Bajçinovci, B. (2018). Variegated Dynamic Functions as a Blend of Architectural Design and Contemporary Integrated Conceptualization. European Journal of Technology and Design, Vol. (5), Is. 2. 2018. DOI: 10.13187/ejtd.2018.2.46

31. Bajçinovci, B. (2018). The Vertical Farm - Architectural Design Principles - in the Albanian Language. Unpublished, part of the Project: The Vertical Farm - in the Albanian Language. DOI: 10.17160/josha.4.5.354

32. Bajçinovci, B. (2018). Research Centres and Laboratories - Architectural Design Principles.. JOSHA, Journal of Science, Humanities and Arts. Volume: 4 Issue: 5, Freiburg Germany. DOI: 10.17160/josha.4.5.355 
33. Bajçinovci, B. (2018). Research Centres and Laboratories - Part 2.Architectural Design Principles.. JOSHA, Journal of Science, Humanities and Arts. Volume: 5 Issue: 3, Freiburg Germany. DOI: 10.17160/josha.5.3.414

34. Bajçinovci, B., Gjinolli, I., Beqiri, Rr. (2018). Measuring Vitality of the Ottoman Public Space in Kosovo Cities. JOSHA, Journal of Science, Humanities and Arts. Volume: 5 Issue: 4, Freiburg Germany. DOI: 10.17160/josha.5.4.417

35. Bajçinovci, B., Nushi, V. (2018). Building Rating System: Kosovar imperative in sustainable context. JOSHA, Journal of Science, Humanities and Arts. Volume: 5 Issue: 2, Freiburg Germany. DOI: 10.17160/josha.5.2.387

36. Bajçinovci, B., Aliu, V. (2018). Visual Organization of Industrial Functional Compositions. JOSHA, Journal of Science, Humanities and Arts. Volume: 5 Issue: 5, Freiburg Germany. DOI: 10.17160/josha.5.5.437

37. Bajçinovci, B. (2018). Creativity of Interactive Academic Education for Sustainable Urban Development. JOSHA, Journal of Science, Humanities and Arts. Volume: 5 Issue: 5, Freiburg Germany. DOI: 10.17160/josha.5.5.441

38. Bajçinovci, B. (2018). Sustainability of Waste Materials in Affinity with Ecologically Sustainable Development: A Case Study of Kosovo. ECOL CHEM ENG S. 2018;25(2):279-293. DOI: 10.1515/eces-2018-0019

39. Banka evropiane për rindërtim dhe zhvillim. Strategji për Kosovën. 2013.

40. Birkby, J. (2016). Vertical Farming. NCAT. A program of the National Center for Appropriate Technology.

41. CAA. (2006). An Architect's Guide to Designing for Sustainability. Edgware. UK:Commonwealth Association of Architects.

42. Commission. EACI. Brussels, Belgium:Executive Agency for Competitiveness and Innovation. 6.

43. Clayton, S., Opotow, S.(2003). Identity and the Natural Environment, The Psychological Significance of Nature. London, UK : MIT Press.

44. Corbusier, L. (1989). Towards a new architecture. Oxford: Butterworth Architecture.

45. Degen, M. M.(2008). Sensing Cities. Rgeneration public life in Barcelona and Manchester. London, UK. New York. USA : Routledge. Tailor \& Francis Group.

46. Dhankhar, S. S. (2010). Environmental Studies. CSS HAU. Hisar.Dept. Agrometeorology: Agricultural University. 28.

47. Drejt zonës evropiane të sigurisë rrugore: orientimi i politikave për siguri rrugore 2011-2020 . COM82010, 389 final, 20.7.2010.

48. Downton, P. (2009). Architecture and Cities for a Changing Climate. Colligwood, Australia:Springer.CSIRO Publishing.

49. Ed. C, Gallo., M, Sala., A.M.M, Sayigh. (Eds). (1988). Architecture: Comfort and Energy. Elsevier.

50. Ed. Banister D.(Eds).(2005). Transport and Urban Development. London.UK: Taylor \& Francis. E \& FN Spon, an imprint of Chapman \& Hall.

51. Ed. Clayton, S., Opotow, S. (Eds).(2003). Identity and the Natural Environment, The Psychological Significance of Nature. London: MIT Press.

52. Ed. Quatman. W., Dhar, R.(Eds).(2003). The Architect's Guide to Design-Build Services. American Institute of Architects. New Jersey \& Canada: John Wiley \& Sons. Inc.

53. Ed. S. William et al..(Eds).(2005). Understanding the Global Dimensions of Health. New York, NY: Springer. 
54. Ed. Wilson, A.(Eds).(2001). Greening Federal Facilities., Brattleboro, Vermont: U.S. Department of Energy.

55. EU. (2004). Architect's Council of Europe. Architecture and Quality of Life, Bruxelles, Belgium: EU.

56. Evans S. D.; Schmalensee, R.(2007). Catalyst Code: The Strategies Behind the World's Most Dynamic Companies, Harvard: Harvard Business School Press.

57. Forrester, J. 1969. Urban Dynamics. Pegasus Communications, Inc.

58. Forrester, J. 1979. World Dynamics. Productivity Pr, 2 ed.

59. Gallo, C., sala, M., Sayigh. M.(Eds).(1998). Architecture : Comfort and Energy. Oxford, UK : Elsevier.

60. Hadorn, H. G. et al.(2008). The Handbook of Transdisciplinary Research. Zurich.Switzerland : Springer.

61. Hadrović, Ahmet. (2008). Bioclimatic Architecture: Searching for the Path to Haven. Booksurge Publishing: Amazon. com.

62. Highmore, B. T.(2010)Ordinary Lives: Studies in the Everyday.London, UK. New York. USA : Routledge. Tailor \& Francis Group.

63. Ibrahim, R., Fruchter,. R., Sharif, R. (2007, November). International Journal of Architectural Research. Framework for a cross-border transdisciplinary design studio education., 100(03).

64. I. Krasniqi, G. Latifi. (1982). Teknika e tensioneve te larta. FET, Universiteti i Prishtinës.

65. Kargon, R.,Molella, A.(2008).Invented Edens. Invented-Cities of the Twentieth Century. Cambridge, Massachusetts : Massachusetts Institute of Technology.

66. Krasniqi, Fejzullah. Selimaj, R., Malsiu, I.(2004). Instalimet Makinerike. Universiteti i Prishtinës.

67. Krasniqi, Fejzullah.(2000). Ngrohja dhe klimatizimi-II. Universiteti i Prishtinës.

68. Kwok G.A. et al.(2007). Environmental strategies for schematic design. Oxford. UK : Elsevier.

69. Lawson B.(2005). How Designers Think. Oxford. UK :Elsevier.

70. Lebel J.(2003). Health, An Ecosystem Aproach. Canada : IDRC.

71. Lee, G., Sacks, R., and Eastman, C. M. (2006). Specifying parametric building object behavior (BOB)for a building information modeling system. Automation in Construction, 15(6), pp.758-776.

72. LEED. (2011). U.S. Green Building Council, standard certificates : USA.

73. Mallgrave, F. H.(2010). The Architect's Brain : Neuroscience, Creativity, and Architecture. Chichester, West Sussex, UK : Wiley Blackwell, Wiley \& Sons,

74. Margolis, L., M., Robinson, A.(2007). Living Systems : InnovatIve MaterIals and technologIes for landscape archItecture. Berlin, Germany:Birkhäuser Verlag AG.

75. Mega, P. V.(2010). Sustainable Cities for the Third Millennium: The Odyssey of Urban Excellence. New York, Dordrecht, Heidelberg, London : Springer.

76. Meijer, F., Visscher, H., Sheridan L.(2002). Building regulations in Europe. I. Nederlands :Delft Uni. pp. 6-188.

77. Ministria e Energjisë dhe e Minierave, (2008). Raport

78. MMPH. Raport për gjendjen e ajrit. 2012.

79. OECD (2010), Cities and Climate Change. Paris, France :OECD Publishing.

80. OGC, CABE,.(2002). Improving Standards of Design: in the Procurement of Public Buildings. London,UK:OGC. 24.

81. OPR. (2007). ASHRAE.Energy Efficiency and Environmental Sustainability. ASHRAE Standard 90.1-2004. Atlanta, USA :ASHRAE. 
82. Orr W. D. (2002). The Nature of Design. Oxford, UK :Oxford Uni. Press.

83. Plani Global i dekadës së strategjisë së sigurisë rrugore 2011-2020, e shpallur nga Asambleja e Përgjithshme e Kombeve të Bashkuara me 2.3.2010

84. Piotrowski, A.(2011). Archirecture of Thought. Minneapolis, USA : University of Minnesota Press.

85. Projekti PUP, Prishtinë. (1987). Projeksioni Prishtinës 2000.

86. Pushka, A. (2004). "Statistikat vitale të kohës më të re", ESK. Prishtinë.

87. Politika evropiane e transportit per 2010: Koha te vendosim . COM(2001) 370 final, 12.10. 2001.

88. Programi evropian për siguri rrugore - Përgjysmimi i numrit të viktimave nga aksidentet rrugore deri me 2010 ne Bashkimin Evropian: Pergjegjesi e perbashket. COM (2003) 311 final, 2.6. 2003.

89. RKS. Qeveria. Strategjia Sektoriale dhe Transportit Multimodal 2015-2025 dhe Plan i veprimit 5 vjeqar. 2015.

90. RKS. Qeveria. Ministria e Infrastrukturës. 2015, v1.6. Strategjia e Sigurisë Rrugore dhe Plani i Veprimit në Kosovë

91. Road Transport, 2012. European Union. Luxembourg: Publications Office of the European Union, 2012.

92. Samuelsson, L. (2008). The moral status of nature. Umeå,Sweden : Umeå University.

93. Shedroff, N.(2009). Design Is the Problem, The Future of Design Must be Sustainable. Brooklyn, NY. USA : Rosenfeld Media.

94. Statistikat dhe analizat e aksidenteve të komunikacionit në periudhën 2013 2014, Drejtoria e Komunikacionit, Policia e Kosovës

95. Smuts, J. (1927). Holism and Evolution. London, UK: McMillan and Co Limited.

96. UN. Habitat: World Cities Report, 2016.

97. UN, DESA. UN. Habitat: Living Planet Report, 2015

98. WHO, World Health Organization. (2009). Global status report on road safety, time for action. Printed in Switzerland.

\section{C) BUJAR BAJÇINOVCI \& VLORA ALIU 2018}

